\title{
(RE)THINKING YOUNG MEN'S VIOLENCE: A DISCURSIVE CRITIQUE OF DOMINANT CONSTRUCTIONS
}

\author{
by \\ Shirley Maree Grace \\ A thesis submitted to the Victoria University of Wellington \\ in fulfilment of the \\ requirements for the degree of \\ Doctor of Philosophy \\ in Education
}

Victoria University of Wellington

2008 


\section{Acknowledgements}

Firstly, I would like to thank the seven young men who participated in this study for their time and willingness to be involved. My thanks also go to the Department of Child, Youth and Family Services and the Department of Corrections for their assistance in allowing me to access the young men in their care.

A very special thank you to my partner, Brian Phillips, for his love and tireless cheerful support. I have appreciated the many theoretical and philosophical discussions we have had and gained much from his computer expertise.

Many thanks to my supervisors, Dr. Lise Bird Claiborne and Dr. Sue Cornforth. I have appreciated the continual encouragement, support and guidance they have provided me across this lengthy project.

I would also like to acknowledge the financial support I received to undertake this research. A grant was provided by the Ministry of Social Development and the Victoria University of Wellington also provided several research grants from the Faculty of Humanities and Social Sciences and the Faculty of Science. In addition, I received a PhD Completion Scholarship and a Jacob Joseph Scholarship from the Victoria University of Wellington. 


\begin{abstract}
Legitimated and thereby dominant knowledges of youth violence that aim to explain its causes and develop ways of responding are primarily informed by a positivist scientifically-based mainstream psychology. The purpose of this thesis is to offer ways of (re)thinking youth violence outside of an objectivist paradigm. By examining the significant contextual issues and numerous complexities involved for young men who have been violent, this research critically analyses normative notions of youth violence.
\end{abstract}

The theoretical and methodological foundation for this research employed a critical psychology framework along with a discourse analysis approach informed by poststructural concepts derived, primarily, from Michel Foucault. This research foundation has enabled the dominant constructions of youth violence that are reflected and (re)produced by mainstream psychology to be disrupted and hence the modernist assumptions in the positivist scientific basis of mainstream psychology are questioned.

The participants in this study were seven young New Zealand men, aged between 14 and 17, who were incarcerated for violent offences. A poststructural discourse analysis of interviews with these young men critically examined the ways they spoke about their violence, their explanations for it as well as their ideas about intervention.

My analysis shows that dominant constructions of youth violence that are (re)produced in mainstream psychology theories as taken-for-granted truths, can position violent young men as 'abnormal', 'deviant' and 'dangerous'. However, participants resisted these pathologising and demonising positions. Instead, they embraced the rational position of 'man'. Dominant discourses around traditional masculinity were identified as being of paramount importance to these young men and showed that successfully performing the subject position of 'man' took precedence for them. Being violent acted as a means for participants to achieve 'being a man'. Against this, therapeutic intervention designed to prevent future violence was viewed as irrelevant to these young men. In addition, the "therapeutic 
subject' position made available within discourses of intervention did not enable young men to perform 'man' correctly.

Contradictions are highlighted in this thesis, showing the multiple subjectivities of the participants, along with various effects of the differing discourses. This was most pronounced in the differences revealed in participants' talk of their general violence compared to their sexual violence. Since general violence was constructed as a way of 'getting it right as a man', participants spoke in considerable detail about their activities. However, participants were reluctant to talk about their sexual violence and silences predominated. As an alternative, they took up an 'unknowing ' position about why they were sexually violent. Sexual violence was constructed as irrational and therefore unknowable. In contrast to not wanting intervention for their general violence, participants talked of a willingness to engage with therapeutic intervention. They positioned intervention experts as being able to make rational sense of their sexual violence and spoke of expectations that this would stop them from being sexually violent again.

The limitations of traditional approaches to youth violence have been highlighted in this research. Such approaches are unable to attend to the contextual issues presented here or the complexities of multiple subjectivities. The construction of violence as a way to perform 'man' contests discourses of 'abnormality' that positions young men who have been violent as 'disordered' and 'deviant'. Future theorising about youth violence and subsequent intervention approaches require attending to the significance that normative notions of 'manhood' have in the (re)production of violence. 


\section{Table of Contents}

Acknowledgements ....................................................................................................................ii

Abstract n................................................................................................................................................iii

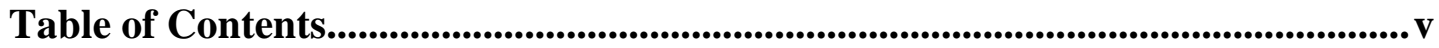

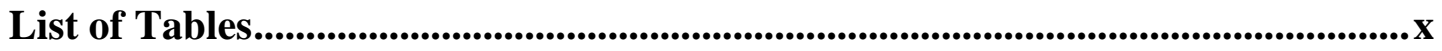

Chapter One

INTRODUCTION...................................................................... 1

My Professional Practice Experiences................................................................3

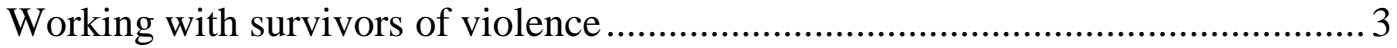

Working with young men who had sexual offences ............................................ 4

Survivors' and offenders' explanations and this research ..................................... 7

Epistemological and Theoretical Turning Points ...............................................9

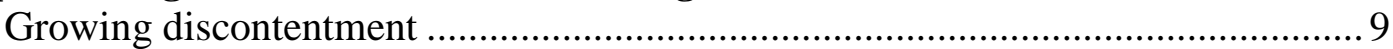

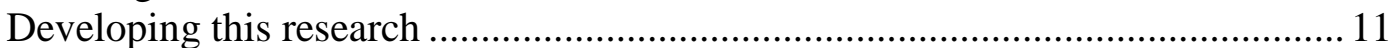

Exploring the philosophical basis of social science research ............................ 12

Experiencing the influence of differing paradigms .......................................... 12

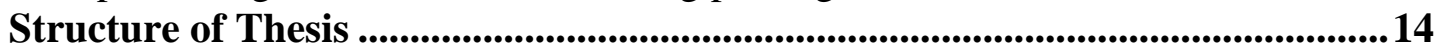

Conclusion .............................................................................................................................17

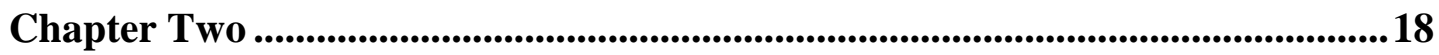

THE RESEARCH SCAFFOLDING ................................................ 18

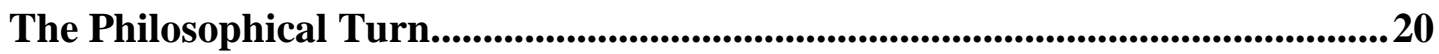

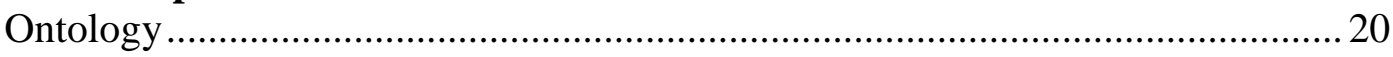

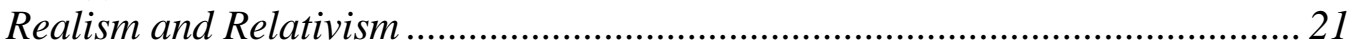

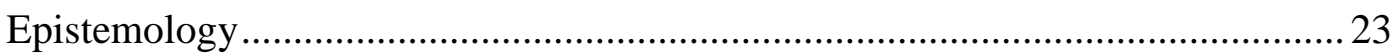

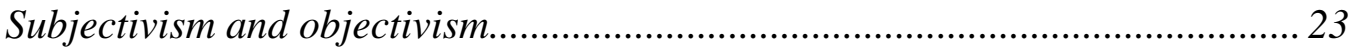

Theoretical Perspective ................................................................................................224

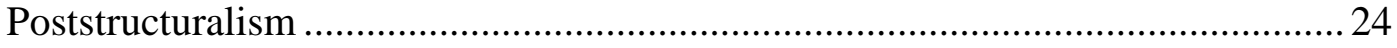

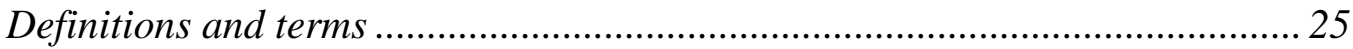

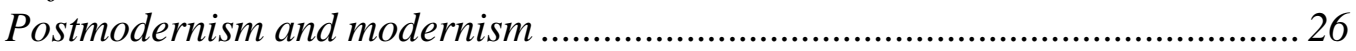

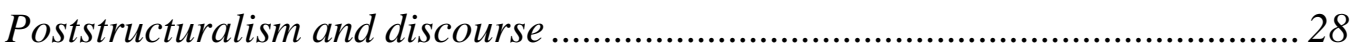

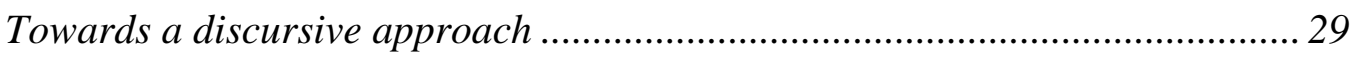

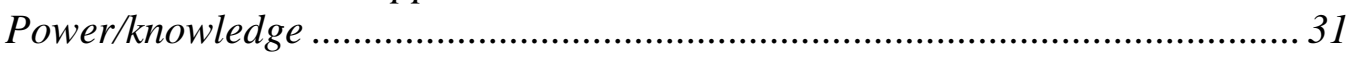

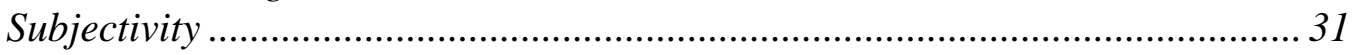

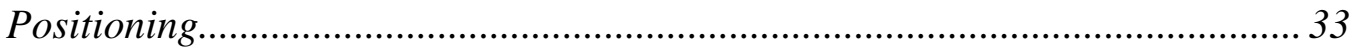

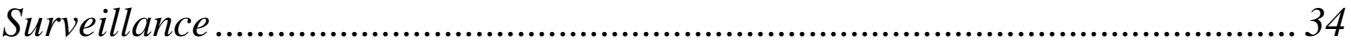

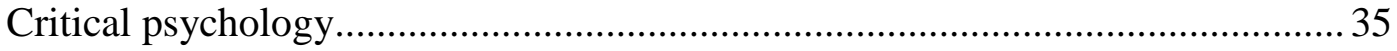

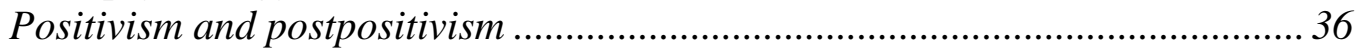

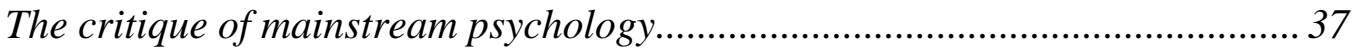

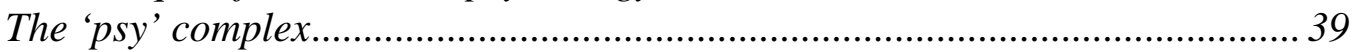

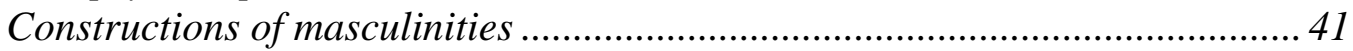

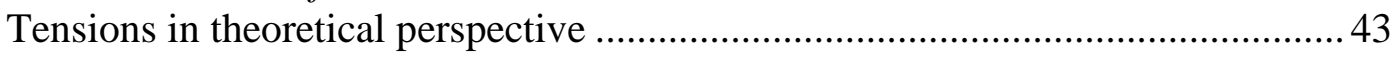


Methodology

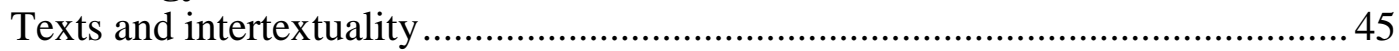

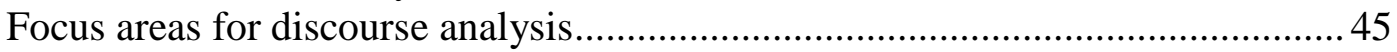

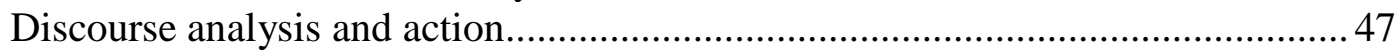

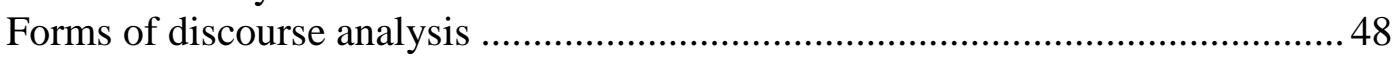

Research Strategies .........................................................................................49

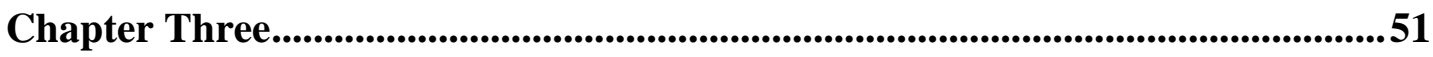

POSITIONING THROUGH THE ETHICAL APPROVAL

PROCESS .........................................................................................................51

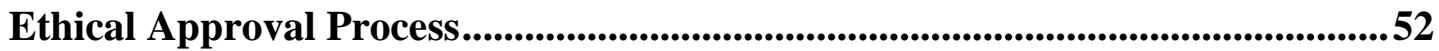

Constructions of Youth and Their Influence ...................................................53

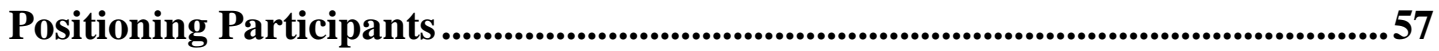

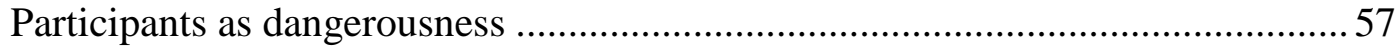

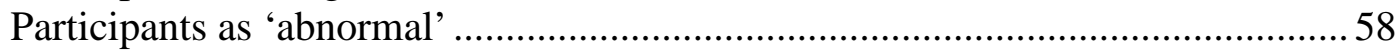

Participant positioning and limitations to my research .....................................59

Positioning the Research as Clinical...................................................................661

Positioning the Researcher's Clinical Competence ..................................................64

Conclusion.........................................................................................................67

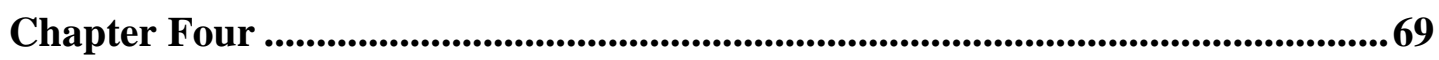

THE RESEARCH STRATEGIES USED............................................ 69

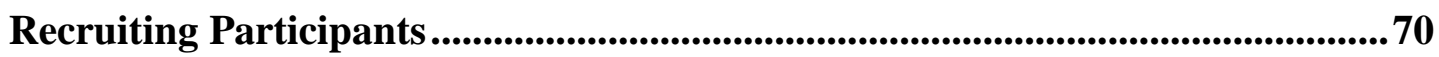

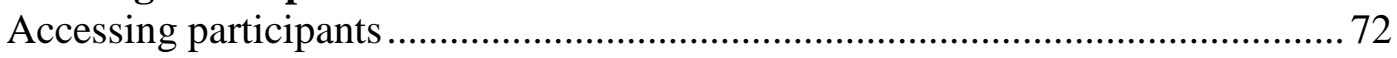

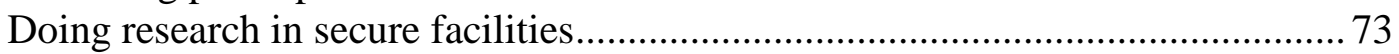

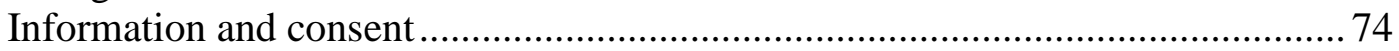

Introducing the Participants ..............................................................................................75

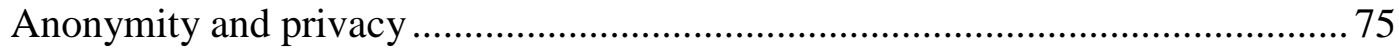

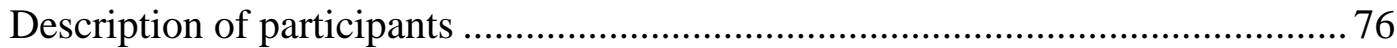

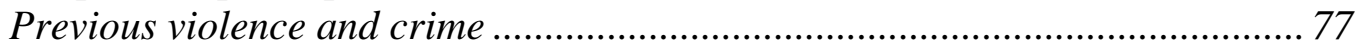

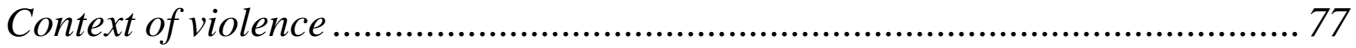

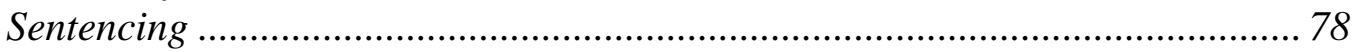

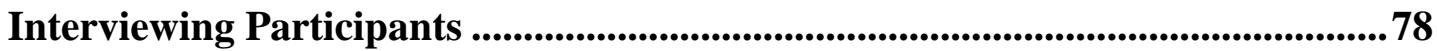

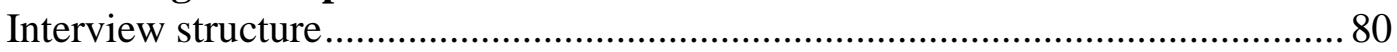

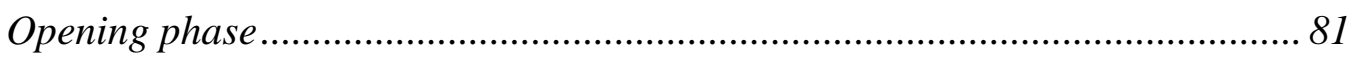

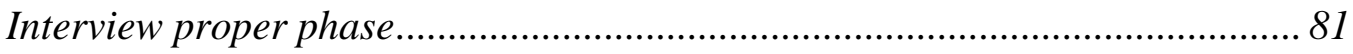

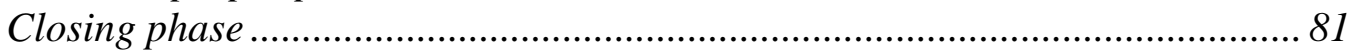

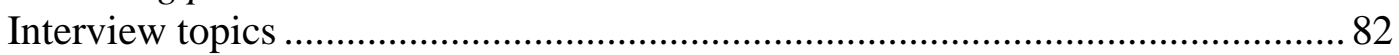

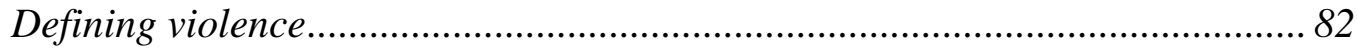

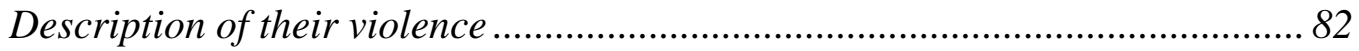

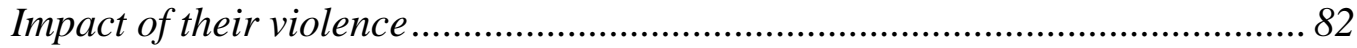

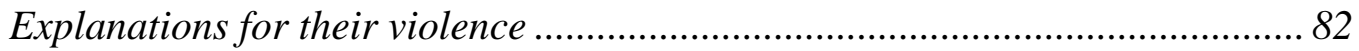

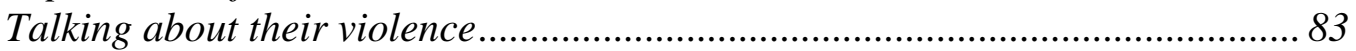

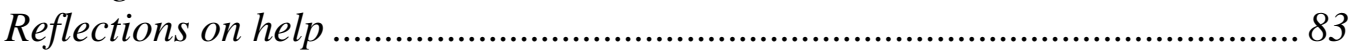

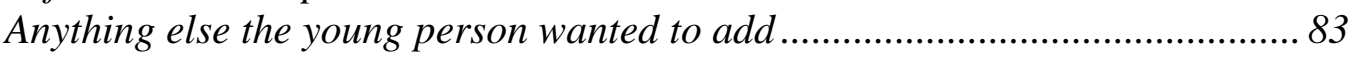

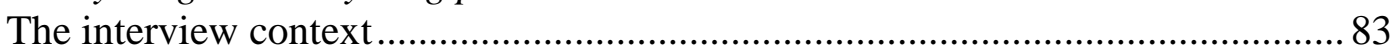




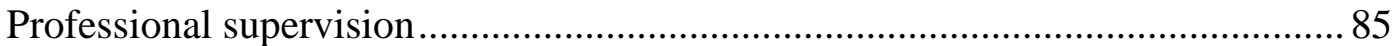

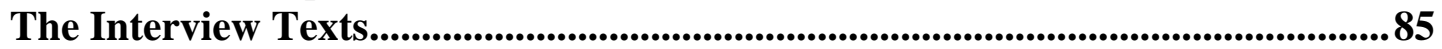

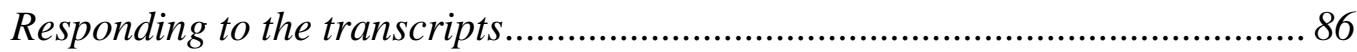

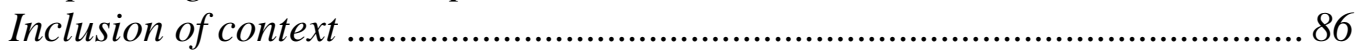

Analytical Approach ...................................................................................................88

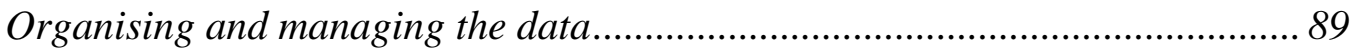

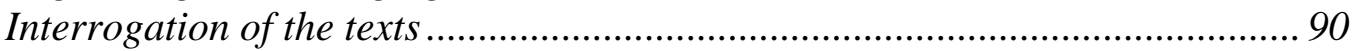

Conclusion .................................................................................................................................................92

Chapter Five ....................................................................................................................93

GRASPING THE DISCOURSES OF YOUNG MEN'S GENERAL

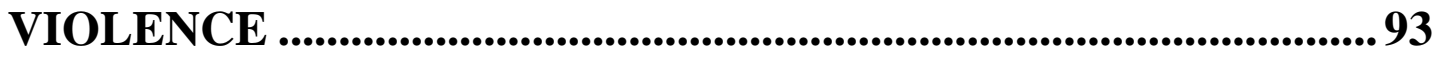

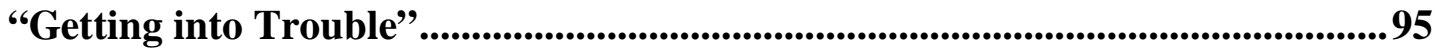

Rational Violence and Anger...................................................................................97

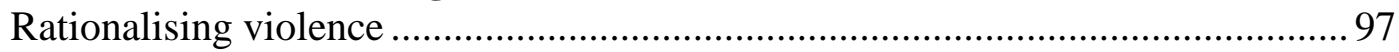

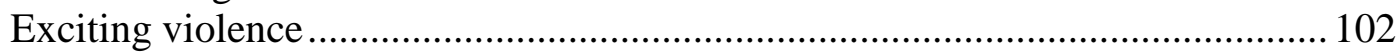

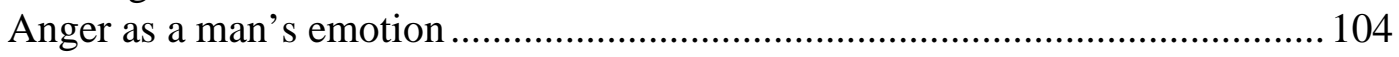

Constructions of Manliness .................................................................................109

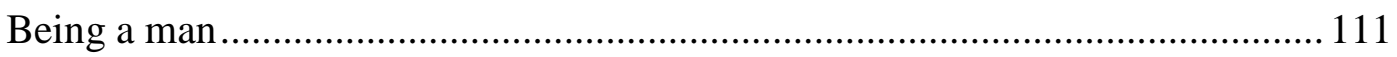

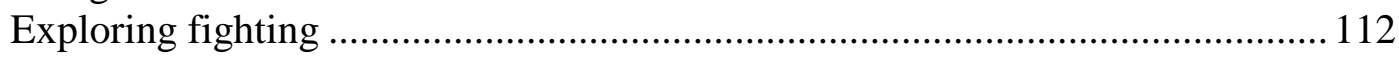

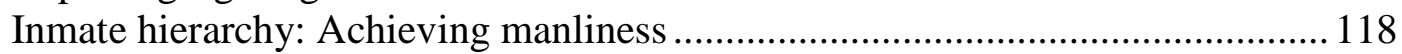

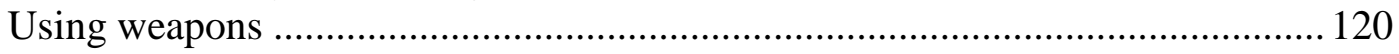

Families and Their Relationship to Youth Violence ...............................................123

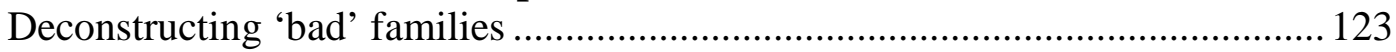

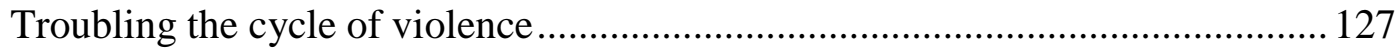

Questioning Learning Approaches to Youth Violence ..........................................134

Friends and Violence................................................................................................136

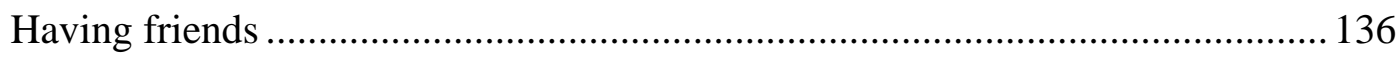

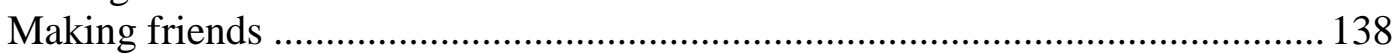

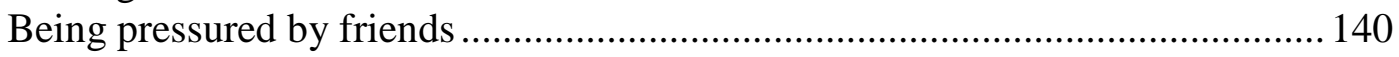

Problematising the Use of Drugs and Alcohol in Youth Violence .......................143

Considering Victims and Empathy ...................................................................................147

Comparison to Other Inmates: Achieving the grade ......................................151

How Others Position Participants: Being Downgraded .....................................153

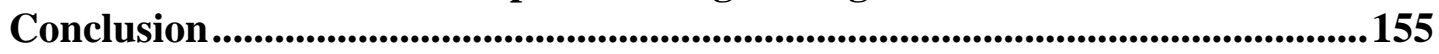

Chapter Six ....................................................................................................................158

INTERVENTION FOR GENERAL VIOLENCE ..........................158

Families and Intervention Approaches .......................................................................160

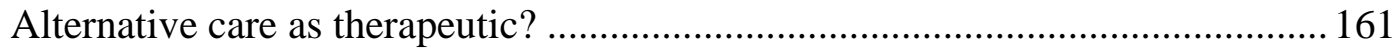

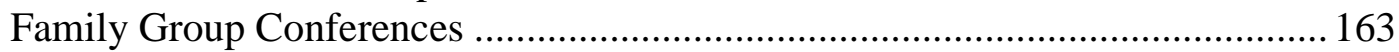

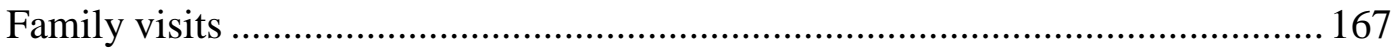

Offender Management Inside................................................................................169

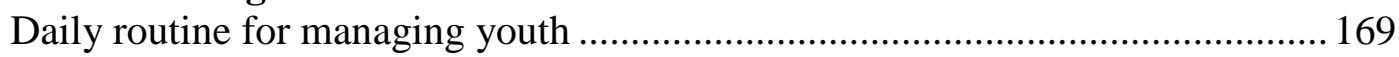

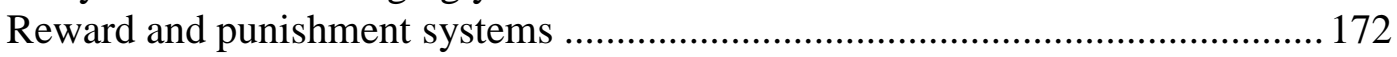

Secure facilities as hyper-masculine environments....................................... 175 
Experience with Therapeutic Intervention Programmes ......................................177

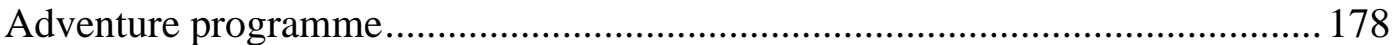

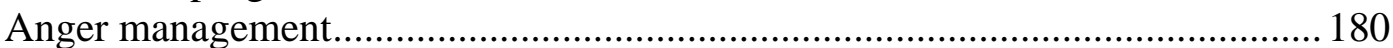

The EQUIP programme for delinquent youth ............................................... 180

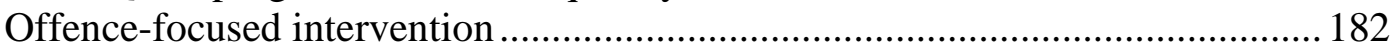

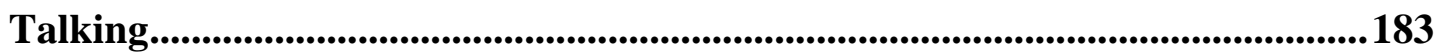

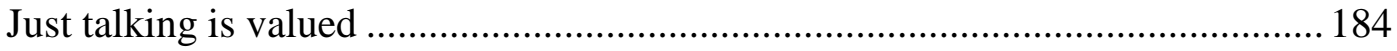

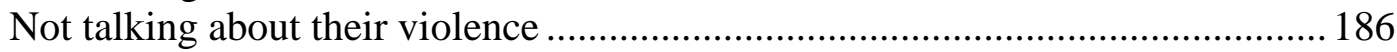

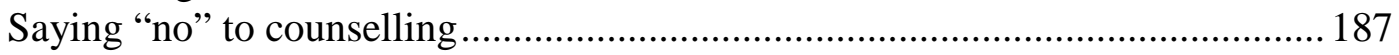

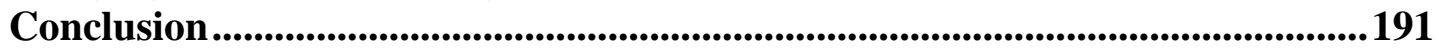

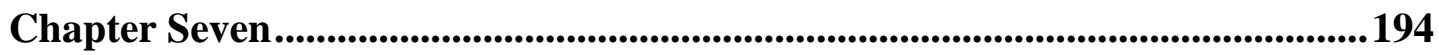

WHEN VIOLENCE IS SEXUAL.............................................. 194

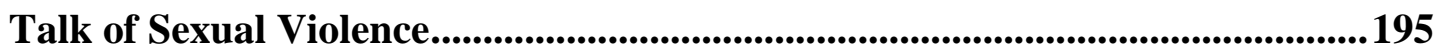

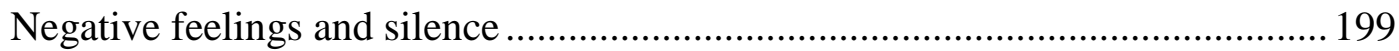

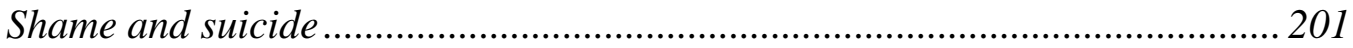

Distancing and separating from sexual violence ............................................ 202

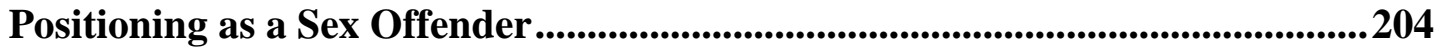

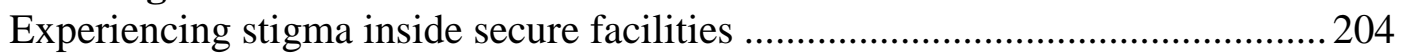

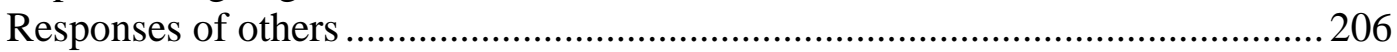

Speaking the Detail of Sexual Violence ................................................................211

Reflections on the Experience of Their Victims .......................................................216

Possible Explanations for Sexual Violence......................................................................218

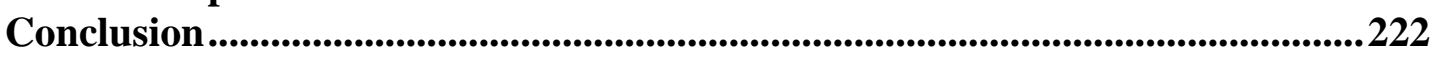

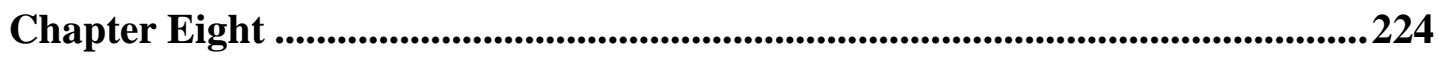

INTERVENTION FOR SEXUAL VIOLENCE ........................... 224

Intervention Experiences ...................................................................................224

The Why Question: A Target for Intervention.......................................................227

Participants' Expectations of Intervention ...............................................................231

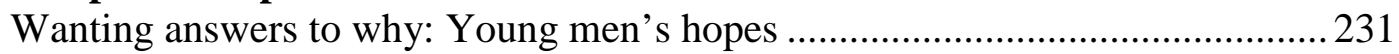

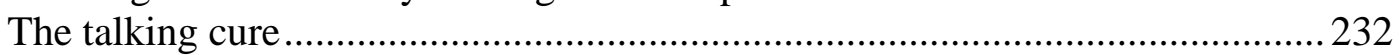

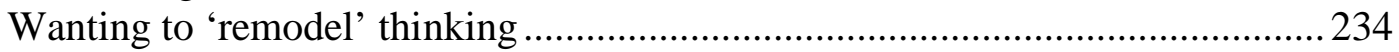

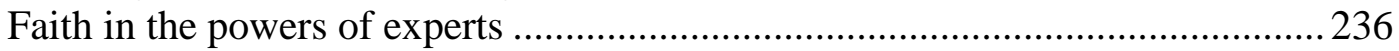

Fears About the Adult Sex Offender Programme..............................................2239

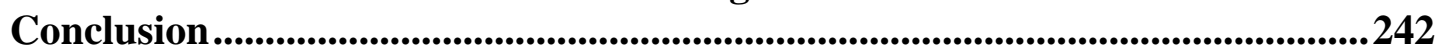

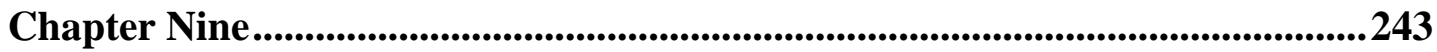

DISCUSSION AND CONCLUSIONS ............................................243

Contradictions and Differences...................................................................................244

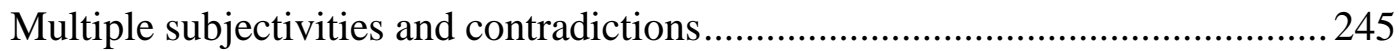

Competing discourses: 'Abnormality' and 'manliness' ....................................... 246

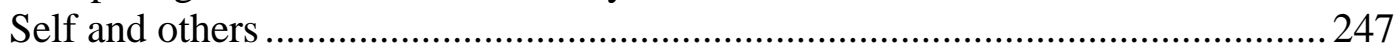

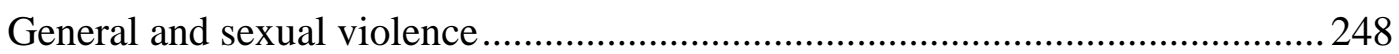

Rationality and emotion in youth violence.................................................... 250 
Taking responsibility and not taking responsibility .........................................253

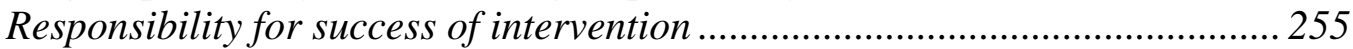

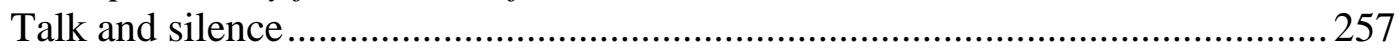

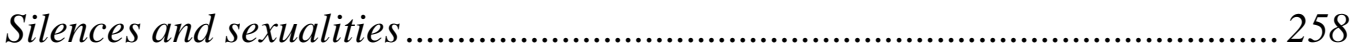

Interventions ...........................................................................................................2259

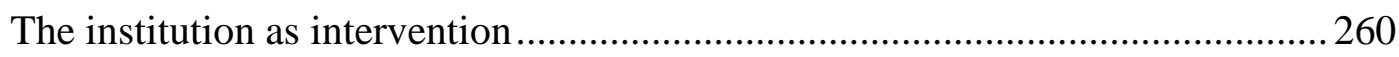

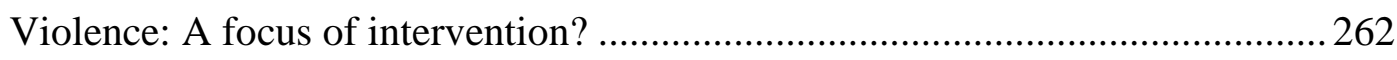

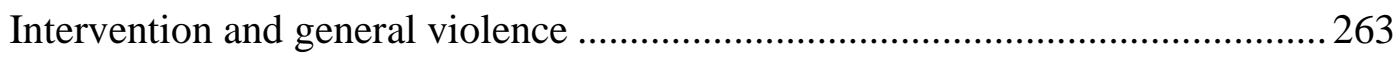

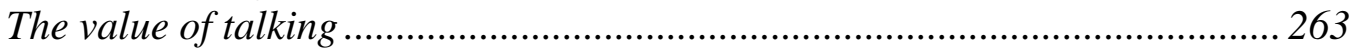

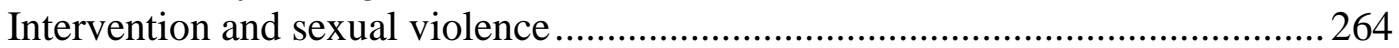

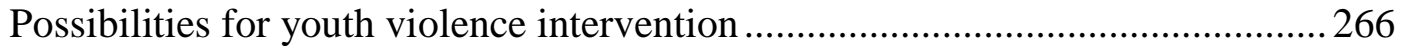

(Re)thinking Youth Violence ........................................................................269

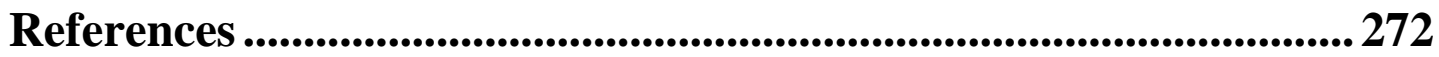

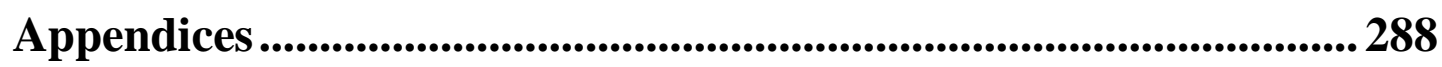




\section{List of Tables}

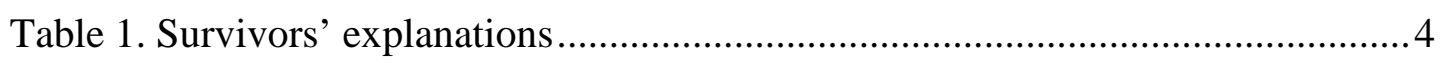

Table 2. Explanations from young men who have been sexually violent ...................6 


\section{CHAPTER ONE}

\section{INTRODUCTION}

This thesis interrogates young men's understandings and explanations for their own violence and explores their experiences of intervention. The philosophical, theoretical and methodological frameworks I have used to undertake this exploration are described. I draw on poststructural concepts of discourse and employ critical psychology to attend to contextual issues, and bring a criticalist stance to the discursive analysis used in this study in order to reveal the complex, contradictory effects of discourses (re)produced by psychological theorising. That is, theorising characterised by a positivist scientific view of human problems that currently dominates the field of youth violence.

Critical psychology proposes that its primary purpose is to offer a critique of what is generally referred to in the literature as mainstream or traditional psychology. These terms can be thought of as referring to:

The psychology most often taught in universities and practiced by clinicians, researchers, and consultants. It is psychology portrayed as a science, with objective researchers and practitioners who uncover the truth about human behavior and help individuals adjust to the demands of modern life. (Prilleltensky \& Fox, 1997, p. 4)

From this definition it is apparent that a reference to mainstream psychology does not include the entire field of psychology, as there are numerous ways of practising psychology and of conceptualising psychological projects. Rather, I read this definition as referring only to those aspects of psychology that rely on a narrowly bounded scientific basis. However, identifying these boundaries is not an easy task, 
given the varied ways such boundaries can be constructed. I offer my reading of these boundaries in Chapter Two when I provide further detail about critical psychology.

Prilleltensky and Fox (1997) go on to say that critical psychology, in general, views mainstream psychology as a social institution, which - through its values, assumptions and practices - contributes to social injustice. Poststructural approaches have been used within critical psychology to query the modernist assumptions of traditional psychology (Gergen, 1990). The discipline's reliance on positivist science where 'truths' are thought to be discoverable through observation, is viewed as limiting because it results in a lack of examination of the social and political implications of its research, theories and practices. This in turn cannot reveal social inequalities and oppression. Critical psychology questions the relevance that scientific methods employed to produce knowledge have for real world applications; for example, laboratory experiments and the use of animals to theorise human behaviour. The dependence on the concept of the individual as a rational, cohesive and unified self has also been problematised to show that inconsistency and paradox are more apparent in individuals than is order.

Exploring the issues of youth violence and intervention from such a critical stance has been a stimulating and challenging journey. At times it has also been highly controversial and politically sensitive. I have actively engaged with these ethical and political aspects and explored how they have influenced the nature and direction of this thesis.

In this chapter, I provide the context within which this research developed. I situate myself in this research by drawing on the professional practice experiences that led me to research young men's explanations of their violence and outline how I started on the path of critiquing my own discipline of psychology. Following this, I provide a guide map of what will be covered in the thesis by outlining its structure and the contents of the chapters. 


\section{My Professional Practice Experiences}

My interest in researching youth violence was initiated by some of the professional practice experiences I had during the 12 years that I worked in the areas of crisis, trauma and violence as a social welfare worker $^{1}$ and psychologist in Australia. I began working in the counselling/therapy field with survivors of violence, who were predominantly women and children escaping domestic violence and surviving sexual violence. $^{2}$ I later worked therapeutically as a specialist counsellor with young men who had been convicted of sexual offences against children, teenagers and adult women. I was surprised by the differences between the survivors' experiences and accounts and those of the young men; I found them discordant and jarring. The types of interventions commonly used were also very different between the two groups.

\section{Working with survivors of violence}

Survivors have always made it very clear to me that their encounter with violence was experienced by them as a life-threatening trauma with negative impacts in many areas of their life, some of which are life-long. These outcomes have been extensively documented (for example, see Briere \& Scott, 2006; Courtois, 2004; Herman, 1992; Putnam, 2003; Salter, 1995) and several journals have specialised in the coverage of the impact of violence on survivors, such as, Trauma, Violence and Abuse and Violence and Victims. Given such trauma, it was no surprise to find survivors trying to make sense of what happened to them by searching for some meaning in the experience and by looking for explanations. This search was often initiated by the question: "Why me?" followed by: "Why did he do it?"

I was troubled by the answers to these questions that most survivors offered when they came into therapy. Their explanations tended to focus on themselves and their behaviour rather than on the perpetrator of the violence. As a result, survivors often blamed themselves for the violence that was inflicted upon them and unwittingly

\footnotetext{
1 In New Zealand this role is called social worker.

2 All the survivors (including male children) that I worked with across these years were offended against by males, except one adult male survivor who was sexually abused by a female. This highlighted the prevalence of male violence to me in my work.
} 
offered justifications for the perpetrator's behaviour. The following are some very common examples I came across.

\section{Table 1. Survivors' explanations}

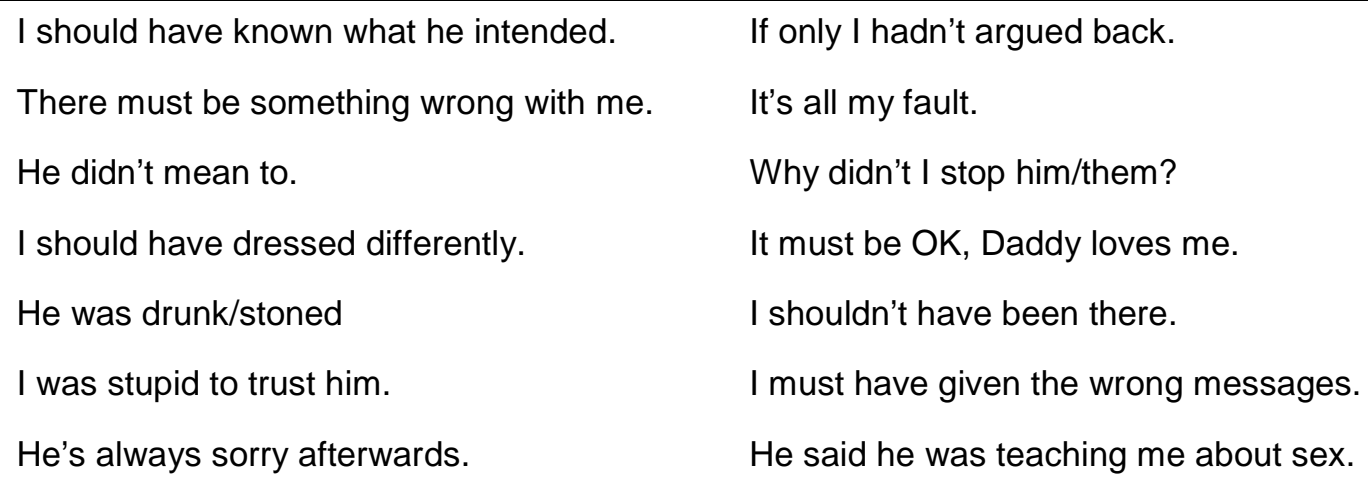

In therapy I saw that these kinds of explanations had significant negative consequences on a survivor's healing, and much of the therapeutic work revolved around resolving these deep emotional injuries. It seemed that to develop these explanations, survivors were drawing on commonly-held ideas about men's violence that are endemic in Western cultures. These ideas have been described by feminist analyses of violence as 'myths' that justify men's violence against women and children (Bograd, 1982; Segal, 1996). As a consequence, many therapists, including myself, focused on these political aspects of violence, utilising a feminist analysis and empowerment model that placed responsibility for the violence on the perpetrator rather than the victim. In this context, it was the survivor who was considered the expert in knowing what she/he needed, and the professional acted as a facilitator of the survivors' recovery journey, offering necessary knowledge and utilising their skills to assist.

\section{Working with young men who had sexual offences}

Working with young men who had been convicted of sexual offences offered a striking contrast to working with survivors. The young men did not appear to be traumatised by behaving violently. Indeed, some described positive outcomes as a result of their violence, such as feeling powerful, taking revenge and gaining sexual 
satisfaction. Although a few reported feeling shameful and guilty about what they had done immediately afterwards, these negative feelings did not motivate them to confess, nor to make restitution to their victim/s nor prevent them from committing further sexual violence.

Some trauma and negative impacts were experienced by these young men in relation to their sexual violence, but less in response to their behaviour than to the consequences they experienced. These consequences were the result of being caught and the ensuing disruption this had on their lives, and included having family, friends and strangers find out about what they did; going to court; being placed under community supervision; being mandated to attend 'treatment', or being sentenced to custody.

I was initially shocked by how commonplace and routine the act of being sexually violent was for a number of these young offenders, particularly for those with a large number of victims. They would describe their violence in matter-of-fact ways, including how it fitted into their daily life.

When asked to explain their violence to me as part of the therapy process (which always occurred after they were convicted and sentenced), the majority of young men I worked with initially denied they had committed the violent act. This denial often occurred despite the court evidence suggesting otherwise, and at times even despite their guilty plea. However, once past this complete denial, the young men offered a range of explanations. While many acknowledged what they had done was wrong and that they should not have done it, their explanations appeared largely designed to justify or excuse their violence. The explanations they gave to me during therapy, in my view, often blamed their victim or an influence or a substance outside their control as being responsible for their being violent, or they were unable to explain their violence at all, as the following examples shown in Table 2 below. ${ }^{3}$

\footnotetext{
${ }^{3}$ These explanations are not unique to young men who have been sexually violent. I have heard similar statements from adult men in therapy. For a discussion of adult men's accounts of their violence against women in a New Zealand context, see Adams, Towns and Gavey (1995).
} 
Table 2. Explanations from young men who have been sexually violent

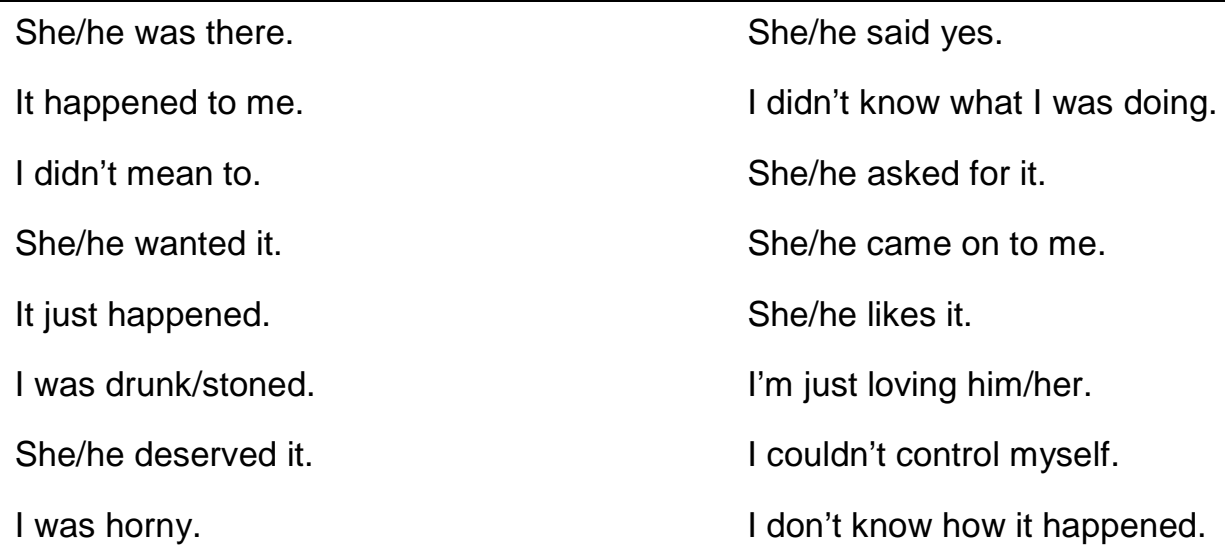

The survivors' search for some kind of meaning in their experience of victimisation cannot be satisfied by the offenders' explanations in Table 2. These explanations suggest that, unlike survivors, these young men were emotionally distant from the harm they caused and some of their explanations functioned to depersonalise the victim and can be read as supporting their violence. I was intrigued by how entrenched these explanations were and how much investment the young men had in maintaining them even while I contested these explanations with them in therapy.

Therapeutic intervention with these young men was therefore focused on challenging their denial, their minimisation of the harm they had caused their victims and their general avoidance of responsibility. The intervention programme for young men who had been sexually violent in which I worked, like most such programmes available, was operated by a government department. It was designed within a psychological paradigm and encompassed a 'treatment' approach, which included the use of cognitive-behaviour therapy (see for example, Hollin, 1990; Hollin \& Howells, 1996; Howell, Reddon, \& Enns, 1997; Howells, 2004). The scientist-practitioner type of approach placed the therapist as the expert who could effectively challenge and confront and who could teach offenders skills with the aim of them changing their behaviour. This was a significantly different type of therapeutic intervention and focus to the therapy I provided to survivors. 


\section{Survivors' and offenders' explanations and this research}

Comparing the experiences of survivors and offenders, despite both having been involved in the same phenomenon (that is, the phenomenon of violence), showed their experience of it to be markedly different. Indeed, for survivors it was a devastating and life-changing event that required extensive reflection and questioning. Yet for most of the young perpetrators, it seemed that their act of violence was experienced, not as a direct opposite of the survivors' experience (that is, not as a life-enhancing, emotionally-positive event), but rather, as a short-lived event to which it seemed they gave little contemplation. Clearly, the phenomenon of violence is neither experienced by survivors and offenders as a dichotomy nor as a continuum where each end is a polar opposite to the other.

Although difference characterised their experiences of violence, the explanations given by survivors and those of the young men who were sexually violent demonstrate considerable similarity. While it was the young men who chose to be violent to their victims, it seemed that both survivors and offenders agreed on explanations that blamed the victim or an outside event. Such complementary explanations have been well described in the domestic and sexual violence literature as resulting from the specific interactions between the perpetrators and victims around the time the violence occurred (for example, see Salter, 1995 for how this occurs with child survivors of sexual assault). However, this does not explain how survivors and perpetrators who do not interact with each other could come up with similar explanations.

Over the years, I have asked individuals as well as various audiences in training workshops and seminar presentations to brainstorm, firstly, the types of statements they would expect survivors of violence to make that would explain what happened to them; and secondly, the types of statements young men would make to explain their violence. With little effort, audiences have been able to come up with examples of explanations much like those listed in Tables 1 and 2 above. Even acknowledging that within any audience there will be survivors and perpetrators of violence, such responses indicate that there is widespread familiarity with these explanations for violence. They are therefore not unique to either survivors or offenders, but rather are 
part of the social world. This research aims to critically examine young men's explanations and understandings of their violence in relation to the social context in which these explanations have developed. How their accounts serve them and with what consequences is also explored.

An additional feature of my work with survivors and offenders of violence was the commonly-reported situation of different types of violence being perpetrated by the same man. For example, relationship violence would include the entire range of physical, sexual and emotional abuse. Some men who offended against female partners also abused their children, either sexually, physically or both. Young men who were sexually violent were also physically violent to their peers. However, many intervention programmes for men who have been violent tend to be restricted to one type of violence, such as either sexual violence or general physical violence (most notably domestic violence). ${ }^{4}$ The purpose of this division into specialty areas is premised on research that has highlighted the unique features of the different types of violence (Barnett, Miller-Perrin, \& Perrin, 2005; Frieze, 2005; Lutzker, 2006; Ward \& Beech, 2006; Ward, Laws, \& Hudson, 2003). When applied to the intervention field, men who have been violent are often artificially categorised as only one particular type of offender (Johnson, 2007).

Unexpected consequences of such specialist labelling of violence within intervention programmes can occur. For example, in the New South Wales Department of Juvenile Justice, those young men in the Sex Offender Programme, in which I worked, described feeling shame and embarrassment from being associated with the programme. Conversely, those in the separate Violent Offender Programme gained status and increased respect from their peers through being labelled a 'violent offender'. This research attempts to probe such differences between general violence and sexual violence and so to offer a perspective that is specific to young men who have committed both types of violence.

The topic of youth violence is often discussed under the broader field of juvenile delinquency and there is considerable literature on violence that focuses on adult

\footnotetext{
${ }^{4}$ For example, New Zealand has an array of programmes for men who have committed domestic violence and specific programmes, such as Wellington STOP, exist for sexually abusive adolescent and adult men.
} 
men. In qualitative work where opinions about violence were sought from young men, the accounts tended to focus on their views regarding the violence of others, or their experiences as victims rather than any violence they have committed (for example, Pollack, 2000; Weaver, 2001). In contrast, my research centres specifically on young men's explanations for their own violence but also looks briefly at their talk about others' violence.

\section{Epistemological and Theoretical Turning Points}

A number of considerations influenced my decisions around ways to investigate the explanations and understandings of young men who had been violent. Firstly, there was my interest in undertaking research that explored the impact of the sociopolitical context of youth violence, such as gender issues. Secondly, I also wanted to find ways to approach some of the complexities of which I had become aware in the practice setting regarding how these young men presented themselves and their accounts. I was aware of the differences between the experience of violence, as described by survivors, and the offenders report of the experience. For example, what I saw and heard in therapy was not what their victims saw or heard during their experience of being assaulted by them.

Discovering what theoretical and methodological approach best suited my research purposes was a journey that occasioned me to question the production of dominant knowledges about youth violence and its subsequent use by the profession of psychology, that is, the application of the scientist-practitioner model. In my view, the discipline did not adequately address those issues of context and complexity that held an interest for me. It was this loss of confidence with the discipline's positivist research foundations that led me onto an unanticipated path towards poststructural thought. Upon reflection, I now think this sense of dissatisfaction with the limitations of scientific psychology had begun early in my professional career and later became more prominent.

\section{Growing discontentment}

From the beginning of my practice within the therapy/counselling field, I was aware that I included what I thought of as additional 'layers' to my work that many other 
psychologists did not. I believed this was because I was dual-qualified, as a social welfare worker as well as a psychologist. These layers that I added gave attention to the socio-political context and encompassed matters beyond the immediate presenting issue clients brought to therapy. I often found the individualism embedded in the scientist-practitioner model of practice to be restrictive. In addition, I considered the pathologisation of people's ordinary reactions to events particularly incongruous for survivors of violence. My way of practising and of interpreting psychological theory and research were therefore strongly influenced by my social welfare training. Such a background provided me with a politicised critical and contextual lens that highlighted the need to pay attention to issues of social justice.

After some years of working professionally, I began further education in clinical psychology. I desired the experience of being part of a like-minded community of lecturers and students to enhance my thinking through discussion and debate. But this did not turn out as I imagined. Given my social welfare background and extensive practice experience, it was common for me to question and critique the theories, research and intervention approaches put forward in the programme. My comments and thinking generally took the form of: "Yes, but what about...?". These questions revolved mostly around such issues as political implications, identifying whose interests were being served, the need for contextual information or the reliance on limited observations as being the only truth. Unfortunately, my questions resulted not in robust academic debate, but rather in silences and uncertainties about the relevance of my questions.

Clinical psychology, as a specialisation within psychology, appeared to exemplify the scientific tradition of the discipline through its focus and emphasis on the scientist-practitioner model. I found the use of critique in clinical psychology to be narrowly focused. Since evaluation of research is made according to precise standards of 'good' science, any critique tends to merely concentrate on the specifics of the research method itself. Hence, it appears that the means to critique the discipline cannot be found within the scientific paradigm.

As a clinical psychology student, I also felt constrained by the privileged status accorded to cognitive-behavioural therapy. My reservations about how this type of 
therapy can be experienced when used in isolation from a broad context were shared by some of the other students. For example, they would often complain about how difficult it was to convince their 'clients' to continue with cognitive-behavioural therapy (so the students could complete their assignments) when their clients expressed their dislike of the approach and requested a change to a more relationship-based interaction.

I turned away from pursuing clinical psychology when I realised that clinical psychology could not meet my needs. This was a time of grief for me, having given up my long-held ambition of being a clinical psychologist, and a time of shattered illusions about the discipline in general. However, my experience was not an isolated one: it is not unusual for some students to discontinue with clinical psychology programmes for similar reasons (Barnett, 2004). ${ }^{5}$

\section{Developing this research}

I had left clinical psychology behind me. Yet, I still believed I could undertake my research within the discipline of psychology, even though I had concluded that much of the scientific research methods would not enable me to explore effectively those issues of youth violence in which I was interested. Consequently, I began to explore what the radical fringes of the discipline could offer me. I was excited by these possibilities. For instance, such writers as Henwood and Pidgeon (1992) provided a critique of positivist scientific research methods and argued for a place in psychology for qualitative methods. Although new to me, qualitative research methods were a useful starting point as I felt such strategies could offer a way of investigation that fitted my research purposes.

Given my extensive enculturation and training in objectivist, quasi-experimental research methods, my initial quest was to find out more about qualitative methodologies and how they differed from those quantitative methods more familiar to me. As I delved into the field of qualitative research, it became clear that I could not simply pick up an approach and use it as a method. For me to gain an

\footnotetext{
5 I have presented some aspects of this research at various conferences and have been surprised by the number of audience members who identified themselves as "recovering psychologists". It has been interesting to hear they had similar journeys.
} 
understanding of what type of qualitative research was the most appropriate for my purposes, I needed to look at the context of research methods, that is, the philosophical basis of social science research (Crotty, 1998). While it may not be unusual for a crisis of confidence in one's own discipline to lead to an examination of its philosophical roots (Hughes, 1990), this led me further away from positivist psychology.

\section{Exploring the philosophical basis of social science research}

As I explored the philosophical basis of social science research, I discovered there were a variety of ways of viewing reality and knowledge, beyond the positivist scientific approach. Given that such conceptions of reality and knowledge influence how specific research methods are utilised and understood (Christians, 2000; Crotty, 1998; Denzin \& Lincoln, 2000), I needed to consider some of the fundamental questions of philosophy that relate to knowledge; such questions as: What is real? What is the truth? How do we know what we know? How is knowledge developed? How do human beings view the world? While these questions were complex, consideration of them was fundamental to my developing an understanding of social science research and also the philosophical foundation for my research.

The more I explored these philosophical questions, the more discontented I became with the methods of research used by mainstream psychology and the philosophical basis. In my previous psychological training, I had not been exposed to the richness and diversity of alternative ways of interpreting the world. Indeed, I recall that rather than being open to such diversity, any research conducted outside the positivist scientific tradition was generally disparaged as being unscientific and was therefore ignored.

\section{Experiencing the influence of differing paradigms}

Grant and Giddings (2002) argue that different paradigms may be useful for particular types of research questions. But determining the value of any research becomes problematic if "we do not understand the paradigm in which the research is located" (p. 12). 
I repeatedly experienced difficulties in communicating and gaining shared understanding with my psychologist colleagues about alternative research paradigms. While some knew of these ideas and we often used the same words, our meanings and understandings were very different and we frequently seemed to be talking past each other.

One way of conceptualising how confusion can emerge when looking at research from different paradigms is to consider how an object in the distance, for example, a snow-capped mountain, may be perceived and evaluated differently if viewed by two people using opposite ends of a set of binoculars. The result is that one person sees a large mountain in great detail, the other sees a much smaller mountain and cannot discern any detail. If these two people were then to discuss and compare their view of the mountain, it is likely that they would assume they had seen exactly what the other had seen. While it is also likely that they would even use the same language to describe the mountain, they would not be able to reach a shared understanding and no doubt confusion about their differences would ensue. However, if each became aware of how the other had used the binoculars, then understanding of their differing views would be immediate.

With hindsight, I have come to realise that the communication difficulties I began to encounter within my profession were the result of a clash of paradigms, that is, seeing different worlds because of using different lenses. Kuhn (1962) points out that misunderstanding is the only possible outcome when trying to communicate across different paradigms.

As a consequence of these turning points, my research uses a different paradigm to that offered by a positivist psychology. Using discourse analysis that is influenced by Foucault and other poststructural writers allows me to consider the socio-political context of youth violence. I identify the discursive effects of the dominant theorising about youth violence evident in the participants' talk. I explore the ways participants both drew on, and resisted these ideas. I embrace critical psychology to critique those ideas that are (re)produced by a positivist psychological paradigm. In addition, the poststructural ideas of contradictory and multiple subjectivities enable this research to engage with the complexities in youth violence. 


\section{Structure of Thesis}

This thesis is made up of nine chapters. Chapter Two: The Research Scaffolding provides a detailed exploration of the philosophical background, theoretical perspectives and methodology that inform this research. This scaffold presents the boundaries and lenses through which to view the rest of the thesis. In expounding the philosophical background of my research, I situate this work in relation to questions regarding the production of knowledge alongside notions of ontology and epistemology. I discuss critical psychology and the poststructural ideas that inform my theoretical perspective, and look at the particular form of discourse analysis, which is heavily influenced by Foucault, that I undertook for my methodology.

In Chapter Three: Positioning Through the Ethical Approval Process, I describe my experience in gaining ethical approval for conducting this research. I use poststructural discourse analysis to look at the texts provided to me by the various ethics committees to explore how the power of the authoritative discourses around youth violence influenced this process and how my research was viewed as a result. I examine how young men who have been violent were positioned in this process as well as myself, and how my proposed research was constructed by the ethics committees.

The specific strategies I employed to interview young men who have been violent are described in Chapter Four: The Research Strategies Used. In this chapter, I provide a picture of the participants and explain the processes I used for accessing these young men. I give some context to the interviews I had with them by describing how I structured the interviews and my experiences of them. I also outline how I went about analysing the transcripts of the interviews, detailing a discourse analysis approach to identifying constructs, examining subject positions and considering implications for subjectivity.

Following this, the next four chapters cover the analysis of the interview data. These analysis chapters focus on how youth violence is constructed by the dominant discourses, most particularly those related to positivist scientific ideas of youth 
violence and intervention. In addition, the positioning of these young men is explored, and the effects of such positionings are of prime importance in the analysis.

My reading of the texts produced by the interviews are therefore woven into a critique of some of the dominant psychological approaches to theorising youth violence and subsequent intervention approaches. I also highlight the unexpected strength of dominant ideas around masculinity that came through from the young men and how these ideas influenced them.

In keeping with a discursive focus, all the participants' contributions are organised collectively and cumulatively in the analysis chapters. Therefore individual stories are not developed, but a general picture emerges about all of these young men. In line with my interest that was sparked by my professional engagement with young men who had offended sexually, my focus for this research was on those who had been officially adjudicated as having been violent and thus labelled an "offender". This process has the discursive effect of these young men knowing how they are viewed by others, but also creates expectations of intervention. Therefore I was not interested in talking with young people who had engaged in violent behaviour but who were not "offenders". However, as I explain in Chapter Four, all participants talked not only about the violence they committed that resulted in their being locked up, but also spoke of the violence they were involved in inside the secure facilities as well as their historical violence and other crimes. The analysis has considered all of this talk.

I have structured the analysis of the interviews with the seven participants into four separate chapters. It became clear to me early in the analysis process that there were significant differences between how participants talked about their general violence and how they talked about the sexual violence they had committed. (Five out of the seven participants were convicted of sexual violence and three of these had also been convicted of general violence). This difference in talk necessitated analysing these two types of violence separately.

In each of the four analysis chapters I explored only those dominant constructions of youth violence reflected and (re)produced within mainstream psychological 
theorising that were revealed in the participants' talk. In this way a focus was maintained on critiquing these constructions in relation to participants' subjectivities and the material effects of the discourses involved.

The first of these analysis chapters is Chapter Five: Grasping the Discourses of Young Men's General Violence, which focuses on my interrogation of the descriptions and explanations the young men gave for their general violence. This covers the following issues: rational violence and anger, being a man and fighting, bad families and the cycle of violence, learning, friends and peer pressure, drugs and alcohol, and victims and empathy. It also describes how the young men compare themselves to others and how others position them.

This is followed by Chapter Six: Intervention for General Violence that explores the experiences of the young men and their ideas about intervention for their general violence. While I expected participants to be involved in some type of therapeutic intervention, such as counselling or therapy; they were not. Because of this, I examined their talk about their experiences of being incarcerated, their experiences of group programmes, and I analyse their ideas regarding the use of talking about their violence as intervention.

The next two analysis chapters concern the young men's sexual violence. Chapter Seven: When Violence is Sexual looks at the young men's understandings of and their explanations for their sexual violence. I examine their talk and their significant silences about sexual violence and discuss how young men who have been sexually violent are positioned.

Chapter Eight: Intervention for Sexual Violence scrutinises the young men's ideas and experiences relating to intervention for their sexual violence. It analyses participants' expectations and fears around such interventions and examines their own questioning about why they were sexually violent.

Chapter Nine: Discussion and Conclusions is the final chapter in the thesis. In this chapter I offer a discussion of the implications of my analysis, including the salience of theorising youth violence differently. I discuss the numerous contradictions that 
are evident. I highlight the differences between general violence and sexual violence, I explore rationality and emotions in relation to youth violence, and discuss the differences between the young men's subject positions and notions of responsibility. I explore participants' talk about their violence and the silences the young men maintain and I also point to some issues to be considered for future intervention approaches.

\section{Conclusion}

Scientific psychological theorising and intervention approaches have become the dominant, legitimised authority on youth violence. This dominance extends beyond the discipline of psychology. This dominance can be viewed as a process of colonisation of the practices of other disciplines, such as social work. As Rose (n.d.) suggests, the techniques of the administration and regulation of people have become "psychologized" (p. 10).

Such dominance in youth violence theorising and intervention, however, appears to have contributed little to changing the extent of youth violence in our societies. Creating a transformative difference in youth violence requires new action and this can only begin with a new way of investigating the phenomenon, which necessitates using a different lens to that of positivist science. 


\section{ChAPTER TWO}

\section{THE RESEARCH SCAFFOLDING}

During the process of developing this research, my shift from the scientific paradigm to one informed by poststructural questions and critical psychology was not without its difficulties. Attempting to understand other ways of viewing the world showed me the power of dominant knowledges. I was confronted with the realisation that my previous ideas about research were based on unquestioned assumptions about the world. These taken-for-granted ideas were so ingrained and 'every-day' that I could not easily recognise them as assumptions, let alone challenge them. Doll (1993) described this encompassing power as resulting from the "adoration of science, its deification" (p. 2) and saw science as:

[O]ne of the dominant obsessions we have had as a people. ... It has performed the task of control so well and so effectively that during this century science has expanded from a discipline or a procedure into a dogma, ... hence creating scientism. (Doll, 1993, p. 2)

Given the impact of such paradigmatic power, it is not possible to embrace an alternative such as one encompassing poststructuralism, as if the scientific paradigm did not exist. Instead, it is first necessary to address this and to allow its inclusion in the formation or development of alternatives, even while this inclusion may be juxtaposed with its rejection as an informative and coherent approach. Guba and Lincoln (1994) suggest that novice researchers in qualitative inquiry "must first be resocialized from their early and usually intense exposure to the received view of science.... Students must come to appreciate paradigm differences" (p. 115). However, such a process of resocialisation may not be the end point. Hughes (1990) 
argues that it is "necessary to respond either by their rejection of the natural science model or by embracing it. Neutrality is not, seemingly, an option" (p. 2). My choice of undertaking a critique of mainstream psychology in this thesis, rather than simply moving on and leaving the discipline behind, may be likened to this resocialisation process; and my take-up of another paradigm indicates my decision to reject natural science as a useful model for investigating youth violence.

The difficulties of understanding research from differing paradigms is highlighted when comparing positivist and non-positivist research:

On some understandings of research (and of truth), this will mean that we are after objective, valid and generalisable conclusions as the outcome of our research. On other understandings, this is never realisable. Human knowledge is not like that. At best, our outcomes will be plausible, perhaps even convincing, ways of seeing the world and, to be sure, helpful ways of seeing things - but certainly not any 'one true way' of seeing things. We may be positivists or non-positivist, therefore. (Crotty, 1998, p. 13)

Research from one paradigm cannot be successfully evaluated against the same criteria employed by another. The social science research literature refers to four interrelated domains that may be considered to make up the context of the research process. These are the philosophical foundation, the theoretical perspective, methodology and methods. Hence, appropriate evaluation of research can occur only against these four specific domains.

My task of disrupting scientifically based psychological theories and practices in relation to youth violence necessitates a critique of the discipline at the paradigmatic level, thus incorporating these philosophical, theoretical and methodological contexts. Not only is it therefore important for me to articulate clearly the methodological aspects of my research, it is also essential that I foreground the philosophical and theoretical aspects as well and make some comparisons with mainstream psychology. In doing so, I depart from the taken-for-grantedness of scientific methods. 
In this chapter, I examine issues of relativism and realism when I discuss the philosophical notion of ontology and look at the epistemology of subjectivism that is related to poststructuralism. I then provide an extensive discussion of the theoretical perspective I take in this thesis, covering poststructuralism and critical psychology. Under the heading of methodology I describe the key aspects of poststructural discourse analysis that have influenced my approach and, finally, when I turn to research methods I discuss the qualitative and quantitative research divide.

\section{The Philosophical Turn}

\section{Ontology}

Philosophical questions are about such fundamental things as truth, being and knowledge. Such questions revolve around ontological and epistemological considerations, which emerge together. Given that ontology is about what exists in the world, the nature of existence and reality (Crotty, 1998), then epistemological questions about our knowledge of this world, how it is made known to us and what counts as knowledge (Grant \& Giddings, 2002) are closely connected. Indeed, some writers have suggested that they can become "one and the same" (Merttens, 1998, p. $60)$.

Philosophical considerations are not open to empirical enquiry nor can any answers to philosophical questions be verified this way (Hughes, 1990). Therefore ontological and epistemological positions may be viewed as being chosen on the basis of what a person believes (Guba \& Lincoln, 1994). Hence, any truth claims made by social science research and the human sciences, including claims about youth violence made by positivist science, ultimately rest on an ontological and epistemological belief system. Such a system in turn subsequently shapes the knowledge produced within the chosen paradigm. These beliefs may be theorised as developing from the various contexts that a gendered and politically-sociallyculturally-and historically-situated researcher inhabits, but these beliefs are often neither examined (Grant \& Giddings, 2002) nor stated. In contrast, I describe the ontological and epistemological positions I take in this research and compare them with those of the scientific paradigm. 


\section{Realism and Relativism}

Issues of existence (ontology) and meaning (epistemology) have become part of an ontological debate between realism and relativism. For example:

Realism (an ontological notion asserting that realties exist outside the mind) is often taken to imply objectivism (an epistemological notion asserting that meaning exists in objects independently of any consciousness).... The existence of a world without a mind is conceivable. Meaning without a mind is not. (Crotty, 1998, pp. 10-11)

The key issue in this debate appears to be what can be regarded as real. Realism considers that objects within the world constitute reality, independent of a conscious mind. A realist approach is closely associated with science, whilst relativism, frequently allied with poststructuralism, views realities as "multiple, intangible mental constructions, socially and experientially based, local and specific in nature ... and dependent for their form and content on the individual persons or groups holding the construction" (Guba \& Lincoln, 1994, p. 111). This relativist notion of realities being constructions is often disputed from a realist perspective. Constructions are considered to be false or an illusion when measured against realist concepts of truth and materiality (Burr, 1998).

The example of a rock has been used to highlight some points of this realism and relativist debate (Montero, 1998; Potter, 1998). There is no doubting a rock's physical existence. It is there. It can be seen. It can be touched. It is real. All these assumptions fit with realism. Yet, what is it that we are seeing? We are not seeing the frenzied action that occurs at the level of molecules. It may be that the rock is not made of earth; it could be plastic. This brings into question the rock's reality. Regardless of its physical make up, the meanings we associate with a rock are endless: we bring our experiences, history and knowledge to this task. A rock may therefore be considered to be many things, such as building material, a stage prop or a weapon, thus showing a multiplicity of possible constructions. 
A common criticism levelled at relativism is that, as a consequence of multiple constructions, the perception is formed that all points of view, opinion and experience are equally valid and so all are considered to be acceptable and legitimate. However, many writers drawing upon relativist notions do not share this view (for example Davies, 1998; Gavey, 1989). Potter (1998) puts it most strongly when he says:

No! Please! How many times does it have to be repeated that 'anything goes' is a realist slur on relativism, ... Anything goes is an extraordinary realist claim, which no relativist has any business espousing. It is a fundamental, timeless, contextless statement about the nature of causal relations, not at all that dissimilar from the laws of physics or psychology. (p. 34)

Potter's response highlights that relativism is frequently evaluated against realist concepts. Yet, as Laclau and Mouffe (1987) suggest, such criticism is meaningless because outside a discursive context, objects can only have existence, they cannot have being.

From a relativist viewpoint, 'truth' is variable and multiple, but 'truths' do not necessarily equate to ethical or social justice values. For example, the truth for some can be about how best to inflict the worse pain, to gain revenge or to get more than others. Relativism does not provide the way to determine issues of justice, fairness or usefulness; instead, there is a need to bring in political, values and ethical frameworks to make these judgements. Such frameworks provide the contexts within which relativist notions can be considered. To achieve this, some writers speak of the need for ideological critique as a means of resistance (Foster, 1998) or a commitment to a political position (Willig, 1998) or acceptance that the aim of research is to provide a possible reading of a topic rather than to convince others or provide truths (Gavey, 1989). In this research, I fully accept that physical and social realities exist, but I take a relativist position when it comes to what those realties mean and therefore offer a particular interpretation around youth violence. In addition, I use critical psychology as a political and ethical framework. 


\section{Epistemology}

\section{Subjectivism and objectivism}

Keeping the above ontological discussion in mind, together with an awareness of the close connection between ontology and epistemology, I now turn to subjectivism, which is associated with poststructuralist thought and is the epistemological stance I take in this research. Subjectivism is the theory of knowledge that is embedded in my theoretical perspective and informs my methodology.

My reading of a subjectivist epistemology considers that meaning is provided by the subject (person) and is imposed on an object (thing). Such meaning comes from other human experiences, understandings and ideas such as dreams, previous experiences or spiritual beliefs. Therefore it is considered that the object itself does not contribute towards the development of meaning. The meaning of words does not come from an object's being; instead, it is the discursive context that provides meaning and different words can be applied to the same object for different purposes (Willig, 1998). For example, a young man who has been violent can be known variously as, 'a student', 'a boyfriend', 'a juvenile delinquent', or 'an animal'. 6

In contrast, an objectivist epistemology considers that meaning and truth are contained within the object itself, independent of human consciousness (Crotty, 1998). Accordingly, it is thought that to discover this truth, close observation of the object is required, and eventually the facts about the object's meaning will be revealed by the object itself. This epistemology forms the basis of mainstream psychology: those aspects of being human, such as our understandings, values and experiences, are objectified and studied in the belief that the objective truth will be discovered (Prilleltensky \& Nelson, 2002).

Epistemologies are not necessarily mutually exclusive and any distinctions may be due to the impact of differing ontological positions (Crotty, 1998). However, the differences between subjectivism and objectivism are highly distinctive and inhibit

\footnotetext{
${ }^{6}$ Another epistemology of relevance is constructionism, which is, according to Crotty (1998) sometimes confused with subjectivism. Constructionism considers that there are no objective facts and, while human beings do give meaning to objects (like subjectivism), they do so through their interaction with what the object reveals. Thus, the multiple meanings that are possible are constrained by what the object offers.
} 
any overlap. It is difficult to imagine how the meaning of an object can be both wholly imposed on it as in subjectivism versus wholly invested in the object itself as in objectivism. Thus I read these as contradictory epistemologies.

Not only does epistemology merge with ontology, it is also closely aligned to theoretical perspectives. Crotty (1998) suggests that any research methods or methodologies can be utilised by any theoretical perspective. However, he cautions that the choice of epistemology will restrict what choice is then possible for the theoretical perspective because of issues of incompatibility. For example, the epistemology of subjectivism is not congruent with the theoretical perspective of positivism. Thus "typical strings" (p. 12) of the four research domains (philosophical foundation, theoretical perspective, methodology and methods) become evident. I have used one such string in this study that includes: a relativist ontology, a subjectivist epistemology, a poststructuralist theoretical perspective, a discourse analysis methodology and interviews as a research method. Another typical string that is common to a scientifically informed psychology includes: an ontology of realism, an objectivist epistemology, a positivist methodology, and research methods involving surveys and statistical analyses. Of course these typical strings are by no means the only possible combinations.

\section{Theoretical Perspective}

There are many promising theoretical perspectives for a researcher. Indeed, it is possible to combine several complementary ones, which I have done for this study. By drawing on both poststructuralism and critical psychology, I am provided with sophisticated ways to examine youth violence as well as to critique dominant approaches to youth violence.

\section{Poststructuralism}

When I first ventured into the world of poststructuralism, I found myself floundering with entirely new ways of thinking that challenged my previously-held concepts. It was a formidable challenge, as Hollway (1989) recognised when she described that those "schooled in an opposing tradition (as psychologists have) will get irritated because they cannot understand" (p. 24). Many writers have described their own 
difficulties and frustrations when engaging with poststructural ideas for the first time (for example, Hollway, 1989; Lather, 1991), and it has been recognised that poststructuralism requires considerable time and study for the material to become familiar (Gavey, 1989). This process of discovery was a painful one and highlighted how strong the influence scientific psychology had on me, but I did not recognise this until I challenged it. "Many psychologists will feel abused and betrayed. What promised to be an interesting intellectual adventure proves a lethal assault on all that is dear and important" (Gergen, 1990, p. 31). However, I persevered because I sensed that this new world held numerous potentials, as Gergen goes on to comment: "postmodernist views, once savoured, can scarcely be abandoned. They are, as one young scholar put it, like a 'sweet poison'. Once tasted, the appetite becomes ever keener" (p. 31).

\section{Definitions and terms}

Several issues contribute to the difficulty in developing an understanding of poststructuralism, including the obscurity around its definition and its contested relationship to postmodernism. Some writers argue that attempts to define poststructuralism are not only impossible, since it is "too new to define itself and too varied" (Doll, 1993, p. 5), but also that a definition is not desirable. "An important part of poststructuralism is its resistance to definition or even identification, presumably because such practices represent an attempt to pin down an essence that does not exist" (Gavey, 1989, p. 460).

There is also some confusion between the terms postmodernism and poststructuralism. It is common to find the terms used synonymously (for example, Lather, 1991). Sarup (1993) is one writer who uses the terms interchangeably, claiming that poststructural theories and postmodernism share so many similarities that distinguishing between them is difficult.

However, many writers prefer to distinguish between postmodernism and poststructuralism to some extent by describing poststructuralism as coming from the broader movement of postmodernism (Cheek, 2000; Gavey, 1989). Cheek (2000) 
offers a way of understanding this relationship that I have found useful when she describes the specific focus of each approach:

Unlike postmodern analyses which tend to be wider in scope and which focus on aspects of culture, society and history, poststructural studies have tended to concentrate of analyses of literary and cultural texts where text refers to a representation of any aspect of reality (p. 40).

Any type of description of poststructuralism risks losing its complexity (Gavey, 1989). Nevertheless, my task here is to attempt to describe the key poststructural ideas I have engaged with for this research in full awareness of the plurality of meanings of poststructuralism (Weedon, 1987). Hence, I provide my current reading with the expectation that others will have different readings of the material.

\section{Postmodernism and modernism}

To fully appreciate which features of poststructuralism would be of most relevance to this research, I found it helpful to look at postmodernism and particularly those aspects that represent a departure from the worldview of a scientific paradigm.

The postmodern world can be conceptualised as being a transformed post-industrial social world with changes in material conditions and significant shifts both culturally and socially (Kenway \& Willis, 1995). These changes are relevant primarily in advanced capitalist societies (Sarup, 1993) and are identified with a revolution in information technology and communications (Lather, 1992), as well as the formation of a consumer culture (Kenway \& Willis, 1995). Added to this are various social movements, for example, the peace and gay rights movements. All of these changes have impacted on social relationships as well as intellectual and artistic directions. Postmodernism, as an intellectual movement, may be considered as attempting to understand this new, radically different socio-political reality (Crotty, 1998).

Interpretations of postmodernism are also associated with definitions of modernism. One definition of modernism refers to social conditions that have sprung from industrialisation (Crotty, 1998). In this conceptualisation of modernism, rationality is judged to be its key feature, defining its science. Therefore postmodernism can be 
viewed as a critique of modernism that calls into question such reliance on rationalism. It is:

A thorough rejection of what modernism stands for and an overturning of the foundations on which it rests. ... Instead of espousing clarity, certitude, wholeness and continuity, postmodernism commits itself to ambiguity, relativity, fragmentation, particularity and discontinuity. ... $[\mathrm{P}]$ ostmodernism typically engages in a radical decentering of the subject. (Crotty, 1998, p. 185)

Postmodernism can therefore be characterised as a rupture from modernist forms of legitimation, which are described as grand narratives (Lather, 1991; Sarup, 1993). These are modernist ways of viewing the social world that speak of "universal knowledge" and of the progression of science for the "liberation of humanity" (Sarup, 1993, p. 132). Postmodernism "break[s] with totalizing, universalizing 'metanarratives' and the humanist view of the subject that undergirds them" (Lather, 1991, p. 5).

When it comes to the production of knowledge, postmodernism challenges the modernist notions of the human sciences, including those within mainstream psychology, in which scientific knowledge is viewed as a value-neutral, universal truth that contributes to the steady progression of civilization (Danaher, Schirato, \& Webb, 2000). Instead, from a postmodernist perspective such knowledge is perceived as being highly politicised, full of contradictions and prejudices; this perspective emphasises the plurality of meanings and the multiplicities of possible views (Cheek, 2000). Thus the modernist myth of coherency is exposed, including the coherence of the subject.

Poststructuralism encompasses this postmodern critique of modernism and in turn offers ways of troubling dominant constructions. Like postmodernism, poststructuralism is about disturbing, confronting and disrupting what has been thought to be safe, incontestable knowledge (Lather, 1992) and "displacing dominant (oppressive) knowledges" (Gavey, 1989, p. 463). Hence, knowledge developed from traditional science is deemed to be the same as any other knowledge, for example, 
people's opinions, and is not deemed to be the only legitimate truth. Unlike the modernist view, knowledge is posited as "constructed, contested, incessantly perspectival and polyphonic" (Lather, 1991, p. xx).

\section{Poststructuralism and discourse}

Poststructuralism differs from postmodernism in its focus on language. The concept of discourse enables this focus on language and texts, and an analysis of discourse is the primary vehicle that poststructuralism utilises to explore meaning, subjectivity, power and knowledge.

Some aspects of poststructuralism have their origins in structuralism, which is a form of thought that considers the social world to be engineered through broad systematic systems and structures. Ferdinand de Saussure (1815-1913) was one structuralist who viewed language as the most significant determining system for human beings and contributed to the 'linguistic turn' within the social sciences by developing his theory of the sign which "expounds it as a union of signifier (a form, or symbol) with signified (an idea)" (Crotty, 1998, p. 197). Saussure saw this relationship between the word and the idea that it signified as completely arbitrary, that is, the signifier did not represent a real aspect of the world, but rather an idea. It is this aspect of structuralism, with its subjectivist epistemology, that poststructuralism has taken up.

Derrida (1976/1997) proposed the idea of signs never being completed, but as always signifying something else. Signifiers thus become signifieds and these become signifiers in a never-ending circular movement. For example, the word 'Ferrari' signifies a make of car but also signifies many other things as well, such as status in relation to power and money, the type of person who drives a Ferrari and even possible motivations for buying this particular type of car.

If linguistic signs do not represent reality, but the meaning of words comes from the relation of meaning to other words, then language can be understood as constructing reality. Consequently, 'truths' may be viewed as an effect of discourse (Merttens, 1998), and "all meaning and knowledge is discursively constituted through language and other signifying practices" (Gavey, 1989, p. 463). Such a view of language is 
strikingly different to that of the dominant psychological one, which relies on "the liberal humanist view of language as transparent and expressive, merely reflecting and describing (pre-existing) subjectivity and human experience of the world" (Gavey, 1989, p. 463).

\section{Towards a discursive approach}

In developing an understanding of discourse from a poststructural perspective, I have found it useful to study the writings of some authors as they attempted to bridge the paradigm gap between poststructuralism and mainstream psychology.

The term discourse is commonly used interchangeably with the term language, and regarded merely as what is said or written on a particular topic. However, a poststructural approach argues that "language is always located in discourse" (Gavey, 1989, p. 463). Therefore discourse is conceived of as a broader concept that goes beyond the modernist concept that language represents reality. Instead, discourse constructs the objects and subjects that it names (Foucault, 1969/1972) so that it is possible to view such objects not as independent realities, but rather as discursive formations (Davies, 1994). Discourses are therefore considered to be the way meaning and knowledge are constructed and transmitted through culture (Parker, 1992).

From a poststructural perspective, discourses determine what can be said and written, as well as what can be done in particular contexts and by whom (Willig, 2000). Discourses make possible, but also restrict our ways of thinking, speaking and being. By focusing on what participants say and what they cannot say in relation to their violence in this study, it is possible to identify the dominant constructions of youth violence that are reflected and (re)produced in mainstream psychological theories and explore their effects. Foucault (1966/1970) wrote of the 'order of things' in which he described the organisation, categorisation and relationships between things that form the basis of our knowledge. But such an order is mostly outside our awareness. Consequently, discourses often fall outside our critical judgment. 
Discourses are considered to form our current systems of meaning and thus construct the social world, but they are also products of that social world so they cannot be considered as objects that are separate. This notion of discourse being both productive and reflective makes the concept a complex one to engage with. Some clarity is offered by Henriques, Hollway, Urwin, Venn, and Walkerdine (1984) who suggested that discourse is a production of material and discursive practices within the social world, rather than originating from the ideas of individuals as a traditional approach to psychology views the process.

Discourses are historically and socially situated. They are specific to particular groups and cultures at specific time periods and they are always changing (Gavey, 1989). Discourses are therefore neither static nor universal. They are also viewed as discontinuous, but because they overlap with other discourses (McHoul \& Grace, 1998), a complex discursive web results, making it difficult to isolate a single discourse. Added to this complexity is the argument that "discourses are multiple, and they offer competing, potentially contradictory ways of giving meaning to the world" (Gavey, 1989, p. 464). Such contradictions enable the recognition that multiple truths are legitimate and that contradictions in relation to subjectivity can be considered a function of the discourses rather than as residing within the individual (Davies, 1994).

Although multiple discourses exist and some are contradictory, not all are considered equal (Merttens, 1998); some are marginalised and others are excluded altogether:

Dominant discourses privilege those versions of social reality which legitimate existing power relations and social structures. Some discourses are so entrenched that it is very difficult to see how we may challenge them. They have become 'common sense'. (Willig, 2000, p. 107)

Discourses are described as being made up of statements that link with other statements, and although few in number, they are referred to constantly (Danaher et al., 2000). Analysis of the statements of a discourse makes visible the discursive formations of dominant discourses that were once taken for granted as Davies (1994) 
pointed out: "by making hegemonic sets of assumptions visible, the nature of what we take to be factual or real is profoundly shifted" (p. 20). A discourse is a body of knowledge, and knowledge is made up of the social, historical and political conditions that enable truth claims to be made (McHoul \& Grace, 1998). A counterreading of these conditions offers an avenue to critique dominant notions and practices of social regulation and control in relation to youth violence.

\section{Power/knowledge}

Foucault (1980) introduced an account of power that was different to a modernist version, which holds that power resides with people and is held by those at the top of a hierarchy. Instead, Foucault saw power as being a function of discourse, that it was "capillary: operating in all levels and directions of society in an extensive network of power relations" (Cheek, 2000, p. 26) and, importantly, that it was inseparable from knowledge. "Knowledge from within one discourse" is "used to exclude knowledge from other discourses" (Cheek, 2000, p. 24). Therefore those discourses whose truth claims become legitimated, that is, the dominant discourses, are a result of power relations. Hence, as Foucault emphasised in his writings, our current knowledge and social practices could have been different.

\section{Subjectivity}

From the point of view of poststructuralism, subjectivity describes the experience of being a person, our emotions and our understanding of how we relate to the social world (Weedon, 1987). Poststructuralism offers a very different conceptualisation of what a person is and how they become who they are, compared to the humanist individual, who is characterised as having an essential self that is stable and fixed, being made up of static factors, for example, sex and race (Lather, 1991). This self is rational and conscious as well as unified and coherent (Gavey, 1989), free to decide their own actions (Sarup, 1993) as well as being the agent of change for society (Weedon, 1987).

Poststructuralism aims to deconstruct or de-centre the subject (Lather, 1991) and show the humanist subject to be a myth (Sarup, 1993). The classic text of Changing the subject: Psychology, social regulation and subjectivity (Henriques et al., 1984) 
has influenced much of the writing and thinking about this shift away from the coherent, unitary individual of mainstream psychology towards a more complex poststructural subjectivity. The poststructural subject instead is revealed as "fragmented, inconsistent, and contradictory" (Gavey, 1989, p. 465), it is a constantly shifting, multifaceted site of conflict that is continually in process (Davies, 1994; Sarup, 1993; Weedon, 1987). The poststructural approach to the subject expects and indeed celebrates complexity and contradiction in its concept of subjectivity. Subjectivity is argued as being constructed through language, discourses and discursive practices, which "makes social and personal being possible but it also limits the available forms of being to those which make sense within the terms provided by language" (Davies, 1989b, p. 1).

Dominant discourses tend to have legitimated authority and therefore have the greatest influence on constituting the subjectivity of "most people most of the time" (Gavey, 1989, p. 464). However, since there are multiple and contradictory discourses, then multiple and contradictory subjectivities are produced. A rather disturbing example of multiple subjectivities is given by Steiner (1972, as cited in Merttens, 1998) of an SS guard at Auschwitz during World War Two who was presumably involved in killing of thousands of people, but who also practised the beautiful music of Bach each evening.

The idea that our desires, generated through one discourse, may be in conflict with our ideas of who we are in another discourse illustrates that such desires are constructed rather than being a part of who we are. It is also clear that they can be changed (Henriques et al., 1984). Such change may be achieved by actively using discourses, which offers powerful possibilities in reproducing one's subjectivity (Davies, 1998). Subjectivity is in a state of flux moment by moment: "we are continually constituting and reconstituting ourselves and the social world through the various discourses in which we participate" (Davies, 1989b, p. xi). Subjectivity that is multiple, never fixed and often in conflict highlights complexity. This idea of multiple subjectivities offers considerable potential for examining the complexities of young men who have been violent. 


\section{Positioning}

The notion of subject positions is how poststructuralism describes and explores the connection between discourse and subjectivity. Discourses construct these subject positions and "make available certain ways-of-seeing the world and certain ways-ofbeing in the world" (Willig, 2000, p. 107). It is through analysing such positioning that power relations can be made visible (Merttens, 1998). Thereby, the effects of dominant discourses are revealed. In this way, examining the positioning of young men who have been violent enables me in this study to trouble the discourses that construct their violence.

Subjects are positioned through a complex mix of how others position them and what they do themselves. Using the example of hailing by a police officer, "Hey, you there!", Althusser (1971, p. 163) shows how this works. The person being hailed is immediately positioned as a suspect. Since discourses interact, and because subjects are positioned within numerous discourses, a position within one discourse has an impact on a position in another discourse. Thus the possibilities for subjectivity become multiple and of course contradictory (Davies, 1994). The police officer's "Hey, you there!" is more likely to be addressed to a young man on the street rather than to a well-dressed elderly man because the young man is already positioned within the adolescent discourse as a trouble maker, and hence as a target for police attention.

Subject positions are constructed in relation to others (Davies, 1989b). Thus others are needed to maintain a particular subject position in a specific discourse. For example, psychologists working in the clinical field require 'clients'; police officers require 'offenders'. Other people assist the maintenance of subject positions by providing information on whether a person is performing the position correctly. However, whether such a performance is deemed correct will differ depending on the situational context and who else is present (Laws \& Davies, 2000). What is considered correct performance is determined by dominant discourses in which such performance has become 'normative'. For example, knowing how to correctly perform the subject position of 'man' relies on the dominant discourses around masculinity, which are easily recognisable and the behaviours consistent with this 
position are taken up and performed. Any transgression of normative behaviour will be quickly criticised by others.

This idea of correct performance of normative subject positions raises the question of the extent to which people have agency in 'taking up' subject positions. There has been some debate around this issue (see Davies, 1997; Jones, 1997 for a useful discussion). Jones argues that references to agency within some poststructural writing risks introducing a prediscursive, humanist subject. However, as Gavey (1989) points out it is important to read such agency not as the rational choice of an essentialist humanist subject, but rather as the product of the discursive practices that people engage in. Discourses constitute subjectivity and that "very shaping" is considered to be the process by which power and agency is gained. "The dual nature of subjectification is hard to grasp: one is simultaneously subjected and at the same time can become an agentic, speaking subject" (Laws \& Davies, 2000, p. 206). This notion makes it possible to accept that resistance to subject positions is feasible, as is actively taking up particular positions. But these can only be positions available from discourses people have learnt via discursive practices (Davies, 1994) and thus any taking up or resistance to subject positions requires engagement with subjective as well as social constraints (Davies, 1989b). It is possible to consider agency as an effect of discursive practices and technologies, thus resistance to any regulation of conduct is an act of judgement between available discourses.

\section{Surveillance}

The concept of surveillance demonstrates how subjectivity is shaped and how people work to perform subject positions 'correctly'. Foucault (1975/1977) described this process eloquently when he outlined the effects of the 'gaze' using the metaphor of the 'panopticon'. The panopticon was a prison design that enabled only one guard, who was centrally located but unseen by the prisoners, to be able to see all the prisoners, all of the time. Being under constant scrutiny, and being punished severely for any misbehaviour but never knowing when they were being watched, led the prisoners to discipline themselves to avoid punishment. 
It is this process of disciplining subjects that shows the power of discourses. Such power is exercised without the need for force because each person turns this gaze upon themselves and becomes a compliant docile body, the subject of regulatory practices (Foucault, 1975/1977). In this way, the social regulation and disciplining of subjects by the human sciences is achieved:

Modern societies control and discipline their populations by sanctioning the knowledge claims and practices of the human sciences: medicine, psychiatry, psychology, criminology and sociology. The human sciences have established certain norms and these are reproduced and legitimized through the practices of teachers, social workers, doctors, judges, policemen and administrators. (Sarup, 1993, p. 72)

Being subjected to and by such knowledge claims and practices that control and regulate, thereby produces our subjectivity (Davies, 1994). Hence, discourses are not only oppressive but they are also productive and as such are readily accepted by people, but this acceptance is, most often without awareness. Subjects become the vehicle of the power that constituted them and so become part of the relations of power (McHoul \& Grace, 1998). From this notion of the subject being both constituted by and constitutive of power/knowledge relations, it is possible to consider the effect of discourses as occurring at the level of the individual subject. By focusing at this level, the broader discursive context and the operations of power can be revealed. Therefore interrogating the talk of young men who have been violent will show how they are positioned and how their violence is constructed.

\section{Critical psychology}

Another important part of the theoretical perspective I take in this research is critical psychology. Critical psychology can be thought of as a framework from which it is possible to critique mainstream psychology. The seeds of critical psychology appear to have begun in the 1960s and 1970s within a broader context of social change when much about the industrialised social world was being questioned and concerns were raised about oppression and inequalities (Henriques et al., 1984). 
Critical psychology is concerned with issues of social justice and human welfare and argues that a modernist psychology contributes to unjust social conditions, hampering social justice and maintaining the status quo of unequal power relations. This critique is directed toward its scientific basis, as well as the specific theories and practices that are produced (Prilleltensky \& Fox, 1997).

\section{Positivism and postpositivism}

The discipline of psychology is often described as modelling itself on the physical sciences in its efforts to achieve the status of a legitimate science (Prilleltensky \& Fox, 1997). Critical psychology questions the discipline's positivist theoretical perspective that is based on the objectivist epistemology of modernist thought and critiques its use of experimental methods, viewing its findings as maintaining the social status quo of inequality and injustice.

Positivism can be defined as viewing knowledge as objective 'truths' that are discoverable through direct experience of the phenomenon (Crotty, 1998). Direct experience is what can be observed via the five senses whilst using the scientific method. Objective, verified knowledge discovers objective meaning through empirical study and differs from opinion, reasoning, beliefs or feelings. This knowledge becomes established as 'fact', making claims of validity and generalisability.

It has been suggested that the dominant psychological paradigm is now postpositivist rather than positivist, but this depends on the definition given to these terms. Some writers (such as Lather, 1992; Ussher, 1992) identify postpositivist approaches as challenging positivism and so are fundamentally different, as Lather (1992) describes:

Postpositivism refers to the great ferment over what is seen as appropriate within the boundaries of the human sciences. Postpositivist philosophies of science turn more and more to interpretive social theory, where the focus is on constructed versus found worlds. (p. 89) 
However, the above definition of postpositivism does not describe scientifically based psychological approaches. For other writers, postpositivism refers to a development within positivism that simply makes less stringent truth claims (for example, Crotty, 1998; Guba \& Lincoln, 1994). However, such an advancement is little different to positivism, as the underlying belief systems (philosophical foundation) remain the same (Grant \& Giddings, 2002). Therefore mainstream psychology can still be considered to hold a positivist theoretical perspective.

There is a recognised dominance of positivism in social science inquiry (Lather, 1992), yet such dominance is seen to be weakening. This is perceived as occurring mostly across specific disciplines, such as sociology (Hughes, 1990) and the theoretical arena of education (Lather, 1991). However, this weakening does not seem to be the case for a modernist psychology, where the orthodoxy of positivism is still thought to hold sway (Grant \& Giddings, 2002). Such dominance continues to exert powerful effects, "as anyone knows who tries to get published in most journals, obtain grants from most funding agencies, or have research projects accepted by dissertation committees" (Lather, 1992, p. 90).

The commitment to positivism seems unusual given the extent to which criticism is levelled at positivism. For example, the physical sciences themselves are changing because of the challenges that "the indeterminancy and relativism of quantum physics" (Doll, 1993, p. 2) and chaos theory have brought. Instead, "the mainstream marches blithely on, relatively undisturbed. The lines of debate are confusing with criss-crossing alliances and numerous border-crossings, some counter raids" (Foster, 1998, p. 108), but the positivist basis remains intact.

\section{The critique of mainstream psychology}

For those new to the discipline of psychology, many of its aspects can appear to have a rather unexpected focus, for example, statistics and animals, rather than explanations of how and why human beings are the way they are. It has also been critiqued on the basis of its relevance and usefulness from outside the discipline, as an introductory mental health nursing text explains: 
Overall, mainstream psychology has reduced people to separate bits, such as cognition, perception and behaviour. Apart from consisting of disconnected areas of knowledge, psychology too omits the political, economic and social environment of the people whose cognition (for example) is studied or treated. The experiential aspects of being a person with a particular sex, class, ethnicity, age and sexual orientation is also ignored. Similarly, the qualities that we probably do not share with animals ... such as spirituality, soul, emotional complexity and unconscious processes, fall outside present-day mainstream knowledge development in psychology. (Horsfall \& Stuhlmiller, 2000, pp. 59-60)

A recognition of the limitations of positivist psychology has also been evident inside the discipline, with some efforts for improvement being attempted. Indeed, Rennie, Phillips, and Quartaro (1988) suggested some time ago that consideration of qualitative methods was a way to overcome the "growing indications that psychology as a discipline is undergoing a crisis of confidence about its research methods" (p. 139). Yet simply adding qualitative methods to a scientific modernist paradigm can not challenge the discipline's philosophical foundation, theoretical perspectives or methodologies.

Psychology is not necessarily always practiced within the confines of a scientific paradigm with its objectivist epistemology and its positivist theoretical perspective. Within the broader field of psychology there are resistances to the dominant disciplinary discourses, and there are various ways in which people associate with mainstream psychology. Foucault, for example, experienced dissatisfaction with the discipline and it became one of the human sciences that he aimed to disrupt and challenge (Sheridan, 1980). Those who position themselves as critical psychologists draw upon a wide collection of philosophical, theoretical and methodological possibilities, thus in no way do they represent a united group, instead, such diversity is welcomed.

The critique of traditional modernist approaches to psychology has a multitude of focus areas. Gergen (1990) provides a feel for this diversity: 
Critical psychologists question the individualistic and exploitative ideology underlying such inquiry; feminists question the androcentric biases inherent in theory and method. There is increasing talk of epistemology [and] alternative methodologies. ... There is increasing concern with theoretical as opposed to empirical issues (pp. 23-24).

\section{The 'psy' complex}

The role of scientific knowledge in the lives of human beings has been questioned by critical psychologists working from a poststructural perspective. "Science is treated as a set of social practices, of organized procedures and ways of talking - that is, science is a 'discursive enterprise'" (Morss, 1996) and is constituted by human interest (Rose, n.d.). Positivist psychology has acquired a status as an effective scientific endeavour, but the constitutive force of the discipline and its role in regulating the population is deemed as problematic by some critical psychologists (Davies, 1998).

Rose (1985) offers a comprehensive critique of psychology and the related "psychosciences" in his history of the 'psy' complex, that is, "all those disciplines which, ... have designated themselves with the prefix psy - psychology, psychiatry, psychotherapy, psychoanalysis" (Rose, 1996, p. 10). Of primary significance in this history is to point out that objectivist psychology was not simply an academic pursuit but played an active role in the regulation of society:

The psychology of the individual existed as more than merely a set of arguments and explanations of problems embodied in books, articles, reports of experiments and so forth. It also consisted of a set of practical instruments and techniques which embodied the explanations proposed and deployed them in relation to the practical problems which had occasioned them. A whole technology was constructed, consisting in manuals of instruction, testing and assessment procedures, rules of diagnostic practice and classification, techniques of therapy and reformation.... These new practices were carried out by agents designated competent to pronounce the explanations of the psychology 
of the individual and to utilise its practical skills, by virtue of their training, qualifications and experience. (Rose, 1985, pp. 8-9)

The construction of the normal/abnormal dualism, Rose (1985) argues, has not developed from psychology's study of 'normal' human functioning, which is then applied to problems of 'abnormality'. Instead, the focus was on the deployment of psychological expertise to those problems of abnormality that individuals' experienced. It is from this basis that "psychology invented the normal individual" and invented "therapies of normality or the psychologies of everyday life" (p. 17). This normality was constructed as that which lacked "socially disturbing symptoms, an absence of social inefficiency: that which did not need to be regulated" (p. 6).

The regulation of individuals was described as the "conduct of conduct" by Rose (n.d., p. 9), drawing on the Foucauldian concept of governmentality, in which the beliefs and conduct of the population is shaped. Rose described this as being achieved through numerous programmes, techniques, policies and practices not only to "control, subdue, discipline, normalize, or reform them, but also to make them more intelligent, wise, happy, virtuous, healthy, productive, docile, enterprising, fulfilled, self-esteeming, empowered" (Rose, 1996, p. 12). In this way, all human activities and subjectivity have "become psychological" (Rose, n.d., p. 8) and historically psychology gained its authority and its legitimacy in the institutions of the day, such as, schools, prisons, the military and the factory (Rose, 1996).

Gergen (1990) proposes a postmodern psychology, one that critiques the modernist assumptions of traditional psychology and offers instead "the vanishing subject matter" as a suitable target for study. He recommends moving "from universal properties to contextual reflection", and suggests "the marginalization of method"; he also challenges the modernist scientific notion of "the grand narrative of progress" (pp. 29-30). In keeping with this view, a poststructural discourse analysis offers a way to challenge the taken-for-granted dominant constructions of the discipline, such as the humanist subject. 


\section{Constructions of masculinities}

Science, and therefore psychological approaches based in the positivist paradigm, have been described as being highly masculine endeavours with an anti-feminine stance and a focus on rationality, prediction and control (Ussher, 1992). Such masculinisation may appear to be 'natural', and taken-for-granted, having the effect of being hidden and untroubled. This embeddedness of masculinity within scientific projects may help explain the objectivist psychological conceptions of gender that have been widely criticised. The notion of essentialised and fixed sex-roles that are a natural consequence of a biological category is perceived as limiting (Connell, 1995). Much of the positivist research based on this premise revolves around the simple idea of sex differences, including concepts of masculinity and femininity (Constantinople, 2005).

In contrast, discursive notions of gender emphasize its productive aspects, that is, how doing gender or enacting gender is practiced and this is viewed as being dependent on historical and social contexts (Eagle, 2006). The male/female dualism has been extensively investigated by feminist poststructuralist writers (for example, Burman, 2005; Davies, 1989a; Walkerdine, 1988). Such work has detailed how subjectivity is gendered and Davies (1989b) has shown that performing one's gender is a complex undertaking even during early childhood. At school, despite girls learning mathematics as competently as boys, they are judged by teachers as having less understanding of the field than boys (Walkerdine, 1989). Rose (1996) speaks of 'gendering' as being:

A matter of a meticulous and continually repeated prescription of the deportment, appearance, speech, thought, passion, will, intellectual in which persons are assembled by being connected up not only with vocabularies but also with regimes of comportment (walking, looking, gesturing), with artefacts (clothes, shoes, makeup, automobiles, cooking pots, writing implements, books), with spaces and places (classrooms, libraries, railway stations, museums), and the objects that inhabit them (desks, chairs, books, platforms, display cabinets). (p. 186) 
Outside a psychological view of gender, considerable literature has been produced from a range of perspectives that put forward various ways of conceptualising gender. In looking at ideas about being a man, according to Eagle (2006), there are a "variety of interpretive forms that masculinity can take" (p. 51) and there are equally, "a number of intersecting parameters, such as race, class, sexual orientation and feminist consciousness, [that] influence the ways in which masculinity is interpreted and played out" (p. 52). There are numerous approaches to understanding issues of masculinity within the burgeoning field of men's studies (see Phillips, 2006 for a review of some of these approaches). Despite this diversity in masculinities, Eagle goes on to say there is "considerable agreement that some forms of masculinity can be identified as common, dominant or hegemonic. A variety of terms such as conventional masculinity, traditional masculinity, the masculine mystique, masculinism and hegemonic masculinity, have been used to describe this central thread" (p. 52).

The work of Robert Connell, in particular, offers a way of looking at such a hegemonic masculinity that I have found useful for this research. Connell (1995) describes this dominant form of masculinity as legitimating patriarchy in which men dominate and women are subordinated. Such masculinity is viewed as a cultural ideal and is portrayed in the media and social institutions as the 'natural' or 'normal' way to perform the subject position of man. Connell suggests that alternative performances of masculinity are considered as inferior and positioned as subordinated, complicit or marginalised when compared to hegemonic masculinity. This hegemonic construction of masculinity was so frequently implicated in the young men's understandings and explanations of their violence in this study that I have paid particular attention to this in my discursive analysis.

Debates, however, are evident in relation to the concept of hegemonic masculinity (for example, Wetherell \& Edley, 1999). One aspect of these debates coalesces around how particular authors consider the term hegemonic masculinity, as it was developed by Connell (1995, 2000, 2001). For Connell hegemonic masculinity is considered as an ideal, never to be achieved by any man, as he argues hegemonic masculinity is never fixed but is "historically mobile", it is multiple and contestable. 
This concept links well with Foucauldian concepts of power being everywhere and always present. Hence it provides the means for my analysis to focus on how participants have attempted to "get it right" as a man (the hegemonic ideal). Complexity is highlighted in the poststructural concept of multiple subjectivities in which subject positions are made available in differing discourses moment by moment. Therefore understanding hegemonic masculinity as an ideal that is contestable and situated, rather than a typology of masculinity or a rigid hierarchy of individual power, links well with multiple subjectivities

\section{Tensions in theoretical perspective}

Potential tensions exist in my theoretical perspective. A critical psychology framework aims to critique what is labelled mainstream psychology (Prilleltensky \& Fox, 1997). From a poststructural perspective, such a label and focused critique risks producing a coherent object, which in turn suggests that a preferred 'other' to this form of psychology exists. Hence, this may be read as creating a dualism. In comparison, poststructuralism queries dichotomies and dualisms that suggest clear, separate boundaries, and instead, views multiplicity and fluidity as constituting the postmodern world (Weedon, 1987).

Whilst such tensions do not need to be resolved or removed, since contradiction and multiplicity are acceptable within poststructural approaches, they do need to be acknowledged. As outlined above, my reading of critical psychology is that it calls into question the relevance and usefulness of psychological practices that originate from a paradigm of a realist, objectivist, positivist science. However, the philosophical and theoretical basis of this paradigm are not inflexible and can incorporate other perspectives, thus, inconsistencies may arise. Therefore, mainstream psychological approaches to youth violence are multiple and varied and cannot be considered to represent a stable or consistent object.

Poststructural discursive analyses can reveal 'the way things are', and at times this may, in itself, offer a critique. Employing a poststructural discursive approach reveals the various constructions of youth violence, the subject positions made available and the material effects these have. Through this process I show that 
alternative ways of thinking about young men's violence are possible beyond that which is currently dominant.

The addition of a critical psychology critique provides a specific focus on dominant ideas that are (re)produced by a scientifically bound psychology. For the purposes of this thesis, this critique is necessary for pointing to the limitations these ideas offer young men who have been violent. However, it is important to refer back to my earlier discussion around the clash of paradigms. Any attempt to understand one paradigm from the viewpoint of a different paradigm is not possible and can only result in misunderstanding (Kuhn, 1962). Mainstream psychological texts are developed within a positivist scientific paradigm, whilst this study is being approached from a subjectivist, poststructural paradigm. Therefore the critique of the dominant constructions of youth violence that are embedded in mainstream psychological theories must be done within the paradigm of this research. Since subjectivity and the effects of discourses is of prime interest in this study, this critique occurs in relation to what is revealed by the participants' talk.

\section{Methodology}

For much of the social science research that is reported, the theoretical background to the study is generally outlined or at the very least implied within the methodology section (Guba \& Lincoln, 1994). At times, methodology is inclusive of the methods used. However, a distinction between methodology and methods is often made, where methodology is viewed as establishing the rationale of the study, while the methods section gives the precise detail on how this will be done (Cheek, 2000). This is the approach I have taken here. Hence, this methodology section outlines features of the poststructural discourse analysis that I employ, while the specific strategies of the fieldwork are detailed in Chapter Four.

I have separated, somewhat artificially, this methodology section on poststructural discourse analysis from the theoretical perspective and from the study's specific research strategies to highlight these various aspects of this research process and as a device to offer some comparisons to the experimental or quasi-experimental methodology of an objectivist psychology. For example, in these methodologies 
anything that does not conform to the concept of the rational, coherent, unified individual is systematically dealt with as bias and removed so that only the elements of interest from the 'true humanistic subject' are measured. Questionnaires are often designed to detect inconsistencies in answers, which, if over a specified level, will influence how all the responses are analysed. This is reported under a method section. The complexity of how people actually respond to phenomena is not investigated and cannot be considered. An explanation of this view of the humanist subject is not given; rather, this view is taken as the received 'truth' about people.

\section{Texts and intertextuality}

Texts are the materials used for poststructural discourse analysis. However, texts from this perspective are not only words or written articles, but can also be symbols, for example, menus or pictures. Even actions and human beings can be read as texts because we interpret the behaviour of others (Montero, 1998). Texts are anything that provides meaning. They are embedded within discursive frameworks. Being constructed by discourses, texts construct understandings that reflect those discursive frames (Cheek, 2000). In addition, any text is considered to be an interlinking of various texts (Davies, 1994). This is intertextuality, where texts can only ever refer to other texts (Sarup, 1993). Derrida's (1976/1997) assertion that nothing is ever outside a text because there can be nothing outside language, can therefore be read as referring to all things that involve meaning. In addition, any reading of a text, produces another, different text (Cheek, 2000).

\section{Focus areas for discourse analysis}

From this description of texts, the actions, behaviours or words of research participants should be considered as discursive productions rather than any representation of a 'truth' or an indication of their 'true essence' as positivist science would interpret them to be (Gavey, 1989). Our practices, that is, our ways of speaking and acting, reproduce and reflect the discourses that constitute our subjectivity. These become seen as 'natural' and 'everyday' (Merttens, 1998), making the ability to see such detail differently, in what appears to be accepted as a common 'truth', very difficult (Davies, 1994). To overcome these difficulties of 'seeing differently', texts are actively interrogated in poststructural discourse 
analysis to reveal their hidden assumptions (Cheek, 2000) and to identify and examine the constitutive effects discourse has on subjectivity and people's practices (Willig, 2000).

The focus of poststructural discourse analysis is as much on the social, political and historical contexts in which the text was constructed, as it is on the actual content of the text. Discourses construct meaning and subjectivity and have material effects. They constitute the social context, which means that understandings cannot develop in isolation. The context in which a particular text was produced also has an impact, as people perform the subject position within particular discourses. For example, how a young man talks about a topic with his mother is likely to be different to how he talks to his mates about it. An objectivist approach would consider such an account to be either 'factual' or mistaken, regardless of context. That is, an account from this perspective will be regarded either as a factual rendition of what happened or as a person's opinion; a change in the situational context does not alter this.

Research also occurs in a specific context and so can only ever offer partial interpretations and understandings. How these are arrived at is influenced by what the researcher brings to and uses in this process. Therefore the research process is a text that is discursively constructed and so is also a target for reflection and analysis (Cheek, 2000).

A critical analysis of texts from a poststructural perspective often makes use of the process of deconstruction. This process is often associated with the view that western thought is organised into pairs of polarities or binaries (Sarup, 1993), for example, normal/abnormal. These dualisms are based on power dynamics in which the second word of the pair is usually subordinated to the first (Bird, 2004). The aim of deconstruction is to break apart these binaries and disrupt them, thus viewing categories as always fluid (Lather, 1992). One way of deconstructing a text is to "read it against the grain". Davies (1994) provides an eloquent explanation of what this entails:

Instead of achieving the reading the author imagined or intended, reading against the grain involves disrupting that frame through a 
deconstructive examination of the detail. Reading with the author is like planing with the grain of wood. The feeling is pleasurable, the wood is unified and whole and smooth as are the curled peels of wood that are planed off. Planing against the grain, in contrast, is unpleasant, the shoulder jars, the unity of oneself with the wood is lost. The gritty, sharp, detailed, complexity of the wood stands up in disorganised spikes. It is not possible to see the wood in the same way any longer. But one's understanding of the wood is much richer and the smoothness is seen as an achieved relation with the wood rather than the essence of the wood itself. (p. 40)

Davies (1998) goes on to inform us that "deconstructive work does not make a category useless" (p. 139). Derrida's (1976/1997) notion of erasure makes this issue clearer, that is, crossing out the word in a way that still made it readable, thus indicating that the word is still necessary, but no longer adequate.

\section{Discourse analysis and action}

Like the criticism of a relativist ontology that 'anything goes', poststructural discourse analysis has been criticised as not leading to action:

It still seems to be the case that constructionists and discourse analysts, afraid of reifying any particular constructions, remain 'observers and commentators' leaving the action to others. ... they seem particularly wary of following this through in terms of recommendations for change. (Burr, 1998, p. 25)

However, such a claim has been debated. Some writers have suggested that the act of disrupting what is, deconstructing meaning, recognising the effects of various subject positions and refusing dominant discourses all have very powerful effects (Davies, 1989b) from which specific recommendations for change can be made (Parker, Georgaca, Harper, McLaughlin, \& Stowell-Smith, 1995).

Willig (1998) suggests that a clear political position is required to ground such recommendations. Therefore acknowledging the political and/or values base to one's 
research is considered important (Gergen, 1990). Critical psychology provides such a base for me and enables me to challenge the dominance positivist, scientific approaches to psychology have in interpreting, understanding and dealing with youth violence.

\section{Forms of discourse analysis}

There are various forms of discourse analysis with different theoretical perspectives and epistemologies, including forms which appear specifically to critique dominant psychological approaches, such as discursive psychology (Willig, 2000) and critical discourse analysis (Stubbe et al., 2003). Different forms of discourse analysis address different research questions. Even within poststructural discourse analysis, there are differences in the way particular writers use the ideas. However, poststructural discourse analysis utilises a relativist epistemology and the poststructural theoretical perspective in relation to language and discourse, outlined earlier. This makes its focus a broad one, paying attention to context and the impact on subjectivity.

In terms of how to undertake discourse analysis, Parker (1992) as well as Potter and Wetherell (1987), are among the significant writers in this area who first provided ways of undertaking the task. Parker, for example, came up with a range of criteria to identify a discourse, including several designed to assess the political and power issues of most concern to poststructuralism and to critical psychology. Potter and Wetherell outlined ten stages in their approach to discourse analysis that focused on what the talk was doing and how people achieved their objectives. More recently, Willig (2000) offers six stages to what she has termed Foucauldian discourse analysis.

While all of these writers have been influential in developing my approach to poststructural discourse analysis, I have found Willig's six stages most helpful. In Chapter Four, I provide more detail and how I drew on these six stages to explore young men's understandings of their violence and the subject positions made available to them and to identify the constructions and discourses involved. 


\section{Research Strategies}

Often called research methods in positivist research, research strategies refer to the particular techniques I used, firstly, to gather research data and secondly, to analyse that data. Great attention is given to research methods as evidenced by the multitude of texts available on the subject, many of which denote a dichotomy between qualitative and quantitative research methods.

It is at the level of method that the qualitative/quantitative divide is argued by some writers (for example, Crotty, 1998; Grant \& Giddings, 2002; Lather, 1992) to actually occur. However, other writers (for example, Denzin \& Lincoln, 2000) embed theoretical, methodological as well as epistemological aspects when they define qualitative research as interpretive and critical. Quantitative research is often linked to positivist scientific methods. Conducting surveys, applying psychometric testing, holding structured interviews and utilising statistical analyses for the numerical data generated are common examples within traditional psychological research. Equally, many qualitative techniques, such as interviews and discourse analysis can and do get used within a positivist paradigm.

Whilst the choice of research strategies is not predetermined by the chosen epistemology, theoretical perspective or methodology, there is usually a strong connection (Grant \& Giddings, 2002). How these strategies are applied is dependent on the methodological and theoretical perspectives used, as well as being influenced by an awareness of the principles derived from epistemological and ontological concerns. In this way, the entire research process, from the development of the research questions to the writing-up of the research, as much as entry into the field and analysis of the data, must be aligned.

Research informed by poststructural thought offers a way to disrupt the dominant psychological knowledge about youth violence, but this cannot be done by critiquing the discipline's research methods (Hughes, 1990). Instead, critique must occur at the level of epistemology, theoretical perspective and methodology. Research based on positivist science does not report the philosophical basis, theoretical perspective or the methodology of its research. It no longer has any need to articulate its 
foundations because positivist science has become the hegemonic form of knowledge production (Hughes, 1990). Instead, only the specific research methods employed are reported and it is at this level that research is evaluated within traditional psychology. This evaluation is generally restricted to an appraisal of whether the research is valid scientifically. Such evaluation does not aim to change or improve the discipline, but rather to contribute to the modernist ideal of the progress of scientific knowledge.

In contrast, this thesis is centred on the broad philosophical and theoretical foundations of mainstream psychology's knowledge production and its particular dominance. For constructions of youth violence to become dominant they must be widely known and legitimated. In addition, these constructions must influence the practices of social institutions, for example, within prisons. Whilst considerable specialisation occurs within psychological theorising, much of this knowledge is not yet widely known nor accepted as dominant across multiple social sites. Therefore, the critique offered here covers broad and common understandings regarding the theories of youth violence, albeit the boundaries of what is common are always shifting and not fixed.

The knowledge produced from different paradigms is different and is used for different purposes. It is used to make significantly different claims. When it comes to youth violence, there has been extensive knowledge generated by psychology informed by positivism, which has become dominant. This knowledge has been produced using a reductionist and context-free approach that is based on the humanist individual that has been stripped of any complexity. Critical psychology together with poststructuralist discourse analysis enables me to trouble this humanist subject. In the next chapter on research ethics I explore the way in which dominant discourses position young men who have been violent and also how research that is critical and outside the positivist science paradigm is viewed. 


\section{CHAPTER THREE}

\section{POSITIONING THROUGH THE ETHICAL APPROVAL PROCESS}

This chapter discusses the material effects that the dominant discourses around youth violence had on the process of gaining ethical approval for my research. This discussion discloses a paradigm clash in undertaking a poststructural research study within a field claimed by the positivist scientific tradition of mainstream psychology.

Like all research, research that aims to talk to young people about their understandings of their own violence brings with it a range of ethical issues that must be considered and managed to minimise any potential risk to participants, the researcher and others. It is my responsibility as a researcher to ensure that my study is conducted in an ethical manner. However, what is believed to be ethical is contestable.

In general terms, my initial plan was to interview, firstly individually and then in groups, up to 36 young people, aged between 10 and 18 years old who had committed serious violent acts. I planned to use a flexible, recursive, conversational style of interviewing to explore participants' understandings of and ascriptions of meaning to their own violence. While the specific strategies I planned to use are common in social science research, they were contested by institutional ethics committees on various grounds as being inappropriate for use with young people who had been violent. It seemed to me that my chosen approach challenged the authoritative, dominant discourses around youth violence on which the institutional bodies that needed to approve my research relied. Through the process of applying 
for ethical approval, I experienced how the power of dominant discourses regulates and positions subjects.

I offer my reading of the various texts (letters, verbal exchanges, memos and emails) that I received from the institutional bodies during the process of obtaining ethical approval. In this exploration, I specifically focus on how the participants, the research and the researcher were positioned by the dominant discourses drawn on by these gatekeepers of research.

\section{Ethical Approval Process}

There were two main institutional bodies from which I needed to obtain approval for my research to proceed. ${ }^{7}$ The first was the Department of Child, Youth and Family Services (Child, Youth and Family), which is the New Zealand government department responsible for young people who have committed violent offences (as well as those requiring care and protection services $)^{8}$. The second was the Victoria University of Wellington Human Ethics Committee (HEC).

My applications to these institutions identified a range of ethical issues that I considered to be pertinent to researching youth violence using my particular approach and I developed strategies for managing these. I considered that such ethical issues revolved around two key aspects. Firstly, participants were potentially vulnerable due to their age and client status (that is, being a client of Child, Youth and Family). Such status may be thought to reduce their level of autonomy and choice as research participants. Secondly, the topic of violence is generally considered to be a sensitive one as it often generates a large amount of fear. Furthermore, discussion of violence tends to produce strong opinions about explanatory theories and proposed solutions. For perpetrators of violence, talking about what they had done could therefore be difficult for them.

\footnotetext{
7 I later applied to the New Zealand Department of Corrections for additional participants when numbers from Child, Youth and Family were low, as explained in Chapter Four.

8 The Research and Access Committee (RAC) of Child, Youth and Family is an access committee and not specifically an ethics committee. Although ethical issues are considered, the RAC is focused on client and operational issues rather than researcher issues.
} 
I undertook extensive consultation and negotiation with Child, Youth and Family to obtain their approval and develop my specific strategies for accessing their clients in a way that best suited the organisation and the participants. It took approximately three months to obtain their approval. This was a relatively straightforward process that involved acceptance of my application after one revision, which incorporated several negotiated changes.

However, it took a considerably longer time (16 months) to gain ethical approval from the Victoria University of Wellington for my research. Due to the organisational structure of the Human Ethics Committees (HEC), I effectively applied to three different University $\mathrm{HECs}^{9}$, and in response to various concerns raised by these HECs several revised applications were submitted.

My first application went to the School of Psychology HEC. Due to changing my enrolment to education, my second application went to the School of Education HEC. After deciding that the issues involved required more expertise, the School of Education HEC then referred my application to the main University HEC. Each change in the university applications required further consultation and negotiation with Child, Youth and Family to ensure their agreement to these changes. There were some distinct differences as well as important similarities in the issues of concern identified by the different University HECs and with Child, Youth and Family that I have highlighted here from a poststructural discursive perspective.

\section{Constructions of Youth and Their Influence}

Prior to looking at how the participants of my research were positioned by the ethics committees, it is important to consider the broader context within which youth is constructed generally. Adolescence is a term that conjures up images of youth, vitality, adventure, excitement, carefree times and the beginnings of intimate peer relationships as well as images of puberty problems and hormonal imbalances, trouble with parents, being disaffected with school, and the use of drugs and alcohol

\footnotetext{
${ }^{9} \mathrm{~A}$ main University Human Ethics Committee provides oversight to the research of the university, and separate Human Ethics Committees (effectively sub-committees of the main one) exist for those Schools that have a sufficient volume of research projects.
} 
as well as alternative clothing and music. Western hegemonic discourses of youth mark young people as different to adults and different to children, and there is also an expectation of some type of 'trouble' associated with being a teenager. However, these concepts of adolescence or youth are socially constructed and have relevance primarily for current westernised societies where these subject positions are available. Within some cultures, the concept of adolescence does not hold any meaning, and therefore the subject position of adolescent does not exist, for example, young Samoan women (Tupuola, 1998).

Developmentalism in an objectivist psychology, that is, the assumption of regulated natural change, has been heavily criticised (Burman, 1994) and an antidevelopmental approach has been developed by critical psychology (Burman, 1994; Morss, 1996). If the construct of youth was a universally accepted, objective category that was a naturally occurring developmental stage, as the construct of developmentalism proposes, then it would be reasonable to expect a clear, welldefined categorisation. But the ways of categorisation are not at all clear cut, and thus the labelling of anyone as a youth is not something that encapsulates meaning.

Various social institutions that regulate and discipline the populace are primarily designed around chronological age to determine the services they provide and when to confer social rights and responsibilities (Morss, 1996). Thus age becomes a strong determinant of what is possible and when, although this differs across different arenas, for example, when someone can drive a car, leave school, drink alcohol, or be considered either a juvenile or adult offender. Merely one day (one's birthday) can make a difference between being a juvenile or an adult.

Prior to the mid-nineteenth century, children were treated the same as adults in the justice system. The construct of juvenile delinquency did not emerge until this time, when the juvenile delinquent became an object for psychological technologies (Rose, 1985). Disorders of behaviour within school children were regularly associated with later criminality in the young, which was viewed as "the symptom of a psychological problem" (p. 174). Hence, mainstream psychology established its authority over juvenile offending. 
When it comes to determining the age at which someone can be held responsible for their criminal activity, there are several aspects to be considered (Urbas, 2000). Firstly, the age at which a child is deemed able to know right from wrong is 10 years in New Zealand, Australia and the UK. Therefore a child under 10 years old cannot be held criminally responsible. Secondly, the legal definition of doli incapax, states that, a child is incapable of committing a criminal act between the ages of 10 and 14 years. Children of this age who have engaged in activity that could be read as criminal are therefore often dealt with by the care and protection system rather than the justice system. Finally, after the age of 14 years, a young person is deemed to be fully responsible for their criminal acts (except for murder and manslaughter in New Zealand, where the age limit is 10 years) and are dealt with by the youth court. However, it is possible to have a young person treated by the justice system as an adult if the crime is considered by the courts to be particularly serious (Urbas, 2000). Therefore age is not always the determinant of the process.

Although young people are often viewed as vulnerable and as requiring protection by social systems of regulation, they are also positioned as highly troublesome and prone to violence. Media reports highlight incidents of serious violence committed by youth and statistics that record violent crime are often used to show that young people under 18 years of age are frequently the perpetrators (Newbold, 2000).

Paradoxically, despite anticipating trouble or violence from young people, primarily young men, there also appears to be an expectation that such violence will not be serious, at least in modern times and in peaceful countries. An idealised version of youth violence exists that seems to reflect the positioning of young people as innocents, having some misguided fun but needing boundaries and protection. Disbelief and shock are generally expressed when young men commit violent atrocities, for example, the high-profile school massacre in the USA at Columbine High School (Pollack, 2000).

Young people can thus be seen as being positioned in various dualisms. First there is the adult/child dualism. Young people are viewed as having adult needs but occupying a child status. For example, some are parents, yet are unable to vote until they are 18 years old. Second, there is a protection/discipline dualism. Young people 
are seen to be in need of protection as well as needing to be disciplined. Then there is a good/bad dualism. They are viewed as having potential for good but are also seen as being essentially bad. For example, young people are seen as the hope for the future and given support to develop to their full potential. Yet, there is also an expectation that young people will often behave in ways that do not support the social good and so they are restricted by school policies and social rules based on this assumption. Additionally, there is a loved/feared dualism in which they are viewed as needing to be loved but they are also seen as being uncontrollable and so are feared. Therefore the provision of a nurturing environment is seen as an essential component to the development of 'good' character. But adolescence is also seen as a time of stress, and the hormonal changes that occur during this time are often regarded as contributing to this notion of uncontrollability.

Given these dualisms, the subject positions available for young people are contradictory and for those who have been violent they are particularly negative. These dominant views of youth are what are available to ethics committees that inform part of the basis from which they make their decisions.

As an ethical researcher, I believed it was necessary to cover in my ethics application any potential distress or other adverse eventuality I could envisage based on my previous experience of working with trauma and crisis, with both mandated and voluntary clients of all age groups. To this end, I ensured I addressed the possibility of negative reactions, such as feeling some level of unease. I also included the most extreme, but in my view (based on my professional experience), the most unlikely reaction, that is, that participants may become violent during the interview. Given that ethical approval is predominantly about amelioration of risk, I provided a range of specific strategies to manage the risk of any negative reaction.

When research participants are constructed as 'youth-at-risk' by institutional ethics committees they are pathologised and become targets of paternalistic approaches (see Cumiskey's contribution in Weis \& Fine, 2000). Thus research can be refused on this basis of protection if considered necessary. It appeared that the participants in my research were positioned as 'youth-at-risk', on the one hand, but also as dangerous, 
violent and 'abnormal' on the other. This was a major obstacle that I needed to overcome to gain approval for my research.

In discussing my experience of the ethics approval process as an example of discursive effects, I refer to the various texts from the ethics committees to show how the research participants were positioned by exploring the concerns raised by the ethics committees.

\section{Positioning Participants}

\section{Participants as dangerousness}

The young people I wanted to talk to were those who had been convicted of a violent offence and therefore took up the subject position of "young violent offender" within discourses of youth violence. They were clearly positioned as dangerous and impulsively volatile, which was the prime concern of the University HECs. There was an expectation that participants were more likely than not to be violent during the interview or afterwards. It seemed that there was a general belief, or an uncertainty for the University HECs that talking about their own acts of violence would create immediate violence. This was reflected, for instance in the following comments:

Research with participants in these kinds of settings where there is an individual working with individuals who have a history of violent behaviour can carry substantial risk to both parties, and others working or living in the setting (University HEC, Memo One, 29 June, 2001).

The researcher will have no control over the state of mind of the participants during the interview. This can affect the safety of the researcher (School of Education HEC, as cited in University HEC, Memo One, 29 June, 2001).

Such a view of young people who have been violent positions them as being so outof-control that they are considered likely to attack anyone at any time and talking about their violence is regarded as enough of a provocation to cause this. 
Furthermore, the young people were viewed as people who would attack without considering the consequences and without the need for a motive. Such violence is seen as irrational and therefore these young people are also positioned as irrational. It appeared that their dangerousness was being predicted on only one factor, their past violence.

In contrast, the dangerousness of these participants was not the main issue of concern for Child, Youth and Family. This lower level of concern with dangerousness may be due to the organisation's familiarity with such young people and an intimate knowledge of the context and how situations may be managed as well as the associated risks. Instead, their primary concern was the potential stress participants would experience, not in the interview but later, when listening to their tapes:

The proposal requires young people to review their audio tapes and transcripts. The Committee thinks that they need to do this in a supervised setting because of the potential harm to them of reliving the material to which they will be listening (Child, Youth and Family, Research Access Committee, Letter, 14 November, 2000).

\section{Participants as 'abnormal'}

Communications to me from the School of Psychology HEC used language that positioned young people who had been violent as 'abnormal', applying diagnostic labels, and suggesting that it was a grave error to regard participants as 'normal':

The population targeted in your research is not a 'normal' adolescent one. Instead, it is children who are [a] engaging in 'abnormal' violent behaviour (and may well be classified as having a conduct disorder); and $[\mathrm{b}]$ most likely to have very troubled psychological histories (School of Psychology HEC, Email, 5 February, 2001). 
The title of your proposal suggests that your research is with a 'normal' group of adolescents, when it is clearly not ${ }^{10}$ (School of Psychology HEC, Email, 5 February, 2001).

From the above comments from the committee, it is possible to see that an normal/abnormal dualism is posited. This language positions young people who have been violent as 'abnormal', rather than allowing this ascription to be associated with many possible positions. In addition, these statements act to position the writer (me) as being ignorant of who these young people 'really' are and hence I am positioned as naïve.

Further comments also conveyed an assumption on the part of the School of Education HEC that participants, because of their violence, would already be subject/ed to therapeutic intervention:

Additionally, the research situation is one with which the participants are likely to be less familiar than the therapeutic one (School of Education HEC, as cited in University HEC, Memo One, 29 June, 2001).

Placing the participants within a setting of therapeutic intervention positions participants within the domain of abnormal psychology.

\section{Participant positioning and limitations to my research}

The subject positions made available - by the University ethics committees outlined here - for young people who have been violent may not only demonise (mark them as evil) (Staub, 2003) but also pathologise them (mark them as 'abnormal'). The committees' language was couched within a particular paradigm: the dominant 'authority' of mainstream psychology, which privileges scientific knowledge, positioning offenders as 'abnormal' and therefore the therapeutic subjects of a clinical gaze, with little opportunity for their own voice. This raises a difficult paradox: an ethics committee cannot deal adequately with other knowledge than that

\footnotetext{
${ }^{10}$ At that point, the title of the research was "Adolescent talk on adolescent violence".
} 
offered by dominant discourses around youth violence if this other knowledge is seen as intelligible within those discourses that it draws upon.

Neither Child, Youth and Family nor the University HECs would approve my proposal to talk to young people who were in the community. Instead, these organisations required me to talk only to participants who were supervised full time in a secure residential facility. Again the issue of concern was the dangerousness of participants. Despite the fact that the young people in question had been through a legal process (either court or a youth justice Family Group Conference) that considered them safe enough to remain in the community, it was not deemed safe for me to talk to them about their violence. Containment of the young person was the only acceptable strategy for mitigating such risk. Consequently, this study was restricted to interviewing those young people who were incarcerated.

A further restriction was placed on my research strategy by the approval process. I planned to hold group discussions with participants following individual interviews. Child, Youth and Family explained their reasoning for refusing these focus groups:

The group process is of concern to the Committee because research indicates that peer relationships are one [sic] a significant contributor to on-going violence. Group work is not recommended with violent young people (Child, Youth and Family, Research Access Committee, Letter, 14 November, 2000).

Such reasoning may be read as reflecting the understanding that peer group influence is a primary and known cause of youth violence and that talking together will reinforce or result in violence. This line of argument is surprising given that authorities, such as Child, Youth and Family, house these young people together and many therapeutic intervention programmes use group-work with young people who have been violent. Indeed, much of my professional practice with young offenders involved working in groups. I was interested in examining the discussion between participants in a group setting. Refusal to approve this aspect of my research on youth violence unfortunately meant that the outcomes of such a research strategy could not be explored, leaving a smaller knowledge-base for future research and 
maintaining a significant methodological and philosophical limitation on the decision-making processes of ethics and access committees.

I propose that there are alternatives to the narrow discursive positioning suggested by the language of the committees' documents above, alternatives that are open to the possibility that these young people occupy multiple positionings in a variety of discourses. For example, there is the young man who savagely raped his girlfriend. A dominant discourse around youth violence positions him as a savage rapist, therefore dangerous at all times. However, this young man can also be humorous with his friends, a caring brother or son, and passive in the interview situation, suggesting that as well as being violent, young people take up other positions in other discourses. For example, some years ago in New Zealand, several young men sexually assaulted their male mate with a broom-handle (Hay-McKenzie, 2002). The media accounts positioned these young men as sex offenders within a discourse of 'abnormal' youth violence (Taylor, 2002). However, these same young men were also positioned as leaders in their school and considered high achievers in another discourse that constructs pro-social behaviour. This contradiction of multiple positions helps explain the shock, confusion and disbelief of people that was reported in the media, because these young men did not fit the singular subject position of being dangerous that is created by dominant discourses of youth violence and the humanist subject of a modernist psychology.

\section{Positioning the Research as Clinical}

In addition to positioning the participants as the therapeutic subjects of traditional psychological approaches, the research itself was viewed as being clinical research. Comments from the School of Psychology HEC make specific reference to this:

Although we understand you are not a New Zealand registered clinical psychologist, your application contains material that suggests you are approaching the research from a clinical perspective (School of Psychology HEC, Email, 5 February, 2001). 
It is SOPHEC's [School of Psychology HEC] understanding that CYFS [Child, Youth and Family] was more interested in a therapeutic storytelling approach, which would again give the research the appearance of clinical research which it cannot be (School of Psychology HEC, Email, 5 February, 2001).

Although I did not use clinical language in my ethics application or suggest I would be using a clinical approach, if a dominant psychological viewpoint considers the topic of youth violence and those who commit violence as 'abnormal', then this could lead to viewing any research in the area as falling within the clinical domain. In addition, my written strategy to assist participants to monitor and manage their own stress levels could also be read as clinical.

In the paradigm of clinical research, the question of appropriate knowledge, experience and training becomes pertinent. Thus it appeared that for the School of Psychology HEC, only a registered clinical psychologist was viewed as an appropriate person to undertake the research that I proposed. However, marking research as clinical with such requirements can act to exclude exploration of the phenomena by other disciplines and by other research approaches.

The power of this claim and the discursive positioning of the research as clinical and the participants as therapeutic subjects are reflected in subsequent comments from the University HECs. For example:

The Committee believes that for the safety of all parties this proposed research must be supported by appropriate clinical relationships with the offenders and that such clinical support should be quite clearly separate from the researcher (University HEC, Memo Two, 14 August, 2001).

Related to the positioning of the research as clinical was concern that the research would become confused with therapy in the minds of the participants, which was viewed as potentially harmful, regarding the issue as: 
At present, the proposal seems to show inadequate awareness of the potential for research and therapy in this case, to become confused, and thus exacerbate risk (University HEC, Memo One, 29 June, 2001).

Yet, at the same time, there were concerns that there was a need for a clinical aspect to the research process:

The applicant proposes to go into the research situation as a researcher not as a therapist. The committee is concerned that the research process might raise issues that would disturb the participants. Since the researcher will not be in an ongoing therapeutic relationship with the participants, she will not be involved in a follow-up if this were necessary. These disturbances may also not be immediately clear (School of Education HEC, as cited in University HEC, Memo One, 29 June, 2001).

While the University HECs viewed the approach and content of my proposed interviews as therapy and saw this as problematic, Child, Youth and Family saw the potential for my approach to the interviews as being 'healing' for the young people and associated healing with safety. They suggested a storytelling approach:

The data collecting process would be safer because of the healing characteristics in the storytelling process and the more equal relationship between the researcher and the young person (Child, Youth and Family, Research Access Committee, Letter, 14 November, 2000).

The comments by Child, Youth and Family highlight a number of issues. It is possible to read an assumption that these young people need healing and that it is possible and desirable that this occurs within a research process, there is also an apparent assumption that healing occurs from the process of telling. This offers a contrasting approach to the concerns of the University HECs regarding the fusion of research and therapy.

A critique of these contrasting perspectives suggests that what is considered to constitute human kindness or ethical human interaction and what is viewed as 
therapy or therapeutic outcomes depends on the theoretical perspective being used. From a positivist psychological perspective, it is possible that positive outcomes for people resulting from respectful interactions with another may become labelled as therapeutic. However, such therapeutic outcomes are viewed as being the exclusive domain of clinical professionals. Therefore such a concept of therapy can lead to a view that a conversation about a particular topic that also covers a person's understandings and emotions is therapy. Unfortunately, this means that the value of friendships, social networks, supportive family relationships as well as considerate interaction within a research process are at risk of being diminished in particular contexts.

The University HECs' concern regarding the confusion between research and therapy had an unfortunate impact on me during the fieldwork. The first two participants referred to their fathers' violence in the interview and my anxiety of moving the interview into territory that could have become highly emotional led me to choose not to follow up on their comments. I felt very dissatisfied with this choice I made. I felt that I was disrespectful to the participants in not exploring what they had offered me. In later discussions with my supervisor, I learnt that researchers without 'clinical' experience would have followed-up their comments. Upon reflection, this suggested that I had experienced the material effects of the discourses around positivist research and therapy as constraining.

\section{Positioning the Researcher's Clinical Competence}

The discursive framework of clinical research used by the ethics committees operated to position myself, as the researcher, as unqualified and ill-informed. Coming from a theoretical perspective informed by poststructural thought and critical psychology, I chose my language carefully in writing up my ethics applications, for example, referring to participants as young people rather than as offenders, and I did not position the research as clinical. Additionally, since I was doing the research as a postgraduate student, I also did not refer to my professional experience. Yet, it seemed that by taking this approach, I found myself positioned as naïve, and as not knowing the area, the issues nor the potential risks involved: 
It would be undesirable and inappropriate for a person without proven clinical skills to be conducting this research (School of Psychology HEC, Email, 5 February, 2001).

Unless you can satisfy the committee that you have had the experience and registered qualification to undertake the research proposed here, the committee is of the view that very substantial changes to the project would be necessary before the proposed research was safe for all participants, and the University's potential liability was adequately protected (University HEC, Memo One, 29 June, 2001).

Within the dominant discourses around youth violence, I was initially positioned as having "inadequate awareness" (University HEC, Memo One, 29 June, 2001) because I did not speak of diagnostic labels or methods that are associated with a positivist psychological approach to clinical research with a so-called 'abnormal' population. Despite their concerns regarding the fusion of research and therapy, one consequence of constructing the proposed research as clinical was that the University HECs considered research that talked to young people about their own violence required the clinical skills and qualification of someone experienced in working therapeutically with such a group. Consequently, I utilised the same discursive framework to provide a detailed professional portfolio.

The language used for job titles, descriptions, qualifications and so on contained within the portfolio employed highly 'clinical' language, such as assessment, treatment, psychological reports, clients, clinical supervision, specialist programmes and juvenile offenders. While the University HEC was then satisfied that I had "substantial professional experience" (University HEC, Memo Two, 14 August, 2001), the discursive effect of my response was that the language in our correspondence became increasingly clinical and more offender-focused. Rather than continuing to talk about young people as "participants" and "individuals" (University HEC, Memo Two, 29 June, 2001), the University HEC now referred to "violent young offenders" (University HEC, Memo Two, 14 August, 2001). 
Professional experience and knowledge alone, however, were not sufficient for me to gain approval, but a revised ethics application that positioned the research as clinical and participants as therapeutic subjects correctly within the expected discursive framework did. In this application I used the same clinical discourse in which I described how I would utilise my 'clinical' skills to assess, monitor and manage risk in the interviews and provided my rationale for specific strategies using a clinical discourse. This application was given approval (see appendix A).

It would appear that having specific psychological qualifications and clinical skills offered some type of guarantee of safety to the University HECs, since only those with such skills are considered as being able to talk safely to these particular youth about their violence. This ignores that others, for example, police, teachers, parents and caregivers can and do safely talk to young people who have been violent about their violence. However, from a dominant psychological perspective, clinical authority is thought to be the legitimate power.

Concerns regarding power and authority within the research setting were also raised. The School of Education HEC considered that I had not taken a position of authority in the research interviews that I proposed:

The committee is concerned that participants (who have committed violent actions) may not distinguish between a researcher's nonjudgemental response and the response of a therapist. In other words they may perceive the researcher as "not fussed" about the violent behaviour. If so, we are concerned about the potential message that the participant/s might get about the desirability or otherwise of violent behaviour (School of Education HEC, as cited in University HEC, Memo 1, 29 June, 2001).

"Non-judgemental" seemed to equate with 'permissiveness' in this context, and the HEC can be read as viewing the role of the researcher as authoritarian parent, to emphasise the 'wrongness' of their violence to the participants. While this could be seen to be outside the responsibilities of a researcher, taking such a patronising and 
protective role towards young people can be considered a valid one from the perspective of the dominant discourses around youth discussed earlier.

\section{Conclusion}

Alternative views of young people who have been violent are subjugated by the dominant discourses used by the various committees I applied to. The subsequent constraints on what is permitted as research had the effect of silencing the voices of many young people who have been violent. By excluding certain kinds of studies, it is possible that only the discourses around abnormality, for example, can be heard.

As the government department that works with and has statutory authority for these young people, Child, Youth and Family clearly had a different view on aspects of the research process to the university HECs, including what they labelled as risks and how to manage these risks. Such a difference suggests that Child, Youth and Family was informed by a different discursive framework. Indeed, the organisation appears to operate from a predominantly social work perspective, with many of their principles and workforce based within that discipline. However, this perspective was not legitimated as the authority by the ethics committees for my research. Instead, it was considered to fall within the boundaries of mainstream psychology.

An interest in youth violence is shared by many disciplines and professions, so that making such research the sole province of scientific psychology is very limiting, given the restrictions that are inherent in its positivist approach. However, science is considered the legitimated authority on which 'truth' claims are made, as Sarup (1993) describes:

The state spends large amounts of money to enable science to pass itself off as an epic. The state's own credibility is based on that epic, which it uses to obtain the public consent its decision-makers need. Science, in other words, is governed by the demand of legitimation. The two myths which have acted as justifications for institutional scientific research - that of the liberation of humanity and that of the speculative unity of all knowledge - are also national myths. (p. 137) 
My experience of the ethical approval process demonstrates the difficulties of conducting critical research generally, but more particularly for research that investigates socially sensitive phenomena (Bird, Cornforth, Duncan, \& Roberson, 2005). In reflecting on this journey, I have pondered on how my proposed research would have been received if I had changed only one aspect, for example, if I wanted to talk with adults or examine school bullying, or if I had proposed a structured interview or survey approach. I question whether the same discourses would have prevailed. I expect the research would have been constructed as less sensitive and therefore fewer restrictions would have applied.

Several significant questions are raised by my experience and my exploration of the texts from the ethics committees.

- How do we resolve the challenge of how dominant discourses can position research participants?

- How can critical research take place in areas deemed to be 'clinical' when the discipline of 'clinical' psychology is scientific and by its very nature uncritical?

- Finally, how can ethics committees operate outside dominant discourses?

Ethics committees appear to have a dilemma. They must rely on current, dominant authority on which to base their decisions, yet this is limiting as it encompasses the privileged scientific knowledge of the dominant discourses. Therefore critical research is constrained. 


\section{CHAPTER FOUR}

\section{THE RESEARCH STRATEGIES USED}

In response to the high level of risk perceived by the various ethics committees that my proposed research initially generated, I made a number of changes to my ethics application. This revised application was approved. As well as using a clinical discursive framework and outlining how I would ameliorate risk through clinical expertise, I reduced the number of participants that I had originally put forward. To achieve the research purposes with this smaller number of participants, I needed to focus the research more tightly. To do this, I increased the lower age limit of participants from 10 years to 13 years, as it would have been difficult to access the younger aged participants, and I chose to interview only males, which allowed me to concentrate on their specific gender issues.

After receiving approval from the Victoria University of Wellington's Human Ethics Committee; Child, Youth and Family then gave their final approval. These approvals were for me to interview between 5 and 8 young males of European descent, ${ }^{11}$ aged between 13 and 16 years who resided in a Child, Youth and Family secure residential facility for having committed one or more violent offences (see Appendix B).

\footnotetext{
11 Interviewing participants with a similar cultural background to my own was a mandatory requirement specified by Child, Youth and Family. This requirement was premised on the view that cultural safety would be maintained by reducing what was seen as a risk that indigenous Maori would be objectified by white European research. This was described as having occurred in the past.
} 
In addition to discussing the relevant ethical issues and how I addressed them, this chapter also provides the detail of how I went about researching youth violence, the way in which I interviewed the participants and my approach to analysing the information I gathered. I describe the young men who were involved and how I accessed them in the facilities that held them. I also outline how I structured the interview and include something of my experience in the interviews. This is followed by a brief explanation of how I managed the interview transcripts. Finally, I outline the procedures I employed to organise the information for the analysis and the types of questions that I used to interrogate the interview texts.

\section{Recruiting Participants}

My expectation of the fieldwork component of my research was that I would be able to choose who to interview from a list of possible young men, and I anticipated that this would allow me to select from a range of ages and types of violence. I also expected to undertake an intensive period of fieldwork to complete all the interviews within a relatively short space of time. Interestingly, despite the political rhetoric of the New Zealand elections at that time, which was concerned with plans to "crack down' on increasing youth violence ("Time to act on youth," 2002), there were very few incarcerated young men who met the selection criteria. ${ }^{12}$

I interviewed seven participants for this study. The first two participants who were eligible were identified and then interviewed in April 2002. However, after six months there were no further potential participants identified. As a consequence of the small numbers of eligible young men available in Child, Youth and Family, I approached the New Zealand Department of Corrections to access young men of European descent, aged under 18 years who were in their Public Prison youth units for violent offences. After some negotiations, I received approval from Corrections (see Appendix C) and the Victoria University of Wellington Human Ethics Committee approved an extension to include these participants. Corrections did not require any additional changes to my approach, presumably because by that stage I

${ }_{12}^{12}$ There were Maori and Pacific Island young men who had committed violent offences in the secure facilities, but they were outside the approved selection criteria for this study. 
already had University and Child, Youth and Family approval, and two interviews had been completed without problems.

Six young men were identified by Corrections as being eligible to participate. Of these, four were interviewed in November 2002. In addition, another two from Child, Youth and Family were identified and of these two, one participant was interviewed. Making a total of seven participants with the two interviewed earlier. However, at this time no more young men were considered likely to be available before the end of the year, as there were none on remand in either Department. Hence, between April and November 2002 I accessed the entire population (10) of young men who met the selection criteria. The specific number of research participants was not a theoretical or a methodological concern for this research. Interpretive research using a subjectivist epistemology and a poststructural approach considers even one participant to be a legitimate research target because it does not attempt to provide generalisable findings as would be the case in positivist research (Crotty, 1998).

All potential participants were approached about being involved in the study and I interviewed seven of these young men. Of the three who were not interviewed, only one potential participant was not interested in finding out more about the study. One other chose not to participate after I had described the study in detail to him. Another participant who was interested in being interviewed was not seen as he was transferred to the community on the day we had scheduled to meet and therefore no longer met the selection criteria.

The seven young men who participated in this study came from five secure facilities, three from Child, Youth and Family and four from Corrections. These facilities are located in both the North and South Island of New Zealand. To protect the participants' identities I will not specify which secure facilities participants came from. Out of five national Child, Youth and Family residences, there are four that house young people aged 10 to 16 who have youth justice issues. Within the Public Prison System of Corrections, there are four youth units that are designed to accommodate all male inmates aged 14 to 17 and vulnerable inmates aged 18 to 19. 


\section{Accessing participants}

The process agreed upon by Child, Youth and Family, and Corrections for recruiting individual participants involved working through a contact person. The practice manager for the Child, Youth and Family residence and the managers for each of the youth units in Corrections were identified by the respective organisations as the most appropriate people to act in this role for each potential participant in their facility.

My purpose in using a contact person was to remove me from the initial phases aimed at informing potential participants about the study. In this way, the identity of those who did not want to be involved would be protected. In addition, this process was used so that participants first heard about the research through someone they already knew, which aimed to reduce the risk of their feeling pressured to be involved.

In this role, the contact person identified those potential participants in their unit who met the selection criteria. When potential participants were identified, each contact person provided me with anonymous demographic information, a brief description of the young person's offences and their sentencing information. I accepted all the participants that were suggested as being appropriate for the study.

The contact person then met with each young man to explain the study, provide the Invitation To Participate (see Appendix D) and to answer any questions. Most of those approached were very keen to be involved, and only one chose not to go ahead at this early stage. It was interesting for me to hear that one of the younger ones was initially puzzled as to why he was invited to be a participant as he viewed neither his assault convictions nor his sexual offences as violent; nevertheless, after some explanation by the contact person, he wanted to be involved. For those participants who were interested in taking part, I made arrangements with the contact person for me to meet with each young man in order to provide more specific information about the study, to gain his consent and to organise the interview.

To prepare the contact people for their role, I provided documentation and discussed the nature and purpose of the study, the processes that I would use and their specific role in the study. I was in close contact with each one by email and telephone during 
the process of identifying potential participants and to make arrangements for my visit to meet with the young men and undertake the interviews.

The contact person also had another role. They were to be the person to whom I reported any concerns I had regarding the safety of participants or others or myself. Ultimately, there was no need to use this precaution.

\section{Doing research in secure facilities}

My dealings with each facility also included making arrangements that took account of their security issues and procedures. These arrangements related to the timing of the interview and its location; arranging for participants to be able to contact me; gaining permission for me to bring in taping equipment, refreshments and materials to participants; the availability of an adult support person for participants to bring to the interview if they wished; and arranging for participants to access staff for debriefing after their interview if necessary.

Prior to meeting potential participants, I met with each contact person on my arrival at their facility. I was provided with a tour of the facility, discussed security procedures and arrangements, and in most cases viewed the interview rooms I would be using. I familiarised myself with safety and security protocols in each location so that in the event of any emergency, or any problematic behaviour by the young person or in the general population, I would be able to act swiftly and appropriately. I also carried a personal alarm. As I was familiar with similar facilities and their procedures through my professional experience in Australia, this was not an unusual process for me and I appreciated the importance of this orientation for both myself and the staff of the facility. The process of going through a series of locked doors and security procedures (for example, having my bag searched), although not new to me, reminded me of the type of environment these young men were in. During one of these tours, a young person whom I did not interview became agitated by something I was not aware of and started swearing and kicking some furniture. Staff responded immediately to calm him down. This incident was also a reminder of what it can be like for those who live and work in these secure environments and reminded me of the pervasiveness of the institutional context. 
I also provided information about my research both formally and informally to facility staff. I felt it was important to inform as many staff as possible about my presence in their usually restricted workspace. During my breaks or while I was waiting to see a young man, I was fortunate to be able to ask questions of staff members regarding the unit and discuss issues of relevance to my research. This information helped provide me with the larger context in which these young men were held.

\section{Information and consent}

The contact person was available to introduce each participant to me. I met with each participant privately to explain the nature and purpose of the study as detailed in the tri-fold Information Brochure (see Appendix E), and answered any questions. This process generally took between 10 and 15 minutes. I provided each young man with both an audio and written copy of the Information Brochure. I considered that the audio tape would enable those who preferred hearing information rather than reading it (whether because of literacy issues or as a better fit with the youth culture) to access this information more easily again after our initial meeting. Participants were very happy to receive the tape; some mentioned that they planned to tape over it with music.

It was in this meeting that we also discussed what would occur in the interview, why I wanted to talk to them and what would happen to the information they provided. In addition, we covered what it might be like for them to talk about their own violence, and if they thought it might be uncomfortable I suggested they may wish to have an adult come to the interview with them or talk to staff about it afterwards. We also discussed the issues around the limited confidentiality of the interview. Such limitations involved me informing staff about any risks to the participant's safety or that of others, any specific detail of unreported serious crime that would lead to a conviction and my use of a clinical supervisor. These limitations did not elicit any concern from participants and in fact were accepted by them as if it was a taken-forgranted process. 
I also gave them a copy of the Interview Topics (Appendix F) and we discussed these. I considered that awareness of the interview content would enhance informed decision-making about their involvement. A further advantage of providing participants with the topics ahead of time was to allow them time to consider how they wished to respond to the topics before the interview. Thus, I hoped to increase participants' preparedness for the interview and so reduce any anxiety they may have had about it and ensure their voluntarism. I also explained and provided the Consent Form (Appendix G), which allowed me to document informed consent.

It was not necessary for potential participants to make a decision about participating immediately. I encouraged them to take some time to consider their decision, to reread or listen to the information about the study again and to let me know later whether they wished to participate. Most of the participants expressed that they did not wish to take extra time to decide, and all except one agreed to be involved. It seemed to me that most had already decided to go ahead even before they met me. Five participants chose to sign the consent form during this first meeting, followed by the interview the next day, while two signed the consent form and had the interview immediately.

For those aged under 16 years (in Child, Youth and Family care only), the legal authority to provide consent rested with the Chief Executive Officer of Child, Youth and Family and in turn was delegated to each facility manager under the Children, Young Person's and Their Families Act (1989). The consent process for these young people was that if they consented after a first meeting with me, then their specific current situation was evaluated before consent by the manager was provided.

\section{Introducing the Participants}

\section{Anonymity and privacy}

New Zealand is a small country and violent youth crimes attract some notoriety and are extensively reported in the media. Additionally, participants mentioned their friends, family and victims in the interviews. Therefore, with as little information as age and a description of the crime, the chances of someone being recognised 
increases. To protect anonymity, I used pseudonyms for participants and disguised or omitted potentially identifying information from the transcripts.

To further protect the participants' privacy, I have chosen to provide a collective description of the group of seven young men who participated in this study rather than describe each individually. Although I consider that individual profiles of participants provide a rich source of information and firmly place them in the study, the need for anonymity is the overriding concern. However, I believe the reader will still be able adequately to form an impression of the young men as their stories come through strongly in the analysis chapters.

\section{Description of participants}

The seven participants: Anthony, Drew, Kelly, Quentin, Rick, Sean and Wade were aged between 14 and 17 years at the time I interviewed them. The type of violent offences for which these young men were incarcerated included assault, aggravated robbery, robbery with assault and sexual offences. These particular acts did not result in retaliation from their victims, such as getting into a fight.

Two participants had current convictions only for general violence. Five of the seven participants were sentenced for having committed sexual offences. Three of these five were also convicted of general violence. The sexual offences included both 'hands-off' offences, such as exposing genitals and masturbating in public as well as 'hands-on' offences, such as fondling, forced oral sex, and anal and vaginal rape. ${ }^{13}$

Participants were also serving time for other non-violent offences including burglary, car theft, ram raids, drunk driving, dishonesty offences and escaping custody. Some also committed further crimes whilst inside that led to additional charges, such as using drugs and fighting. The number of charges varied, but one participant had up to 45 .

\footnotetext{
13 The terms, "hands-on" and "hands-off" are frequently used in the sexual violence intervention field to distinguish between these specific types of offences.
} 


\section{Previous violence and crime}

As I was interested in talking with these young men about their violence, I did not restrict our conversation to the violent offences for which they were incarcerated. We also discussed their other experiences of being violent - all described perpetrating some type of violence in the past. This covered not just past convictions, such as other robberies, but forms of violence that did not lead to charges, such as fighting, including gang-related fighting and sexual assaults. Given my previous professional experience, I was specifically interested in exploring the effects and practices surrounding the subject position of "young violent offender". However, in recognising that youth violence is not confined to convictions, this broader coverage of their violence enabled me to explore other possible subject positions embedded in discourses around youth violence.

\section{Context of violence}

The acts of violence that were discussed in the interviews occurred both in the daytime and at night; in the city and in rural areas; in both the North and South Islands of New Zealand. The locations of the violence were in either the victim's or offender's home, in a public place such as a park or street, or in some type of shop, most often a dairy (corner store) or petrol service station.

Whilst all the sexual offences were committed alone, some of the assaults and robberies involved at least one other co-offender. Of course, the young man's body was the primary means of inflicting or threatening violence (for example, fists), but a variety of weapons was also used such as screw-drivers, bottles, baseball bats and knives.

The victims of the young men's violence covered both genders and the entire age range from young children, same-aged peers, to adults and older adults. Victims were both known and unknown to participants. The number of victims of each young man was difficult to judge when all their violence is taken into account, particularly if their fighting is included. 


\section{Sentencing}

As a group, the participants had been sentenced to spend from between three months to five years in custody. With good behaviour, they expected to serve from two months to a little over three years. At the time of the interviews, participants had served from three weeks to 11 months of their sentences and were being released within three days of the interview or up to three years later.

For all the participants in Corrections, it was their first time in an adult prison, but some had been in a secure residence for youth justice issues previously. In contrast, those in Child, Youth and Family had not previously been held in a secure facility. Some participants also had involvement with alternative care arrangements in the past, for example, foster families for either care and protection issues or for offending.

\section{Interviewing Participants}

Although I met with almost all the participants on two occasions (the first meeting was to provide them with information about the study and to gain consent), I interviewed each one only once. Methodologically, it is not possible to exhaust all meanings of words using a discourse analysis approach informed by poststructural thought. One interview with each participant therefore yielded a considerable amount of material for analysis. The high level of complexity and detail involved in the analysis also required me to consider issues of focus and space in the thesis. On a practical level, several of the participants were due for release soon after I interviewed them, making them no longer eligible to participate and so a further interview was not feasible.

The duration of these interviews ranged between 45 and 90 minutes. There are many ways to approach research interviews and considerable guidance is available from different traditions (Geanellos, 1999; Janesick, 1998; Kvale, 1996; Minichiello, Aroni, Timewell, \& Alexander, 1990; Wengraf, 2001). In developing my approach, there were several other key influences. 
Firstly, my professional experience in the counselling/therapy field has provided me with a practice-base from which I can ascertain what works practically to achieve engagement and gain information. Additionally, my background (described in Chapter One) and my personal attributes influence the research interviews as well as my interpretations of the interview data. Such a background is also what I bring to contexts of working therapeutically with young men who have been violent.

Secondly, I was interested in particular in these young men's understandings, specifically their understandings of their own violence. I wanted to explore their explanations, their accounts of what they did and how they talked about their violence, focusing on their own language and their use of language. In addition, I was also interested in their experiences and ideas around intervention for their violence. Therefore, I chose an approach that asked them directly about their understandings and experiences and used a recursive style to extend the detail.

Thirdly, my approach was informed by my theoretical perspective. A poststructural approach recognises participants as co-producers of knowledge in the research context and what a researcher brings to the context is of importance, it cannot be separated out and is not viewed as bias or as a limitation. A recursive interview style stands in stark contrast to the structured interview style commonly used in clinical assessments and objectivist research. Such highly structured interviews focus on the interviewer asking specific questions, often using very precise wording, mostly with closed questions that require a 'yes' or 'no' response (Rogers, 2001). These interview scripts are often referred to as an 'instrument' within empirical psychology. The purpose of a highly structured approach is to eliminate bias - the personal opinions and beliefs of the human beings involved. Instead, the present research actually seeks to explore the subjectivities expressed discursively as its central focus.

The process I used for the interviews was an informal recursive, conversational style, informed partly by Hollway and Jefferson's (1996) description of interviewing. Opening statements were used to initiate a conversational engagement into the interview topic, with open-ended questions designed to follow up on the content of the participants' talk in order to gain depth and increased clarity and encourage the 
expression of the participants' viewpoint. From a poststructural discursive perspective, I am as much interested in what these young men do not or cannot say, as I am about what they are saying. Subjectivity can be eloquently expressed by what is not said (Noble, 1999).

As the conversation proceeded in the interviews, I employed the language of the participant and the context of the dialogue to explore further, check their understandings and elicit greater contextual detail. For example:

- Can you tell me what ... means?

- How does ... influence you?

- Where does ... come from?

- What happens when ... ? ${ }^{14}$

\section{Interview structure}

In my experience in working with young offenders, I have found that some structure is useful to reduce the occurrence of the ubiquitous "I dunno" response to questions. Besides the usually successful tactic of responding with, "Yes, but if you did know what do you imagine your answer would be?", I also hoped that knowing the interview topics beforehand may help. Of course, there are numerous possible interpretations that could be made of the "dunno" response, including: it is very difficult to talk about; it is hard to think about; he is unable to make sense of the question; can not apply the question to themselves; the young man doesn't know the answer; or they do know the answer but do not wish to say. Another frequent response I anticipated was: "What do you want to know?" It seemed that if some structure was not imposed, then the participants would create it by limiting the discussion to specifics only and would not provide any additional information beyond what was requested.

I therefore structured the interviews with participants in two ways. Firstly, I used a global three-phased sequence that I developed based on my knowledge and experience with therapy/counselling interactions. These phases were the Opening

\footnotetext{
${ }^{14}$ Where (...) represents a term or comment made by the participant.
} 
Phase, the Interview Proper Phase and the Closing Phase. Secondly, the Interview Topics themselves within the Interview Proper Phase provided additional structure, along similar lines.

\section{Opening phase}

The purpose of this phase was to develop a connection with the young person and prepare them for the Interview Proper Phase. This included briefly reviewing key points in the information brochure such as their right to withdraw at any time, to only talk about what they wanted to and I reminded them of the limits of confidentiality. I also ensured the young man still wanted to go ahead with the interview and assessed the appropriateness of doing so. I often ended this phase by asking what it was like for them to be inside to initiate talking about themselves in terms of their own experience.

\section{Interview proper phase}

In this phase, the Interview Topics, which participants had already seen, were discussed in depth. These are described more fully below. Like the three phases of the interview, the order of the interview topics themselves was also designed to provide some structure. I began with introductory topics about violence in general, followed by more personal topics related to their own violence, including some reflection on the experience of talking about these topics, and finally ended with topics that were once again more general and further removed from the specifics of their violence, but included what help they had received. Such a movement from general to specific then back to general again was designed to ease them into discussing personal experience and then to leave it behind. Towards the end of this phase, I invited participants to add anything else they wanted.

\section{Closing phase}

To re-connect the young person to their daily lives and to leave behind the potentially difficult issues raised in the Interview Proper Phase, I moved the conversation away from the Interview Topics and into more pragmatic areas. This was achieved by asking them how they had found the interview and discussing the 
immediate plans the participant had following the interview. I also ensured participants were aware that they could debrief with a staff member after the interview if they wished.

\section{Interview topics}

The interview topics covered six areas of interest and were ordered in such a way as to move the participant gently into talking about their own violence. While this order was generally followed, in practice, at times the conversation jumped backwards and forwards between the different topics. The six topics areas were as follows: defining violence, description of their violence, impact of their violence, explanations for their violence, talking about their violence, reflections of help and anything else the young person wanted to add.

\section{Defining violence}

The focus of this topic was getting to know what participants considered to be violent and what they did not. Their general exposure to violence was also explored.

\section{Description of their violence}

For this topic, participants described the violence they had committed that led to their incarceration as well as other violence they had committed. This included the context of their act(s), and their awareness of the perspective of others.

\section{Impact of their violence}

This topic explored their awareness of the personal and social consequences of their violence, for themselves as well as others, including their victims, their family and their friends.

\section{Explanations for their violence}

The reasons and explanations the young men gave for being violent in the various contexts they described were the focal point of this topic. It also covered what they considered were other people's ideas about and explanations of why they were violent. 


\section{Talking about their violence}

The main points covered under this topic were their experience of talking about their violence. This covered the reasons that made it easy and hard for them to talk about their violence, and their experience of talking in different contexts, for example, in groups versus one-to-one.

\section{Reflections on help}

This topic on help was included to obtain participants' description of any intervention they had received for their violence and whether they found it useful. Their views on why they thought others try to help them were also canvassed.

Anything else the young person wanted to add

Most participants did not have anything else to add. Some asked me a few questions, such as how many I was interviewing for my study and about the other places I had been.

\section{The interview context}

Security measures varied at the different sites. Windows offered a view into the room except in one case where non-audio camera surveillance was used instead. In all locations, staff were close by and at times staff entered the room during the interview as a security check. Outside distractions were an inevitable part of the process. General noises of other staff and residents and, on one occasion, a lawnmower just outside the window, also intruded.

Prior to their interview, some participants volunteered to help me in preparing the room, for example, shifting furniture or setting up the recording equipment. These activities also assisted in developing rapport with the young man and reducing any anxiety they may have been feeling. For those who did not have this opportunity, we often started by discussing the recording equipment or other general topics such as my travel arrangements or the weather.

All participants appeared interested, and were respectful and attentive. They also seemed to enjoy the interview process and many commented that they found it useful 
to have discussed the issues. However, one chose to end the interview before I wanted to, saying that he was bored.

Throughout the interviews, participants ate and drank the refreshments I provided. The chocolate biscuits were particularly popular. The juice I provided came in a cardboard container with a hole for a straw. Drinking through the straw sometimes added background noise to the tape. One young person at the end of the interview was excited that I allowed him to record the noise the drink container made when he jumped on it. He was disappointed to find that the tape-recorder was unable to record such sudden loudness.

I brought in two soft neoprene balls to each interview in response to an unexpected outcome of pilot interviews I had conducted in preparation for going into the field. One of the pilot interviewees' was very restless and often used a piece of paper to occupy his hands. This was very noisy on the audiotape. Consequently, I decided to bring along soft balls to provide an object for participants to handle during the interview that did not make a noise. These were a great success. Most participants simply picked them up and started to play with them, others were more cautious and only did so after I had. Some participants used them quite energetically, while others simply held them or moved them from one hand to the other.

The participants' level of movement and activity varied minimally during the interviews, making the technical task of taping our conversation easy. Most appeared very comfortable to sit quietly the entire time. However, one young man was very active and enjoyed throwing the balls high into the air and moving in his seat most of the time. I felt fortunate that none I interviewed needed to walk around the room as they talked.

I became aware of some of the potential problems in conducting research in secure residential facilities when, on one occasion, several potential participants were grouped outside together and introduced to me. I would have preferred that other residents or inmates did not become aware of who else was involved in the study. I assumed this example of a group introduction reflected the practice and protocols of how young people are managed in these settings. The reality of these confined 
settings is that what other residents or inmates are doing becomes well known in a short time. For example, at another location I thought only staff would know which residents or inmates I would be talking to, but at the end of my first meeting with one participant he asked if I wanted him to send in the next participant and named him. Despite the challenge these facilities created, the confidentiality of the content of participants' contributions has been clearly protected by the use of pseudonyms and by changing identifying information in the transcripts.

\section{Professional supervision}

At the conclusion of each interview, I had supervision with a professional experienced in the provision of therapeutic intervention to young men who had been violent. This occurred in person after the first two interviews, then via email and phone for the remaining five interviews. The purpose was to discuss my reactions to the interviews and to debrief on any issues that arose for me. Supervision was also a mechanism to protect participants as it offered a process for me to discuss my observations of how participants had responded in the interview. The detailed content of what participants shared with me was not discussed, nor were the transcripts or tapes made available to the professional supervisor.

\section{The Interview Texts}

In order for participants to have some control over their research data, it was important that they had an opportunity to review their interview tapes and transcripts. However, this could only be offered in a limited way because of the need for close security in these facilities. There were also particular risks in adequately protecting participants' privacy and the anonymity of their data because of the reduced level of individual privacy in these settings. It was not possible to ensure the material would not be checked by staff, nor could participants' ability to access the tapes and transcripts in complete privacy be assured, and finally the ability to store them securely when not in use was problematic.

In response to these difficulties, the audiotape and transcripts of the interview were not sent to participants. Instead, I offered to meet with participants in person to review them. This review was designed to give participants the opportunity to 
highlight any material they did not want to have directly quoted, to withdraw any data from the study or to add comments. However, none of the participants chose to take up this option of review.

I used the services of professional transcribers for all seven interview tapes. The transcriber signed an agreement to keep the information confidential (see Appendix $\mathrm{H})$. At the completion of the transcribing process, I debriefed the transcriber, discussing the impact the content of the tapes had.

\section{Responding to the transcripts}

I listened to each audiotape several times as I reviewed the transcripts, filled in any gaps, for example, where the transcriber could not decipher the contents, and corrected any errors. All that was said by both myself and the participant was transcribed as close to verbatim as possible.

My first reading of the transcripts surprised me. The responses by the young men came across as very heavy, serious and somewhat unfriendly. However, that was not my experience of the interview. I found the participants friendly, interested, more tentative in their responses than the transcript suggested and quite ready to laugh. I felt that the transcripts as they were, while a reasonably accurate portrayal of the verbal content of the interviews, were missing vital contextual information that I thought would provide a better indication of what occurred.

This showed the limitations of focusing solely on the content of the talk abstracted from the context. Within the interview situation, I was responding to more than content. I was responding to body language, including facial expressions and tone of voice; and to the young man's movements and his actions; as well as the physical environment.

\section{Inclusion of context}

As a consequence of the disparity between the transcripts and my experience of the interviews, I went through the audiotapes and added contextual information to the transcripts where I could. I attempted to capture the atmosphere that existed in our 
exchange by adding descriptive information, such as the tone of voice used; the noises that were made, for example, banging objects and enthusiastic drinking through a straw. I inserted where the laughter and simple chuckles occurred. I also included the use of "ah", "mmm" "eh" and the repeated words to demonstrate the general hesitancy, and the level of fluency and articulateness of participants. I also added brief descriptions of movement and activity, for example, when the balls were thrown out of reach.

I timed the pauses in participants' talk that were longer than just a few moments and recorded them in parenthesis within the transcripts. I considered pauses important because they offered further contextual information that described the interview. The reasons for the pauses were not of interest since they could have related to anything. For example, at times, the participant was eating or drinking and so chose not to respond immediately. Indeed, one participant was very strict about not eating with his mouth open, which of course precluded talking while he ate the biscuits.

I have often been disappointed when reading accounts of young people's talk because the text seemed to have been 'cleaned-up' to such an extent that the accounts have appeared inauthentic and somewhat disconnected to the youth involved, portraying the youth as more articulate than they actually are (for example, Pollack, 2000; Weaver, 2001). Therefore I have kept as much of the participants' slang and grammar as possible, while balancing this against keeping the transcripts easy to read. I did not want to approach the text in the style of conversation analysis and for this reason avoided the phonetic approach. For example, I have included the "g" on such words as "morning" when it is in fact often missing in their talk; I used "cause" instead of "because" and "na" instead of "no" to capture the quality of their talk. For similar reasons, I have also kept participants' swearing intact. Swearing within the interview context may be interpreted a number of ways. For example, it can be read as demonstrating that the young people were comfortable with me and so did not find it necessary to monitor their language. Conversely, it may be that swearing is so 'everyday' for the participants that they do not monitor this aspect of their language at all, in any context. Alternatively, they may have wanted to shock me, an adult, 
with their swearing. Hence, swearing is more than simply adding 'colour', it highlights aspects of the participants' talk that have some meaning to them.

By adding this contextual information to the interview texts, I am presenting my interpretation of what happened in the interview with the additions that I made to the transcripts. Such additions cannot stand as a precise proxy for what actually occurred. Hence, the transcripts are texts that I have created, albeit with a link to the actual event and how I experienced it.

\section{Analytical Approach}

While the data for this study were primarily obtained as the transcripts of the seven interviews, I also made use of field-notes that I recorded after conducting each interview. These covered specific observations about each young man, including their behaviour, speech intonations, appearance and presentation. I also included descriptions of my interactions with staff and any happenings within the unit while I was there. These field-notes provided a rich reminder to me of the situational context of the interviews as I listened to each tape and read each transcript, which was useful in the analysis.

The analysis followed a process of identifying constructions of interest in the text and interrogating that text with various questions. This draws on Wolcott's (1994) trio of description, analysis and interpretation, in which description is the process of identifying what is happening in the data, analysis is focusing on the features and relationships, and interpretation emphasises meaning. To achieve this, I have utilised some of the ideas from Willig's (2000) six stages of Foucauldian discourse analysis to inform my analysis of what the young men had to say to me during our time together. The six stages are:

Stage 1: Discursive constructions. The focus of this stage is on examining the ways in which the discursive objects of interest are constructed. Even if the text does not specifically refer to the discursive object, this absence provides information about how it is constructed. 
Stage 2: Discourses. This stage entails locating these discursive constructions of the object within wider discourses. This is achieved by focusing on the differences between the constructions, that is, how the same discursive object is constructed differently.

Stage 3: Action orientation. The third stage examines the discursive contexts to identify possible gains accruing from this construction. This concerns the function such a construction has and how it relates to other constructions in the text.

Stage 4: Positionings. This stage explores the subject positions that are constructed, which offer a discursive location from which subjects can speak and act.

Stage 5: Practice. The fifth stage considers how the discursive constructions as well as subject positions limit or enable opportunities for action. Some practices become acceptable behaviour within specific discourses but not in others, and subsequently reproduce those discourses.

Stage 6: Subjectivity. This final stage is the most speculative stage and attempts to suggest not what is actually experienced, but "what can be felt, thought and experienced from within various subject positions" (Willig, 2000, p. 111), as a person's subjective experience is a consequence of particular subject positions.

Organising and managing the data

I found the QSR N6 computer software programme (QSR International, 2000), useful as a tool to organise the interview text data. It enabled me to manage and retrieve large amounts of textual data in an efficient and effective manner. Each transcript was initially searched separately within N6, and the discursive objects of interest were identified. This entailed marking from a few sentences to several paragraphs in the text and included my additional contextual information I had added to the transcripts. I used a descriptive term for such discursive objects to aid the retrieval of data across all seven interview transcripts for later examination. The descriptive terms identified areas of specific interest. 
In looking at the young men's explanations of their violence and their understandings of what they did, as well as their descriptions of their specific violent acts, their talk described a range of ideas that related to the use of drugs and alcohol, relationships with friends, the role of feelings and family relationships. In relation to intervention, participants spoke of their experiences of court and of being locked up; they also spoke about the issue of talking about what they had done, as well as their expectations of intervention and what they considered useful and not useful to them. In addition, their talk was organised around such issues as the impact their violence had on themselves and others, including victims. Since their talk on their sexual violence was considerably different to how they spoke of their general violence, this text was of particular interest.

Being able to organise the data in this way within N6 enabled me to exclude parts of text that were of no further interest and so were excluded from further analysis, such as information about school, jobs, likes, dislikes and so forth.

\section{Interrogation of the texts}

Having completed organising the data, which can be likened to Willig's (2000) first stage of identifying the discursive constructions, I was now in a position to interrogate the texts as suggested by Willig's remaining five stages. This was mainly achieved by approaching the text with a variety of questions in mind.

To locate the varying discursive constructions within wider discourses, I looked at the different ways the same discursive object was constructed in the text and so explored these differences. This entailed asking, for example: How is violence constructed? What are the differing ways violence can be constructed?

To identify the effects of the construction, I looked at the discursive context and asked: What is gained from this construction? What function does it serve? For example: How is responsibility of their violence attributed? How is one construction of violence promoted over another? 
I also identified the various subject positions that were made available to participants by the different discourses. This included asking: How does he see others positioning him? What are the effects of these various positions?

By focusing on what could be said and done in the text, as well as what could not be said and done, it was possible to see how the discursive constructions and subject positions made some actions possible for the participants and excluded others. The questions which assisted this included: What did he do? How does he explain his violence? What is not being said here? What practices are suppressed?

Since discourses are systems of meaning that provide ways of being and ways of seeing the social world from particular subject positions, they also construct psychological realities (Willig, 2000). I attempted to consider the consequences such positions may have on participants' subjective experience. Questions included: What might be felt and thought from this position? What kinds of subjective experience is made available from such constructions of violence? What tensions exist between the multiple subjectivities produced?

In addition to the above ways of interrogating the text, I also investigated relations of disciplinary power, in particular, psychological discursive constructions and practices around youth violence. This critique focused on the dominant constructions within theories put forward by mainstream psychology to explain youth violence and its subsequent approaches to intervention with young men who have been violent. This aspect of the analysis involved interrogating the text when I located references to such theorising and practices. In comparing these dominant constructions of youth violence with participants' talk, the contradictions were highlighted. Some of the questions that guided the analysis included: What discourses, practices and positions exist that support violence? How does this help establish a scientifically based authority?

The young men in this study frequently drew upon dominant discourses around what it meant to be a man when describing their understandings of their violence and ideas relating to intervention. Such masculine constructions, and the resulting subject 
positions in which they were located, differed significantly from constructions of youth violence as 'abnormal'.

\section{Conclusion}

The analytical approach I have used for this study has enabled me to critique the discursive world inhabited by these young men who had been violent, to explore the implications the various subject positions had on their subjectivity, and to consider what actions and practices were compatible with such positioning. I have focused on both their general and sexual violence, and subsequent intervention. The text received from the seven interviews which I conducted provided rich and interesting material. The following four chapters offer the outcomes of this analysis. 


\section{CHAPTER FIVE}

\section{GRASPING THE DISCOURSES OF YOUNG MEN'S GENERAL VIOLENCE}

The experiences I had developing this research - shifting paradigms, and obtaining ethical approval - suggested that dominant discourses around youth violence position young men who have been violent as having nothing to say that would be considered intelligible within positivist psychological knowledges. When it comes to researching youth violence from a different paradigm, such dominant discourses can act to restrict certain lines of inquiry and potentially silence alternative sources of information. Indeed, the research ethics committees (described in Chapter Three), held the view that it was dangerous to talk to young men about their own violence, as this might risk causing them to be violent again.

These same constructions of youth violence that are currently dominant and are embedded within mainstream psychological approaches have material effects that constitute the subjectivities of young men who have been violent. For example, as I have suggested in Chapter Three these constructions can demonise and pathologise them. Throughout my analysis, therefore, the way that youth violence is constructed becomes a key issue. How any act of violence is viewed must depend on the discursive context to understand the specific action itself; that is, who is doing what to whom and with what effect. For example, an act that leads to someone dying can be viewed differently: it can, for instance, be seen variously as murder, euthanasia, capital punishment, reckless driving or medical intervention. Therefore, it is not the 
act itself that is of interest, because the very same act will be rendered either positive or traumatic depending on the discursive context.

In this chapter, I examine the participants' talk in relation to the discursive context (re)produced by psychological theories of youth violence that are based on positivist science. These theories have become legitimated knowledge in the area of youth violence, affecting not just the practices of psychologists but also impacting on all other human science disciplines and regulatory social institutions, for example, social work, schools, health services, police and child welfare agencies (Rose, 1985). Dominant discourses legitimate and reinforce existing social structures and these in turn support and validate the discourses (Foucault, 1975/1977). It is in this way that the dominant psychological view of youth violence reflects as well as (re)produces public knowledge. In their talk, participants both took up and resisted normative ideas about youth violence that I identify as originating from a scientific psychological paradigm. Therefore, the particular constructions of youth violence embedded in psychological theories that I focus on and disrupt are those that are broad in scope, well recognised and have become widely accepted as 'truth' and therefore are considered to be commonsense explanations and have strongly influenced social and institutional practices.

These include dominant ideas on the way that rationality and anger are believed to be implicated in youth violence and the role that so-called 'dysfunctional' families are thought to play in causing youth violence, along with the concept of a cycle of violence. Also covered is the function that learning is thought to have; how friends and peer pressure are believed to be involved in initiating and maintaining violence as well as the influence of drugs and alcohol. I also explore how participants positioned their victims, how others positioned them in turn as well as how they compared themselves to others. These dominant constructions that I have focused on here are similar to the five discourses O'Neill (1998) has identified "as informing and constituting the social scientific discursive field of wife abuse" (p. 459). These are: (a) pathology, (b) expressive tension, (c) instrumental power, (d) social system and (e) learned behaviour. 
In addition to troubling those key ideas from a modernist psychological perspective, I offer contrasting constructions of youth violence. Participants drew heavily on dominant notions of what 'being a man' entailed. I identify these notions as constructing an idealised masculinity that Connell (1995) theorised as hegemonic, a concept I introduced in Chapter Two. The discourses around normative masculinity offer alternative constructions of youth violence and different subject positions for participants to those considered from a dominant psychological perspective and I highlight these differences throughout my analysis. However, they become particularly evident when I specifically discuss these constructions in detail under the section, Constructions of Manliness. Overall, I demonstrate that how these young men construct their violence. The subject positions they take up show that in many ways the world these young men inhabit is radically different to that which a positivist psychology suggests.

\section{"Getting into Trouble"}

I struggled with how to begin introducing the participants' talk in this chapter. Initially, I wanted to provide a connection between the type of violence the young men had committed and their understandings of their violence, linking how they talked about what they had done with their talk about their reasons for doing violence. However, the obvious problem with this approach is that it assumed that an abstracted, decontextualised telling was possible. From a discursive viewpoint, this is not possible; a particular positioning would be produced in the telling of it, thus constructing the participants' subjectivity (Henriques et al., 1984; Hollway, 1989; Parker, 1992). I concluded that I was immediately being drawn back into the positivist scientific paradigm. I was to encounter this type of slippage continuously during the analysis as I tried to move more towards a poststructural discursive approach.

I was also aware that no matter how I presented the participants' talk, these young men's language would tend to be (re)positioned according to dominant discourses of youth violence. My particular concern was with the dominance of positivist psychological constructions of youth violence. For example, the young men could be 
positioned as having a predisposition towards serious violence if I started the text with some of their less serious offending stories that nevertheless showed a history of violence. Alternatively, they could be positioned as very dangerous if I started with the more severe violence, particularly if I used quotations that could be read as their having demonstrated a lack of remorse. A different positioning would also be available if I began with their talk of how important their family and, the friends who still visit were to them and their fears of adult jail. Such talk would position them as vulnerable boys/young men who were perhaps misunderstood and who simply have not had the 'right' chances in life. But such a positioning does not easily account for the seriousness of their violence or the harm that they have caused. What was therefore important to me was to be able to demonstrate how these young men are positioned in all of these often contradictory ways and for my analysis to show this complexity.

Keeping this awareness of how these young men are positioned in mind, I begin this chapter by discussing ways that participants constructed their involvement with the justice system. All except one participant spoke of "getting into trouble". It soon became clear that this phrase was used as a euphemism for getting caught doing something illegal by the police, rather than describing having disagreements with parents or other authority figures. For some, "getting into trouble" with police went hand-in-hand with trouble at school and also created trouble for them at home with their parents, for example, "being kicked out of home" (Sean) and being sent to live in a "family home" (Rick). When considering the circumstances and consequences of their situations, it is easy to position them as vulnerable young men who perhaps need more care and protection than they have received so far.

However, another way to position them discursively is to consider their activity as being the norm for adolescents, so they can be positioned not as needing care and protection but rather as needing time to mature. There was a range of activities that participants spoke of being involved in that constituted different forms of what may be considered problem behaviours that are connected with youth, such as truanting from school, getting into fights, smoking, shop-lifting, getting drunk or stoned, stealing cars and doing burglaries. Violence to things, such as smashing up an 
abandoned car, was described as "having fun" (Anthony). The subject position that emerges here is one of a typical teenage boy having some harmless fun. A developmental discourse considers such behaviour as 'normal' teenage activity, particularly in relation to juvenile delinquency where there is an expectation that most young men will 'grow out' of such behaviour when they mature (Walsh \& Ellis, 2007).

\section{Rational Violence and Anger}

Violence can be categorised in many ways. One way is based on the intent of the perpetrator that differentiates between two types of violence, namely instrumental (intentional) and expressive violence (less intentional) (Blackburn, 1993). These types of violence are widely known to those outside the discipline of psychology, though perhaps not necessarily by these labels. This dualism of instrumental/expressive violence is based on what is theorised as the motivation behind the violence. Instrumental violence is viewed as a choice made to achieve a rational purpose, such as gaining money, power or status. Expressive violence, on the other hand, is thought to result from an emotional state, primarily anger, and reducing or relieving this emotion is seen as the motivating force behind the violence. These same constructions of violence are evident in the participants' talk, but they make less of a distinction between them compared with positivist psychological theorising and draw on these notions in complex and particular ways that are supportive of the normative constructions of 'manliness' they take up.

\section{Rationalising violence}

The concept of rational, instrumental violence was (re)produced in participants' talk of choosing violence as a means to an end. Drew, for example, was able to explain most of his reasons for doing crime and violence as being related to getting money:

$\begin{array}{ll}\text { Drew: } & \text { Yeah. Ah, it was me and my mate ah ... [name of mate omitted], } \\ & \text { yeah he got four and a half years. But he, I just met him up town, I } \\ \text { was just walkin' round town I wasn't planning to do nothing that } \\ \text { night. I was planning to go and ring my Mum and tell her to come } \\ \text { pick me up and I just seen him up town, bumped into him. Say he } \\ \text { asked me what I was up to and we just decided to go make us } \\ \text { some cash. Yeah. }\end{array}$


Drew: I dunno. But I think it was on a Thursday night I think. He just goes oh we should go make us some earn for some cash this weekend 'cause he was going to, me and him was supposed to go to this party on the weekend. We had no cash and we wanted to. I was keen so he knew a car to steal so we went around and stole this car.

\section{$[\ldots]^{15}$}

Drew: $\quad$ And once we got it started we driving around looking for a place to rob. We don't have a place then to, to hit so then we just decided to ah rob the ... [name of business omitted] for all their ... [type of item omitted], it's worth thousands in the shop 'cause we'd already, we'd already done one of them before. Stole it from another ... [type of shop omitted] and we made about, quite a lot of money. About three grand each. So we decided to do it again, and rammed the car through the shop and got all that stuff. Got about 15 [containers] of it and they're a grand each so it was quite a bit.

[...]

Drew: And ah went and stashed that stuff and 'cause we had no cigarettes, we were just, no cigarettes or cash at the time. We were just driving past a petrol station and he goes should we just hold up that shop for their money and get some smokes. I said yeah 'cause I was keen at the time. So we held them up, got their money and then we're off.

Drew's description of these two crimes seems reminiscent of the 'ordinary' nonviolent world: "we just decided to go make us some cash" and "we just hold up that shop for their money and get some smokes". If the reader suspends consideration of the illegal activity, the description can be read as being matter-of-fact, and as how most people describe their decision to go shopping with a friend. The difference, of course, here is that Drew and his mate's category of shopping was illegal and violent. Drew constructed the instrumental use of violence as rational. In turn, such positioning likens Drew and his accomplice to business men making logical decisions in order to get money. The motivation is logical and rational and is not about having an intention of hurting others. However, the enterprise has an element of spontaneity: "I wasn't planning to do nothing that night", with little preparation or planning involved. In this case, rationality does not extend to planning or consideration of negative consequences.

In contrast, Drew went on to describe the robbery of a service station he did with a friend that demonstrated slightly more planning, since they took weapons with them:

15 [...] This symbol is used throughout the analysis chapters. It denotes material from the interview that I have omitted because it is irrelevant to the current discussion. Such material can include a high level of unnecessary detail, or tangential information or it discusses a different topic that is dealt with elsewhere in the analysis. 


$\begin{array}{ll}\text { Shirley: } & \text { So did you both go in? } \\ \text { Drew: } & \text { Yeah. } \\ \text { Shirley: } & \text { Did you have any weapons? } \\ \text { Drew: } & \text { Ah. Just a tomahawk, my mate and I had a screwdriver. } \\ & {[\ldots]} \\ \text { Shirley: } & \text { And what did you say to him? } \\ \text { Drew: } & \text { Oh, oh, my mate done all the talking. He just goes, straightaway he } \\ & \text { just, straightaway the fella just backed off when he seen us run into } \\ & \text { the shops. Me and my mate just told him to open the till and I was } \\ & \text { already going, filling up my bag with the smokes and when I, and } \\ & \text { he was just, then after my mate got all the cash he was just holding } \\ & \text { him and asking him if there's a safe or any cameras around. So he } \\ & \text { grabbed the video tape from the camera so they don't know who it } \\ \text { is but there was no cameras and by the time l'd finished getting all } & \text { the smokes we left. He was just holding them till I finished so he } \\ & \text { didn't do nothing. }\end{array}$

Drew's description portrayed some clearly defined roles that he and his mate played in this robbery, suggesting again, that a controlled and business-like approach was taken, while the threat of violence was clearly communicated to their victim as instrumental. Although Drew's purpose in committing the robbery may have been to get money and smokes for the weekend and not necessarily to hurt someone physically, the planning, the deliberateness of roles and the threat involved, positions Drew as a serious and dangerous criminal within the discourses around violent offending.

Sean too described an aggravated robbery that could be characterised as instrumental violence, which he committed while he was "on the run" for another crime. Prior to this robbery he spoke to me of: "living off others, stealing" and "shop-lifting" for "food and clothes".

$\begin{array}{ll}\text { Shirley: } & \text { Okay. Do you want to tell me about the aggravated robbery, what } \\ \text { happened? } & \text { Oh yeah. I was just, I left town from ... [name of location omitted] } \\ \text { and I went to ... [name of location omitted] and I went like to stay } \\ \text { at a mate's place and then I was just low on money and like that } \\ \text { was before the, that was after the other one. And I thought I like I } \\ \text { had a suspicion that I know I'm gunna get caught for this one, so I } \\ \text { didn't care what happened then so I aggravated robbed a shop } \\ \text { 'cause I was ah low on money and that. That's about it really. } \\ \text { Seah so was it a dairy? } \\ \text { Shirley: } \quad \text { Yeah a dairy. } \\ \text { Shirley: } & \text { Did you use any weapons? } \\ \text { Sean: } & \text { Just a like imitation gun like a pistol, yeah. }\end{array}$


Shirley: Right. So did you threaten to shoot them or any of that sort of stuff?

Sean: $\quad$ No l just pointed the gun at her and asked for the money. Yeah.

Shirley: $\quad$ So when you did the dairy you weren't worried about adding to your charges or any of that sort of stuff?

Sean: I didn't really think about it, I just wanted the money so I done it.

Sean's rationale for the aggravated robbery can be viewed as an act of necessity, as he was desperate for food and clothes. Within the poverty discourse, the struggle to have the necessities of life has legitimacy and is likely to gain sympathy from others. Thus, Sean is positioned as being forced to do crime for his own survival, particularly since he could not utilise the usual means of assistance easily as he was "on the run". However, Sean's mode of survival also positions him as both desperate and dangerous, a young man who poses a risk to the community because he may choose to repeat his actions at any time and because he was determined to get what he wanted: "I just wanted the money so I done it" without "really thinking about it".

Drew appeared to move outside the concept of instrumental violence, when he talked of his involvement in crime as being like an addiction. According to some dominant psychological theories, addictions are often associated with emotion rather than rationality, for example, cravings for a drug or alcohol. Drew linked this addiction to crime to his desire for money, a normative rational desire. He spoke of making big money fast:

\footnotetext{
Shirley: $\quad$ So how come you do that?

Drew: $\quad$ I dunno, it's like, like ah addiction, crime.

Shirley: Is it?

Drew: $\quad$ Yeah you just want to keep doin' it and doin' it once you start. [...] It's ah some quick easy cash and then after you do it a couple of times and then you get away with it and you get paid for it, go sell all your stuff, you just want to do it again. And keep doin' it.

Shirley: So what do you think that's all about? Where does that sort of come from?

Drew: I dunno.

Shirley: It's a hard question, I don't know either. That's tricky isn't it? [...]

Drew: $\quad$ Yeah. I think it was just do the crime for money. So when I had my job I get paid $\$ 200$ a week and ah that would be gone by Sunday. I spend it on alcohol and drugs then plus if I done crime before like say if I got paid, well I usually got paid on Thursday or Friday. I got paid on Friday, that night I would, or that day l'd get my cash then l'd go do some more crime that night, sell my stuff on Tuesday and then, I mean the Saturday and be cashed up, with money, About 5or 600. Like you can just make a lot of cash fast.
} 
Shirley: $\quad$ And you like the money? So what do you do with the money?

Drew: I spend it, spend it on drugs, alcohol. Yeah. Buy anything really. Sometimes I buy clothes and food. Yeah oh when I had my car I spent quite a lot of money on that. Fixing it up and all that kind of stuff.

How Drew used his money certainly fits dominant expectations of the youth consumerist culture, centred on parties, smokes, drugs, alcohol, food, clothes and his car. It also highlights the pervasive influence consumerism has in our postmodern society, the ability to have and to purchase a range of products is one measure of individual 'success'. Like successful, rational business approaches to making money, the consideration of the speed and the amount of wealth that can be accumulated seemed to have influenced Drew's decisions - "Like you can just make a lot of cash fast". Drew's "addiction to crime", within the construction of violence as instrumental, can be read as taking up the subject position of a consumer, constructing crime as merely a way to achieve the means (money) to purchase and use products. Drew went on to say that he did not think he would continue with crime if he had a well-paid job, but he immediately qualifies this by saying he would need quite a lot of money to stop. Within the discourse of capitalist business, Drew can be seen as rationally weighing up the risks of crime versus the benefits of making large amounts of money very fast.

Being violent and doing crime as a rational way to achieve goals is a commonly accepted notion, used to explain the actions of criminals. However, such rationality can also be viewed as dispassionate, and if young men demonstrate a significant level of emotional detachment to their violence, then they are often positioned as psychologically disordered (particularly sociopathic) ${ }^{16}$ (American Psychiatric Association, 1994) as there is little evidence of their conscience playing a role in their violence nor much consideration towards victims. Therefore, having some emotional response related to their violence positions perpetrators as being less dangerous than the unfeeling rational (objective) villain. Laws (2001) outlined this negative positioning when she wrote about children who were forced to attend a 'special school' because their violent behaviour was not manageable in the

\footnotetext{
16 Also referred to as psychopathy or antisocial personality disorder that is described as having a disregard for or violating of the rights of others, with a callousness towards others and a lack of empathy (American Psychiatric Association, 1994).
} 
mainstream school system. She referred to children being positioned as 'abnormally bad' because they could not demonstrate any emotional reaction when their actions hurt others. This contrasted with those who were positioned as simply 'bad'. This subject position was normative because some 'bad' behaviour was accepted and even expected from 'normal' children and young people.

\section{Exciting violence}

Despite their robberies being able to be categorised as instrumental violence, the participants' violent actions can also be read as not being solely mediated by rational decisions. Some described an emotional component of excitement for these robberies as well as for their gang fighting, which demonstrated the difficulty of separating emotion from rationality.

Drew, for example, found doing ram raids (driving a car through the entrance of a shop and then robbing it) exciting:

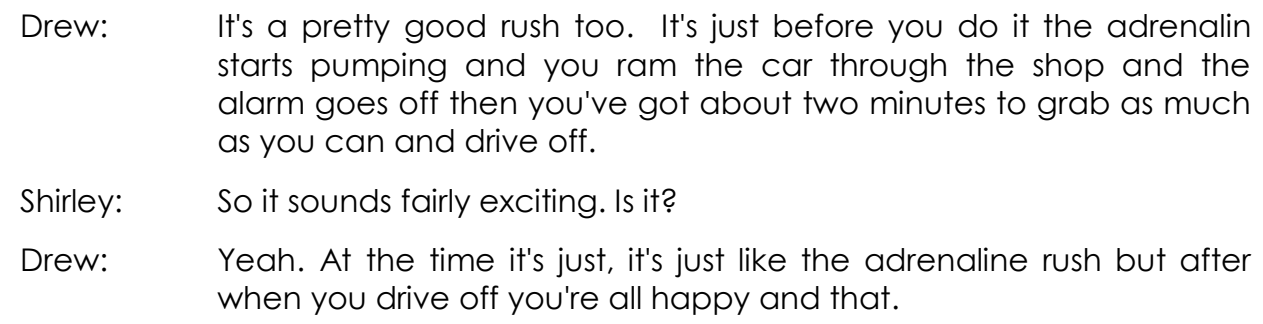
starts pumping and you ram the car through the shop and the alarm goes off then you've got about two minutes to grab as much as you can and drive off.

Shirley: $\quad$ So it sounds fairly exciting. Is it?

Drew: $\quad$ Yeah. At the time it's just, it's just like the adrenaline rush but after when you drive off you're all happy and that.

Likewise, Sean found the adrenalin rush and nervousness contributed to his experience:

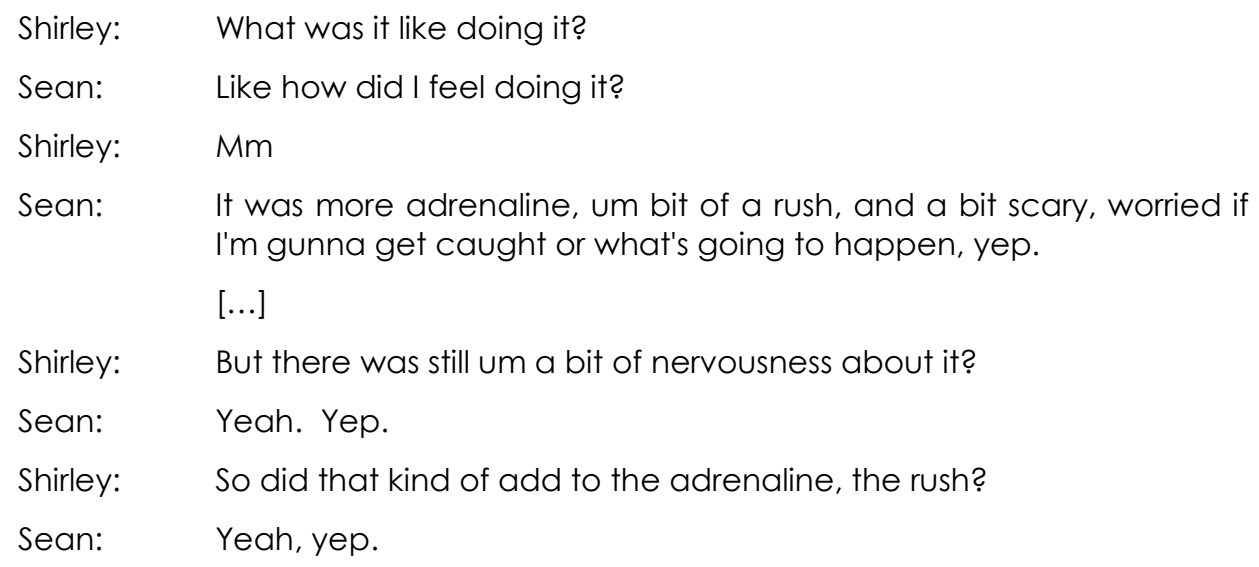

Sean and Drew's references to feeling an "adrenalin rush" and "enjoyment" during their crimes demonstrated that they felt excitement. That type of excitement, seeking 
an adrenalin rush particularly as part of the dominant discourses around youth, positions young men as risk-takers looking for action. This is often extreme action, such as crime and violence and is also frequently seen in a range of extreme sports. Such risk-taking behaviour is generally viewed as being associated with young men's developmental processes, but also as behaviour that needs to be contained and controlled (Hayward, 2006). Yet, within the dominant discourses around normative masculinity, risk-taking and action are fundamental practices of being a man, and perhaps even considered as a 'rite of passage' into manhood for young men, albeit an informalised one (Delaney, 1995).

Conversely, enjoyment or experiencing excitement in the commission of crime and violence will position the young men as either 'mad' or 'bad' within dominant discourses of abnormality. The subject positions available would appear to depend on what specific crime or which element of the crime provided the "adrenalin rush". If the adrenalin rush is from non-violent crime, then it is more likely to be viewed through the youth discourse as positioning the young men as 'boys will be boys'. But if the excitement derives from a crime of violence that is harmful to others then young men will be positioned as 'bad'. However, for a scientifically based psychology the subject position of 'bad' is not a viable one. The discipline aims to explain human behaviour scientifically, but being 'bad' is a common-sense explanation that has strong links to pre-scientific moral or religious concepts of 'evil'. Consequently, being 'bad' becomes being 'abnormally bad' (Laws, 2001) and getting a "rush" from hurting someone is viewed as being as pathological as the rational, 'non-feeling' young man who is violent.

Enjoying violence is therefore discursively portrayed as being 'abnormal' and 'disordered'. The creation of the concepts of conduct disorder ${ }^{17}$ and psychopathy (Hare, 1970, 1999) become categories to capture and mark those who are 'abnormal'. Within such a psychopathology discourse, it is not possible to consider that young

\footnotetext{
${ }^{17}$ Conduct disorder is often used to explain why young people are violent. However, the disorder itself actually describes the behaviour and is therefore a tautology (Kutchins \& Kirk, 1997). A young person is said to have been violent because he has a conduct disorder, but a criteria for conduct disorder is to have engaged in antisocial behaviour, often being aggressive and violent to others. The label of conduct disorder is changed to antisocial personality disorder when people (mostly men) reach their adult years (American Psychiatric Association, 1994).
} 
men who enjoy doing violence can be anything except 'mad' because being 'abnormally bad' is constructed as a form of madness or mental illness.

Given the dominance of the psychopathology discourse and the 'mad' and 'abnormally bad' subject positions for these young men who have spoken of experiencing an adrenalin rush in relation to their violence, I wondered about their ability to talk about their excitement without fear of being pathologised. There are of course other contexts and discourses within which fighting and hurting others is rewarded and enjoyed. The participants' ability to say such things becomes clearer when considering the discourses around sports such as boxing, wrestling and martial arts. These sporting discourses produce similar effects of excitement and adrenalin that participants' discussed in relation to their violence. However, it could be argued that sports are bounded by rules that make them different to the types of violence described by participants. Nevertheless, the participants suggested that gangs operated according to certain rules of engagement that were understood by all and so offered similar boundaries as sports.

\section{Anger as a man's emotion}

Human emotion is seen as being closely connected with the body, which in turn is linked to nature (Seidler, 1994). Many aspects of the scientific enlightenment project have aimed to control nature. Hence, controlling emotion has become the province of mainstream psychology. Additionally, being female is closely associated with nature and therefore so is emotion. Rationality is clearly linked to masculinities as, "men are rational and women are emotional" (Connell, 1995, p. 164). Rational control not only suppresses emotionality but also desires and values (Walkerdine, 1988). While violence can be the rational, such as instrumental use of the body, violence is also associated with anger. Anger (within limits) is an emotion that is normative within masculinity discourses.

Constructing violence as being caused by anger is a dominant, taken for granted concept that fits with the notion of expressive violence. Some participants talked about their experiences of feeling angry. Quentin described it as "psycho-ness", 
when he smashed up his place. Although anger was not part of his offences, Anthony spoke of what it was like for him when he felt angry:

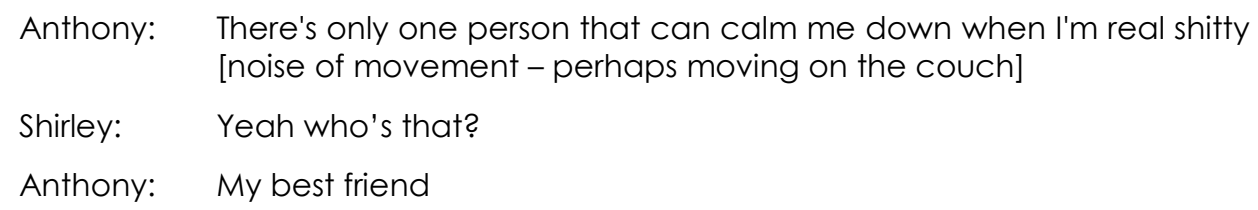

Anthony talked of his anger as being so far outside his control that he had to rely on his friend to control it for him. Dominant discourses of anger conceptualise such strong emotional arousal as a human experience that needs to be controlled and managed because it is assumed that there are risks if such emotion is allowed full expression or is acted upon (Davey, Day, \& Howells, 2005; Howells, 2004; Novaco, 1994; Novaco, 1997). Unbridled expression of very strong emotion is often characterised as some type of madness because of this lack of (rational) control. Indeed, the Diagnostic and Statistical Manual of Mental Disorders (American Psychiatric Association, 1994) pathologises angry outbursts as "intermittent explosive disorder" (p. 609) - one of the impulse-control disorders.

At least two processes are theorised to take place in relation to strong emotions and violence (Gerard, Krishnakumar, \& Buehler, 2006). Firstly, emotion may be internalised, that is, it is seen as being focused on the self and so presents a psychological and physical risk, for example, depression and suicide. This is usually associated with women. Secondly, emotion is described as being externalised. In this process full emotional expression occurs and involves acting on the emotion, for example, anger turns to violence. Externalising anger is most often associated with men. The most commonly assumed risk is that acting on anger will entail hurting others. Therefore angry young men are positioned as dangerous because there is an expectation they will be violent. Their violence, however, is viewed as unpredictable because emotional arousal (read anger) can be triggered by various internal or external events; and these young men are theorised to have no control over their anger.

However, this mechanistic idea that anger caused their violence seems to be at odds with what the young men said about their violence. While some participants talked about experiencing anger, none of them described anger as the primary motivation 
for most their violence. Instead, the young men talked of anger as being a very controlled (rational) aspect of what they did.

I expected to hear more comments from participants about their uncontrollable anger, such as Anthony who needed a friend to control his, because of the dominance of the discourses around anger that construct its expression as needing to be controlled. Anthony showed how he inhabits a range of subjectivities when he offered the following contradictory position about his anger:

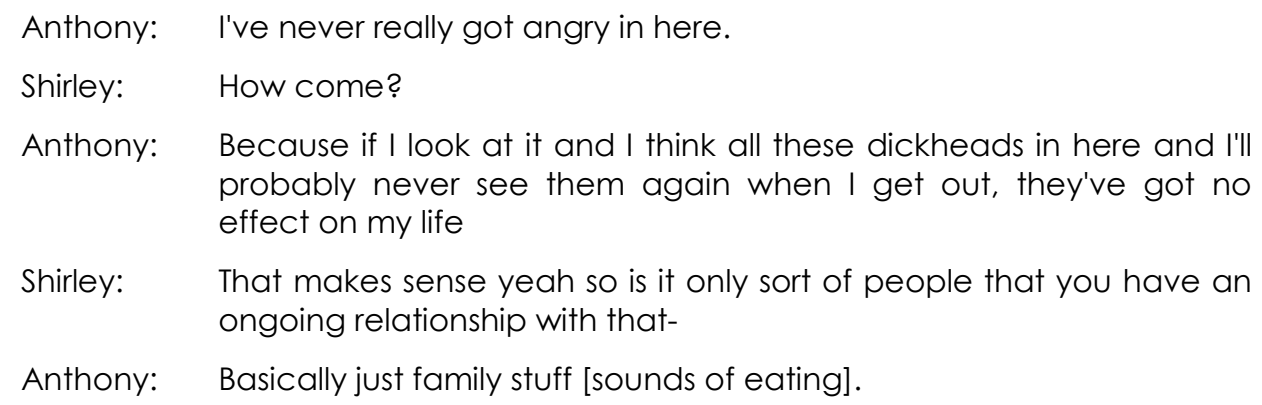

Anthony drew on rationality to explain how he was able to choose whether, firstly, to get angry or not and, secondly, whether to fight or not. He described having control over his emotional reactions to the other inmates because "they've got no effect on my life" and "I know none of these people in here" and "it's not going to matter anyway" after being released.

A position of rational reasoning is taken up by Anthony to control his emotional arousal when dealing with others inside. In contrast, Anthony spoke of family as an appropriate context for feeling angry, "basically just family stuff". The family discourses reflected and (re)produced in objectivist approaches to psychological theorising suggest that the family is the environment where emotional expression is not only acceptable but expected. Expressions of love, support, care and nurturance are constructed as necessary to good functioning. Likewise, other emotions, such as anger, annoyance and irritability are also seen as part of the picture and their expression is also viewed as appropriate, but only within acceptable boundaries. Such boundaries are determined by the regulatory practices of social institutions, like schools, health services and welfare agencies that rely on scientific authority to legitimate their practices. 
Anthony again drew on a position of rationality to describe how he found it difficult to understand why others smashed up their own things when they were angry:

\begin{tabular}{|c|c|}
\hline Shirley: & $\begin{array}{l}\text { Well that's good. Because l've met a lot of guys who find themselves } \\
\text { stuck like that too and the only thing that they can do is actually hit }\end{array}$ \\
\hline Anthony: & $\begin{array}{l}\text { Oh yeah but yeah I don't understand people that do that, like if } \\
\text { you're at your house and you get real angry, I don't understand why } \\
\text { you smash all your windows because you've only got to go around } \\
\text { and fix them and pay for them }\end{array}$ \\
\hline Shirley: & Yeah it doesn't make a lot of sense does it? \\
\hline Anthony: & $\begin{array}{l}\text { Na see I don't' do stuff like that, if I'm going to break something, it's } \\
\text { not going to be mine and I'm not going, there's going to be nobody } \\
\text { around to see that it was me. }\end{array}$ \\
\hline Shirley: & Oh okay that's sensible \\
\hline Anthony: & $\begin{array}{l}\text { But usually if I do that, I'm not in a bad mood anyway, I'm just doing } \\
\text { it to be an arsehole to somebody. }\end{array}$ \\
\hline
\end{tabular}

Anthony presented a viewpoint that does not accept that violence necessarily results from explosive and uncontrollable anger. He was not suggesting that he would not break things, rather that he would do so strategically: "it's not going to be mine and I'm not going, there's going to be nobody around to see that it was me". Strong selfinterest can be read as motivating Anthony's suggested logical and rational purpose. Furthermore, such action can be strategic even when its appearance seems to be an angry response: "I'm not in a bad mood anyway, I'm just doing it to be an arsehole to somebody". Thus, a performance of anger can be successfully completed even when the emotion is not being experienced. Most people experience fear when confronted by another's anger. This may be because of the expectation that they will be hurt by the other. The expression of anger - whether or not, the person is actually experiencing anger - can by itself therefore achieve desired results without the need for actual physical contact.

When it comes to young men's fighting, anger is often thought to be a significant determinant of the violence. However, both Sean and Drew offer a different perspective when they talked about their experiences:

Shirley: $\quad$ Yeah. So you're not one of those that get into the scrapes?

Sean: No. No I think I'm quiet.

Shirley: Okay.

Sean: $\quad$ Own person. Had a few fights but never hit them. You know I don't want to go around hitting people like ... [unclear]. 


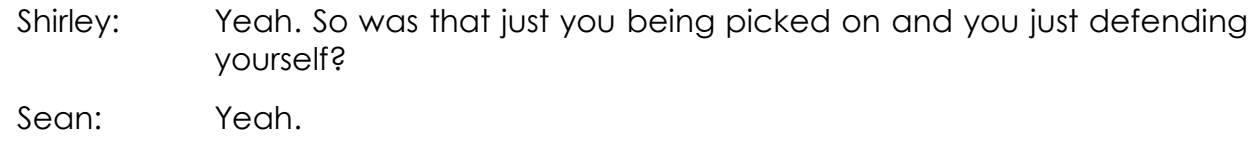

Although he got into fights, Sean talked of choosing not to hit his opponents during these fights. While he did not say whether he did or did not experience anger during these fights, Sean chose his actions even in 'the heat of the moment', which contradicts dominant theories in which exploding anger is thought to be implicated in men's fighting (Howells, 2004). Not wanting to hurt anyone by hitting also seems to contradict what one aim of fighting is thought to achieve; that is, inflicting the maximum possible damage on the other. Therefore Sean can be read as containing his violence and as controlling himself. Perhaps by not hitting, Sean may experience himself subjectively as not being violent. In addition, by not hitting, Sean can be positioned as defending himself since he can present himself as being unable to avoid the fight.

Drew also made rational choices not to harm others in the midst of a gang fight:

$\begin{array}{ll}\text { Shirley: } & \text { So have you ever fought with weapons? } \\ \text { Drew: } & \text { Oh I've never had, had the guts to hit someone with a weapon. } \\ \text { Shirley: } & \text { No? } \\ \text { Drew: } & \begin{array}{l}\text { Once I threw a bottle. I was supposed to hit him with the bottle but I } \\ \text { didn't want to hit him so I threw it at him and I didn't aim for his head } \\ \text { either, I aimed for his body. I don't like using weapons, I might kill } \\ \text { someone. }\end{array} \\ \text { Shirley: } & \text { Okay and you don't want to kill anyone? } \\ \text { Drew: } & \text { No. }\end{array}$

Drew spoke of exercising considerable control in choosing not to use a weapon, even though he "was supposed to hit him with the bottle". He constructed the act of using a weapon as courageous, but that he did not have what it took to do so: "I've never had, had the guts". This also suggests that he would potentially admire those who did use weapons. The possible consequence of killing someone seemed to outweigh any glory Drew may have experienced from using a weapon.

Both Sean and Drew's descriptions contradict the idea that uncontrollable anger motivated their fighting. Instead, considerable control and rationality are predominant in their descriptions. 


\section{Constructions of Manliness}

The more the participants' talk offered alternative, complex and variable ways to consider the key ideas of mainstream psychology's theorising about youth violence, the more I needed to explore the discourses in which their understandings of their violence were located. It became clear to me very quickly when talking with these young men that 'getting it right as a man' was fundamentally important to them. The discourses around manliness had a significant impact on the positioning participants took up in relation to their explanations and practices of violence.

The impact masculinities has for young men has been highlighted in various research studies. Phillips (2001; 2005), for example, described a study she undertook with 32 American school boys aged 12 to 18 years that incorporated an examination of media sources, interviews and group discussions. The study aimed to explore the "links between cultural discourses of masculinity, performativity of masculinity, and practices of male violence" (2001, p. 50), using feminist, poststructural, psychoanalytic discourse analysis. Phillips considered violence as an "unhealthy" practice of masculinity. In her analysis of media sources, violence was depicted as being linked to being a man in computerised games, news items and advertisements. In the interviews and discussion groups Phillips explored the incidences of violence that were described by participants, these were fighting with peers, physical and verbal bullying and what Phillips described as self-violence, that is, boxing and skate boarding in which personal injury was seen as part of the activity. In this work, Phillips identified eight discourses: (1) Popularity and necessity of the outcast, (2) Reproduction of hegemonic masculinity: practices of punking, (3) Proving masculinity: discourses of daring and risk, (4) Proving masculinity: heterosexuality and homophobia, (5) Slick masculinity: in your face, (6) Masculinity as domestic incompetence (7) Enforcing masculinity: discourses of violence, and (8) Father and sons: bonding and the reproduction of hegemonic masculinity.

Phillips (2006) has argued that violence is a performance or practice of masculinity, she stated “...acts of a [sic] physical strength, aggression, competitiveness, heterosexuality, risk taking, and emotional stoicism signify an assumed 'essential' masculine core or identity" (p. 417). Phillips (2001, 2005) also lists the following as 
signifiers of hegemonic masculinity: toughness, physical strength, tall or large body size, playing sports, the ability to fight, independence, risk taking, heterosexuality, popularity with boys and girls, cars, boats, Whiteness, the military, particular clothes, middle or high socio-economic status. A number of these signifiers were evident in the talk of participants in this current study.

Hegemonic masculinity, according to Connell (1995), is an idealised description of manhood, which is conceptualised as a fixed and 'true' masculinity, of a 'real' man, the 'natural' man that permeates the social world in Western cultures and which reproduces the patriarchal order (see Chapter Two). Such a normative definition of masculinity is reflected culturally in numerous ways, for example, movie characters played by Russell Crowe or Tom Cruise, and in advertising campaigns, such as those showing the 'Great Southern Man' in beer advertisements in New Zealand. David and Brannon (1976) characterised this traditional masculinity by describing four sex roles. These include: No Sissy Stuff, which revolves around avoiding all things feminine and includes homophobia; The Big Wheel, relates to competition, achievement and success; The Sturdy Oak, which emphasises physical toughness and emotional repression; and finally, Give 'em hell, which focuses on being aggressive and forceful.

These examples provide the means to offer descriptions of traditional masculinity, but "'hegemonic masculinity' is not a fixed character type, always and everywhere the same. It is, rather, the masculinity that occupies the hegemonic position in a given pattern of gender relations, a position always contestable" (Connell, 1995, p. 76). It is more useful to view hegemonic masculinity as an ideal, and as Connell suggests, few men are successful in reaching the normative standard of masculinity that the dominant discourses produce. Therefore, to use the concept of getting a subject position correct (Laws \& Davies, 2000), young men will be constantly aiming to achieve the subject position of being a 'real' man. This aim was evident throughout the participants' talk. 


\section{Being a man}

Rick spoke of immaturity being the main reason he made some bad choices and that puberty was an important time for him. It was a time when he changed a great deal, he became bigger and stronger, he preferred to work for his money and turned away from crime and violence. He was no longer a child acting as, what he called, "a little hood rat".

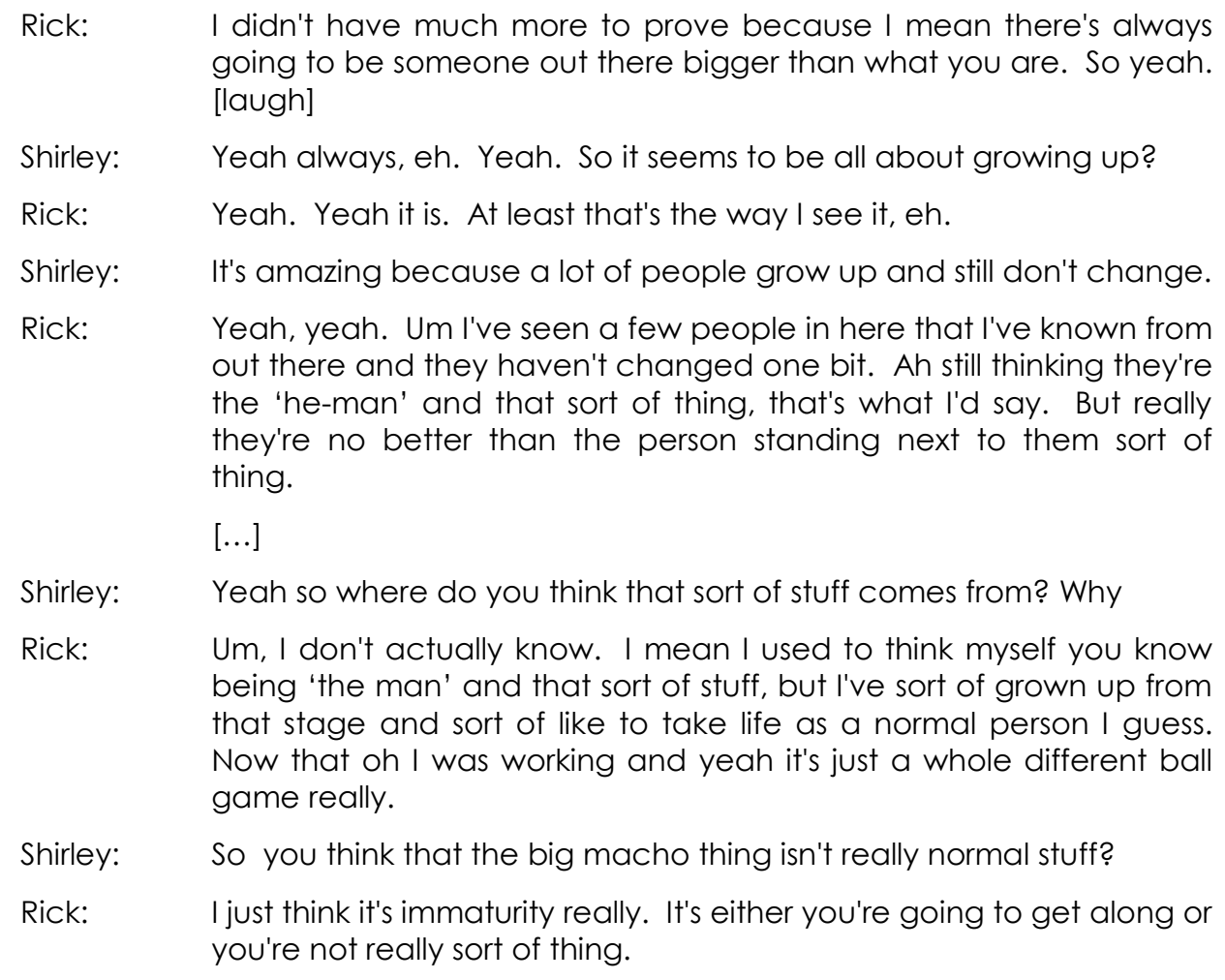
out there and they haven't changed one bit. Ah still thinking they're the 'he-man' and that sort of thing, that's what l'd say. But really they're no better than the person standing next to them sort of thing.

Rick suggested that becoming a man occurred through the signification of puberty via the physical changes produced. Alongside this came maturity and, together with having a job, he could now be read as having achieved manhood. He "didn't have much more to prove".

While becoming a man is, of course, highly significant for Rick, it appears that it is possible to get the subject position of man 'too right' (Laws, 2001). Rick also referred to notions of hyper-masculinity when he spoke of being a "he-man", and doing "the man" thing, as being immature. Instead, he suggested that being a "normal person" required growing up to move beyond such a macho performance. Therefore, being 'too much of a man' is not performing the position of man correctly. 
Reflecting back on his past violence, Rick spoke of how there was a need to prove his 'manhood'.

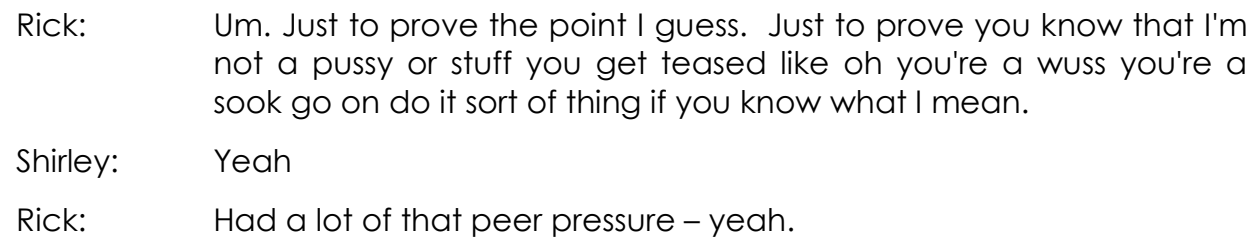

According to Connell (1995), 'manhood' is generally not defined as what a man is, but rather what a man is not and "a specific masculinity is constituted in relation to other masculinities and to the structure of gender relations as a whole" (p. 154). Most notably, a man is defined as not a woman. It is unsurprising, then, to see such terms used as "pussy", for example, which often denotes the feminine in general, or a woman's genitals. Therefore "pussy" becomes a derogatory term to describe a man. As masculinity is constructed in relation to others, it is also always contested. Thus, the hegemonic concept of 'manhood', must always be proved (Connell, 1995). Fighting and violence become the ultimate means of doing so.

\section{Exploring fighting}

One view of fighting is that it is a deviant behaviour, caused by anger and that the opponents do not have the necessary social skills to settle their disagreement in any other way. Fighting was an activity that participants frequently engaged in, both fighting individually and in gang fights. The reasons fights began varied considerably and the outcomes were complex. Participants spoke of their fighting experiences inside the secure facilities and prior to being incarcerated for their current offences. Drew explained that his annoyance with another inmate was implicated in his agreeing to a fight:

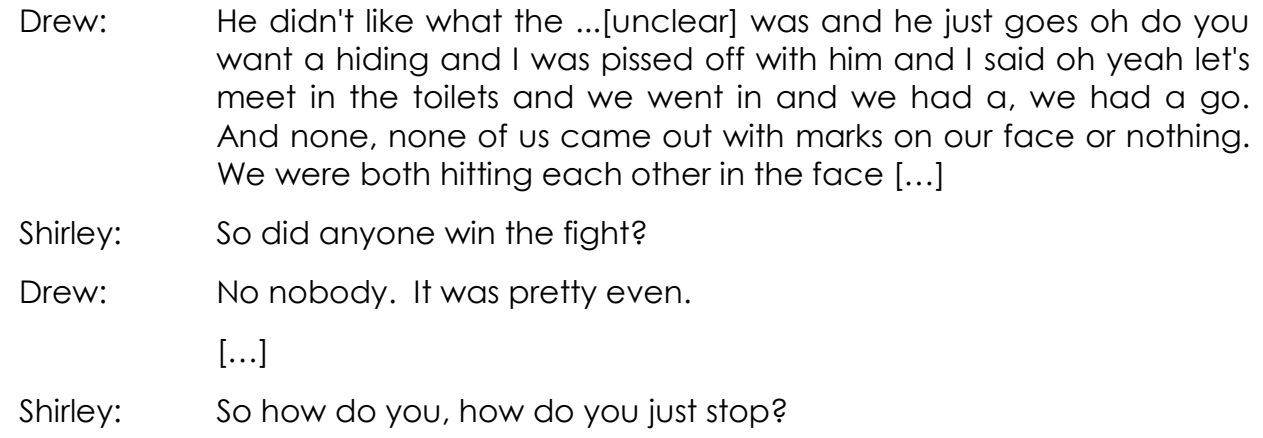



Drew: We just both stopped. Went for ages and we just both stopped because we were tired.
Shirley: $\quad$ Kind of called even was it?
Drew: $\quad$ Yeah

Drew's description of the progress the fight took did not focus on his anger, but instead his talk can be read as admiring both himself and his opponent. His comment that the fight was "pretty even", suggests he had a worthy opponent. Drew constructed the other as honourable; respecting one's enemy can be seen as enabling male friendships to emerge from such violent beginnings. At the same time, success in fighting establishes his place within the hierarchy. This contrasts to the assumption that fighting is simply a way of releasing anger and an 'uncivilised' way of resolving a dispute.

Although he previously spoke of himself as being mature now and not needing to prove himself, Rick also got involved in fights while inside:

$\begin{array}{ll}\text { Shirley: } & \text { Do you get into any of the fights and stuff that go on? } \\ \text { Rick: } & \text { Well to be honest I do. Um, but you know you can't always stop } \\ & \text { them from happening and as they say there's always one sour } \\ & \text { grape isn't there, yeah so. [small chuckle] } \\ \text { Shirley: } & \text { So what are those sort of things about most of the time? } \\ \text { Rick: } & \text { Um. Most of the time it's just stupid things. Just little things really. Um } \\ & \text { yeah I mean someone starts an argument with one person and } \\ & \text { then the other person gets in and another person, then the two } \\ & \text { original people that were going to fight don't even fight and then } \\ & \text { there's another two that will. So it's just stupidity I guess. }\end{array}$

While Rick described his involvement in fights as if he had no choice, "you can't always stop them", he nevertheless called such fighting "stupid" and occurring over "little things". But he then went on to talk of fighting as being a way to solve problems:

Shirley: Does it, does it fix things. Like having a fight or what does it do?

Rick: In some ways it does. From what l've seen being here um I've experienced a few fights. Um a couple of people just biased of each other but now they get on quite well, due to - I think it's just a macho man sort of act to see who's bigger than who and but I mean I suppose in here that thing does go on. I mean no one's ever going to change that. There's always got to be one person that wants to be the top.

Fighting appeared to resolve differences between young men. But Rick identified this with being "a macho man sort of act to see who's bigger than who", a process he 
saw as enduring because "there's always got to be one person that wants to be the top".

The consequences of winning and losing fights that occur in the justice system appeared to be a complex matter:

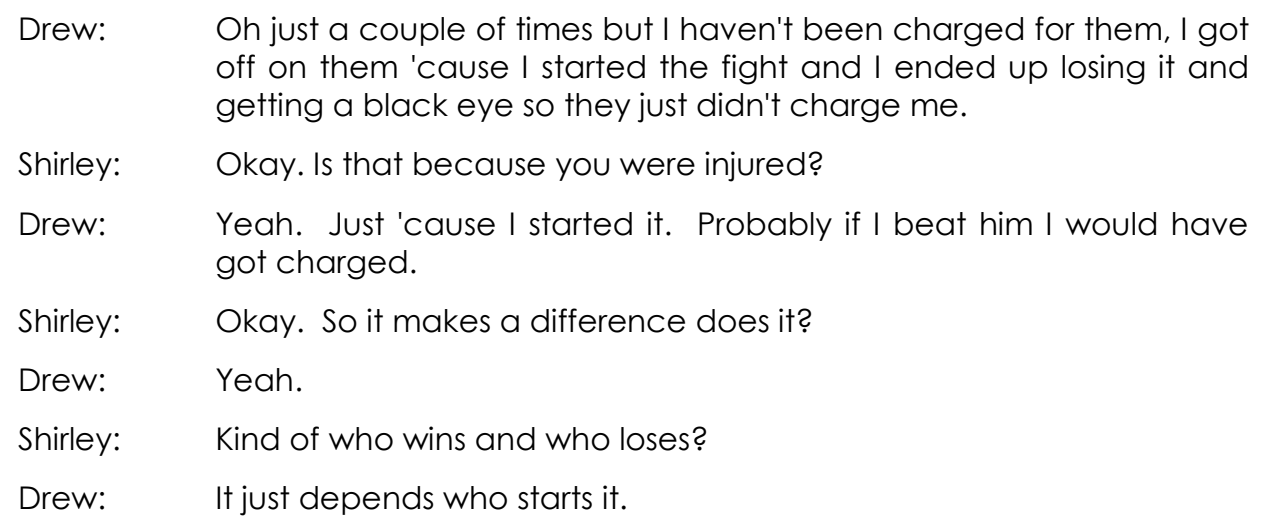

It seemed that whoever started the fight was generally the one who was charged. However, Drew described that this was not the case for him because he lost: "Probably if I beat him I would have got charged". He also talked of his injury as being influential in his not being charged. Such a situation can be read from a natural justice point of view in which the person who started the fight does not necessarily need to be punished any further since justice has already been meted out, firstly, by having lost the fight and, secondly, by sustaining an injury. The practice of fighting discursively constructs 'manliness' and self-defence becomes a necessity to get it right as a man.

Participants spoke of various injuries they sustained from their fighting, with the most serious being concussion after being hit with a baseball bat during a gang fight. Within the normative discourses around manliness, an injury sustained by fighting or sport can be read as a marker of 'getting it right as a man' (Connell, 2000). Therefore Drew's black eye is not so much a negative or shameful mark, rather, it is a mark of honour from which he gains status. However, such injury is constructed as masculine only if it is not disabling (Sparkes \& Smith, 2002). Disability does not fit with the subject position of a 'real' man, which is constituted by a physically strong and healthy body. 
There were other situations in which fighting, or more precisely, "beating up" others occurred. Drew described a situation in which there seemed to be an obligation to do So:

\begin{tabular}{|c|c|}
\hline ew: & $\begin{array}{l}\text { Oh yep 'cause I've beat up a lot of people that didn't even want to } \\
\text { fight. }\end{array}$ \\
\hline Shirley: & So what, what happened then, what was that about? \\
\hline Drew: & $\begin{array}{l}\text { Just, just um one fight was when um, when I had my girlfriend and } \\
\text { we were in town like we were out partying for the night and we } \\
\text { were at a burger bar, a late night burger bar that's open. And I } \\
\text { went to the toilet and I came back and there was a fella that was, } \\
\text { wasn't sitting next to her but was close to her and I just used that as } \\
\text { an excuse to beat him up. }\end{array}$ \\
\hline Shirley: & Okay. So you say excuse, what's that about? \\
\hline Drew: & Yeah. I was just, just hit him up if he's trying to get into my girl. \\
\hline Shirley: & $\begin{array}{l}\text { So it really didn't matter whether he was or wasn't did you just want } \\
\text { to fight or something? }\end{array}$ \\
\hline rew: & well I just didn't want him by my girlffriend. \\
\hline
\end{tabular}

Drew could be positioned as dangerous since he picked a fight with someone without apparent provocation. Provocation is often used as a mitigating factor in explaining violence, and particularly in the court system it is used to reduce the seriousness of the offence and thus to reduce the sentencing outcomes (Gelsthorpe \& Padfield, 2003). It is also possible to construct Drew's violence as unpredictable, positioning him as even more dangerous. But Drew's explanation, "I just used that as an excuse to beat him up", instead, can be read as his being in control and rational. There is no suggestion that he was actually angry in this situation.

Drew also alluded to still other positions. He appeared to be taking up a position of the 'macho' male as he went on later to describe himself as being a "hard-out type", which he said was the reason his girlfriend first liked him. His violence can also be located within the romantic discourse in which he is not only attempting to impress his girlfriend but also keeping her interest in him alive. There are also sexual connotations in Drew's comment, "he's trying to get into my girl", suggesting that his girlfriend is simply a passive vessel for a man. Although Drew talked of fighting on behalf of his girlfriend, which suggests he is being protective, Drew can alternatively be read as protecting his own interests, that is, his ownership and control of his girlfriend, a performance enabled by concepts of traditional masculinity. 
In talking about their involvement in gang fighting, participants described themselves as being motivated by "someone [getting] smart with us", but most frequently, it was the presence of another gang or one of its members being in what they considered to be their territory, as Sean explained:

Sean: Like you've got different parts of town and it's like somebody from another part of town comes into your place and they're not welcome sort of thing. So they probably get into a fight.

Rick also had something to say on this:

Rick: $\quad$ Depending on like say if you're walking through town or something you might see another person from another gang or something and sort of beat up on him.

It is easy to consider these young men are constructing their gang violence as warfare. The protection of territory is important and 'taking out' the 'enemy' is part of this process. Even though this can plausibly be read as rational, instrumental violence, it seems contrary to rationality to be creating harmful warlike conditions where no such war exists outside their own small groups. It would appear that any beneficial outcomes of their gang fights relate to the opportunities they provide these young men to prove their manhood to each other.

As I asked more about gang fights, I was not surprised to find the young men drawing on dominant discourses around manliness to explain what goes on:

$\begin{array}{ll}\text { Shirley: } & \text { So why do they pick fights, what's that all about? } \\ \text { Sean: } & \text { Um, to see who's the strongest really. Just to hurt somebody. } \\ \text { Shirley: } & \text { So why would anyone want to hurt someone, why would they? } \\ \text { Sean: } & \begin{array}{l}\text { Don't like them, ah they've done something to them or somebody } \\ \text { else has been done and they've got a grudge against them so } \\ \text { they've got to take it out on them. }\end{array} \\ \text { Shirley: } & \begin{array}{l}\text { So what's this thing about being strong, is there some kind of a } \\ \text { competition or something going on? }\end{array} \\ \text { Sean: } & \text { Oh sort of is. }\end{array}$

The familiar competition between men "to see who's the strongest" or to settle "a grudge" or "just to hurt somebody" demonstrates how acts of violence enable them to prove their manhood and so perform the subject position of man correctly. 
However, not all participants stayed in the gangs. Rick left because of his sense of fairness:

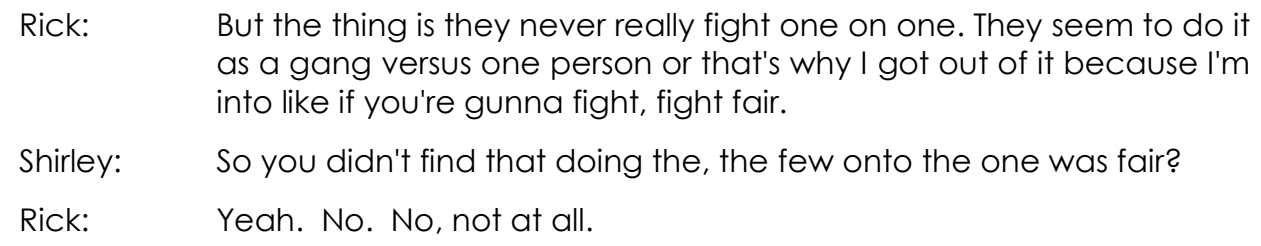

Rick can be read as taking up the position of a more mature person who can reflect back on his history and see the unfairness of bashing others, at least "as a gang versus one person". However, he did not suggest that no fighting should occur; "if you're gunna fight, fight fair". The discursive notion of fair-fighting is an important one in male-to-male violence, which acts to construct fighting as a performance between equal combatants, utilising particular rules of engagement with winners and losers. However, where fair-fighting does not occur there is no opportunity for the male victim to enact manliness (Eagle, 2006), as in the case of a gang against one person.

But not all fighting was always so serious. Drew also spoke of a type of fighting he called "play fighting":

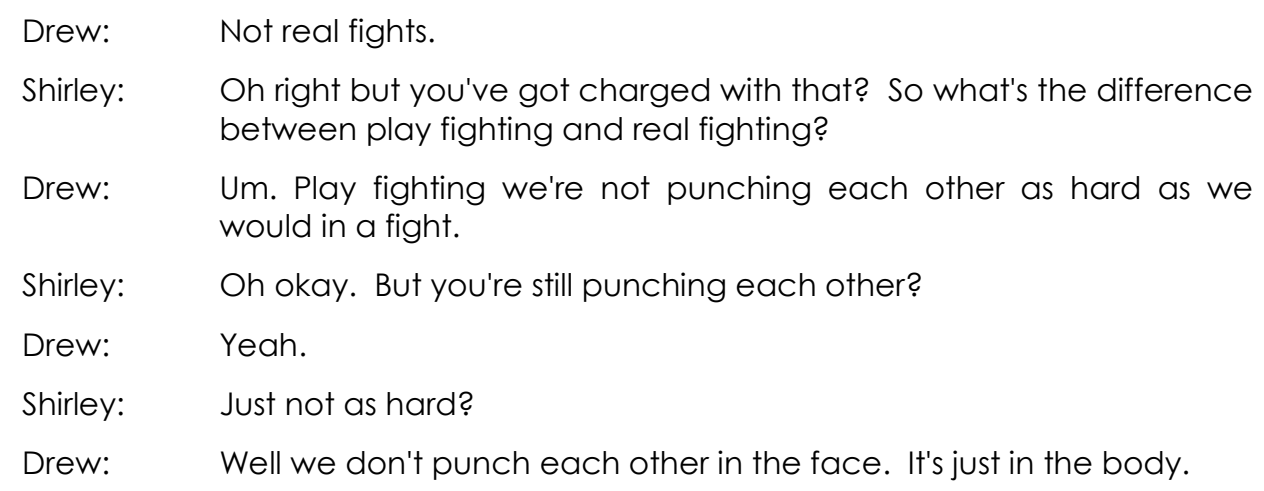

While Drew clearly distinguished between "play fighting" and 'real' fighting, the authorities did not, since he got charged for it. Drew spoke of "play fighting" as a common, everyday activity in which young men engaged. However, there is nothing in his talk that allows us to know whether his "play fighting" opponents knew that this was just for fun and not 'real' fighting. According to Eagle (2006), the contest discourse constructs male-to-male violence as a contest or a game, in which various rules exist, including the concept of fair-fighting. While this activity is chosen as 
play rather than as serious fighting it still appears to be a practice of manliness and may in some way assist in establishing relationships and the male hierarchy participants referred to.

\section{Inmate hierarchy: Achieving manliness}

Participants talked about how fighting inside was linked to maintaining a hierarchy amongst inmates. As Drew explained:

Drew: When I first came like all the tough fucks were here then, like heaps of bullies and that. I got along with most of them. But that's when I had one fight when I first came in here but from that fight because he was one of the tough dudes and I had to fight him, I started getting on with everybody after that.

Drew can be positioned as successful in this context of male competition, since he was able to demonstrate his 'manhood' in only one fight. But Sean talks of a system that required a young man to constantly maintain his standing in the hierarchy. $\mathrm{He}$ described those inmates at the top of the hierarchy as the "king pins", whom he viewed as the "quiet ones", but also who he thought were "more vicious":

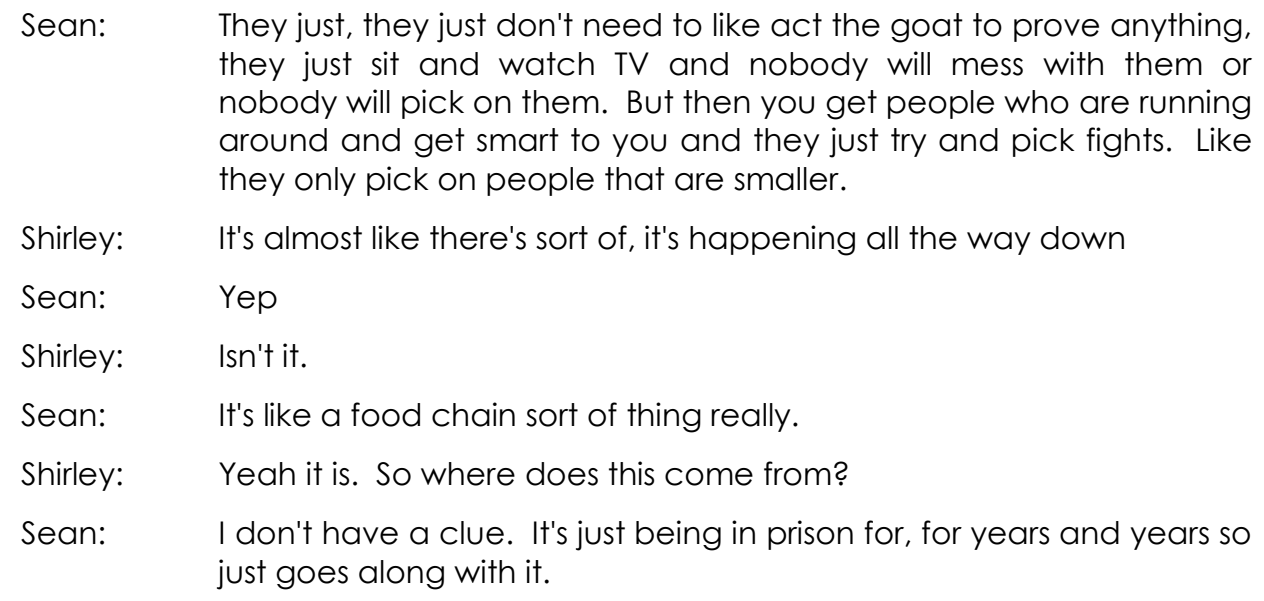
they just sit and watch TV and nobody will mess with them or nobody will pick on them. But then you get people who are running around and get smart to you and they just try and pick fights. Like they only pick on people that are smaller.

Shirley: It's almost like there's sort of, it's happening all the way down

Sean: Yep

Shirley: Isn't it.

Sean: It's like a food chain sort of thing really.

Shirley: $\quad$ Yeah it is. So where does this come from?

Sean: I don't have a clue. It's just being in prison for, for years and years so just goes along with it.

In listening to Sean's description, I felt that I was hearing about scenes from a movie that I have seen numerous times before. Sean positioned the "king pins" as quiet and somehow as heroic because they have nothing to prove. It appears that those at the top need only act on occasion, and the threat of what they can do suffices to control others. Yet those lower down the pecking order are more active and "pick fights", presumably to establish their standing as men in the hierarchy. However, those inmates involved in "running around and get[ting] smart" who "pick on people who are smaller" do not seem to be convincing others of their masculinity. 
When I asked about it, Sean went on to explain how he saw that there was a necessity in having the hierarchy to control the behaviours of other inmates

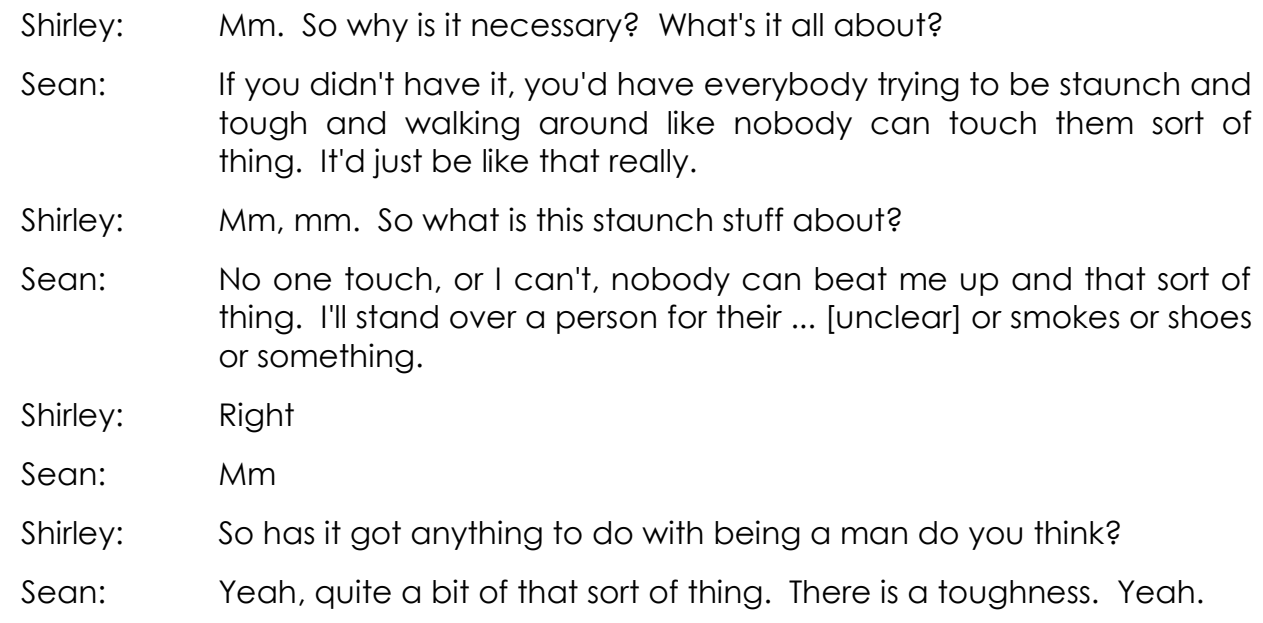

Being "staunch and tough" can be read as performances of their masculinity, "and walking around like nobody can touch them" appeared to be how these young men could prove their 'manhood'. Sean provided a rational reason for the existence of the hierarchy. It is a 'given' that violence sets-up the hierarchy and in turn is what determines being a man. Sean also makes it very clear that not all young men can legitimately act "staunch and tough". This highlights the competitive aspect of male relationships inside and raises the question of what would be so problematic with "everybody trying to be staunch and tough". Connell (1995) points out, there are always subordinated masculinities and part of the gender order involves power over other men. Connell writes that two patterns of violence result from the inequality of the patriarchal order. First, there is the use of violence by the dominant group to maintain their dominance, for example, men against women. Second, within the gender politics among men, there is such violence as war and armed assaults between groups of men, for example, youth gangs or heterosexual men against homosexual men. Violence is therefore used to define boundaries between men and exclude certain types of men, for example, homosexuals. The hierarchy inside that these young men discuss can be viewed as an institutional reflection of the gender order.

The effects of these practices that occur inside are not limited to the environment of the jail but have a powerful constitutive effect outside that context. Despite not all 
inmates being able to be "staunch and tough" inside, Sean talked of how simply the label of being an inmate can add to their 'manly' image on the outside:

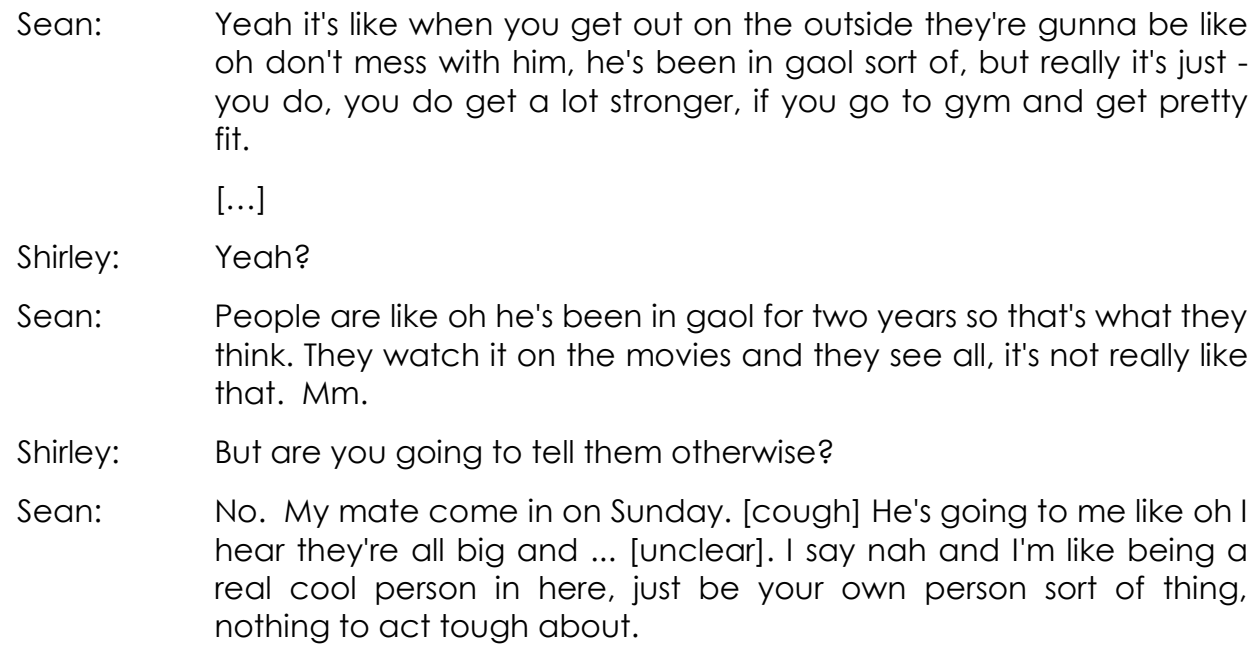

Sean: No. My mate come in on Sunday. [cough] He's going to me like oh I hear they're all big and ... [unclear]. I say nah and I'm like being a real cool person in here, just be your own person sort of thing, nothing to act tough about.

Sean saw an advantage in being positioned by those outside as tough because he had been in jail. This reflects the common idea that jail produces a toughened and perhaps more dangerous person. Such positioning assists young men to get it right as a man according to hegemonic masculinity. Therefore admiration for those doing violence is (re)produced. The use of weapons in the commission of their violence also adds to this positioning of man as being tough and dangerous.

\section{Using weapons}

Some of the participants talked of a range of weapons being used during aggravated robberies and gang fights. These included baseball bats, screwdrivers, beer bottles, hammers and knives. But as Sean described, the presence of weapons in gang fights increased the level of fear he experienced:

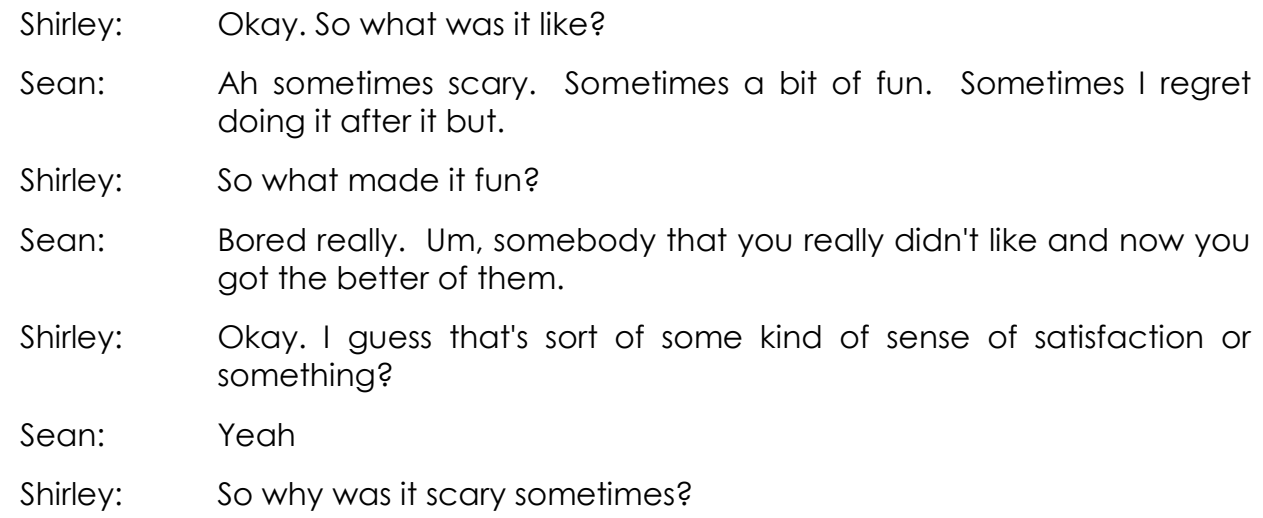


Sean: Um, out numbered, the sort of weapons they use. And there's this, you know if you're up against somebody that you might win, you're going to get um knocked out or a few broken bones or something. [chuckle] So it gets a bit scary sometimes.

Sean constructed the fighting as "fun"; it relieved his boredom, and also provided the satisfaction of getting "the better of them". But, he also talked of being scared in relation to weapons. Sean's description of the use of weapons highlighted the potentially serious injuries that could result. Yet, the sense of risk he portrayed when he chuckled about possibly being "knocked out or [getting] a few broken bones" demonstrates that violence that is potentially dangerous may enhance it as being "fun", but also positions those involved as courageous within discourses around traditional masculinity.

For those young men who use serious weapons, such as knives and guns, they can be positioned as particularly dangerous. Drew highlighted this when he spoke of being shown a gun after he and his mates attempted to pick a fight:

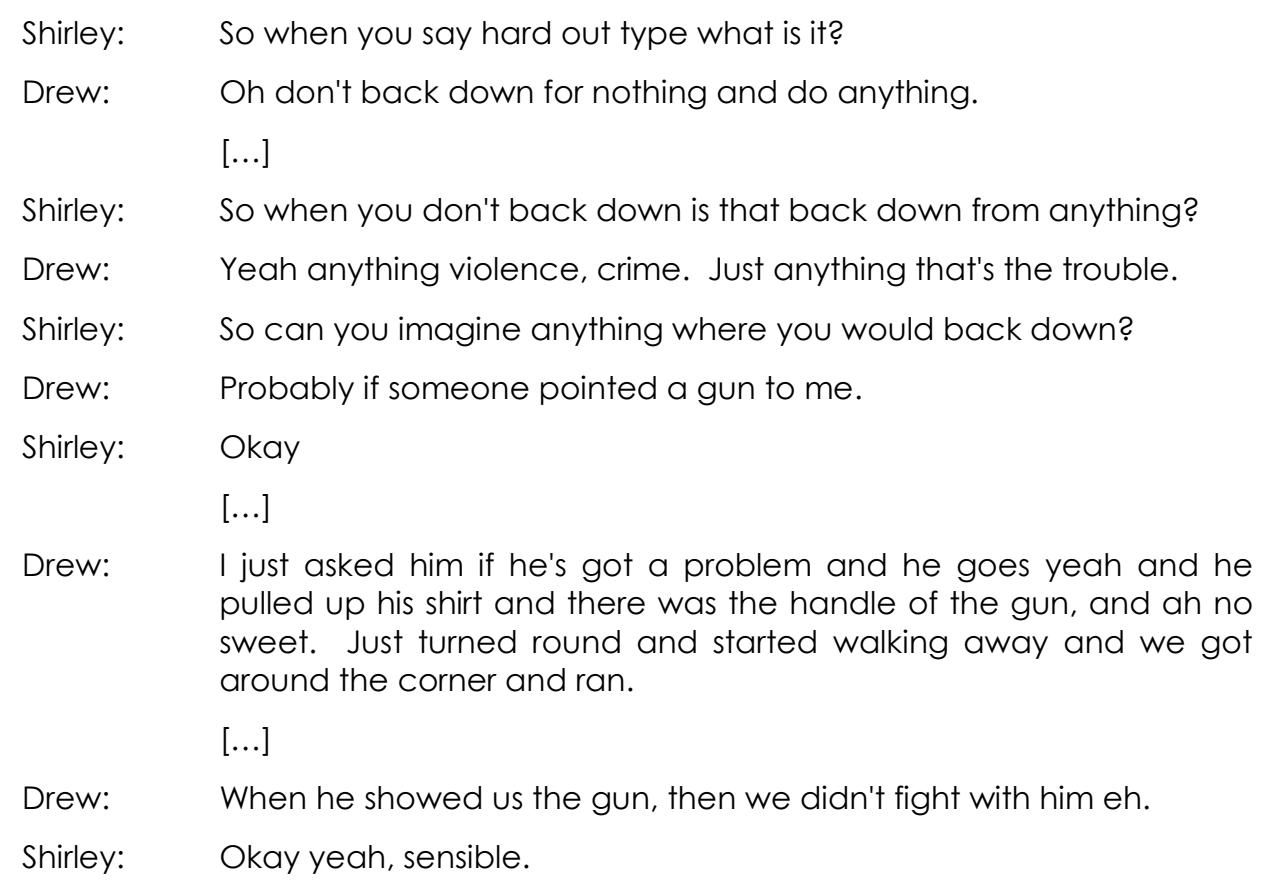

Drew and his mates "just turned round and started walking away". Their response can be read as a very controlled one with an exit out of a potentially dangerous situation, but one that did not result in a loss of face for them. The fact that they "got around the corner and ran", however, suggests a very different reaction. A reaction that may have been about experiencing fear or even excitement. In considering 
getting it right as a man within the discourses around normative manliness, it would seem that fear or excitement in relation to certain types of weapons is acceptable because the use of them is outside usual, everyday experience in New Zealand.

The use of weapons can have very powerful effects, as Drew pointed out when he went on to describe people's reactions when one of his mates stabbed someone with a knife during a gang fight:

\begin{tabular}{|c|c|}
\hline Shirley: & So do you remember how you reacted when you saw that? \\
\hline Drew: & $\begin{array}{l}\text { Ah yeah we went to this party [...] there was only a car-load of us, } \\
\text { the five of us and we don't know no one at the party, rolled into the } \\
\text { party and some people turned up, just about the whole party tried } \\
\text { to pick a fight with us. Then my mate just pulled out his knife, ah one } \\
\text { fella was having a fight. Ah, one fella was fighting with one my } \\
\text { mates and my mate pulled out a knife and like stabbed this fella in } \\
\text { the back. And we just grabbed my mate and we cruised. }\end{array}$ \\
\hline Shirley: & So were you scared when you saw that happen or? \\
\hline Drew: & $\begin{array}{l}\text { Oh I dunno we were just freaking out. Thinking far out, fuck what a } \\
\text { game on, stab someone. }\end{array}$ \\
\hline Shirley: & So everyone was freaking? \\
\hline Drew: & $\begin{array}{l}\text { Yeah. And after that no one wanted to mess with us. They all just } \\
\text { stood back and just gazed look and shock. Thought we were alien } \\
\text { fellas so. }\end{array}$ \\
\hline Shirley: & So does that like increase your rep or something? \\
\hline Drew: & Yeah, yeah. Don't mess with us or that's what will happen. \\
\hline Shirley: & So how do you feel about that, is it? \\
\hline Drew: & $\begin{array}{l}\text { Oh yeah it's good having that kind of reputation on the outside. } \\
\text { 'Cause then, now I'm just, people just um, I mean they're being my } \\
\text { mates and don't try and mess with me. }\end{array}$ \\
\hline
\end{tabular}

Again Drew talked of an initial shock reaction in which people were "freaking out" and they "just stood back and just gazed look and shock. Thought we were alien fellas". But there was also a sense of excitement too, "fuck what a game on", and perhaps admiration for his mate from Drew. Weapons and their use appeared to be associated with bravery, power, being tough and building reputations, all of which assist young men to get it right as a man within manliness discourses. Drew can also be read as expressing gratitude for the powerful impact the incident created: "it's good having that kind of reputation", since few will now want to "try and mess with me". There is a form of respect for violence and the threat of violence has powerful effects. 
Just as the participants offered differing ideas about fighting and anger compared to dominant psychological theories, they also provide alternative views of families and relate some of their early experiences to their goal of performing man correctly.

\section{Families and Their Relationship to Youth Violence}

\section{Deconstructing 'bad' families}

Dominant discourses around family construct the family as the most fundamental social unit. The primary function of a family is commonly seen to be that of raising and caring for children. However, families are also theorised to be the site where youth violence originates. What is termed a 'dysfunctional' family has historically been closely associated with causing disorder and abnormality in children and youth (Dishion \& Stormshak, 2007; Gerard et al., 2006; Laws, 2001; Rose, 1985). Home and family were also important to participants and was emphasised in their talk. While they acknowledged experiencing a range of problems, they all spoke about their family as being their greatest source of support:

Rick: $\quad$ Um yeah I reckon they work quite good because I've always in my life had a lot of family support.

For many of the participants, having committed the offence for which they were incarcerated had a huge impact on members of their family and the young men's relationships with them. They expressed concern for their family; but their main focus was on their mother. Such concern for others seemed to be at odds with how the young men talked about their experiences of fighting earlier. Sean responded emotionally when I asked about the effects his crimes and imprisonment had on his parents:

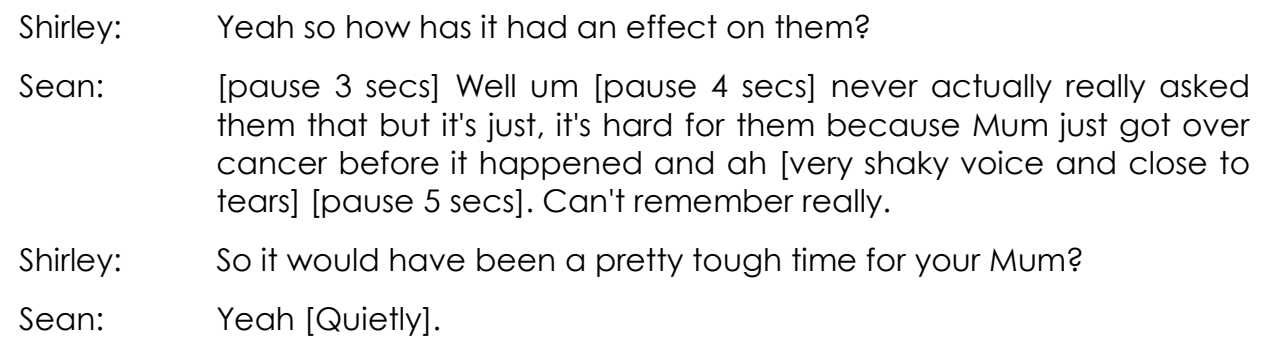
them that but it's just, it's hard for them because Mum just got over cancer before it happened and ah [very shaky voice and close to tears] [pause 5 secs]. Can't remember really.

Shirley: $\quad$ So it would have been a pretty tough time for your Mum?

Sean: Yeah [Quietly].

Being a mother's son seemed to be a position that was an important and inescapable one for these young men. There seemed to be both positive aspects (for example, 
support) and difficult aspects (for example, shame and guilt) for them in this subject position.

Even when their relationships with their mothers was not an easy one, participants still made efforts towards communication:

\begin{tabular}{|c|c|}
\hline Anthony: & $\begin{array}{l}\text { Oh it's had an impact on my mum but my dad it hasn't - oh it might } \\
\text { of but he hasn't shown it }\end{array}$ \\
\hline Shirley: & So how has it impacted on your mum? \\
\hline Anthony: & $\begin{array}{l}\text { Oh she just won't talk to me. Ah I can get her to talk but I'll ring her } \\
\text { and she'll say oh yeah yeah, I'll ring you, but she'll never ring and I } \\
\text { write her a letter and I'll say write back on it and she'll never write } \\
\text { back she just [pause } 5 \text { secs) }\end{array}$ \\
\hline Shirley: & That sounds pretty tough \\
\hline Anthony: & Oh it's all right, 'cause I never used to get on with my mum anyway \\
\hline Shirley: & It sounds like things are a bit worse now though? \\
\hline Anthony: & Yeah \\
\hline Shirley: & Is it or do you think it's just pretty much the same? \\
\hline Anthony: & $\begin{array}{l}\text { It's a bit worse but oh I don't know. I just [pause } 8 \text { secs] just sort of } \\
\text { think oh she ain't gunna ring me, I'm not going to ring her. }\end{array}$ \\
\hline Shirley: & So it's been a while since you talked to her? \\
\hline Anthony: & $\begin{array}{l}\text { h nay I talked to her the other night, that was like the second time } \\
\text { at I've been here, I've been here two months }\end{array}$ \\
\hline
\end{tabular}

Anthony's attempts to maintain contact with his mother can be read as him trying to get the subject position of being a 'good' son right within the dominant family discourse. My expression of sympathy in the above exchange showed that I was drawing on notions of what makes a 'good family', which assumed that a positive, loving relationship should occur between a mother and her son and that regular communication was part of this. However, Anthony immediately re-positioned himself as not being overly concerned about 'getting it right as a son' and moved towards the position of having the ability to withdraw from the relationship himself in response. This may reflect the notion that independence and autonomy are more important than relationship for young men and should be sought after, to achieve manhood. This is particularly so in separating from their mothers.

Rick raised the issue of experiencing a range of family problems over the years:

Shirley: $\quad$ Absolutely. So when you talk about having quite a few sort of family problems and everything growing up so do you think that's in any way kind of shaped some of the things that you've done? 
Rick: Um, well not really. Um a lot of people have blamed my family and stuff for what I have done and stuff like that but I mean you're your own person so you can't really. [...] But you know, at the end of the day you're the person that makes the decision, so yeah.

Shirley: $\quad$ So there's no point in blaming your family for what you did?

Rick: $\quad$ Yeah, yeah well.

Rick was aware that "a lot of people have blamed my family and stuff for what I have done". This highlighted the claim that "family problems" are responsible for the negative behaviour and disorders of children, and are the direct cause of their violence and crime. As previously discussed in Chapter Two, mainstream psychology draws upon, re-produces and supports this discourse of 'dysfunctional families' when it theorises that a range of pathologies and antisocial behaviour are derived from children's experiences of family problems and negative family environments (Rose, 1985).

Rick makes it very clear that he did not think it appropriate to blame his family for what he had done because "at the end of the day you're the person that makes the decision". It is possible to read his explanation as taking up a position as an active, rational agent who has made his own choices. This position is conceived as a powerful one with its emphasis on agency. It fits well with notions of manliness that positions men as rational; in control of themselves and their environment (Connell, 2001). The position could also describe the agentic, humanist individual (Henriques et al., 1984). This subject position is preferable to that available within the bad family' discourse, which is one of a powerless victim, since a child's future is thought to be pre-determined by the actions of their parents.

It is possible to discount Rick's agentic position and his claim that his family is not to blame. He can be positioned as not knowledgeable and not able to make the conceptual leap about how family problems could have affected him since he is not a professional with relevant training in family dynamics or human development. Alternatively, but still considering mainstream psychological developmental theory of individuation (Garbarino, Gaa, Swank, McPherson, \& Gratch, 1995; Scharf, Mayseless, \& Kivenson-Baron, 2004), Rick can be positioned as having separated ('individuated') from his family of origin and dealt with his issues to become an independent fully 'functioning' person who is now taking responsibility for what he 
did. This process then can be viewed as having repaired the damage of his earlier upbringing, but does not mean the damage never occurred.

The discourses around abnormality that construct 'dysfunctional' families describe certain families as not offering 'good enough parenting' seeing them as not able to care for their children in ways that meet certain standards (Laws, 2001). In Western countries, an entire child protection system exists with professionals who are charged with labelling which families are dysfunctional (for example, Child. Youth and Family in New Zealand). However, how some families are identified as 'bad families' remains unclear. Does such a construction come into being only after the young man has committed violence and has himself been positioned as having come from one of those 'bad families'? Can families even be considered 'bad' if their children become model citizens? Based on empirically based psychological theorising it would seem logical to expect that all the children or at least most of them from a 'bad' family would engage in problematic behaviour. But as the participants have said, for many of them they were the only ones amongst their siblings to be considered a problem. As Rick says: "Um, a lot of people in my family say I was the problem one, coming from a big family".

With notions of a 'dysfunctional' family comes a focus on those families as creating the most adverse environment for their children. The act of being labelled 'dysfunctional' constructs other families as 'functional', rather than as being simply less dysfunctional (Laws, 2001). However, it is possible to consider all families as creating problems for the children within them.

Alternatively, if there was greater recognition that the broader community, peers and society (for example, schools) are also major players in creating environments which have adverse consequences for children, there might be less of a focus on viewing 'dysfunctional' families as the primary cause of children's problems. However, this is a subjugated discourse in the current Western social, historical and political climate, wherein the family is constructed as the cornerstone of society that produces the rational humanist subject. 


\section{Troubling the cycle of violence}

Taking the concept of 'dysfunctional' families further, positivist psychology theorises that children who are victims of violence within their own family will become perpetrators of violence later in life and refer to this process as the theory of intergenerational transmission of violence or the 'cycle of violence' (see for example, Chapple, 2003; Lambie, Seymour, Lee, \& Adams, 2002; Schwartz, Hage, Bush, \& Burns, 2006; Widom, 1989). I suggest that this notion of the cycle of violence has become the most popular and well-known belief regarding causes of violence today. It has become a dominant discourse, making it now common sense. The cycle of violence appears to be a simplistic and deterministic theory as it is unable to account for the difference between the large numbers of child victims of family violence, but the relatively smaller number of perpetrators of violence. If there was a direct causal relationship as theorised, then it would be reasonable to expect that most people would be violent since the numbers of children thought to be victims of physical, sexual and emotional violence in the home are reported to be staggeringly high (see for example, Finkelhor, 1994; Hobbs, 2005; May-Chahal \& Cawson, 2005; Putnam, 2003; Russell, 1983). However, since it seems that the vast majority of people are not perpetrators of violence, the cycle of violence does not match up to its own logical conclusion. The idea of the cycle of violence also cannot explain the complexities of gender involved in family violence (Bograd, 1990; Dobash, Dobash, \& Noaks, 1995; Kernsmith, 2006) nor why most offenders of family violence appear to be male and most victims are women and children of both genders. Although these key limitations of the cycle of violence raises questions regarding the usefulness of the theory, nonetheless it remains a dominant one that is widely known and accepted.

Participants talked of early experiences that could be labelled family violence (a euphemism for male violence against women and children in the home). Here, Rick described an incident which involved his father threatening to shoot his mother when he was a young boy:

Rick: Well my mum and dad split up as, when I was young. Ah, which I don't know whether that changed a lot or. Um seeing my dad being violent to my mother was a different, different sort of experience. Um I recall one time I was probably six or seven maybe 
my dad was an alcoholic but still frequent, like frequently drinks now, but just wanders off. I recall one time he came over because I my mum were separated, came over to the house with a shotgun and um threatened to kill my mum. Um, I sort of stood in front of her and said well if you're going to kill her you may as well kill me too. Sort of a learning experience.

Shirley: $\quad$ That's huge.

Rick: Yeah.

Shirley: $\quad$ So what did he do?

Rick: $\quad$ Um well he ended up leaving because um my mum got remarried and my step dad sort of pushed him out the door sort of thing. So.

Shirley: $\quad$ That's an incredibly brave thing for a little kid to

Rick: $\quad$ Yeah I love my mum dearly as well, she's been there a lot for me over my lifetime, so far. I have a feeling a lot more to come as well.

Shirley: $\quad$ Mm. So that must have been incredibly scary?

Rick: $\quad$ Yeah it was. Apparently it happened more than once but that's the only one time I can really recall.

My responses to Rick's description of the incident with his father show that I constructed his actions as courageous because I considered standing up to a person with a gun as risky, particularly for a young child since they are physically smaller. However, by positioning Rick as courageous I also constructed alternative action, such as running and hiding or taking no action at all, as being marked by fear and helplessness and potentially as failure. This may have acted to stop Rick talking any further about his fear, since fear is not manly. A lack of action in response to the violence of other men contradicts the "hero discourse" (Eagle, 2006, p. 62), which is a masculine construction that requires active, masterful behaviour when subjected to such threat.

Another reading of Rick's action is that of fulfilling one of the tasks of being a man, that is, protecting women (usually from other men). Within the discourses of traditional masculinity he took up the position of the hero; being his mother's protector enabled him to perform 'man'. Eagle (2006) identified a powerful discursive construction of the "protector" (p. 67) for men who felt responsible for the safety of others in situations where they were confronted by the violence of other men. However, these men were unable to enact the 'hero' position and take action because they felt constrained by the need to be the protector. Therefore the 'protector' and 'hero' positions can be at odds with each other. 
Sean also told of protecting his mother from threats by his father over a period of a year when he was 14 years old:

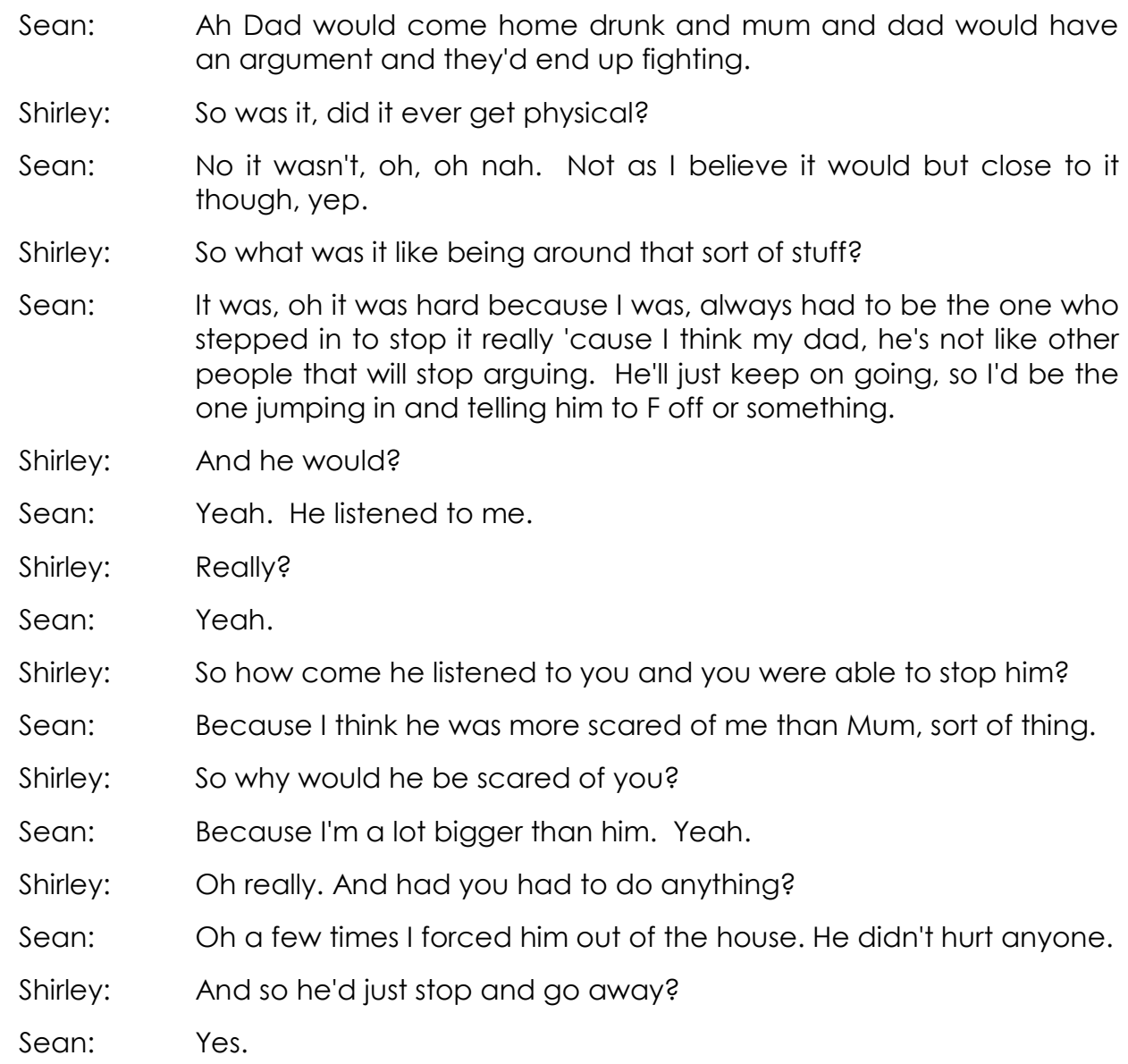

Like Rick, Sean can also be positioned as a hero. He took charge of the situation and saved his mother from harm. One feature of both Sean and Rick's talk when describing how they protected their mothers from their violent fathers is the way they downplayed the seriousness of the situation and demonstrated a degree of modesty about their role: "Sort of a learning experience", "apparently it happened more than once", "he listened to me", "oh a few times I forced him out of the house". They seemed to minimise what happened and what they had done, the position of the 'quiet' hero fits notions of modesty.

Within traditional masculinity discourses, being a hero and then boasting about it is not possible because what is required of the position is to be stoic and to deny being brave and courageous. The hero subject position does not allow a young man to 
claim the status for themselves, this is for others to attribute, hence minimising what they have done is all that is possible from the hero position.

The effects of using minimisation can be seen to be very different for different subject positions. The concept of minimising is often used within the offender intervention field (particularly with sex offenders) to describe how the offender minimises their responsibility for their violence, the seriousness of it, the level of harm done to others and so forth (Salter, 2003). Using the minimising technique from the subject position of protector, as Sean and Rick have, can lead to performing 'man' correctly by taking up the position of the 'quiet' hero. However, if they were to use this same minimising technique to describe their own violence, then they would be positioned negatively within intervention discourses as trying to avoid responsibility for their violence.

Sean and Rick's experiences of family violence can be read as producing opportunities for them 'to get it right as a man' within the discourses of normative masculinity. Such a proposition, that a negative violent experience provided these young men with an opportunity to take up a positive position, contrasts markedly with the notion of a cycle of violence.

The construction of the cycle of violence positions children who have witnessed or been subjected to family violence as victims. Sean and Rick can then be considered to have got the position of victim wrong. Despite agreeing that the situation and what they did was "scary", and describing it as "hard" (Sean), they did not talk of their experience in a way that is expected of the subject position of victim, that is, talking of trauma and referring to pain, distress or suffering. Eagle (2006) argues that it is impossible for men to perform traditional masculinity and also be a victim, the two subject positions are incompatible. This leaves male victims with "few discursive strategies to engage with their victimisation" (p. 47) and consequently, they cannot express their experience to others. Manly action then becomes a way of resisting the victim position.

When participants talked of their experiences of violence within the secure facilities, they spoke of what they did to stay safe from other residents or inmates and their 
experiences of being a victim. Significantly, their reasons for being either violent or not violent inside were often related to ideas of a cycle of violence. The reasons given centred on their own experience of victimisation inside.

Sean described being "quite scared" when he first arrived, but by observing how the other inmates fought with each other he judged them as "not very good fighters", so after a time he was no longer scared of them because he believed he could beat them:

Shirley: $\quad$ So have you sort of um had to, have you actually done anything to
give other people a hard time?
No. 'cause I know, I know how much, how hard it was for me when I
first came here so I've never had, dished it out to anybody else.
'Cause just the feeling of first, when I first came here like I wouldn't
come out of my cell, I wouldn't talk to nobody and just, just so hard.
[...] I wouldn't give it to anybody else.

Sean chose not to give others inside a "hard time" because he was a victim of such violence himself and explained that he would not want someone else to experience what he had. If we apply the notion of a cycle of violence to what happened inside, Sean's decision contradicts the prediction that his violence would be inevitable because he was a victim. Instead, he linked his experience of being positioned as a victim directly to his choice not to be violent, which assisted him to resist the subject position of victim. Sean can also be read as demonstrating some sympathy for other inmates in his reasoning here.

Kelly's actions, on the other hand, fully endorse the idea of the cycle of violence. Kelly used the same rationale as Sean to explain his actions, that is, because he was a victim of violence, but he came to the opposite conclusion to Sean and decided to victimise others:

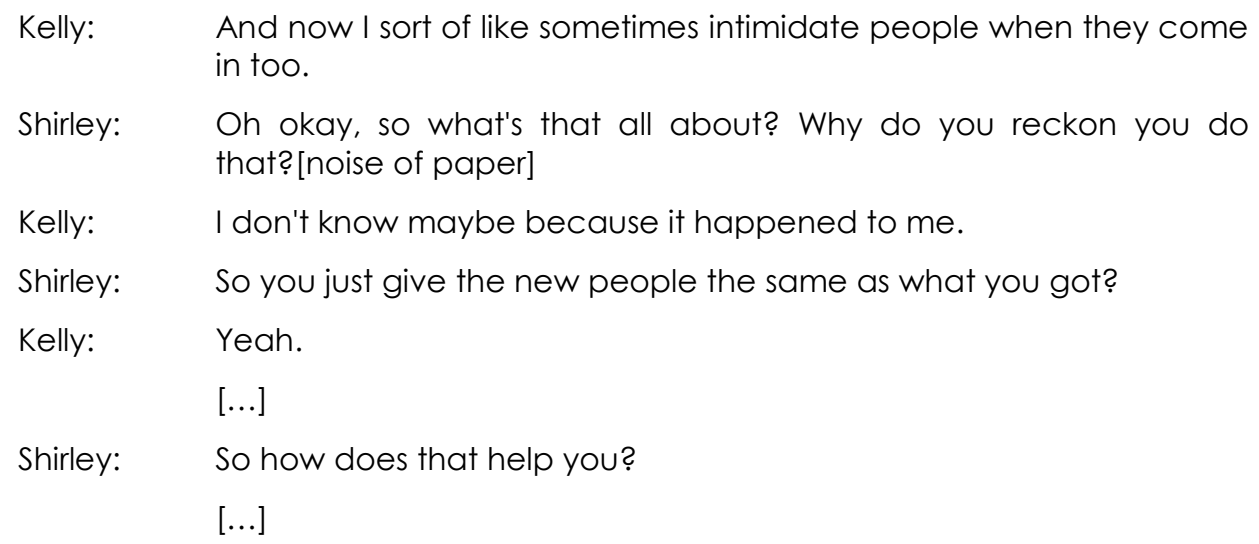


Kelly: It doesn't really. It doesn't really, it's just a bit of fun I reckon while you're in here.

By drawing on the notion of the cycle of violence, Kelly is positioned as having a more legitimate claim for his violence when he states that: "it happened to me" as the reason for him harassing new inmates. This is a more favourable position than if he had expressed a need for revenge, which positions him as being more dangerous. When Kelly described his experience of victimisation when he first arrived in the unit, he said that the purpose of the "teasing and doing stuff" by the other inmates was to "see how easy they can snap you,". Kelly's method of managing the situation was to ignore it and not respond, so according to him, that was why they eventually gave up on him. Kelly has shifted subject positions from being a victim to becoming a perpetrator, where he picked on those new to the unit. The perpetrator position offers Kelly a very different experience: he now considers the bullying simply as a "bit of fun".

Sean's choice not to do violence and Kelly's choice to do violence can both be read as individual agency. They could both explain their choice easily to me, drawing on the same idea of the cycle of violence, although resulting in different outcomes. However, the logic of the cycle of violence, by itself, constructs the development of perpetrators as an inevitable outcome of being a victim. This would mean that Sean would not have been able to make a non-violent choice and the theory cannot offer an adequate explanation for his response.

Given the limitations of the cycle of violence theory, that is, that most victims do not become perpetrators, objectivist theories of child resiliency offer an effective explanation instead. Individual children, regardless of their history of victimisation who manage to achieve the markers of success, for example, school achievement, having friends, and being prosocial are identified. This shows that not all victims of family violence or those from 'dysfunctional families' become violent or 'delinquent', or become 'disordered' and 'abnormal'. In general, the notion of resilience suggests that children can acquire attributes in environments and circumstances of adversity (Lambie et al., 2002) that mitigate their development into perpetrators. Resiliency is constructed as an outcome of a series of protective factors that include the attributes of the child, such as cognitive abilities, effective emotional 
and behavioural regulation; a positive family environment, such as effective socialisation practices and socioeconomic advantages; and external support systems in the community, such as access to emergency services, effective schools (Goldstein \& Brooks, 2005).

Unfortunately, the discourses around resiliency are like a double-edged sword, as Laws (2001) so eloquently described when she detailed how those children, whom she depicted as being positioned as 'sad', the victims of familial abuse and neglect, are in fact made to be responsible for their own recovery. To be seen as resilient, they must become a brave child and overcome the adversity relatively quickly; if they do not, then they are positioned as 'mad', as 'disordered' and 'abnormal' for not recovering, which is then seen as being their fault. Thus, they are re-victimised by the various social institutions designed to help them.

From such a reading it is possible to consider the cycle of violence and resiliency theories of scientific psychology as offering linear cause-effect models, which are believed to impact on all people in the same way (Jenkins, 1990). Yet, the participants' responses offer a more complex picture. Consideration of the meaning that is attributed to the experience appears a more fruitful endeavour than simply accepting that the experience itself results in predetermined outcomes. The impact of any experience can have multiple and conflicting effects with both positive and negative consequences. But how these experiences are evaluated depends on the discursive context of the experience. Therefore what is deemed a negative experience needs to remain open to question so that any positive outcomes are able to be acknowledged.

When exploring the meaning attributed to an experience, attention to the discursive context, including the time period and the socio-political context that show up the systems of meaning being accessed to understand the experience, will allow engagement with the complexity of the effects of an experience. For example, participants have not talked about being traumatised from their fighting with other young men; rather, they speak of excitement and proving themselves. Conversely, male victims who have been beaten up by a young man often describe the experience as traumatic. The act itself is the same, but the discursive context shifts how the act is 
experienced and understood. I am acutely aware that there are dangers in proposing that a threatening, traumatic experience may not, in itself, have specific negative effects. The biggest concern for me is that my comments may be read as suggesting that such horrific violence as child abuse and sexual assault may be viewed as not being harmful and so be used to justify atrocities. I do not want my comments to be read in this way. What I am wanting to highlight is that, just as our desires are constructed, (Davies, 1990) so too is what we deem as harmful.

\section{Questioning Learning Approaches to Youth Violence}

The concept of the cycle of violence attempts to explain a negative human activity, namely violence, where explanatory comments along the lines of, 'He did it because it was done to him' become the common expression of this theory. Yet, when it comes to positive activity or success, such as achieving a loving relationship or winning an Olympic gold medal, the same explanation is unlikely to be heard. There is no theory of a 'cycle of success' that works in a similar way to the cycle of violence. Instead, achievement is explained as individual agency, most often related to a person's character or because of their individual effort (Bandura, 1997, 2006).

Theories around positive role models, however, may be considered an approximation to a 'cycle of success'. A positive role model is a person, often an adult, who is viewed as being a good example of an individual who portrays the type of prosocial attributes and behaviours deemed necessary for children and young people to emulate (Goldstein \& Brooks, 2005). To imitate others infers a learning process.

Not only are concepts of learning thought to be relevant in the process of imitating positive role models, but learning is implicated in the cycle of violence and for children who are raised within 'dysfunctional families'. One of the most influential learning theories that has formed a foundation from which some learning approaches to youth violence have developed is social cognitive theory developed by Bandura (1977; 1986). In brief, social cognitive theory claims that children learn values and behaviours, including skills, from their social environment and do so in part by imitating role models (Bandura, 1977). Bandura did not subscribe to the passive, blank slate concept of the individual, as classical conditioning theories of learning 
often do (Domjan, 2006). Instead, he offered a view that saw the child as an active learner.

While gender differences are not well accounted for by the cycle of violence notion, social cognitive theory proposes that the imitation of role models occurs through a process of identification with the same-sex parent (Bandura, 1977). For example, in a domestic violence situation in which a man is beating up a woman, according to a cognitive, rational argument it would seem logical for any child, regardless of gender, to imitate the parent who is the most powerful, that is the man. But according to social cognitive theory identification occurs with the same-sex parent; girls will identify with the woman being beaten, who is scared and powerless. Therefore a girl child is unlikely to become a perpetrator of violence, but more likely to become a victim of a man's violence.

In looking further at the concept of identification within social cognitive theory, a contradiction exists regarding skills deficits. In learning approaches to youth violence there is a commonly held idea that empathy is a skill young men who are violent lack. However, according to Bondi (2003), the concept of identification that is used in social cognitive theory is closely linked to empathy. She argues that in order to be able to identify with their same-sex parent, children must employ empathy skills. From this perspective, the idea of a skills deficit in empathy runs counter to the idea that boys identify with their father's violence, perpetuating the intergenerational cycle of violence.

Theories of youth violence based on learning principles generally make either one of two claims about skills. Firstly, the young person has learnt undesirable skills or, secondly, the young person has not learnt appropriate skills within their family environment where such learning is assumed to occur (Goldstein, Glick, with Reiner, Zimmerman, \& Coultry, 1987). This second claim appears to be the one that is most frequently highlighted in the literature and in intervention settings. The main skills in which violent youth are spoken as being deficient include empathy, prosocial skills and skills in the management of emotional arousal (primarily anger). As a result, these skills deficits have become intervention targets (Gibbs, Potter, \& Goldstein, 1995; Howells, 1986; Novaco, 1997). I deal with the implications of such 
intervention in Chapter Six when I explore how the young men respond to intervention programmes based on this premise.

The expectation that a child must rely primarily on their parents/family (as implied in much objectivist psychological literature) to learn social skills does not appear to be a good fit in our postmodern world with information and communications technology and the extensive social networks to which we now have access, for example, television, schools, advertising, the internet, peers, institutions. Developing how to perform subject positions correctly occurs across a wide range of social contexts in which relationships and friends play an important role.

\section{Friends and Violence}

\section{Having friends}

When considering the participants' talk about their friendships, it was worth considering learning approaches to youth violence that assumed deficits in prosocial skills caused violence (Gibbs et al., 1995; Goldstein, 1988). A prosocial skill that is considered important is the ability to develop meaningful and positive relationships with peers.

The participants spoke of having many friends, which at face value suggests no shortage of prosocial skills. They described their friends as playing an important part in their lives and as being supportive, for example, visiting them inside. But some friends were lost as a direct consequence of participants' convictions and their being locked up. They also spoke of having particular friends that often resulted in getting into trouble (with the police), and many friendships appeared to be closely associated with violence. Their ability to make meaningful peer relationships did not seem to be in doubt, however, their practices of violence did not fit the dominant notion of prosocial peer relationships. The participants' offer a complex picture around the discourses they drew on in relation to their friendships.

For some participants, fighting played a significant role in their friendships, whether that was fighting alongside mates against others or as a way of making friends. Participants spoke of being able to rely on their friends. In the discourses around 
male friendships, fighting can be seen as a mechanism for these young men to gain support and protection from their mates. Drew provided a good example:

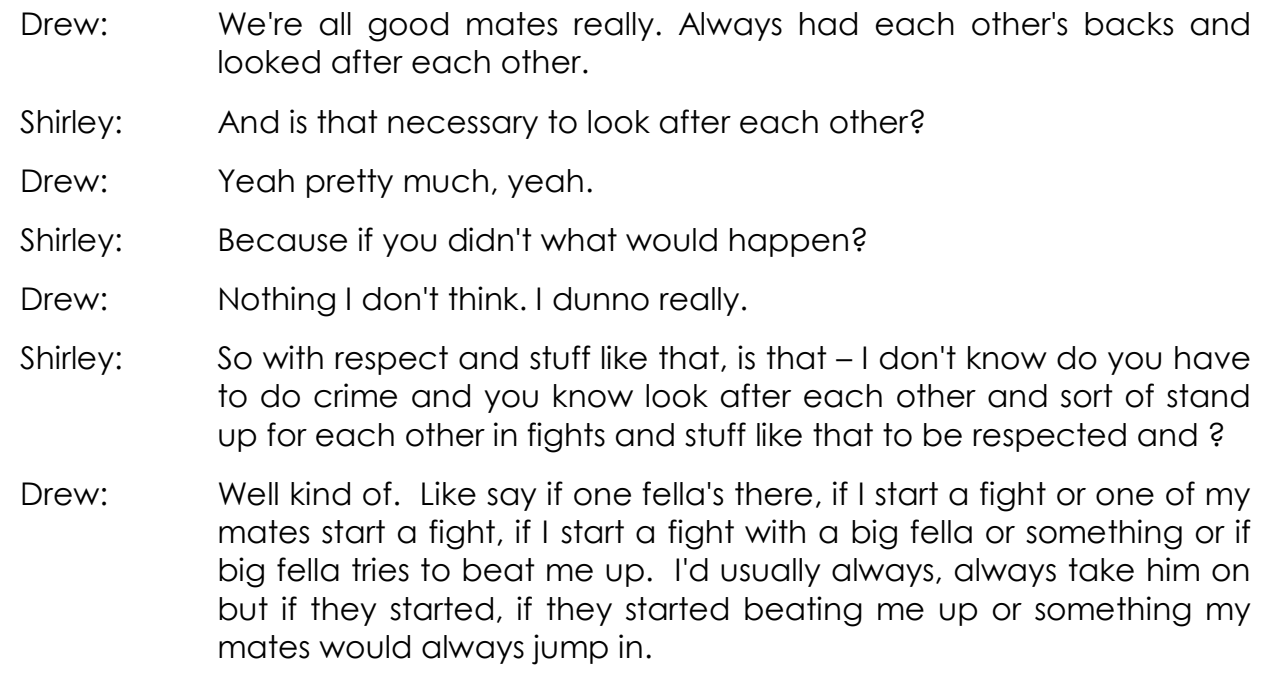
to do crime and you know look after each other and sort of stand up for each other in fights and stuff like that to be respected and?

Drew: Well kind of. Like say if one fella's there, if I start a fight or one of my mates start a fight, if I start a fight with a big fella or something or if big fella tries to beat me up. I'd usually always, always take him on but if they started, if they started beating me up or something my mates would always jump in.

Protecting each other seemed to be a primary way to enact friendship according to Drew - "Always had each other's backs and looked after each other", although he was not too sure what would happen without it - "Nothing I don't think. I dunno really". As Drew talked more about fighting, he was able to describe how this type of protection worked. While he talked of not backing-down from a fight, he knew he had the protection of his mates, "my mates would always jump in". Since proving oneself as a man is a necessity in dominant discourses of manliness, then fighting achieves this purpose. In addition, mateship is also seen as an important part of being a man: protecting one's mates is a part of this performance. Not only is this about protecting them physically, but also about protecting their reputation as men by fighting.

However, such loyalty is not part of all friendships. For example, Drew described another situation where he got bashed up in a fight at a party that he had attended with friends, but this particular group of friends were not his mates who "were into beating up people and fighting" and so they did not get involved. Drew's answer was to get some other mates who did like fighting (waking them up at 3.00am), to return to the party and "beat them up", which they willingly did. 
Drew positioned one group of his friends as those who did violence. It was not surprising to hear Drew talk about how he and these particular mates were positioned by others as dangerous:

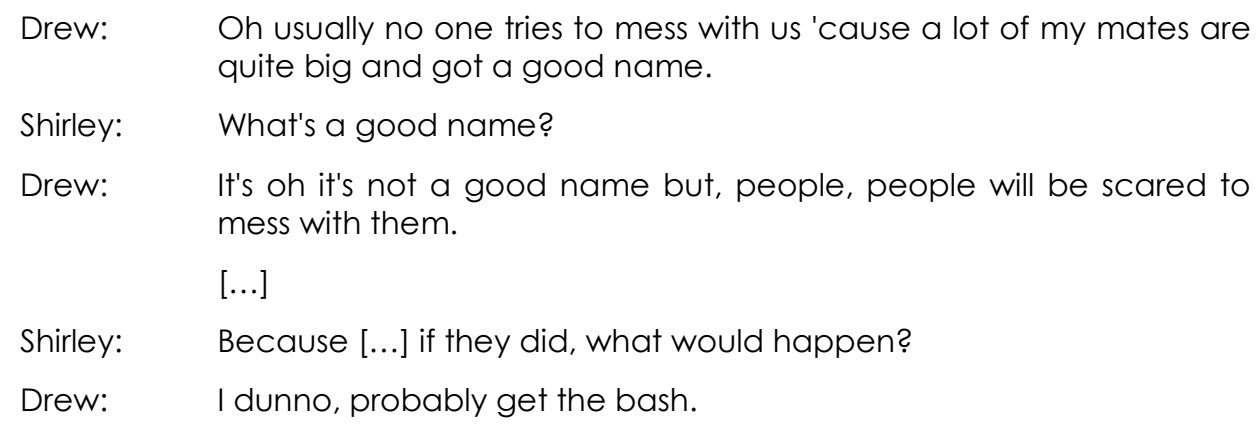

Being good at fighting and winning assisted with positioning Drew and his mates as having the reputation of being feared, their "good name". While Drew recognised that having people "scared to mess with them" was not the dominant understanding of the term "a good name", he highlighted the benefits of being part of a gang that was feared.

\section{Making friends}

Not only was fighting other men with mates part of the discourses around friendship that participants used that emphasised trust, protection and respect, but fighting with another young man was also sometimes how friendships were formed. As Drew explained when he described starting a fight with another inmate:

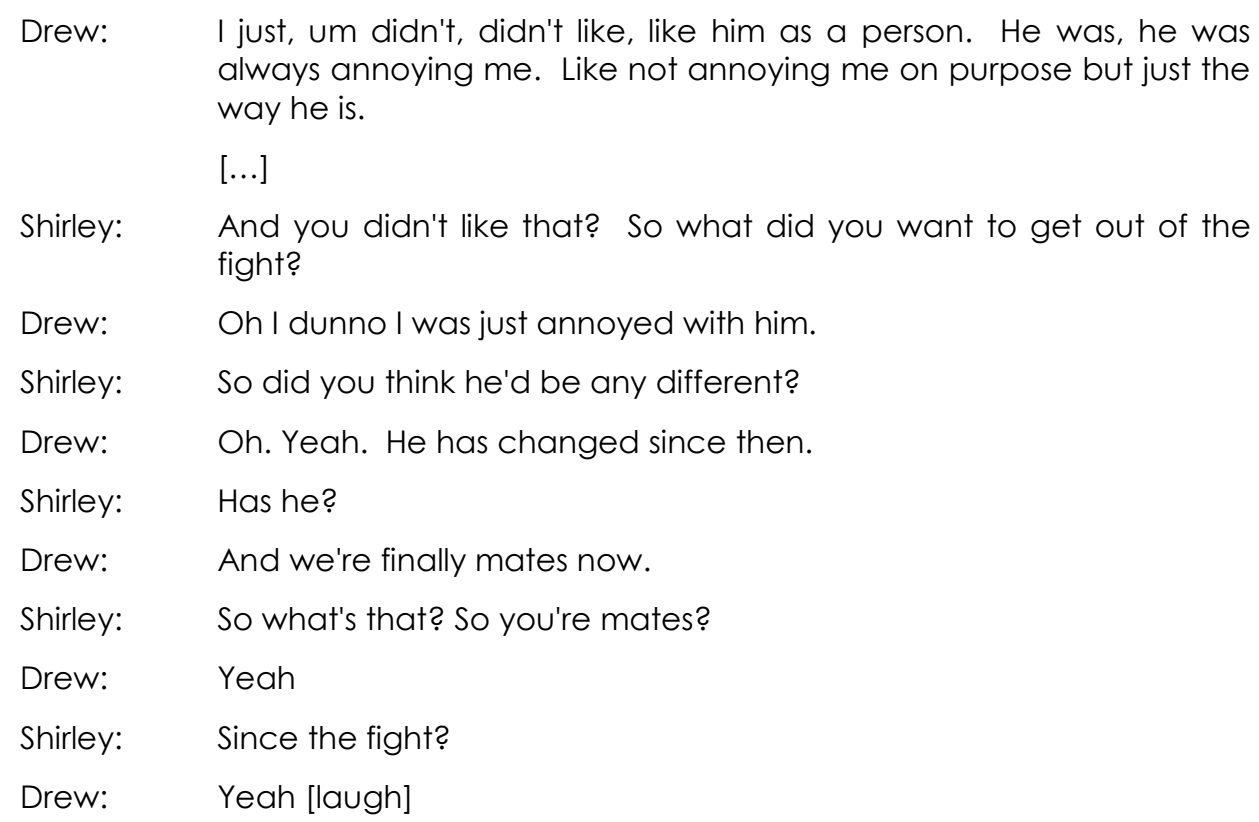




\begin{tabular}{|c|c|}
\hline \multirow{2}{*}{$\begin{array}{l}\text { Shirley: } \\
\text { Drew: }\end{array}$} & So how did that happen, so what happens? \\
\hline & $\begin{array}{l}\text { Oh I dunno he just, he just said sorry to me for being an egg all the } \\
\text { time and all that stuff. And he's just quietened down since. }\end{array}$ \\
\hline & {$[\ldots]$} \\
\hline Shirley: & $\begin{array}{l}\text { Do you think you would have been friends if you hadn't had the } \\
\text { fight? }\end{array}$ \\
\hline Drew: & No l'd probably still would have hated him. \\
\hline
\end{tabular}

My incredulity was apparent in this exchange, "So what's that? So you're mates?". I was very surprised to learn that fighting was a process for making friends. However, I recognised that Drew was describing what can be viewed as a common practice of developing male friendships: "we're finally mates now". Drew positioned himself as being right and winning, and positioned his new friend as accepting that he was wrong and losing. This fits with the construction that male-to-male violence occurs within a discourse of "contest" (Eagle, 2006, p. 69) in which there is honour in defeat when abiding by the rules of the game. Drew's statement that: "he just said sorry to me for being an egg" suggests a hierarchy has already been established in this new friendship in which only particular behaviour is acceptable.

While Drew talked of becoming friends after fighting, Kelly spoke of making friends because he did not fight or even respond to intimidation:

$\begin{array}{ll}\text { Shirley: } & \text { So you mentioned that you've made friends here? } \\ \text { Kelly: } & \text { Yep } \\ \text { Shirley: } & \text { So have you been able to do that easily? } \\ \text { Kelly: } & \text { Um. At first it was quite hard because you come in and you don't } \\ & \text { know anyone and people just start picking on you. And they start } \\ & \text { like intimidating you and stuff just to see how, like um how you can } \\ & \text { react to things. And um they just test your patience and like they } \\ & \text { just call you names and stuff that if you don't react to stuff they } \\ & \text { simply go oh what's the point in that and they just end up becoming } \\ & \text { your friends. }\end{array}$

Being able to withstand the constant intimidation and bullying without giving-in positioned Kelly as courageous and heroic and thus made him worthy of being their friend. Even though Kelly's response is different, this can be seen as being a similar process to Drew's fighting to make friends. Within the discourses of manliness, respecting one's opponent or enemy is honourable and may be read as an act of 'manliness', particularly when considering the fight as a contest of strength and courage. 


\section{Being pressured by friends}

Participants described being involved in a considerable amount of violent activity with their friends, particularly gang fights, and many talked of "getting into trouble" with specific friends. A commonly held belief about youth violence relates to the negative influence that some friendships can have. It is theorised that peer pressure causes youth violence (Flowers, 2003). Consequently, young men are positioned as being vulnerable to the influence of their peers, and this implies a lack of control. Young men are thought to be unable to withstand this peer pressure and likely to act almost against their will, or at the very least against their 'better judgement'. However, a discursive analysis of the participants' comments in relation to peer pressure provides a more complex depiction.

Rick described what seemed to me to be a typical pattern of peer pressure, about starting to do crime when he was in state care, living in a family home:

\section{Shirley: $\quad$ So do you know why you started getting into crime then? \\ Rick: Um I think it was just to act cool really. Just to say to the rest of the guys hey I can do this too and but in the end all it did was seem to get me in trouble so that was quite a dumb idea.}

Rick spoke about wanting to "act cool", and so he committed crime to enact this subject position of 'doing cool' correctly and presumably, to gain a sense of belonging and to be like the other residents: "I can do this too". Being in state care is a subject position that is negative, as it is suggestive of Rick not getting it right as a son. Thus the 'cool' positioning can be read as providing an invitation to Rick to take up this more positive alternative.

Likewise, Kelly's description of how he came to commit two aggravated robberies could be read as peer pressure:

\footnotetext{
Kelly: Um, I did two aggravated robberies. It was in ... [month omitted] and um my ex-girlfriend showed up in my house with her two friends that I didn't know. [...] And um, I got in the car and I met her two friends, ... [name omitted] and ... [name omitted] which I didn't know. And um we started driving around and um went to ... [girlfriend's name omitted] house um for about ten minutes, fifteen minutes. And then um, we went for a drive into ... [name of location omitted], one of the suburbs, and um they told me to go in and rob the dairy because I was, I had a few drugs. Yeah a bit too many drugs. And um, yeah they told me to go and rob a dairy and um I
} 
did. Just grabbed a screwdriver and I went in and just done a robbery, then yeah did it again.

It may be possible to position Kelly as a naïve young man who was duped into doing the robberies by his peers. While the notion of being 'pressured' by these 'peers' allows a way for Kelly to place responsibility for his actions onto his peers, it does not allow him to perform 'man' correctly. An added complication exists with the involvement of Kelly's ex-girlfriend as one of the peers who pressured him. Firstly, because she is a girl and, secondly, because she is a girl with whom he was previously romantically linked positions Kelly as unmanly and perhaps also as foolish within dominant discourses of traditional masculinity. But as Kelly had "a bit too many drugs" this may be used to alleviate the negative "unmanly' positioning because he may take up the position of being a stoned, unthinking youth and this can be the reason he succumbed to peer pressure. Being intoxicated is also part of the manly tradition.

Participants also spoke of making choices in the face of what might be thought of as peer pressure. Anthony, for example, talked of developing a new group of friends after "drifting away" from his old friends whom he described as people he got "into trouble" with. This suggests he exercised a level of autonomy that is contradictory to the peer pressure explanation.

Drew also described having different groups of friends, one group that did crime and another that did not. Drew positioned himself as being able to move between these two groups of friends depending on what he preferred to do at the time. He spoke of doing crime because he liked it rather than doing so in order to belong to the group. This can be read as adopting a position contrary to the expectation that peer pressure is very difficult to resist. Additionally, when it came to those mates with whom he did do crime, Drew said:

\footnotetext{
Drew: I don't have to do crime with them. I could have said no because they're, they were all looking for, sometimes I didn't do crime with them. If they're saying oh yeah going out this weekend and go make an earn, l'd be oh no I'm going somewhere else or something. Yeah well sometimes I stopped them, I mean there's a party or got some cash. And they won't do it.

Shirley: $\quad$ So you can, you feel okay about saying no?

Drew: Yeah.
} 
Drew spoke of being able to say no to peer pressure to do crime, and indeed he talked of convincing the group not to do crime at times. Drew highlighted his agency and control, resisting the idea of peer pressure that diminishes his sense of agency.

Rick goes further and refused the idea that peer pressure played a role in his violence. Instead, he positioned himself as completely responsible:

$\begin{array}{ll}\text { Shirley: } & \text { So what about getting in with the wrong crowd and stuff, do you } \\ \text { think that, is that how you saw it? } & \\ \text { Rick: } & \text { Um. Not at all. Um, oh well in some ways, yes. [...] Like I said at the } \\ \text { end of the day it was me that chose to get in the car or me that } \\ \text { chose to break into the house or so I mean you can't really blame } \\ \text { the people that you're with. } \\ \text { Shirley: } \quad \begin{array}{l}\text { Mm. Because ultimately you were the one who decided it and you } \\ \text { did it? }\end{array} \\ \text { Rick: } \quad \text { Yeah. For sure. Mm. }\end{array}$

Taking such responsibility suggests a rationalist and agentic positioning, in which Rick is seen to be in control of his life. Such a position enables him to get being a 'man' right within dominant discourses of manhood. This appeared to be a preference to the powerless position offered by the notion of peer pressure.

Dominant theorising on peer pressure focuses on the 'followers' in this process, those influenced by peer leaders to be violent. However, less attention is given to those leaders thought to have such influence.

Before I met Drew, he was described to me as a "follower" by the manager of the unit he was in and as getting involved with the "wrong crowd". In contrast, Drew positioned himself as a leader rather than a follower: "usually me that always decides to do, to go do crime". He explained that this leadership had developed over time: "it used to be them when I first met them". There are negative connotations of being positioned as a follower as it does not match up with being a successful man so it is not surprising he would resist the positioning of follower suggested by the manager.

\footnotetext{
Drew: $\quad$ Yeah. Yeah. They usually um, sometimes usually me that always decides to do, to go do crime, go start something and that. And all that kind of stuff.

Shirley: $\quad$ How come, like would you expect that it would be them rather than you?

Drew: $\quad$ Yeah it used to be them when I first met them. But then I started getting hard out into it, and it'll always be me.
} 
Within those learning approaches that utilise the concept of the positive role model, being a leader and having leadership skills are usually constructed as being successful and prosocial (Gibbs et al., 1995). However, when considered within a discourse of peer pressure, a leader who leads friends into trouble is positioned as a 'bad influence'. Drew cannot therefore get being a leader right in the dominant discourses around learning. If he was to become a positive role model in that discourse such positioning becomes problematic in relation to discourses around manliness. 'Leading' into trouble appears to be his preferred position, rather than risk the less masculine position of being a good role model.

There appears to be a contradiction between the two concepts of positive role modelling and peer pressure. On the one hand, peer pressure, positions young men as unmanly, because being influenced by others presumes a lack of agency. On the other hand, role modelling is a construction about getting it right as a successful citizen. Both concepts use persuasion and influence over others. However, such processes are not confined to young men. Influencing others and being influenced by one's peers is a well-recognised process, and indeed advertising makes use of this process to good effect. In advertising discourses, peer pressure is not constructed negatively as it is in the discourses of youth violence.

\section{Problematising the Use of Drugs and Alcohol in Youth Violence}

All the participants spoke of using illicit drugs as well as alcohol as a regular part of their life. Some spoke of addiction. Several of the young men talked about the availability of drugs inside. Drew was charged for testing positive to drugs. Quentin only hinted at being able to get drugs while inside rather than speaking outright about their accessibility as other participants did: "So you've just got to bloody wait like I go to some programmes and get - yeah [laugh]. You know" (Quentin). Quentin's talk contrasted with other participants whose talk about the availability of drugs inside the secure facilities could be read as being more matter-of-fact and every day. I read Quentin as trying to impress me with the risks he takes. The more the significance of the risks of drug taking is played down by these young men, the more they can take 
up a position of 'being tough' within traditional masculinity discourses. Thus they can demonstrate their bravado by minimising the risks, which paradoxically can be seen as highlighting them. Drug-taking and its associated risks can be considered a way of 'getting being a man right', since risk-taking features strongly in masculinity.

When I asked about their use of alcohol and drugs being associated with their violence, participants gave quite varied responses. Some attributed their violence directly to being affected by drugs or alcohol, while others stated there was no connection. The relationship to drugs and alcohol was a complex one shown in their detailed descriptions of how drugs interacted with their social context.

Kelly was one participant who talked extensively about the effects of both drugs and alcohol, claiming that they were a causal factor in his aggression, violence and crime: "I've never been like a violent person, it's just when it comes to drugs and alcohol". At the time of the aggravated robberies, Kelly judged himself to be, "pretty mildly oh pretty heavily stoned I think." He also stated that he did not like alcohol because of its effects on him:

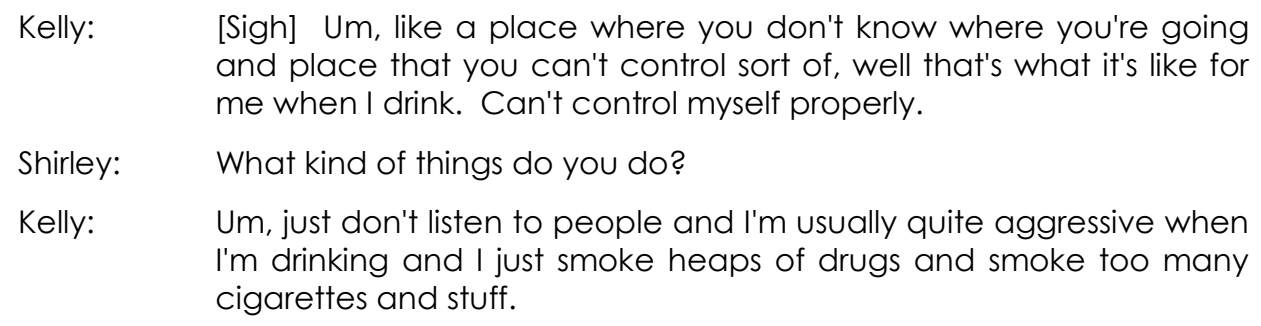
and place that you can't control sort of, well that's what it's like for me when I drink. Can't control myself properly.

Shirley: $\quad$ What kind of things do you do?

Kelly: Um, just don't listen to people and I'm usually quite aggressive when I'm drinking and I just smoke heaps of drugs and smoke too many cigarettes and stuff.

Contrary to the complexity shown in these and the following quotes, objectivist psychology theorises a connection between drugs and alcohol and youth violence in two ways (Walsh \& Ellis, 2007). Firstly, young men are thought to be violent because they are either intoxicated or 'crazed by the craving' and therefore seen as unable to control their behaviour. Secondly, they are believed to do violence in order to get money for drugs and alcohol (instrumental violence). Kelly, above, can be read as subscribing to the first idea that intoxication caused his violence. He described a loss of control: "Can't control myself properly". One effect that this notion of intoxication has is that it enabled Kelly to be positioned as not being responsible for his violence since drugs are an external force that is seen to be the cause. 
Quentin talked of hitting a younger boy on the head as, "it wasn't a big deal". He explained that he did it because, "I was out of it at the time anyway. I was stoned." Like Kelly previously, Quentin can be read as minimising his responsibility for his violence through drawing on discourses around drug use in which being intoxicated is constructed as the cause of violence. He explained that he only did crime when intoxicated by drugs or alcohol:

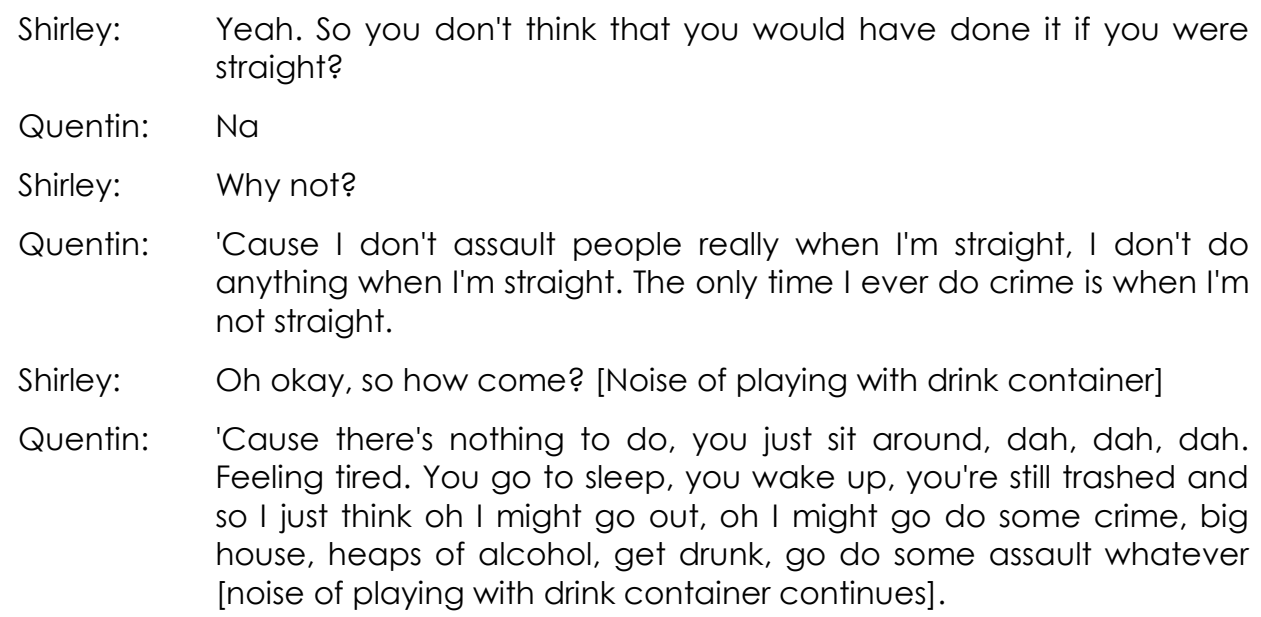
Feeling tired. You go to sleep, you wake up, you're still trashed and so I just think oh I might go out, oh I might go do some crime, big house, heaps of alcohol, get drunk, go do some assault whatever [noise of playing with drink container continues].

Significantly, Quentin's talk of his experience when stoned can be read as contradicting the idea that the effects of drugs determine violence. There is a casualness in his language about drugs that constructs their effects as benign, yet Quentin used the explanation of being "stoned" for his violence towards a younger boy. He provided a more complex view of the connection between drugs and violence when he talked of how his violence was misguided as a result of being stoned, not for having been violent per se, but because his judgement was impaired regarding his choice of violence and his choice of victim. His discursive positioning in relation to drug effects is that he is in control - an important distinction with respect to masculinity:

\footnotetext{
Quentin: Well I wouldn't, wouldn't really assault a little kid if I was straight eh.

Shirley: No? You can get it. [referring to a ball he had thrown out of reach]

Quentin: Na, I'll leave it there. [referring to the ball] Yeah if it was a 14 year old or 15 year old and I was straight, l'd punch them in the face.
}

Quentin's suggestion that he would increase the severity of his violence, "I'd punch them in the face", and choose an older boy, "a 14 year old or 15 year old" as a victim if he was straight, can be read as constructing violence whilst intoxicated as not 
performing violence 'properly'. Within discourses of traditional masculinity, Quentin's action of picking on a younger, weaker boy may not be viewed as 'proper' violence for men. However, violence against a peer and using a punch in the face is constructed as being more 'manly'.

Conversely, despite having "a lot of problems with drugs" (Rick), Rick constructed his violence as not being related to his drug use:

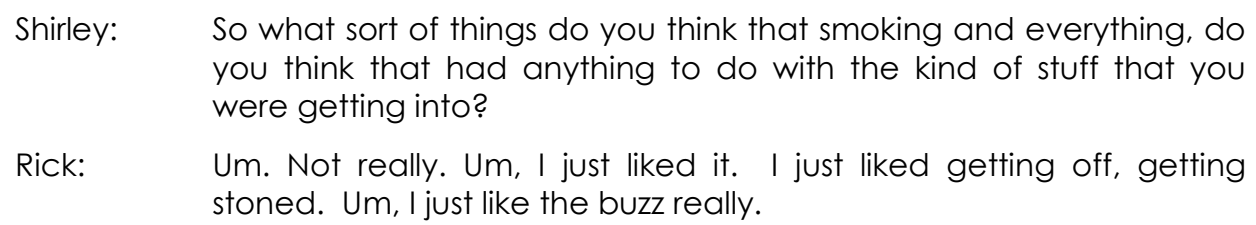

Rick highlighted the pleasure he experienced from his drug use but did not see it as causing his violence. However, Drew added to the complexity of how drug and alcohol use was related to being violent in the following quotes. He talked of specific drugs being associated with specific violence and types of crime. Firstly, he stated that he and his mates did not do acts of violence or crime when drunk - "I haven't got into crime drunk" but they only did their fighting when they were drinking alcohol and when drunk:

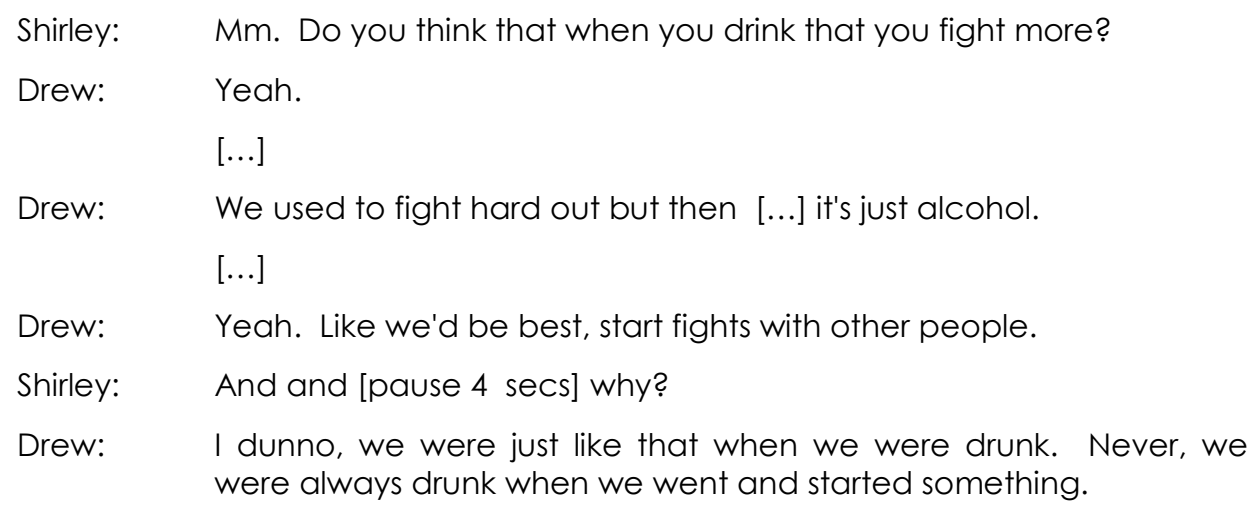
were always drunk when we went and started something.

In contrast to the effects of alcohol, Drew talked of other drugs stopping any desire for fighting. Like Quentin, he spoke of marijuana's relaxing qualities and therefore as having no association to committing violence:

Drew: $\quad$ Any um dope or acid or something that makes you stop fighting too 'cause you just want to relax and do something fun, not beat up people. Especially marijuana it's just relaxing you just want kick back, enjoy it. 
Drew's contradictory claims about the effects of drugs extended further. He spoke generally of being "straight" for aggravated robberies, but the use of acid was important when energy and a fast pace was required, such as in the ram raids that he and his mates frequently did:

Shirley: $\quad$ So were you drunk when you did the aggravated robbery or?

Drew: Oh no. Usually we were always ah, usually pretty straight. Sometimes we might be on acid or something, like that gets us ah moving faster, hypes us up.

From the participants' explanations it seems that there is more complexity to the issue of the association of drugs and alcohol with violence than is suggested by the dominant notions of a simple cause and effect relationship between intoxication and violence. It is possible to begin to trouble explanations of how young men choose to use drugs and alcohol at a discursive level. Drew can be read as suggesting that he and his mates made rational choices to use specific substances to achieve the specific effects they were after. This contrasts to the idea that being intoxicated causes violence. Instead, Drew and his mates made a choice about the type of intoxication effects they were after before using the drugs. In relation to his drug use within the context of committing violence and crime Drew can be positioned as being in control and making rational decisions. Such agency enables him to perform man correctly, rather than being positioned within dominant discourses of drug use and intoxication as a young man whose behaviour is out of control, which is not manly. The dominance of traditional masculinity discourses in the participants' talk was also evident when they referred to their victims, a topic to which I now turn.

\section{Considering Victims and Empathy}

In talking about their victims, participants were able to describe what they did to them, their victims' behaviours and responses at the time, and they also speculated on some of the longer-term effects their violence may have had on them. While participants often knew their victims, for example, in some cases of assault and fighting. In certain circumstances, knowing one's victim was not viewed as the best situation:

Shirley: So when you, when you robbed the service station, was there just, just one person on, working or? 


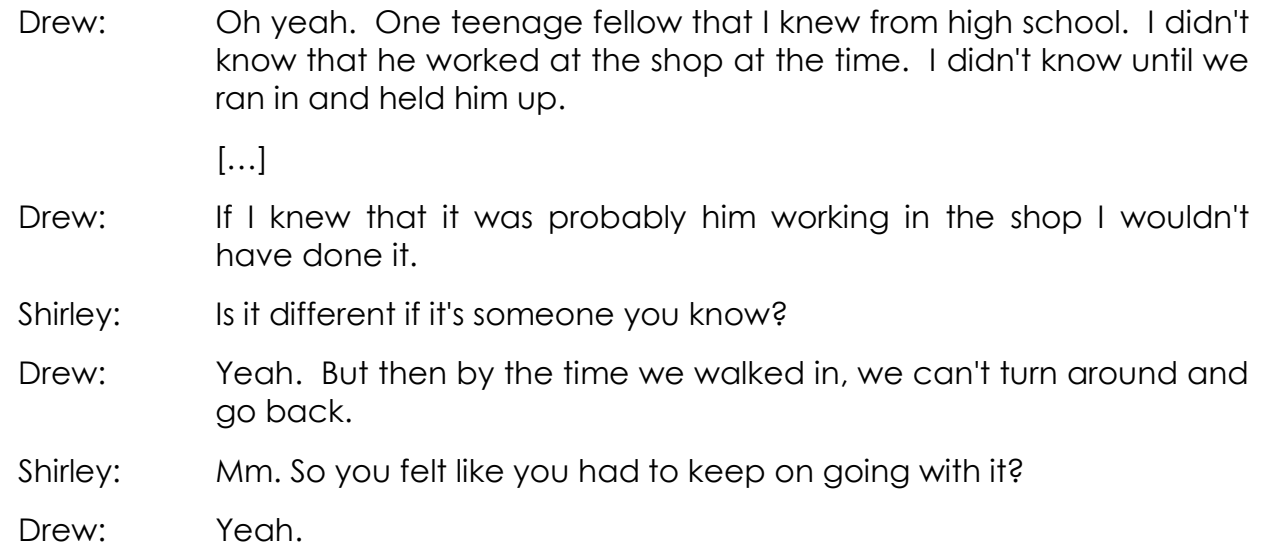
know that he worked at the shop at the time. I didn't know until we ran in and held him up.

Drew mentioned knowing his victim, but said that if he had realised this he "wouldn't have done it". One reading of this is that Drew had some standards about who he robbed, which is reminiscent of the old adage 'honour among thieves'. Alternatively, his reluctance may be read as Drew's self-interest in protecting himself, that is, he may not have wanted to rob someone who knew him because he was more likely to be recognised. However, that risk of recognition did not deter him from going ahead, "we can't turn around and go back", suggesting that Drew himself felt powerless against the momentum of the robbery. Drew's actions of going ahead with the robbery may be constructed as being manly, since he was prepared to take the risk and so 'tough out' the situation, rather than run away like a coward. Performing bravery, for whatever purpose, is one of the practices that enables 'getting it right as a man' within dominant discourses of masculinity.

There was some reticence by participants in discussing some of their interactions with their victims, as Kelly demonstrated:

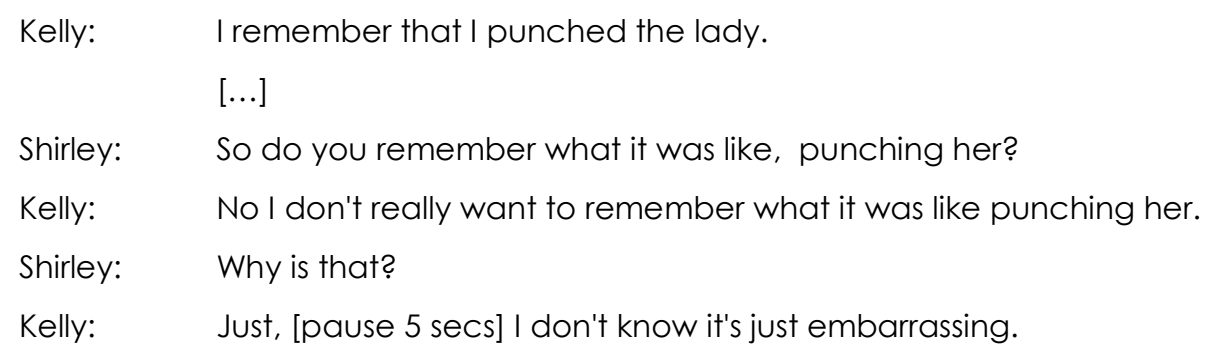

Not wanting to remember what it was like punching the woman in the face because Kelly found it "embarrassing" can be read differently through a number of discourses. Firstly, embarrassment can be constructed within a discourse around emotional response that he felt a sense of shame and therefore remorse. Dominant 
discourses around remorse reduce the likelihood of Kelly being positioned as dangerous. The concept of being remorseful for their violence is often used as a measure of whether an offender is able to be 'rehabilitated' by clinical assessments. The police and court systems also draw on this notion when they gauge the extent of remorse expressed by offenders to assist their decisions around charging and sentencing (Hawkins, 2003). Alternatively, drawing on dominant discourses of youth, Kelly's emotion of embarrassment may be seen as evidence of an immature, egocentric youth and who, therefore, may not be remorseful at all. A further reading of Kelly's comment, "it's just embarrassing”, could be related to the gender of the victim. Discourses around masculinities include sanctions against men hitting women. Therefore Kelly's embarrassment may be viewed in relation to not performing man correctly on this basis.

Participants also talked about their victims' responses. They described what they judged as the victims' immediate responses to their violence. When Kelly "intimidated" and "hassled" the new inmates, he thought that:

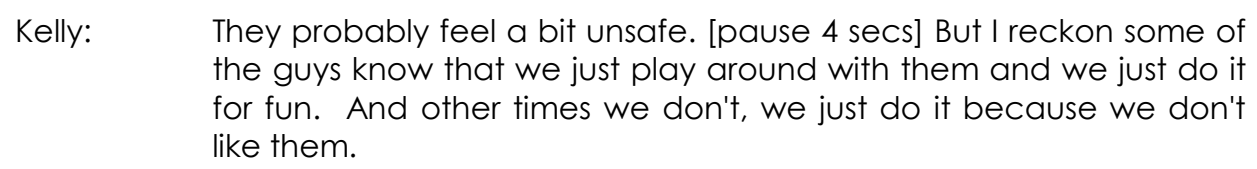
the guys know that we just play around with them and we just do it for fun. And other times we don't, we just do it because we don't like them.

In contrast, Kelly saw a more severe reaction from the victims of his aggravated robberies: "I reckon they were scared and shocked at the same time", "They didn't know what to do."

As did Drew: "Oh yeah, the old man looked like he was having a heart attack. And he just suddenly started shaking." Drew was also able to describe in detail the response of the victim of his service station robbery, which may be read as a highly traumatic reaction:

\footnotetext{
Shirley: $\quad$ Okay. So how did he react, you said he just sort of stood back?

Drew: $\quad$ Straightaway yeah he just jumped back and just, he was just frozen on the spot and he got scared. My mate's pretty big too. Probably just felt like he was ... [unclear]

Shirley: $\quad$ Yeah that's big. So that would have been pretty scary for that guy do you think?

Drew: $\quad$ Yeah. Oh yeah he was scared and he just, my mate was telling him to do stuff and he was saying, "Take everything. Don't hurt me".
} 
Within traditional masculinity discourses, it is not acceptable for a young man to be scared, or rather, to show that he is scared. It is possible then for Drew to position his victim as not measuring up to what being a man is all about. Further, Drew may experience a sense of embarrassment and distaste for his victim because of this. From such as perspective, it follows that blaming the victim for what happened to him is a logical progression, because the victim did not act tough, that is, like a man.

Although Drew stated he was not influenced by the above victim's response, "I don't care at the time", upon reflection Drew talked of feeling sorry for him:

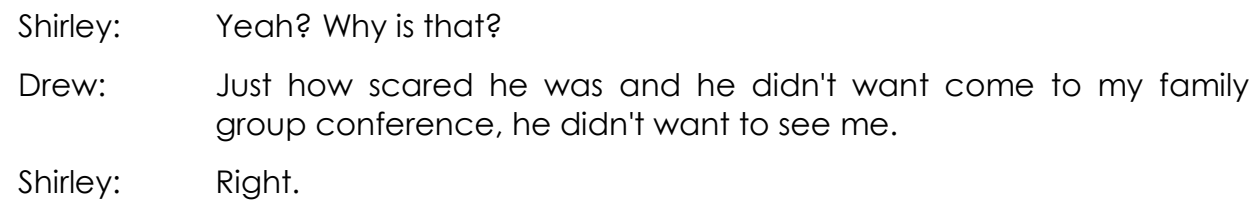

In discourses around empathy and remorse, Drew's compassion for his victim can position him as having empathy and consequently as not dangerous. According to some dominant theories, being violent and having empathy skills are seen as mutually exclusive; it is not possible to have empathy, that is, the skill to view another person's experience as one's own as well as be violent (Lovett \& Sheffield, 2007).

Kelly too showed his understanding for the plight of his victims:

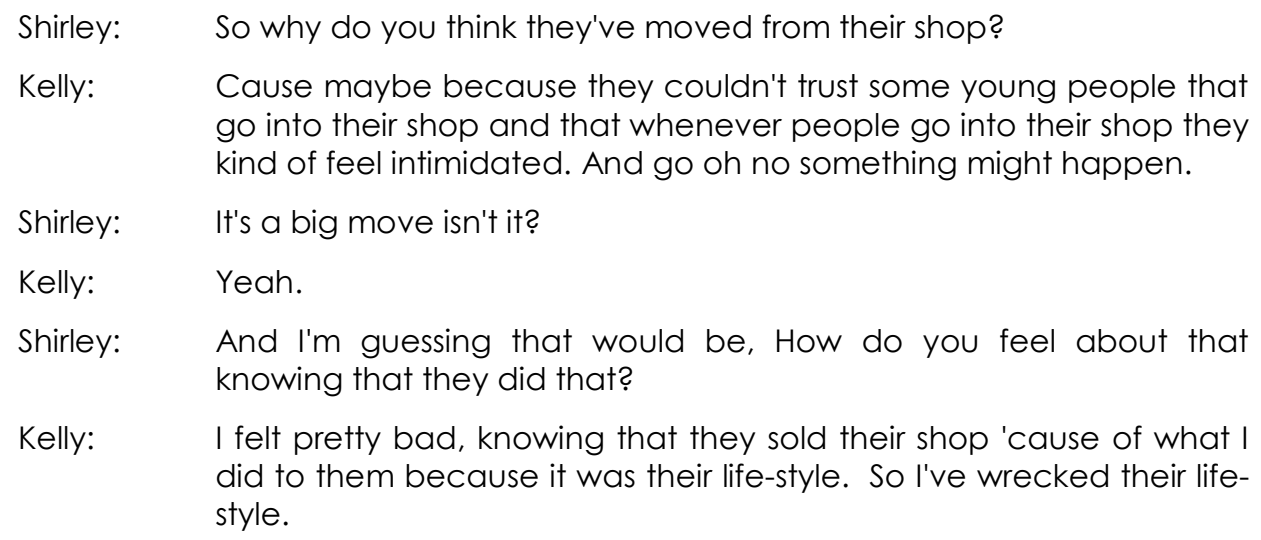

When perpetrators of violence demonstrate empathy towards others, it is sometimes argued within dominant theories that these young men who are violent only lack the skill of empathy for their victims. But Drew and Kelly's comments above can be 
read as showing victim empathy. It may be that performing empathy at the same time as being violent is possible.

The dominant notion of having empathy skills assumes the ability not just to consider someone else's experience, but as far as possible to feel and understand it as one's own experience (Lovett \& Sheffield, 2007). There did not seem to be any illusions held by the participants about how their victims would likely view them, as Kelly said "they might feel happy" about his being "locked up":

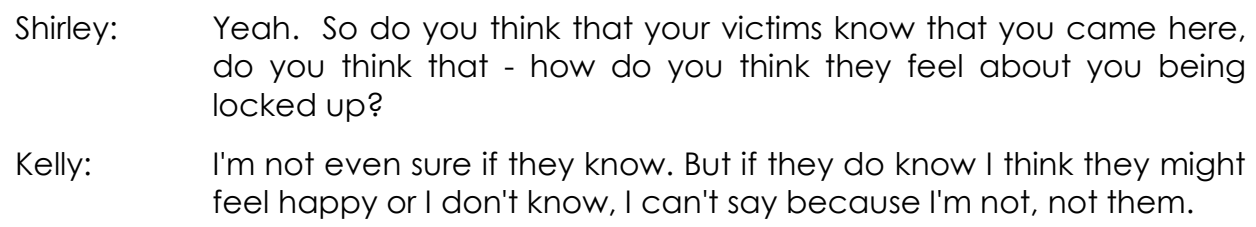

Kelly's comment, "I don't know, I can't say because I'm not, not them" can position him as not having the skill of empathy. However, there is an alternative reading that positions Kelly as showing respect to his victims in that he is not making any claims to know what they have experienced, since to do so, particularly by the one who caused the harm, could be constructed as disrespectful. Kelly may experience himself as being more respectful this way.

\section{Comparison to Other Inmates: Achieving the grade}

While empathy is concerned with having some understanding about another's experience, the participants also compared themselves to other young men who had been violent. They positioned themselves as not as 'bad' as other young men in two ways, firstly, in terms of their specific violent acts and, secondly, in relation to their intentions.

Although Quentin and his mate were serving similar sentences, Quentin pointed out the difference between them; his mate had "103 charges" (Quentin), which was "way more" (Quentin) than he had: Quentin had 45. When Kelly compared his aggravated robbery to his mates' armed robbery, he suggested that his mates' violence was worse than his because their weapons were more serious than the screwdriver he used: "Ah a couple of them used knives and a couple of them used guns and stuff." He also thought that "they had more physical force in theirs than I did", and he 
speculated that "their victims were more scared" than his. One possible effect of such comparisons is that participants can be positioned more positively in relation to the level of seriousness of their violence. Violence is constructed as being more seriousness when the frequency of violence is high, more harm is inflicted on victims, and the weapons used are more deadly. In this way, the level of seriousness assists the justice system to determine sentencing.

When it came to distinguishing themselves from other inmates, another significant point of difference seemed to focus on how participants felt about their violence and their plans for the future:

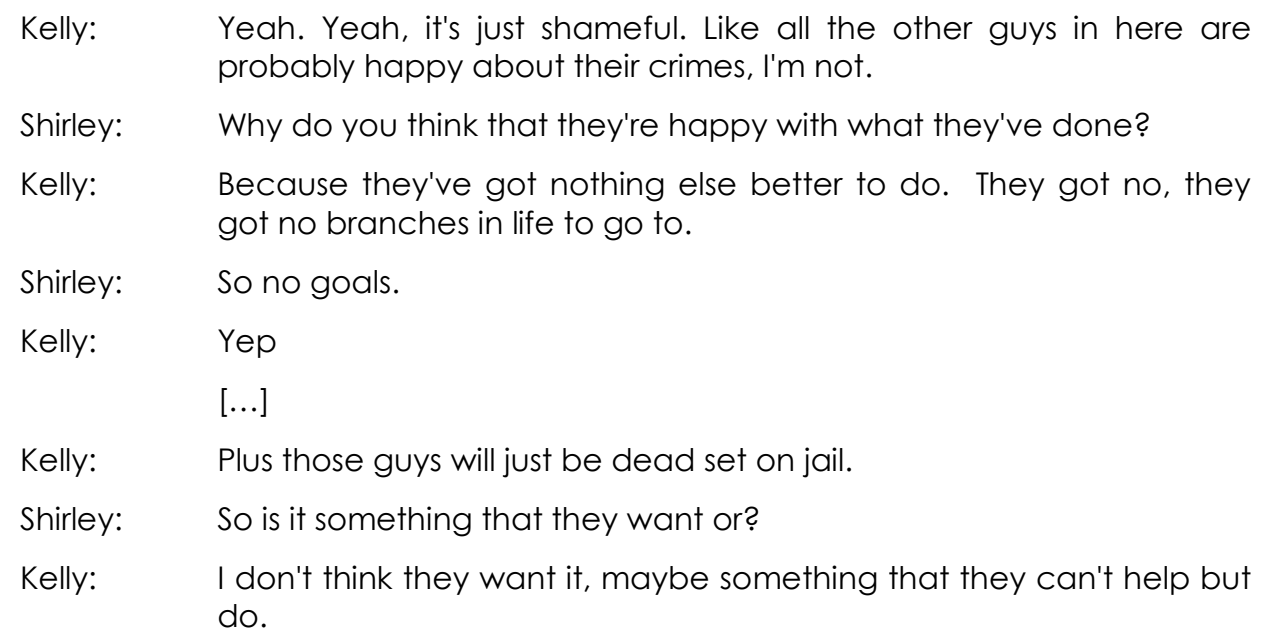

Kelly positioned himself as being better than the other inmates in several ways. He described feeling remorse for his violence, "shameful", which to some extent constructed his violence as less likely to be repeated in the future, placing him lower on a hierarchy of seriousness. He also constructed his future plans as demonstrating that he had a positive future, which again positioned him as prosocial and thus less dangerous. In contrast, he positioned the other inmates as not remorseful and as not having future plans. Kelly went further to suggest that his peers inside are "dead set on jail", as if their future actions will inevitably lead them to adult jail.

Quentin's description of why some young men ended up coming back inside seemed to paint a gloomy future:

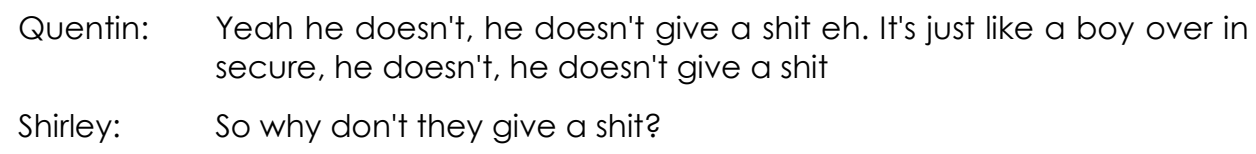




\section{Quentin: $\quad$ Cause they're stoned. They just like being locked up I think}

In their attempts to explain the violence of other young men, participants drew on dominant discourses of youth violence, for example, "they get so angry", and "it's their background". This contrasts significantly with how they often described their understandings of their own violence. Participants often resisted the mainstream psychological explanations of violence that positioned them as 'disordered' or 'abnormal', such as being angry or coming from a 'dysfunctional' family, or being a victim within the cycle of violence, or that drugs or alcohol determined their violence. Despite their own experience of being violent and being held in a secure facility, participants drew on the same theories that they had resisted for themselves to explain the violence of other inmates and positioned these other young men negatively, as 'disordered' and 'abnormal'. The opinions they held of their peers seemed little different to what is commonly believed about prison inmates, that is, that 'they deserve what they get', and that 'they don't care'.

According to dominant psychological theories, attributing negative reasons for another's actions and more positive reasons to one's own can be linked to what is theorised as attributional biases (Kelley, 1987). Within this theory, the process is considered to be self-aggrandisement. Willig (2000) notes that this theory assumes consensus on the object in question, but is undermined by evidence that some people will attribute negative reasons to their self and positive ones to others. Another reading of participants positioning themselves more positively than others is possible. Since dominant discourses are taken as truths, then logically, these commonly accepted theories about youth violence put forward from a modernist psychological perspective must apply to someone. Since these ideas do not seem to fit the participants' own understandings or experiences of their violence, it follows that these theories must apply to the other young men who have been violent. Hence, these theories position these young men accordingly as 'disordered' and 'abnormal'.

\section{How Others Position Participants: Being Downgraded}

While participants described themselves favourably compared to others, they themselves were often positioned quite differently by others. At times the staff of the units offered contradictory descriptions about the participants. For example, Quentin 
described himself as getting along well with the others in his unit but staff positioned him as a victim, often being picked on by others.

In contrast, several staff members described Anthony as being not only aloof and not joining in, but also as intimidating towards staff and other young men. Yet Anthony explains his choice of not getting involved as his way of avoiding being involved in fights:

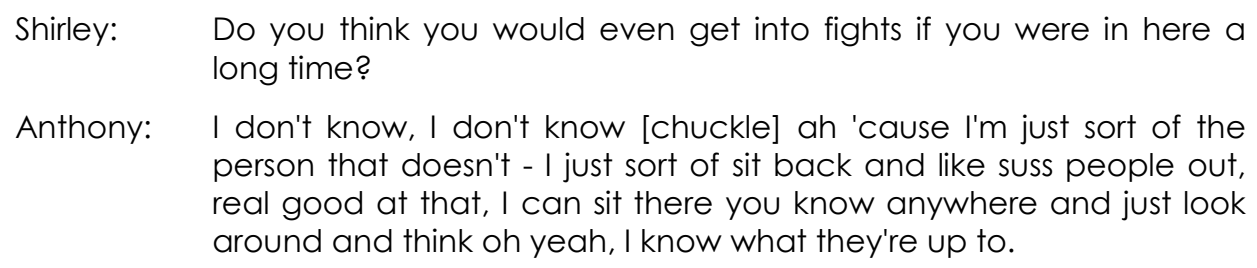

Instead of fighting, Anthony talked of evaluating others: he liked to "suss people out". But his technique of avoiding violence was read as being intimidating, which was constructed as an invitation to violence. Within dominant discourses around prosocial behaviours, an individual is expected to join in with peer groups and not be isolated. Staff positioned Anthony negatively and read his separateness as sinister. However, taking up such a prosocial position could be a dangerous one in an environment where there is a need for vigilance for one's own physical safety. Within this prosocial discourse, the expectation of trusting others is often considered to be the goal for young people to get it right as 'normal', that is, as having and applying the necessary and appropriate social skills. Yet such a goal of trusting others may put children and young people at risk of being violated by those they trust, particularly by adults.

In talking with staff members within the secure residences, the appropriateness or otherwise of particular participants being a part of this research on youth violence was judged by some staff on the basis of the inmates behaviour inside. During one visit to a facility, some staff members described some of the participants whom I was interviewing as "pussycats" because, although their crimes were violent, their behaviour inside was not. They suggested I interview other inmates who were more violent inside than the participants, even though these inmates were incarcerated for non-violent crimes. The staff's comments support participants' descriptions of difficult and violent environments that these young men are confined to and also 
where staff are required to work. This highlights the important point that the subject position of a violent youth can be considered in discourses other than those of offending. The probability of a young man being caught for any violent act he commits is very low. Whether a young man faces police charges or receives a conviction through the justice system for his violence is determined by many factors, such as access to effective legal representation, or their class or ethnicity. Therefore, the subject position of "violent youth" may be constructed within discourses of youth violence in a number of ways, having violent convictions is only one avenue.

\section{Conclusion}

Being a 'real' man has surfaced as a significant - sometimes implicit - discourse for participants. The extent to which participants drew on traditional notions of manhood was not anticipated at the outset of the interviews. Within dominant discourses around masculinity, being a man is about being rational, being in control and being able to manipulate his world. It is about being tough, being in competition with other men. It is about being strong and physical (Connell, 1995; Eagle, 2006; Wadham \& Pudsey, 2005). Violence then becomes a very common and effective way for young men to get it right as a 'man'. Indeed, traditional concepts of manliness dominated the talk of participants and the subject positions available within these discourses were frequently in direct competition with the subject positions derived from discourses of 'abnormality' and scientifically based psychological theories.

In this chapter, I have offered a more complex picture about young men's violence than is usually captured by dominant theories of youth violence. A poststructural analysis shows that the multiple subjectivities these participants inhabit are often contradictory. As they negotiate moment-to-moment subject positions, participants have talked about their experiences and understandings of their violence in ways that highlight multiple explanations, effects and outcomes, unlike more dominant linear cause-effect relationships (Jenkins, 1990).

As I have already discussed in Chapter Three, theories on youth violence from a positivist psychology perspective constructs violence as a pathology and therefore outside a person's control (Jenkins, 1990). Such a construction can position the 
young men as not being responsible for their violence (O'Neill, 1998). From the participants' talk, it is possible to read the occasions where they did take up these ideas and so avoided responsibility for their violence (for example, being drunk or stoned and hence, behaviour is caused by intoxication). As a result, a young man can be positioned favourably by others, since he cannot be blamed for his violence. If he is not responsible for his violence, then equally there is nothing he needs to do to resolve the problem; indeed, there is nothing he can do because there are no issues thought to be involved in his violence over which he has any control.

However, there is a negative side to being positioned as not responsible for their violence of which participants seemed to be aware and that is, they can have no agency or control if they have no responsibility. In terms of agency, normative psychological theories of youth violence and dominant discourses around traditional manhood tend to offer competing positions for these young men. For a young man who has been violent to take up the positions offered by mainstream psychology, for example, as being 'disordered', 'abnormal', a product of his 'bad family', affected by drugs or in need of help, does not enable him to be a 'man', because he has no rational control. By getting it right as 'abnormal', that is, by being a therapeutic subject, he can be read as getting it wrong in performing 'man' correctly within the manliness discourse. In contrast, to get 'man' right, these young men discursively take responsibility for the violence they committed in their talk.

From the participants' talk, it is possible, although not traditional, to read many of the material effects that being violent produces as positive ones. Being violent provides benefits to the young men in terms of being positively positioned as a man. This includes specific payoffs, such as solving problems, making friends, protecting their reputation, controlling others, showing their skills and courage, as well as obtaining things, (for example, money and drugs). Even the consequences of being violent, that is, getting caught, convicted and incarcerated, can enhance their positioning as a man, (for example, the reputation of being tough because of being in jail and being able to prove themselves (their manhood) through fighting). Such benefits make violence an attractive proposition and make it difficult to consider non-violence a realistic choice. This tension is unmistakable in the next chapter 
where I explore the participants' experiences and ideas of intervention intended to assist them in avoiding future violent behaviour. 


\section{ChAPTER SIX}

\section{INTERVENTION FOR GENERAL VIOLENCE}

In designing this research, I was interested in not only looking at the young men's understandings and explanations about their violence, but also exploring participants' ideas and experiences of intervention. The focus of this chapter is on young men's talk regarding interventions (in a very broad sense) that was related in some way to addressing their violence. This coverage begins with the participants' experiences of strategies related to their family, such as alternative care, the processes of restorative justice in Family Group Conferences and family visits to the secure facilities. Next, I examine how they were managed 'inside', looking at the highly structured daily regimen and the behavioural reward and punishment systems used. I also explore the therapeutic group programmes that participants were involved in, such as anger management. Finally, I discuss the practical support they viewed as important, as well as their experiences of using talk as a means to resolve issues. I identify the constructions of intervention that the young men use and locate them in relation to dominant psychological theories of youth violence. I also highlight the normative discourses around manliness that were significant when participants enacted the subject position of 'man'.

Given my professional background of working therapeutically with young violent offenders was within the counselling/therapy field, I particularly wanted to examine this area. However, I was surprised to find that participants were given little exposure to such therapeutic experiences. Although some spoke of being involved in group programmes that clearly had a therapeutic basis inside the secure facilities, there was 
no on-to-one counselling or therapy. Consequently, the in-depth discursive exploration of such therapy that I had envisaged was not possible.

I did not expect to encounter such a limited amount of therapeutic intervention because, firstly, the rhetoric of imprisonment suggests that prison exists for the purposes of 'correction' and 'rehabilitation' not simply punishment (Bruinsma \& Loeber, 2004) ; and, secondly, the widespread pathologisation of many human behaviours and issues is based on the assumption that behaviour can be 'rectified' and issues 'refocused' (Rose, 1985). This is a pervasive issue. For example, counselling was reportedly planned to be provided to all the volunteers at the Sydney Olympics in 2000 to ameliorate the expected sense of sadness and loss the volunteers would experience when the event was over (Williams, 2000). Such intervention into, what may be read as, an ordinary human experience (loss and sadness) highlights the production of a pathologisation process. One reading of sadness resulting from something very pleasant coming to an end, such as the Olympics, is that it would add value to the experience, not detract from it.

Before looking at what participants have said about 'intervention', I first need to mention my unease with the term. As I have developed my ideas around the concept of intervention, the more I realise the inadequacy of the available language. I used the term 'help' to communicate to participants the notion of what I refer to as intervention as a way of avoiding jargon and to simplify the language. But I find even this term unsatisfactory since it risks being patronising. The terms 'therapy', 'therapeutic' and certainly 'treatment' are equally problematic as they imply pathology and a subsequent position of being abnormal. Thesaurus and dictionary definitions suggest that the terms, 'therapy' and 'treatment' are associated with change and the concepts of cure and disorder that arise from the dominant medical discourse. This discourse highlights three issues. First, therapy/treatment is done to others; second, the therapist is positioned as the expert; and third, therapy/treatment is designed to fix something that is wrong with a person.

There has been widespread critique of the dominance of psychiatry, and hence the medical discourse, in relation to the mental and emotional wellness of human beings (Kutchins \& Kirk, 1997). Consequently, a range of alternative models of 
'intervention' has developed, for example, utilising a recovery process (Coleman, 2004), narrative therapy (White \& Epston, 1990), and numerous feminist approaches. Unlike the scientist-practitioner model, particularly within clinical psychology that still employs the term 'treatment', these alternative models no longer use such language because, originating from pathologising medical discourses, it signifies disease or disorder. Significantly, this constructs the goal of 'treatment' as cure. Instead, alternative models use terms, such as 'therapy' and 'intervention' in order to encapsulate the idea of working with people dealing with troublesome issues to assist them in reaching resolution (Hubble, Duncan, \& Miller, 1999). Unlike clinical psychology, the therapist is positioned as a facilitator or partner rather than an expert. However these terms can still be read as pathologising.

Unfortunately, there are no alternative terms for 'therapy' and 'intervention' that are completely devoid of some of the problems of meaning outlined above. The most appropriate alternative phrase that comes close to fitting what I have in mind would be something along the lines of "involvement in change", which offers a concept of walking alongside someone during a change process. However, since this phrase has little credibility, I have continued to use the terms 'intervention' and 'therapy' in this thesis, but do so with an awareness of the difficulties they pose. From a poststructural perspective, meanings of what constitutes intervention varies dependent on the discourses involved. The interventions covered in this thesis that participants talked about do not easily fit into ideas of intervention constructed within discourses of therapy, but fit more in line with a concept of "involvement in change" as they identified many experiences inside and interactions with staff as being designed to help them not be violent in the future.

\section{Families and Intervention Approaches}

The family is often a target for intervention. As I outlined in Chapter Five the influence of the family is theorised to cause young men to be violent. The two ways in which this is thought to occur is, first, through being a member of a 'dysfunctional' family and, second, through the process of the cycle of violence. 
Participants talked about families being a focus of the intervention approaches and regulatory practices used by the social institutions responsible for these young men.

\section{Alternative care as therapeutic?}

A common intervention for children who are assessed as coming from a 'dysfunctional' or abusive family is to remove them from that environment (Rose, 1985). The use of foster care and 'family' homes are common alternatives. In the excerpt below Rick outlined the circumstances of his behaviour towards his older brother that led to his removal to foster care at the age of eight years:

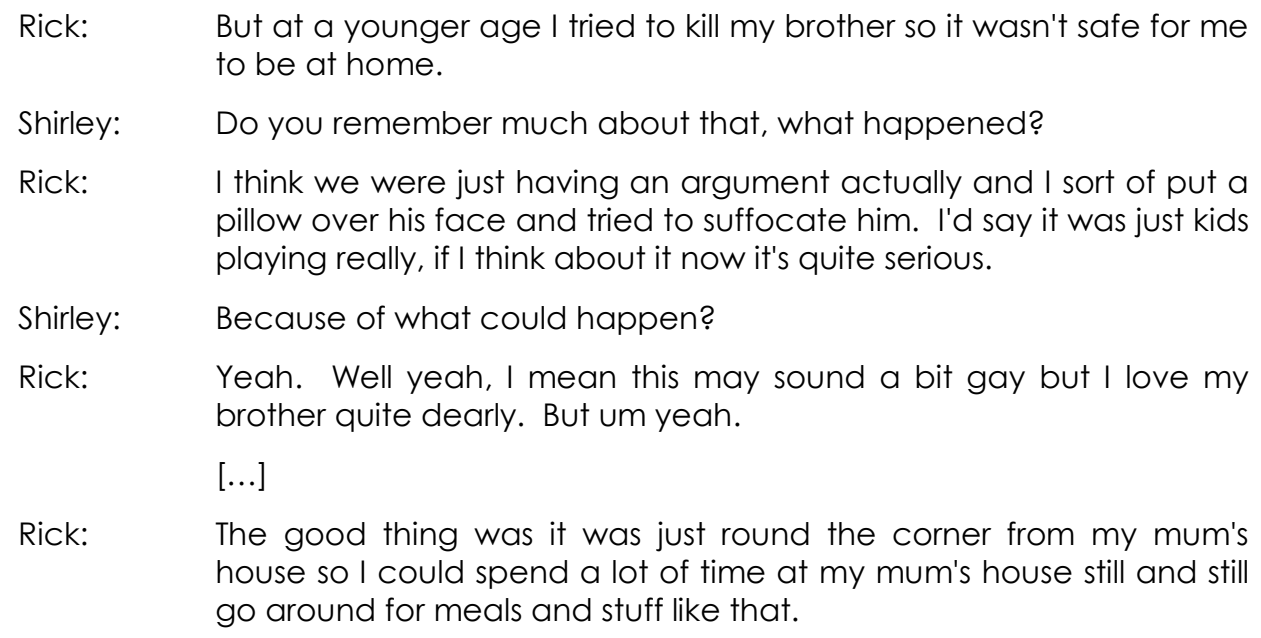

Rick offered contradictory constructions of his violence against his brother. First he described his behaviour as attempted murder "I tried to kill my brother" but then described his actions as "just kids playing really". To be positioned by social service agencies as dangerous and a potential killer at age eight may fit with Rick's first construction of attempted murder, but could be seen as an extreme reaction to what Rick described as "just kids playing really".

As a result of his actions Rick was placed in foster care, but as he says, "it was just round the corner from my mum's". Such an arrangement where he was still able to "spend a lot of time at my mum's house" can be read as contradicting the assumed dual purpose of removing him, that is, to save him from the influence of a negative family environment and to protect his brother from further violence by Rick. In Rick's comments there does not appear to be any interventions designed for the whole family, instead the focus was on moving Rick out. 
Dominant discourses around families constructs families as a primary location where children can be successfully raised to become good citizens. Therapeutic interventions for children and young people, such as psychotherapy, may be deemed useful only if family life is considered stable (Laws, 2001). For abused children and young people, psychotherapy is often made available to those abused outside their own family, but cannot easily be provided to those abused by their family when they are still living there. Instead, a new family becomes the intervention, but that is seen to be all that is required (Laws, 2001).

The construction of 'dysfunctional' families as the cause of youth violence can be seen as the basis for such interventions as foster care; state authorities provide a substitute family, that is deemed to be functional, for the child positioned as the 'problem'. Therefore, 'alternative care' in and of itself becomes the intervention. However, Laws (2001) argues that 'care' services are often merely residential services (some institutional), which do not provide specific interventions to meet the needs of the children nor do they aim to work with the family labelled as 'dysfunctional' to resolve issues.

Alternative care was not only relevant to the participants' past, but was a current issue for some. Anthony reported how he arranged his own care placement for when he would be released from the secure facility:

Anthony: Oh like they've been looking for a place for me to go live for like two months and they had to use my option, which was go live with my boss but that worked out pretty good. [...] I told him that - I rung him up a couple of weeks ago and I says look I've got nowhere to live, they can't find anywhere for me and he says oh well I'll ring up your social worker and I'll see if you can come stay with us and I was like oh thanks.

While arranging appropriate alternative care for children and young people is considered to be the statutory role of state agencies, Anthony positioned the authorities as having failed him in this function: "they can't find anywhere for me". Anthony can be read as taking up an agentic position and solving his own problem in finding somewhere to live. Anthony's ability to take action seemed to contradict his positioning as needing to be cared for paternalistically and be under the guidance of a state agency. 
Unfortunately, decisions about alternative care by state agencies do not always have positive outcomes. For example, placing children with members of the extended family has led to child deaths. In addition, not all residences are ideal, for example, young people who have justice issues, are housed in the same facility as those with care and protection issues and family homes are described by participants as places where it is easy to learn how to do crime. While alternative care is one strategy used with young men who have been violent, New Zealand has a process for young offenders that does involve their families when possible, called Family Group Conferences.

\section{Family Group Conferences}

Within the context of youth offending, Family Group Conferences are based on the notion of restorative justice in which the victim, the perpetrator and their families are brought together with others, such as police and lawyers to offer an opportunity to discuss the crime, its impact and the reasons it occurred. It also determines how the young person will be dealt with, for example, whether the matter will be taken back to court, whether there will be restitution or community service (Johnstone \& Van Ness, 2007). This discussion and the decisions made in the Family Group Conferences can be read as an intervention strategy that involves the family of the young offender. However, in doing so there are risks that dominant notions of blame, that is, family 'dysfunction' causes youth violence may become part of the process.

Participants spoke of their families being involved in their Family Group Conferences. Their talk included the conferences that resulted in their current incarceration as well as their experiences of past conferences. This made for a considerable number of conferences for some of the young men. How participants reacted to the Family Group Conferences differed. Anthony talked of attending a Family Group Conference with eighteen people, the biggest he had ever had, and as he told it, a considerable amount of yelling was also involved. Anthony talked of the Family Group Conference as an adversarial system with him and his family on one side and the victim's family on the opposing side, in addition to the police, lawyers and social workers. He spoke of his negative reactions especially to the victim's mother: 


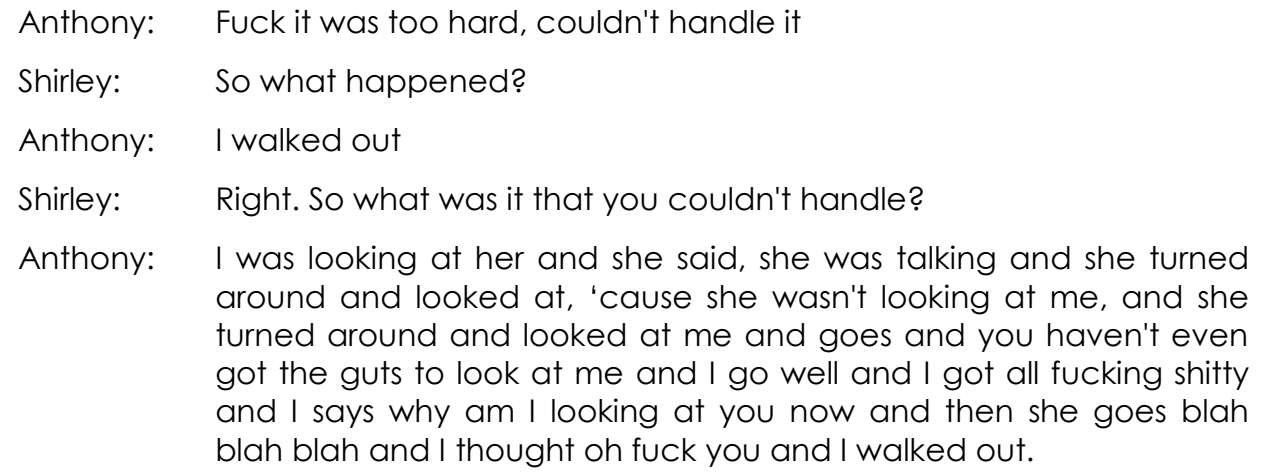

In this excerpt Anthony positioned the victim's mother as being unfair to him and described himself as trying to cooperate, at least initially. It is possible to read Anthony's response of walking out as righteous anger at being treated unfairly, being victimised by the system that he claimed allowed such abuse to occur. Thus, he positioned himself as being reasonable in expecting to be treated with fairness and respect. The contradiction to the subject position as a dangerous young man who inflicted harm on others through his violence stands out sharply and highlights the multiplicity of subjectivities in which he experienced himself. Walking out of the Family Group Conference, even though the presence of authority figures was extensive, can be read as an agentic response by Anthony that reflects the dominant discourses around traditional masculinity of taking control, not just of his emotions but also of the situation.

I received a similar response from Sean about Family Group Conferences, "No I hate them. No. They're a load of bullshit". He talked of experiencing a difficult time at his Family Group Conference and described it as "one of the hardest days in my life really," as those in attendance talked about his offences for three and a half hours in a small room:

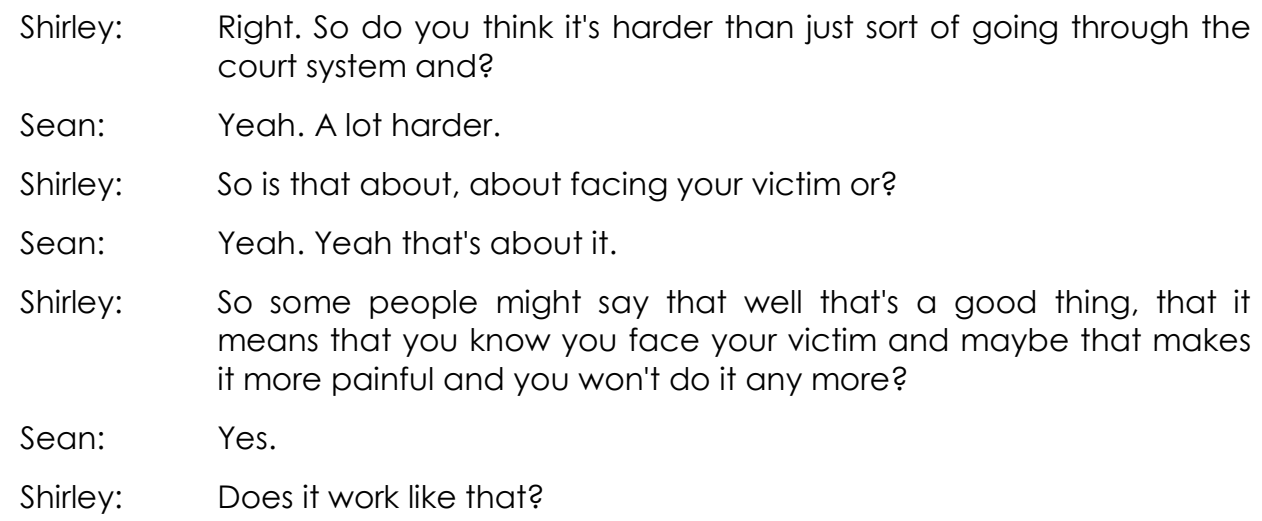


Sean: I reckon it's more so they know who you are and they can put you down, that's about it really, that's what they done and have the ... [unclear] scare the shit out of me. Abuse me and that's about it really. Yeah Mm.

Both Anthony and Sean can be read as constructing the Family Group Conferences as abusive. ${ }^{18}$ However, it is also possible to consider their negative experiences as justifiable from a punishment perspective. Feeling abused may raise the issue of a possible risk that young offenders may retaliate against members of the conference as Sean proposed: "They could get angry with the person and actually go do aggro robbery against them. Yeah". If offenders experience an Family Group Conference as abusive, then it is possible to view the Family Group Conference as unsuccessful and not achieving its aim of being restorative.

Family Group Conferences were also seen as failing in other ways. Rick, for example, engaged in a large number of violent and criminal activities over a period of time. But he reasoned that because his corresponding Family Group Conferences were spread out over time there was no realisation by authorities of the amount of crime he had committed and so he was not locked up. In the justice system the level of seriousness an offender represents is constructed as being determined in part by the frequency of his offending. It appeared that the Family Group Conferencing system missed the extent of Rick's activities.

Unlike Anthony and Sean, Drew did not talk of his experiences of Family Group Conferences as being difficult or negative. Rather he saw them as a way of trying to help him and "to sort out my punishment". Unlike Rick, Drew did not consider light punishments given by Family Group Conferences as appropriate:

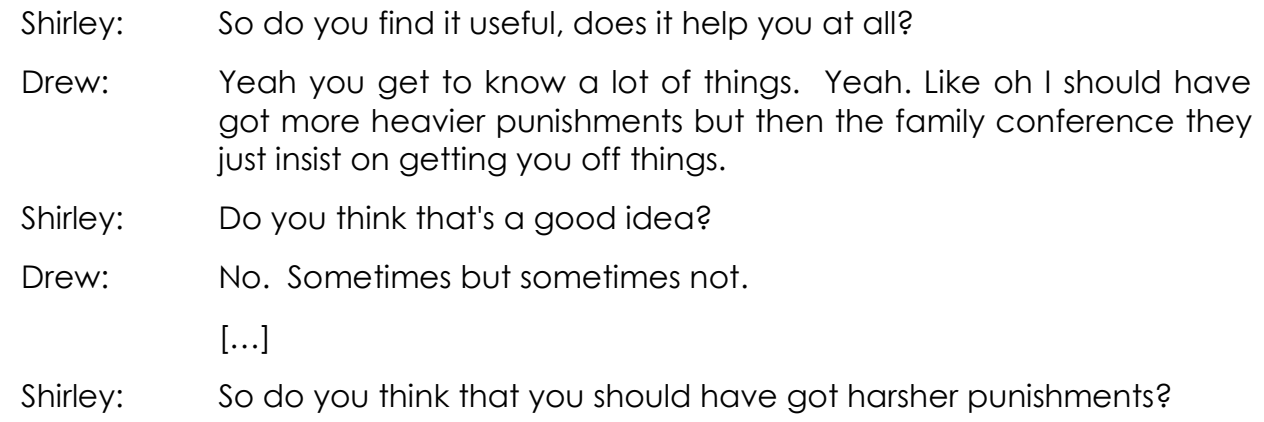

${ }^{18}$ Restorative justice conferences are not designed for this purpose. Part of the role of the facilitator is to prevent any abuse between the parties (Raye \& Warner Roberts, 2007). 
Drew: $\quad$ Yeah. I think, this is my first time actually being punished good.

[...]

Drew: $\quad$ Yeah, I'm glad I came here now.

Shirley: How come?

Drew: It's changed me. So if I stayed in youth court I would have got three months at ... [name of secure facility] got out and done, done some more crime and came to gaol, in a proper gaol.

In the excerpt above Drew offered a surprisingly different perspective on how Family Group Conferences failed him. He suggested that they downplayed his crimes when he said, "they just insist on getting you off things". He saw his current prison sentence as his, "first time actually being punished good". He claimed that this sentence was the result of going to the district court rather than youth court with its associated option of an Family Group Conference. Drew's reasoning for being "glad I came here" was that he saw himself doing more crime if he was not locked up for longer than just "three months". It is possible to position Drew as being out of control and needing containment to stop him doing crime. This fits with his earlier comments in the previous chapter where he constructed doing crime as being like an addiction for him.

However, the Family Group Conference does not always fail in its purpose, as perceived by these young men. When Sean continued to describe his experience, he acknowledged that hearing about the impact of his violence directly from his victims made an impression on him:

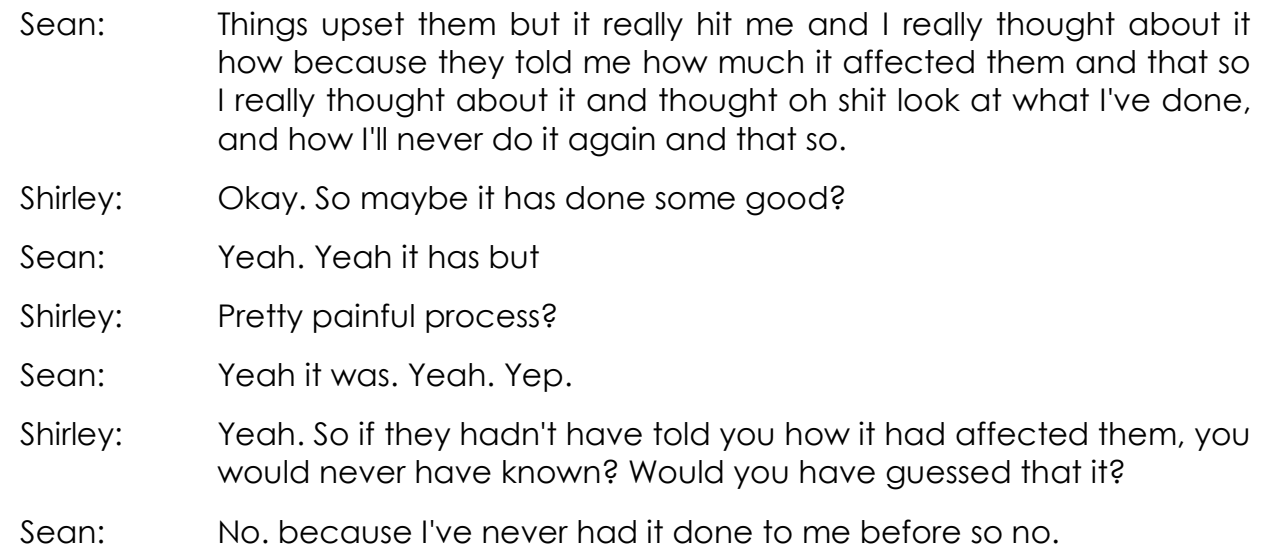
how because they told me how much it affected them and that so I really thought about it and thought oh shit look at what I've done, and how l'll never do it again and that so.

Shirley: $\quad$ Okay. So maybe it has done some good?

Sean: $\quad$ Yeah. Yeah it has but

Shirley: $\quad$ Pretty painful process?

Sean: $\quad$ Yeah it was. Yeah. Yep.

Shirley: $\quad$ Yeah. So if they hadn't have told you how it had affected them, you would never have known? Would you have guessed that it?

Sean: $\quad$ No. because I've never had it done to me before so no.

It seemed that despite Sean feeling abused by the process, the Family Group Conference was successful in that he heard how he had affected his victims, "I really thought about it". It is possible that he may have connected emotionally to the harm 
that he had caused, given his comment: "oh shit look at what I've done". Empathic connection and demonstration of remorse are among the aims that Family Group Conferences are designed to achieve (Raye \& Warner Roberts, 2007). According to some dominant learning theories, youth violence occurs because of a lack of victim empathy. This intervention relies on the impact of hearing a victim's story. It is thought that the perpetrator of violence may acknowledge the harm they caused, develop empathy and feelings of remorse and so be less likely to engage in future violence. Sean pointed out the importance of hearing the victim's story directly because the ability to know about the impact on a victim could only come from being told; it was not possible to guess for Sean: "because I've never had it done to me before".

While having young offenders demonstrate remorse may be an aim for intervention, such displays are not always accepted, as Sean found when he apologised to his victims at his Family Group Conference:

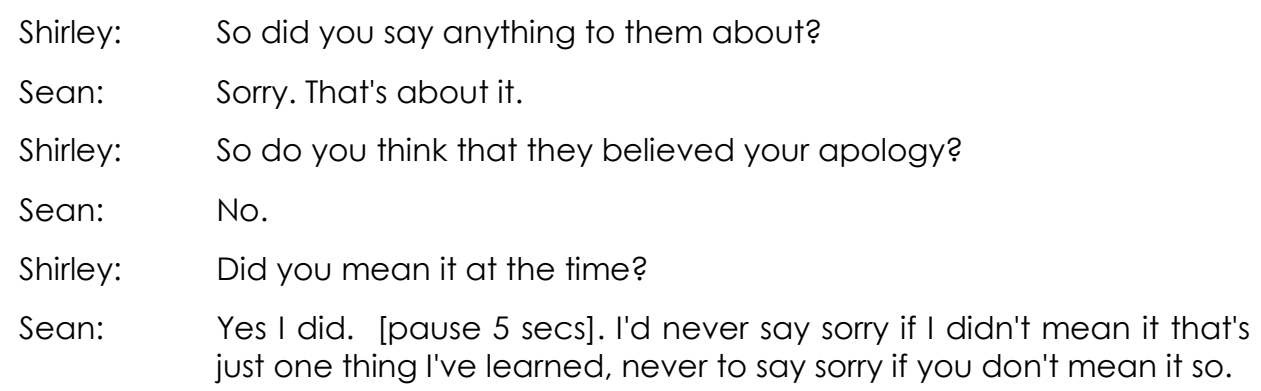

In dominant discourses around justice and offending, evidence of remorse is often used as a indicator of regret and contrition and is frequently considered an important factor by institutional authorities when deciding outcomes, for example, sentencing. It seemed that demonstrations of remorse required acknowledgment for its usefulness to be effective for young offenders.

\section{Family visits}

When it came to talking about the help they had received, participants again mentioned the importance of having family support. Having weekly or monthly visits from their family whilst inside the secure facilities was particularly significant for participants, and enabled them to better manage the stress of being inside, "it sort of keeps a lot off your mind" (Rick). 
But not everyone was so fortunate. Kelly said, "I just feel sorry" for those residents/inmates who did not have any family visiting:

Shirley: $\quad$ So how do you think they'd feel?

Kelly: I reckon they probably feel lonely without their parents. I couldn't imagine myself being without my parents for a long period of time.

No visits from family members can be read as isolating, positioning the young men as disowned. Given that the dominant discourse about the family constructs it as the site where love, trust, nurturance and support are provided, being disowned can have a powerfully negative effect. For those who do get visits, they can at least possibly still experience a sense of belonging. However, 'getting it right as a son' in this discourse is already threatened by being incarcerated because of their violence, and no visits from their family could be read as further evidence of their failure as a son and as no longer belonging.

Family visits are regulated and controlled by justice institutions. Drew talked of the frustration he experienced when he had to have visits with his mother in a booth with glass between them instead of the usual full contact visit. Being restricted to booth visits was a consequence of Drew being caught and charged for using drugs inside:

Drew: I don't like having them. Talking, talking of things and you can't, it's just the glass that's in front of you and just makes it, makes the prison stink so I, I haven't had no visits here on booth visits.

Drew can be read as referring to the importance of not having physical barriers between him and his mother, which constructs the booth visit as an alien form of human contact. He chose to have no visits rather than a booth visit that he did not like. If a learning perspective is applied to this situation, one thing these young men could learn is that not allowing physical contact with those important to them is a powerful way to control people and to disrespect and dehumanise them. For those inmates who go on to commit further violence they may apply this learning against their future victims. While such learning may not be intended, it is nevertheless a possible interpretation that can be put on these events. The techniques of regulation that are used to contain, manage and control young men who have been violent in a secure environment do not enable human relationships to thrive. 
Family visits are part of the institution's methods of offender management where a reward and punishment system is used, based on the learning principles and concepts of behavioural control and modification. Family visits are relatively infrequent once a week or once a month. Such infrequency keeps families away from these young men and cannot assist a family's ability to provide support and boundaries, or to nurture and care for them. Nor can a family be actively involved in what may be constructed as therapeutic intervention with these young men. While this situation may seem at odds with therapeutic approaches, including the emphasis of family work, paradoxically it is consistent with the discourses around 'dysfunctional' families being the cause of youth violence, in which effective intervention is taking the young man out of the family. The system of disciplining offenders within secure facilities can also be constructed as effective intervention, which becomes more evident in the next section where I look at how participants' lives are managed inside the secure facilities.

\section{Offender Management Inside}

While there were differences between the Corrections youth units and the Child, Youth and Family secure residences, many of the offender management practices were the same. Both utilised systems based on controlling the resident population rather than establishing a therapeutic environment aimed at exploring and resolving the issues relevant to these young men's violence.

\section{Daily routine for managing youth}

The level of control exercised by the offender management systems over the young men was extensive. It ordered every aspect of their day. The participants went into great detail about these daily routines. They could tell me precisely what they had to do at what time every day, from the time they were woken in the morning, to when they had showers, school times, meal times, when they were "locked down" (Rick) in their cells/rooms - and bedtimes. Some variation to the routine occurred on the weekends.

Foucault referred to this type of regulation as part of the disciplinary practices designed to produce a docile body (1975/1977). Such regulation is not unusual for 
any institutional settings: the same types of routine can be found elsewhere, for example, in schools and hospitals. However, the difference for the participants of this study is that their routine is associated with a loss of freedom characterised by locked doors. Besides producing disciplined subjects, these regulatory practices are also constructed as being designed to meet the needs of the institution in terms of efficient staffing and administrative functions.

The high level of ordered activity certainly kept the young men to a tight daily schedule. Such practices may be justified according to learning principles in which a highly structured environment is often thought to be a way of gaining control over 'disordered' behaviour, such as violence (Domjan, 2006).

Having a routine can be constructed as being active, which in turn is viewed as a solution in preventing boredom. Such prevention is an important issue because boredom is constructed as a state of mind requiring a person to exercise coping strategies to avoid it leading to violence (Johnson, 2007). However, the daily routine itself appeared to contribute to participants feeling bored inside, "every day in here is pretty repetitive deja vu" (Wade). If punishment is a part of the intention of locking up young men who have been violent, then the inescapable boredom can be read as partially fulfilling this purpose; but if rehabilitation is the intention, there appeared to be few opportunities for these young men to develop helpful ways of responding to boredom.

Having some enforced time alone in their cell/room during "lock down" each day seemed to contradict the rationale for having a highly structured, active day and also created boredom, as Anthony describes:

Anthony: Fuck, the only thing I hate is going upstairs, sitting in your room 'cause you've got to sit there for ages and there's nothing to do.

Lashley (2003) wrote that adult women in prison used this time to reflect on what they had done. She claimed that this was the start of them making positive changes in their lives. However, such a reflective process does not seem to be what these young men engaged in during this time, as Anthony suggested that "I just try to go to sleep (small chuckle)". Without some instruction or skills, hoping for some reflection on their violence to occur spontaneously can be read as an unhelpful covert purpose of 
"lock down" that seemed unlikely to succeed. But for these young men, within discourses around traditional masculinity an admission of such an internal, reflective process may not be considered 'manly'. In addition, it is difficult to see how these young men could view "lock down" in a positive light, given that within discourses of punishment and torture the practice of placing prisoners into solitary confinement is constructed as a common but severe form of punishment.

Even though participants found the highly structured day tedious, some also spoke of positive benefits, such as time going faster because of the routine. In addition, one participant hoped that after having learned a routine, he might be able to sustain this new pattern of behaviour, of waking early, doing more activity in the daytime and going to bed early upon release. In this way, subjects of such disciplinary practices regulate themselves to become the docile body of 'good citizens' (Foucault, 1975/1977).

Some participants constructed elements of their experience of being incarcerated and subjected to these disciplinary practices as beneficial. While Anthony saw one advantage of being inside was that "you've always got a roof over your head", Drew went further in his praise of the specific unit he was currently in when he compared it to a more controlled unit he had been in previously. He did not speak negatively about being inside.

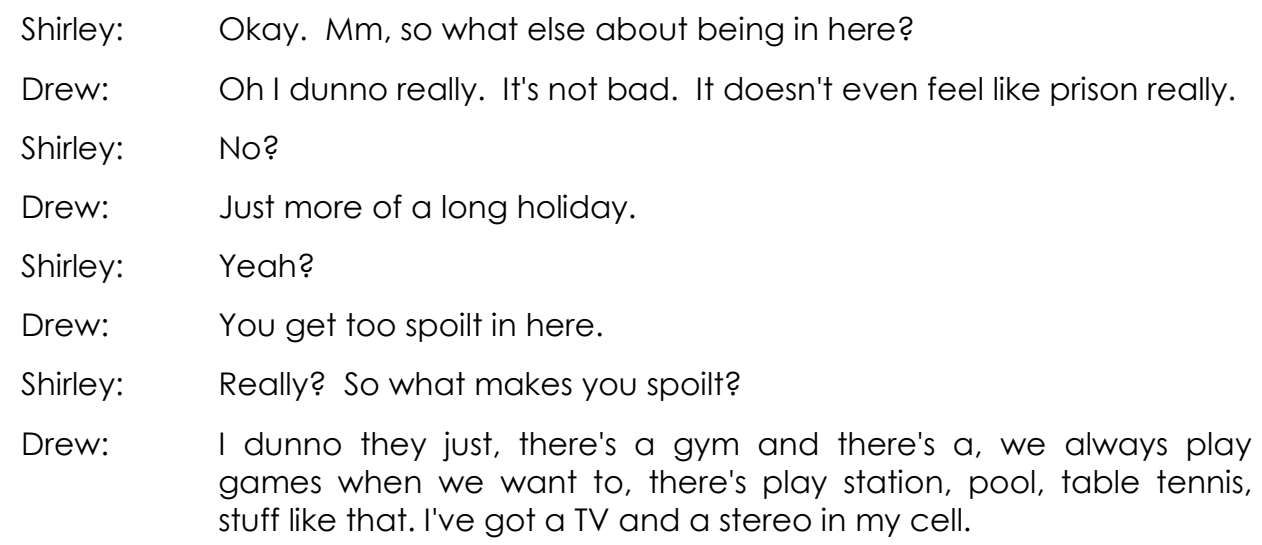

Drew was the only participant that told me he had a TV and stereo in his cell. His description of prison being like a holiday camp is a discourse that is often heard expressed in public arenas where the implication is that prison provides a more comfortable lifestyle than that which inmates have on the outside. It is implied that 
comfortable prisons are an ineffective deterrent because offenders are believed to want to be housed in these comfortable environments, so they commit crime in order to be locked up. From such a perspective, the concept that a loss of freedom alone is sufficient punishment is not considered; instead, the prison environment is seen as the vehicle to provide punishment (Muncie, 2006). Prisons are viewed as places that should be hard for inmates, places of deprivation and unpleasantness and such a punishing environment is believed to act as a deterrent for crime and violence. Prisons are also constructed as places of control and the regulatory practices used go beyond establishing strict routines; there are also systems of rewards and punishments that discipline.

\section{Reward and punishment systems}

As well as being managed and controlled through having a highly structured daily routine, participants were also subjected to systems of reward and punishment based on classic learning methods. From an objectivist psychological perspective, behavioural management and modification are considered legitimate forms of therapeutic intervention (Domjan, 2006).

Regardless of whether participants were in a Corrections youth unit or a Child, Youth and Family residence, the reward and punishment systems were very similar and the participants were able to provide me with a great deal of detail on how these worked. Inmates would be assigned either a colour or a numbered level, that would be based on staff's judgement of their behaviour. Each day, points would be gained for positive behaviour and lost for negative behaviour. At the end of the week, the results would be totalled and either a reward or a punishment would be given that was associated with the colour or level reached.

Most of the rewards seemed to revolve around receiving extensions to the daily routine, for example, having a later bedtime or being able to engage in a favoured activity, such as watching television or having access to a play station game. These activities that were considered to be privileges inside are generally viewed as being very ordinary and everyday on the outside. 
In this system, punishments were often a loss of these types of privileges. However, punishments were also meted out instantly, such as time-out when highly unacceptable behaviour occurred. Indeed, if a young man had received a punishment during the week, that would also be counted against him in this system. For example, because of regular drug testing Drew was charged with using drugs. Having a charge meant that he could not achieve a higher level regardless of his behaviour.

Kelly explained the types of behaviour that were expected for each colour, which was similar to the level system:

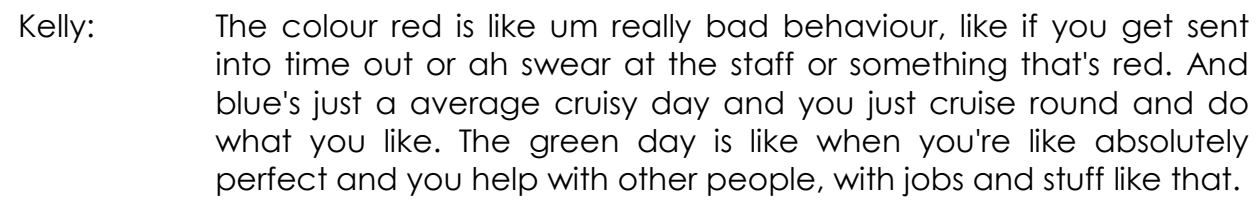
into time out or ah swear at the staff or something that's red. And blue's just a average cruisy day and you just cruise round and do what you like. The green day is like when you're like absolutely perfect and you help with other people, with jobs and stuff like that.

From Kelly's description, it appeared that blue was the usual or average type of behaviour, that is neither unusually 'good' nor negative, "just a average cruisy day". The colour blue equated to level 3 in the other system that most inmates were judged to be at "usually everyone's Level 3" (Drew).

However, this is not the type of behaviour this system seemed to be aiming for; rather, it is the exceptionally good behaviour of 'green' or Level 4 that was idealised. Such behaviour is at the extreme end of what is considered to be prosocial, as Kelly described it, "when you're like absolutely perfect and you help with other people". The hope that these young men will adopt such behaviours as their standard way of being in the world does not seem to fit the subject position of youth. In the dominant discourses of youth, young men are positioned as testing boundaries, questioning authority, developing individuality and independence, all attributes that are considered as positive and necessary for successful development. Therefore some behaviour that is read as 'bad' is expected to be performed (Laws, 2001). Sustaining such positive behaviour over an extended period of time would seem to be challenging for most young men.

At the same time "absolutely perfect" behaviour would not seem to constitute manliness. Instead, within dominant discourses around masculinity being a man is frequently about performing 'bad' behaviour, as we saw in the last chapter where 
participants talked of fighting as a way to make friends and where they described the existence of the inmate hierarchy, which was based on violence.

Kelly's example of behaviour that would be labelled as 'bad', which would receive a red, such as getting "sent into time out or ah swear at the staff", appears to be relatively minor compared with the violent offences that led these participants to be incarcerated. It is possible that precisely the same behaviours may be tolerated more in different settings, for example, in the home or in school. But one way of reading such behaviour is to see it as the beginning of losing control or getting angry, both of which are associated with expressive violence. Hence these behaviours such as 'swearing' may be constructed as being more serious for these young men; like a symptom of their 'abnormality/disorder' within discourses of pathology. Such systems of rewards and punishments are based on a dichotomy of 'good' and 'bad' behaviour, attitudes and morals by which what is judged as 'bad' becomes defined as not reaching the standard described as 'good'. According to Foucault (1975/1977), in this way disciplinary power is constituted through the use of surveillance, observation and the development of norms of 'good' behaviour.

For any reward and punishment system to work, there is an expectation that those subjected to it would be learning how to behave in a way that would achieve the rewards (Domjan, 2006). Interestingly, Quentin was surprised that his behaviour was judged as being 'good' enough to receive greens most of the time but he did not know how he achieved this:

Quentin: I don't know really eh. I'm just - it just happens. 'Cause first day tried
really hard and the second day I tried really hard and the third day I
tried really hard, and now I don't even have to try, just, just, the
greens just flow in. The green is just there everyday. I don't know how
it is eh, (small chuckle) wake up in the morning I'll go shit another
green [laugh]. I'm expecting to get a blue but it's green.

Quentin's experience seemed to be at odds with the theoretical purpose of the reward system. He did not demonstrate any learning, "I don't know how it is eh, (small chuckle)", nor any changes in his behaviour; however, he had "tried really hard". Even if he did not know how, Quentin clearly had the ability to 'behave' in an acceptable way. The disciplinary power of the regime is evident here, Quentin has been subjected to the normalising effect of being constantly judged and observed. 
The extent to which these reward and punishment systems can be claimed as therapeutic rather than as a system of surveillance designed to maintain control is questionable. In New Zealand, a legal challenge to this type of offender management was successful, finding that what was considered a psychological programme, (the Behaviour Management Regime) by an Auckland prison had in fact breached the civil rights of prisoners (Ministry of Justice, 2005). Until such practices are challenged in this way, it seems that Foucault's (1975/1977) claim that "punishment will be able to function openly as treatment" (p. 256) will continue.

Offender management systems, such as the structured daily routine and the reward and punishment systems, constitute a high level of surveillance of these young men. Yet, despite this, participants still became involved in violent activities inside, for example, fighting, they also engaged in illegal activity, such as using drugs, and broke the institutions' rules by smoking cigarettes. Such surveillance increased the possibility that all their behaviour, motivations and attitudes will be read according to their violent and criminal history. Therefore the same behaviour that young men engage in outside prison, that is not even noticed by others, for example, smoking cigarettes, is seen as deviant by the institutional authorities because it is against the rules, positioning these young men as problematic rule-breakers and delinquents. According to Foucault (1975/1977) "the prison cannot fail to produce delinquents" (p. 266). He argued that the "penitentiary apparatus" (p. 251) does not have an interest in the 'offender' or the offence that is constituted by the judicial system, since this has already been adjudicated. Instead, the role of the corrective technology of secure facilities is the "delinquent life", that is, it is the person that needs correcting.

\section{Secure facilities as hyper-masculine environments}

The surveillance and scrutiny of these young men does not only occur through the structured, official offender management systems. The environments these young men are contained within can be constructed as hyper-masculine, competitive ones in which the dominant discourses of manliness determine practices that (re)produce the 'macho' male position (Jewkes, 2005), for example, the male hierarchy inside and the amount of fighting that participants spoke of. Other practices also produced 
similar effects. The existence of gyms was common in these environments and Drew described this as a heroic physical subjectivity:

Drew: $\quad$ Plus my strength has got stronger too like when I first came here went up to the gym and I was pumping about 50 or 60 on the bench press and now, and I'd do ten sets of that and that was struggling. And now I can do 100 to 120.

Attention to improving or maintaining the health of residents/inmates by providing a gym can be viewed as an effective practice. However, the types of equipment and most of the activity appeared to be centred around strength training - lifting weights and building muscle size - which focuses again on supporting and maintaining a traditional form of masculinity. As Drew mentioned above, the gym scene takes on a competitive aspect amongst inmates by focusing attention on who can lift the heaviest weight. For those young men who can not achieve well in this type of 'being a man' competition, their positioning in the population becomes marginal, but maintains the male pecking order that is based on strength, size and the ability to be violent (Jewkes, 2005).

Another example of masculinisation practices inside the secure facilities became apparent at one unit where they held a competition for the Toughest Inmate. This competition consisted of a range of physical activities, such as running, doing pushups and sit-ups, and lifting weights. The inmate who continued for the longest time was the winner, or as Sean described it,

Sean: Oh Toughest Inmate, for life that's about it. About fitness and stamina you know.

Within manliness discourses sport and physical fitness activities are constructed as being highly commended ways for young men to stay away from crime and violence. Hence a competition that focuses on such physical abilities and stamina could be viewed as a positive intervention from this perspective.

While some of the participants enjoyed the competition immensely, one participant chose to do his interview at a specific time so as to avoid being in the competition. Besides having a dislike for that sort of activity, I could also understand how such a competition that is based on dominant discourses of traditional manhood could be potentially risky for some young men who may not be as able as others to measure 
up to the masculine ideal at which such a competition aims. The risk of not being able to perform 'man' correctly in a prison environment where fighting and violence amongst inmates are common would be particularly challenging. The Toughest Inmate Competition then could set up some inmates to fail as men in an environment that has the potential for serious repercussions, most likely of further violence to them.

The competition also highlighted a contradiction within the incarceration system. I was first made aware of this competition when staff apologised to me in case I heard them swearing. This was explained to me as an important part of the competition since, as they said, it was based on Navy Seal training, and loud verbal derogatory statements (including swearing) would be used by staff to goad the inmates into sustained effort. My reading of this approach is that such disparaging statements that aim to motivate by producing anger can be constructed as abusive and violent. It is interesting that such behaviour from staff should be institutionally sanctioned when it condones the very behaviour that these young men receive demerit points for under the internal reward and punishment systems.

\section{Experience with Therapeutic Intervention Programmes}

When it came to receiving help, in addition to such occasional activities as the Toughest Inmate Competition, participants spoke of the practical help they received from staff that they found very useful. This primarily involved obtaining items for participants: "got me some pants" (Quentin) and assisting with exploring new career choices and helping "me get into courses" (Kelly). Participants also had access to a number of programmes within the secure facilities. Educational programmes appeared to predominate in which they could undertake schooling or other skillsbased courses like woodwork that participants hoped could lead to better employment options in the future, as Rick described:

Rick: $\quad$ Yeah it would be good to get a higher paying job sort of, [pause 3 secs] school cert yeah. I think it's quite essential to have really.

My primary interest, however, was in participants' experiences of being involved in therapeutic programmes and intervention strategies designed to respond to their 
violence. Given that participants had little access to such intervention inside I canvassed their previous intervention experiences as well. These intervention experiences of participants were most often in group programmes. There is an interesting contradiction between normative ideas about the role peers are thought to play in youth violence and the interventions that are employed. The negative influence of peer pressure is believed to be a direct cause of youth violence. Yet, in many therapeutic intervention programmes, the use of peer groups is extensive (Frances, 1995; Gibbs et al., 1995; Goldstein \& Glick, 1994; Grant, 2000; Lutzker, 2006). It would seem that the same dynamic, that is, the influence of peers, is employed in these group interventions to achieve positive outcomes.

\section{Adventure programme}

Drew described attending an adventure programme that was based on a range of outdoor activities that he had completed some time before his current convictions and imprisonment. He was very enthusiastic about the programme because he had enjoyed it immensely. The types of activities done in a group with other young offenders included, "rock climbing and we done canoeing, bush survival skills", going to the gym and "cutting wood and helping shear the sheep". School was only for three hours per day, four days a week and Drew had an individual worker who would take him "surfing" and "skateboarding". Drew showed insight into the purpose of the programme, that is, it was to prevent re-offending:

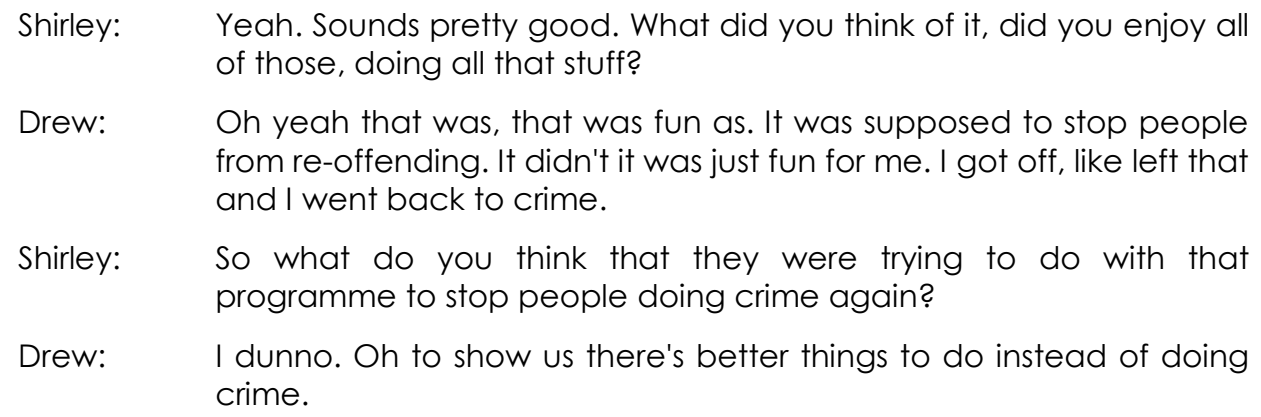

Although the aim of this adventure programme was not met, that is, preventing reoffending, it is easy to see that Drew enjoyed the programme and he wanted it to be longer: "they need to go for longer, I think about six months or something. Two months wasn't long enough". What Drew described appeared to be activities that are about performing 'man' correctly according to dominant notions of manliness, 
typically risk-taking and adrenalin-producing activities. Since much of the violence and crime in which participants have been involved in has enabled them to 'get it right as a man' (as discussed in Chapter Five), adventure-type intervention programmes do not appear to offer these young men an alternative positioning to the 'macho' man within discourses of traditional masculinity.

Drew goes on to describe how he continued to pursue these types of activities that he enjoyed so much. Unfortunately, it seemed that economic pressures were part of his reasons that led him back into crime and violence:

$\begin{array}{ll}\text { Drew: } & \text { Ah yeah I still kept going to the beach. I went to the beach 'cause I } \\ & \text { was surfing, I was keen. But I dunno what I did, oh yeah I went to - } \\ & \text { we used to go, me and my mate, used to go down to the ... [name } \\ \text { of business omitted] a lot, paintball shooting. But then we'd have to } \\ \text { do crime to get the cash [chuckle] 'cause that was expensive. }\end{array}$

Drew's reasoning can be read as very rational as he explained that in order to get involved in non-criminal fun activities, "paintball shooting" and the "A and P show", he had to do crime and violence to obtain sufficient money, "we'd have to do crime to get the cash [chuckle] 'cause that was expensive". I found the idea perplexing that a young man would do crime in order to undertake activities that he was taught in an intervention programme to enjoy as a substitute for crime and violence. Drew can be read as demonstrating a sense of entitlement to do these activities, which unfortunately many people cannot afford to do. While programmes like the one Drew attended may have other aims, such as team-building, developing trust and selfesteem, among others; Drew has constructed the focus as having fun all the time. But such a life-style would seem difficult to sustain and does not reflect the reality of most people's lives. 


\section{Anger management}

By far the most common therapeutic intervention experience for participants was attending anger management courses, which they judged as being somewhat successful. Rick talked of being able to control his anger better by using a technique he had learnt:

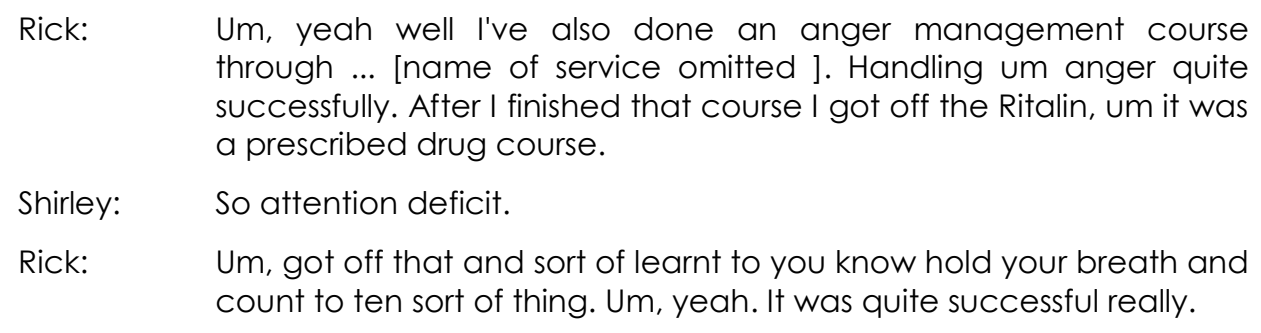
through ... [name of service omitted ]. Handling um anger quite successfully. After I finished that course I got off the Ritalin, um it was a prescribed drug course.

Shirley: $\quad$ So attention deficit.

Rick: $\quad$ Um, got off that and sort of learnt to you know hold your breath and count to ten sort of thing. Um, yeah. It was quite successful really.

Anthony too found that an anger management course helped him with his "attitude":

Anthony: I thought it was all right, it did make me calm down heaps 'cause I used to get real angry eh [small chuckle].

Anger is frequently constructed as a negative emotion that if not controlled will lead to violence. The experience of anger is often constructed as the cause of anger, that is, "I'm angry because I feel angry". Hence, it is a tautology that does not acknowledge anger as an emotion that, when expressed, does not have to lead to negative outcomes. Because of this construction of anger needing to be controlled, the intervention focus is on 'management', which offered specific techniques of control (Gibbs et al., 1995) such as what Rick learnt: to "hold your breath and count to ten", rather than an exploration of anger as an emotion, much like other emotions, such as sadness or happiness. Emotion and its exploration for men has a limited place within notions of traditional masculinity as I have discussed previously in Chapter Five. However, anger appears to be the most legitimate emotion for men to express as it is so closely entwined with getting the subject position of 'man' right (Connell, 1995). Hence, from this perspective, intervention that suggests an alternative view of anger as an emotion to be reflected upon and that its expression could be done safely may well be received by young men as nonsensical for them.

\section{The EQUIP programme for delinquent youth}

The one group intervention programme that many of the participants had access to inside was the EQUIP programme (slightly modified for the New Zealand context). 
This programme was designed specifically for 'delinquent' and 'aggressive' youth. It is based on a cognitive-behavioural approach that focuses on the development of prosocial skills and a positive peer-culture.

Sean talked of how his learning in this programme helped him control his anger and to interact with others, suggesting this programme had some relevance for him:

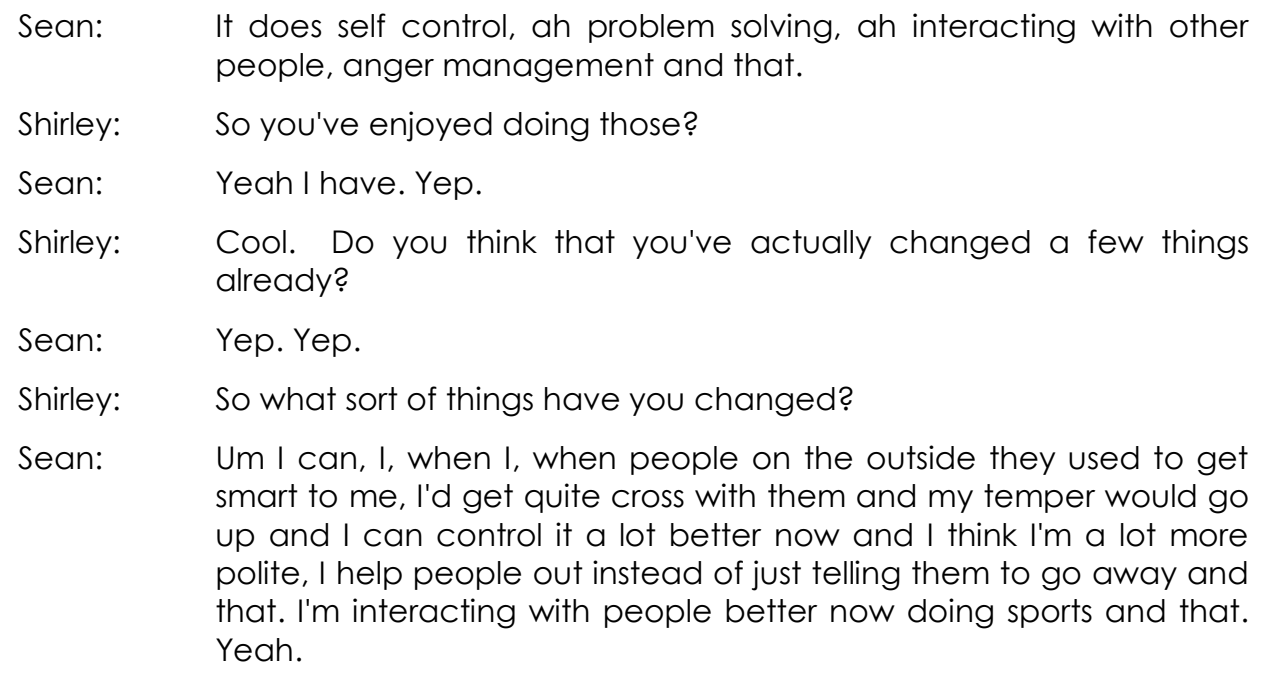

Wade, on the other hand, did not find EQUIP relevant:

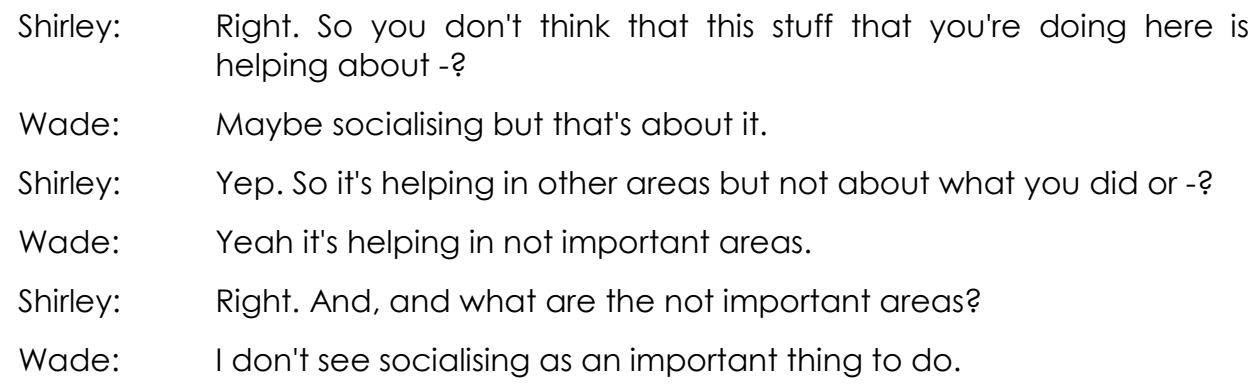

EQUIP is an example of an intervention that has been established on the theoretical learning basis that young men are violent because they are deficit in prosocial skills, which is a situation thought to result from being raised within a 'dysfunctional' family. But while Wade pointed out that the programme was successful in teaching "socialising", he did not consider "socialising as an important thing to do". Wade's evaluation suggested that it was difficult for him to determine the relevance socialising had in preventing future violence. In contrast, although not directly relevant to violence, Sean made the connection that he was "a lot more polite" and "I help people out instead of just telling them to go away" as a result of EQUIP. 
Although Wade picked up on the purpose of the programme, "socialising", he can be read as not having understood the connection between this skills deficit and his violence. This can potentially position him as not having the relevant knowledge to make the necessary conceptual links to understand that developing social skills is seen as preventing future violence. Hence, an additional educational component may be seen as a necessary part of the role of intervention. Even though it is possible to be positioned by theories of mainstream psychology as not being responsible for growing up in an environment that did not adequately teach the necessary prosocial skills (O'Neill, 1998), Wade is made responsible for the success of the intervention. For this approach, he needs to learn the skills to prevent future violence.

However, as Phillips (2006) suggests, socialisation theory and cognitive-behavioural theory are used to 'de-gender and re-educate men deemed 'deviant' to more appropriate behavior" and that "dangerous men, presumably, can be de-gendered away from violent masculine behaviors and re-gendered more like women (presumed not dangerous)" (p. 415). Such attempts are not likely to be successful against powerful, dominant discourses around hegemonic masculinity since the dominant discourses are not necessarily disrupted by such intervention, rather, additional practices become absorbed into accepted notions of ideal manliness. Whether "degendering" is even a possibility must also be considered given that normative notions of masculinities are based on definitions of 'man' being 'not woman' and further, hegemonic masculinity is constructed on the basis of expelling homosexuality.

\section{Offence-focused intervention}

Even though EQUIP was designed for use with young men like the participants, none of the participants talked of the programme as being offence-focused, that is, it did not explore or focus directly on what they had actually done, nor on its effects, such as the harm their violence caused victims. Anthony was the only participant who spoke of having attending such an offence-focused programme in the past. $\mathrm{He}$ described it as providing him with insight into his pattern of offending:

\footnotetext{
Anthony: That's like, it's like challenging offending sort of. I can't, Oh working out why you done the crime, why you know just, yeah, how you done it, why you done it. [Noise of playing with drink container].

Shirley: $\quad$ So have you worked that out?
} 


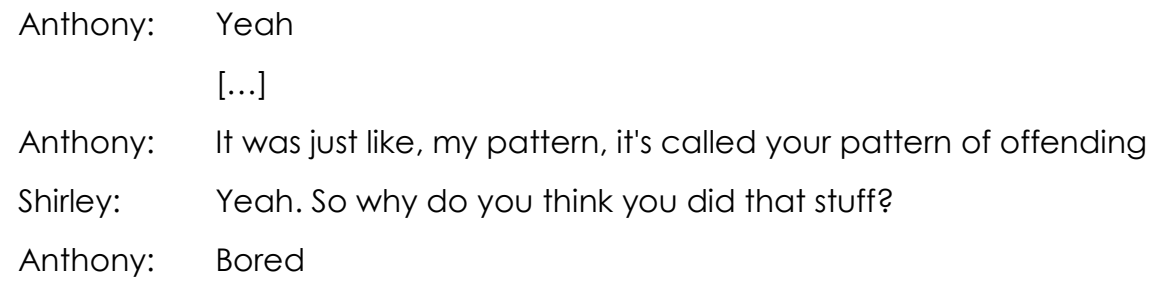

Anthony identified that his "pattern of offending" was caused by being "bored". Despite having developed this insight, this did not prevent him from committing the violence that was responsible for his being locked up. At the time of the interview Anthony did not have any strategies for dealing with his boredom. When I asked him what he did now when he was bored he answered: "Well when I'm with my boss I never seem to get bored". Nor did he consider the offence-focused programme he had attended to have any relevance for his current violence "Na cause it wasn't based on that". Anthony can be read as having developed an explanation of his previous offending after the fact, but he has not been able to make use of this knowledge to prevent committing further offending and violence.

The way in which participants have described the intervention programmes they have been involved with has demonstrated that while some aspects of these programmes have been found to be useful to participants, for those that were attended in the past there has been little success in preventing future violence. I now turn to the use of talking as intervention.

\section{Talking}

Talking can be thought of as the cornerstone of many therapies or interventions because communication is seen as the foundation to human relationships. According to some models, it is the therapeutic relationship that is considered to be the impetus to gain understanding, make changes, challenge beliefs and achieve other such therapeutic goals (Hubble et al., 1999). I was interested in examining participants' ideas and experiences of various forms of talking, but particularly talking that is constructed as therapeutic.

Some participants spoke of the benefits they found in talking, including the importance it played in their relationships with family and friends. Participants also 
described their experiences of talking in group settings. However, most spoke of their dislike for and disinterest in the therapeutic talk of counselling.

\section{Just talking is valued}

Some dominant constructions of youth that are commonly understood position young men as not particularly interested in talking about personal issues and as primarily interested in talking only to their peers. In contrast, most participants described that they valued talking as a way of enhancing their relationships with friends and family. Indeed, Drew pinpointed the ability to talk with his mother as a gauge of success in their relationship:

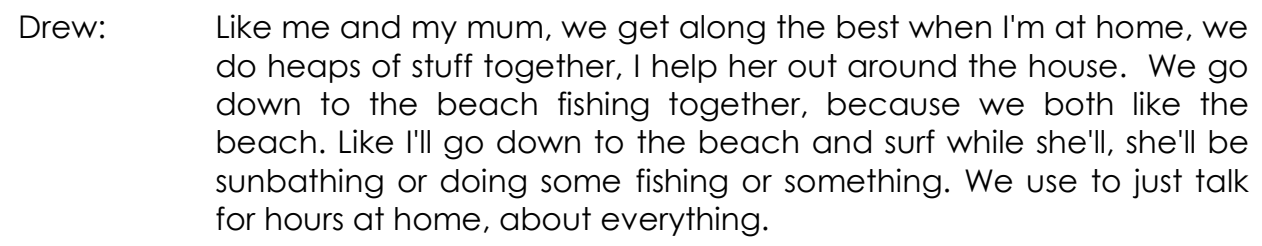

In trying to deal with his parents' disappointment in him as a result of his violence, Kelly found talking with staff and inmates helpful:

\begin{tabular}{|c|c|}
\hline elly: & {$[\ldots]$} \\
\hline Shirley: & So how did you deal with that? How did you manage that? \\
\hline Kelly: & $\begin{array}{l}\text { Um. I just talked to my case worker, ... [name of worker omitted], } \\
\text { and um talk to people that I trust that were in here and um just told } \\
\text { them how I was feeling and stuff and they just used to sit down and } \\
\text { talk it over. }\end{array}$ \\
\hline Shirley: & Just talking about it helped? \\
\hline Kelly: & Yeah. \\
\hline Shirley: & Did you get any sort of good advice from people that helped you? \\
\hline Kelly: & $\begin{array}{l}\text { Um, [pause } 4 \text { secs] no not really. They were just telling me to just } \\
\text { keep my wits about me and just forget about the past and get on } \\
\text { with the future. }\end{array}$ \\
\hline
\end{tabular}

Clearly, talking was something Kelly was comfortable with, judging from the comments above. Within dominant notions of manliness, talking about feelings, "how I was feeling and stuff", would position Kelly negatively, as not manly, but he did not hesitate to mention this. At the same time, the advice given that he judged as useful, "just forget about the past and get on with the future", can be read as traditionally masculine. Leaving the past behind and not considering one's history is a highly rational approach to take, which is constructed as dealing effectively with 
the past and to relieve it of consequences. Such a stance would allow someone to make a statement such as, "I won't do it again", and believe that is all they need to do.

While most of the conversations that participants described having with friends, staff and family did not discuss the young men's violence, Drew and his mates, on the other hand, talked frankly about what they had done:

$\begin{array}{ll}\text { Shirley: } & \text { So if you were in a group um with other inmates and stuff do you } \\ & \text { think it would be okay to talk about what you did? } \\ \text { Drew: } & \text { Ah yeah. I've got a couple of good mates in here and we we talk } \\ \text { about that kind of stuff. Wish we never done it, eh. That kind of stuff } \\ \text { and we talk about how we, talked about how drugs and when we } \\ \text { first started getting into all that kind of stuff and what we were like } \\ \text { before that, before we got into that stuff. }\end{array}$

Although the talking that Drew described with his mates is not within a structured intervention setting, it nevertheless sounded similar to what would be considered useful in challenging their past behaviours and so the talk can be read as offering some therapeutic value. This seems to conflict with the notion that such young men need to be the subjects of formal intervention techniques because no other avenue exists to adequately address their violence. In addition, Drew's example above contradicts the commonly held expectation that violence is facilitated by talking about it, particularly in peer groups. Instead, the focus seemed to be the opposite of this: "Wish we never done it, eh".

When it came to talking about what they had done in the interview with me, most participants found some aspects difficult:

Shirley: $\quad$ So what's it been like for you talking about this stuff today?

Kelly: $\quad$ Um some parts about the crime was pretty hard because I can't remember much of what happened. Yeah. Yeah it's kind of shameful of myself.

Despite this difficulty that Kelly described, "kind of shameful of myself", talking about themselves and what they had done was generally viewed positively. Indeed, Drew even recommended that such talking as we had done in the interview should be a part of intervention programmes for young men who have been violent: 


\begin{tabular}{|c|c|}
\hline Shirley: & $\begin{array}{l}\text { Yeah. So if you were um like in charge of designing something to } \\
\text { help young people not do violence or not do crime, what do you } \\
\text { think would be - what would you do? }\end{array}$ \\
\hline Drew: & $\begin{array}{l}\text { Oh I dunno, probably a outdoor pursuits course or something and } \\
\text { also have like um a oh talking about yourself like how we're talking } \\
\text { now and all that kind of stuff. }\end{array}$ \\
\hline Shirley: & ink that would help? \\
\hline rep & \\
\hline
\end{tabular}

There is a general acceptance that young people prefer to talk to their peers rather than adults, and an intervention focus on peer support programmes has proliferated as a result, for example, Youth Line. However, while the participants spoke of the importance of talking with their friends, they went further. They have highlighted that they wanted to talk, that talk was important in developing good relationships and that talk with adults, including family members and even the research interview with me, was of significance to them.

\section{Not talking about their violence}

Despite the participants' desire to talk, when I asked them about how their violence was talked about within intervention programmes that aimed to prevent a recurrence of their violence, I was told that it was not covered. Across all the different programmes attended and individually with staff, participants did not talk about their violence at all, nor was it required. Even within the EQUIP programme their violence was not talked about:

\footnotetext{
Shirley: $\quad$ So in these programmes that you've done does that mean that you talk about what you did?

Sean: No. No.

Shirley: $\quad$ So what would it be like if you were talking about what you did?

Sean: I probably wouldn't be able to do it as part of a group. Yeah. It's a bit hard.
}

The intervention programmes that participants experienced were all conducted in group settings and talking about their violence was not a requirement. Any reluctance in talking about their violence in a group may be related to the level of comfort participants had in talking within a group setting, which varied among participants. Anthony's view about talking in groups seemed to be that because he did not know the others in the group, talking would not be a concern whereas if he knew the other group members, he may not contribute much: 


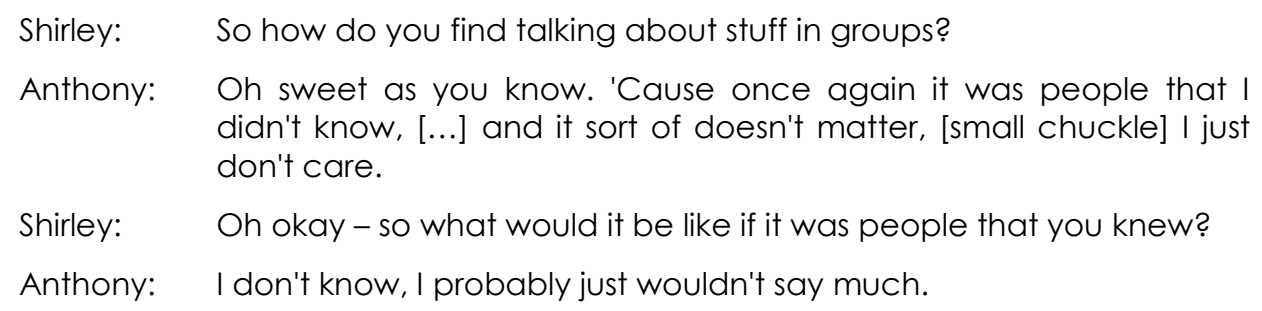

In contrast, Kelly said that talking in a group about his violence would not happen:

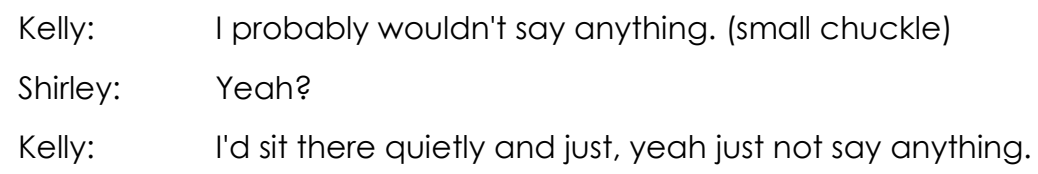

Even if the argument that teaching prosocial skills will reduce violent offending was accepted, it is difficult to understand the logic behind not having these young men talk about what they did, given that learning approaches are theorised to succeed on the basis of the learning being able to be applied (Domjan, 2006). I find this lack of talking about their violence incongruent. This silencing can be read as a contradiction to cognitive-behavioural therapy (currently favoured) approaches to violence. Such approaches often depend on examining the violence in great detail to achieve their purposes (Hollin, 1996; Howell et al., 1997)

Despite these intervention programmes maintaining and even encouraging silence about the young men's violence, talking about their violence does occur. It gets talked about amongst the inmates, it gets talked about with friends and sometimes with family. It also gets talked about in research interviews.

\section{Saying "no" to counselling}

Despite participants valuing the role that talking played in their lives and their mixed reactions to group programmes, their comments about counselling were generally not favourable. Although no participants were involved in any counselling at the time of the interviews, some had experienced counselling in the past and even saw benefits, but for some it generally had little impact, as Rick described:

Rick: $\quad$ Yep when I was younger, ... Um. Oh I can't really remember much about it, yeah.

Anthony, on the other hand, talked of having "had heaps of stuff man" and that he found it "Mmm alright": 
Anthony: Yeah now that was because I was only, yeah little and I couldn't handle people and just being a dick (laugh).

Rick's emphasis, “when I was younger”, and Anthony's "I was only, yeah little”, can be read as constructing counselling as being appropriate at that time, but only because of their younger age. Now, though, being a young man, it may be that counselling is no longer viewed as relevant for them.

When Kelly described talking to staff and other inmates about how he felt regarding his parents disappointment in him, he constructed the talking as "just getting advice", which he then contrasted to counselling:

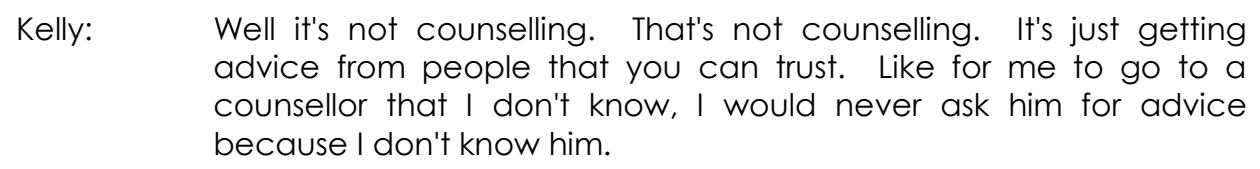

Kelly constructed counselling as being different to getting advice from his friends, in two ways, firstly, a counsellor is a stranger and secondly, a counsellor is not like friends whom he trusts. This positions a counsellor as a professional whose job is talking and constructs the experience of counselling as being outside the realm of 'every day' talking.

By far the most common response to the idea of counselling from participants was not wanting and not liking counselling. As Quentin made clear, "I don't like that shit" nor did Kelly:

$\begin{array}{ll}\text { Kelly: } & \text { No. Don't like counselling. } \\ \text { Shirley: } & \text { No. Why not? } \\ \text { Kelly: } & \text { Boring. }\end{array}$

While "boring", is Kelly's initial response, he added to this when he described that talking about his violence had a detrimental effect and such talk could even be viewed as "boasting":

Kelly: [Cough] Um, [pause 3 secs] not for me I don't reckon, maybe for other people. I reckon talking about it makes it like bring it back up and makes me feel sort of down again sort of. But maybe for other people they may enjoy talking about it and they boasting about their crimes, but I don't.

Kelly's description of talking as bringing "it back up and makes me feel sort of down" is a common reaction to talking about their violence that I have heard from 
many young offenders. I find Kelly's construction of talking about violence as "boasting" unusual. Such a reading would position the talker as unremorseful in the dominant discourses around justice and punishment. However, within discourses of manliness, boastful comments by young men about their exploits are common, which enables them to perform 'man' correctly and allows the identification of their location within a male hierarchy.

Drew was very clear that he did not think counselling was of any relevance to young men who had been violent:

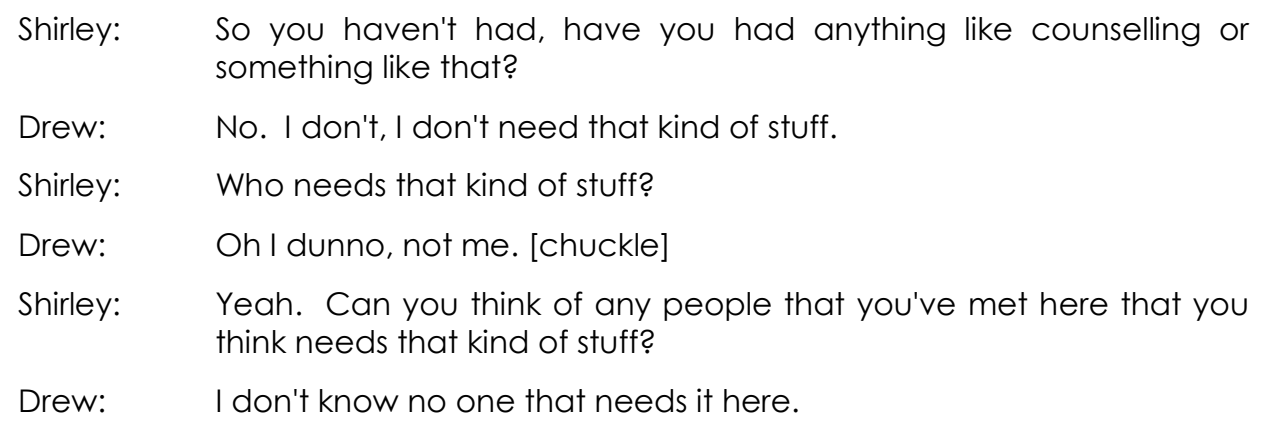

Drew can be read here as constructing counselling as a 'helping' practice that was not relevant to himself, "I don't need that kind of stuff" or other inmates, "I don't know no one that needs it here". Drew went beyond a simple dislike of counselling and questioned its appropriateness for young men who have been violent. For young men to engage in counselling positions them as being 'in need', therefore vulnerable or deficient, none of which enact traditional manliness.

The strength of dislike for counselling that some participants felt came across strongly in my interaction with Quentin when I attempt to explore his dislike of counselling. Firstly, Quentin likened counselling to anger management and then constructed the research interview itself as being an anger management session. As the conversation progressed, Quentin spoke of counselling being boring, and it took some time before I realised that he had shifted to saying that he was finding the research interview itself boring and that he wanted to end it:

\footnotetext{
Shirley: $\quad$ So you don't like counselling?

Quentin: Na I won't do any counselling.

Shirley: Yeah how come?
} 


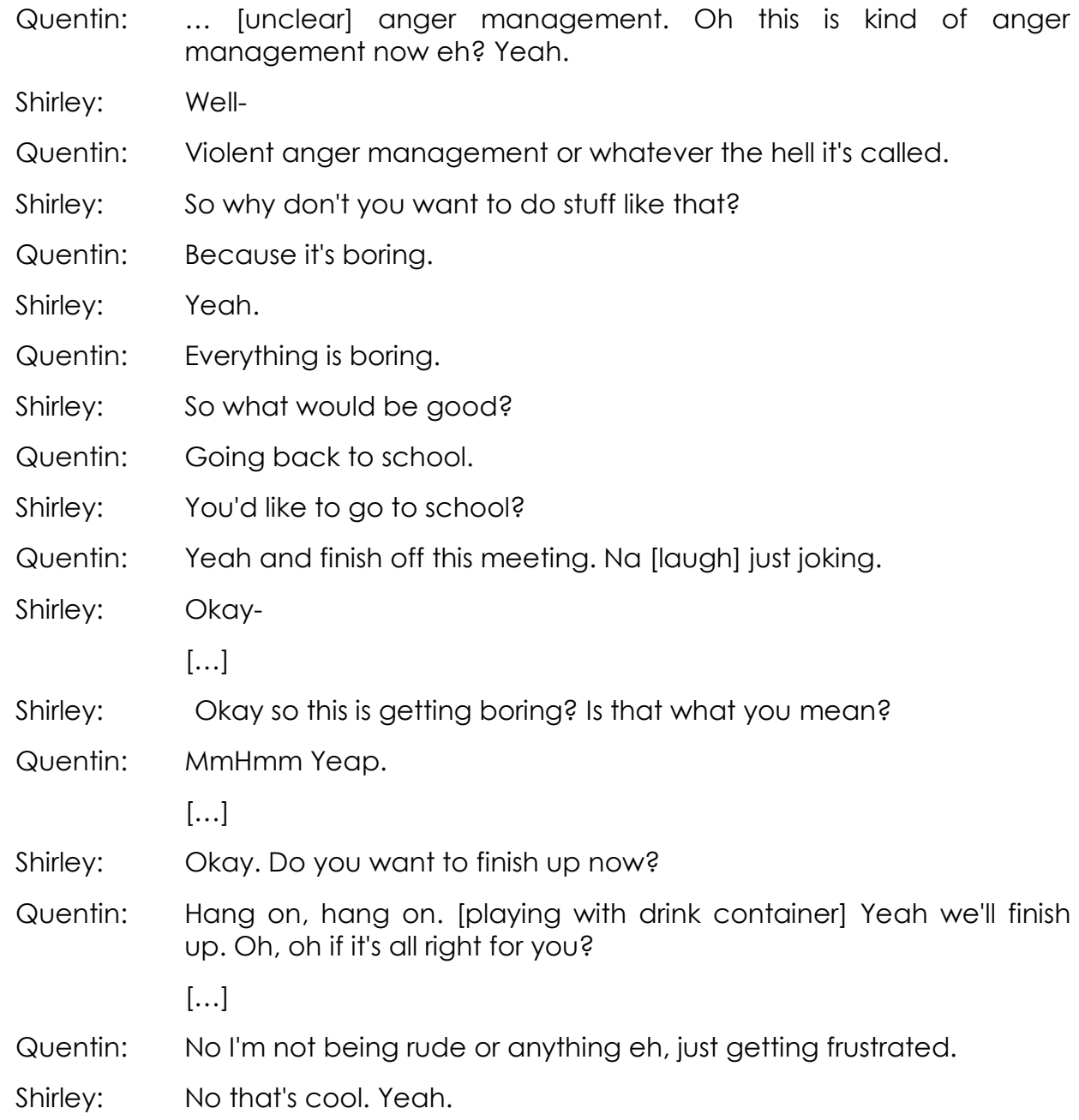

Quentin was faced with an adult wanting to talk about counselling, which could have been read by him as equivalent to counselling or anger management. While it took some time before he was able to be clear about what he wanted, "Yeah and finish off this meeting. $\mathrm{Na}$ [laugh] just joking.", with his dislike of counselling, his wanting to end the interview is logical. Given his possible reading of the interview, his resistance to the authority of an adult by asking to end the interview is impressive.

Quentin employed a high level of politeness to end the interview, "Yeah we'll finish up. Oh, oh if it's all right for you?". Using such a style to finish the interview is not consistent with the subject position of a dangerous young offender who takes what he wants without thinking about the consequences, nor one who is 'cold' and calculating, nor one whose anger is out of control. Quentin can, instead, be positioned as demonstrating considerable prosocial skills, therefore, as not needing that type of intervention. 
Considering their comments, it appeared that participants had not attended any counselling or group programmes that focused on the violence that they had committed. Nor had they been required to talk about their violence, even within the intervention programmes they had attended. However, the value of talking about their violence was recognised and even suggested to me as being a useful thing for intervention. But the practice of counselling was not something participants saw as useful or even relevant for them. This anomaly of valuing talking but not counselling is clarified by considering how these young men are positioned as therapeutic subjects of dominant psychological practices within the context of counselling. This positions them as 'abnormal' and needing help. Such positioning is in stark contrast to performing 'man' correctly within dominant discourses of manliness, which requires rationality and control and implies 'normality' and so not needing help.

\section{Conclusion}

Some of the participants had previous experience of a variety of interventions. For example, some therapy-based interventions, such as counselling and other diversionbased interventions, such as adventure programmes. But these interventions did not prevent these young men committing the violence for which they were now imprisoned. Nor did removing them from 'dysfunctional' families and putting them into care. Furthermore, since being inside none of the participants were involved in any therapeutic engagement that was specifically designed to directly address their violent offending. Even though some did attend an intervention programme inside, they did not talk about their actual offence. Participants described their management in the secure facilities as tightly structured and with reward and punishment systems.

There appears to be an apparent gap between the dominant psychological theories that attempt to explain youth violence and the interventions described by participants. As discussed in Chapter Five positivist psychological theorising positions young men who have been violent as not responsible for their violence. Rather, an external event or element is viewed as the cause, for example, being a victim of family violence or being intoxicated by drugs or alcohol. The interventions that participants spoke of seem to only utilise approaches that rely on basic behaviour 
modification techniques and those that focus on removing the individual from the context that is viewed as the cause. However, it is hard to see how being removed from the family or restricting family visits can adequately resolve the issues thought to be involved in being part of a 'dysfunctional' family. Likewise, having drug testing inside but no assessment, or other intervention to resolve addiction issues, is not congruent with the notion of addressing the causal factors of the offending behaviour.

Within dominant discourses around therapeutic intervention, participants are positioned as being responsible for the success of their intervention experiences. For example, although it is theorised that one outcome of being raised in a 'dysfunctional' family is a lack of skill in being able to respond appropriately to others, it becomes the responsibility of the young man to address this failing of his family by learning the necessary prosocial skills. However, he is expected to do so in isolation from his family. If he does not succeed in learning these skills, or if he does, but continues to be violent, then it is the young man who is judged as having failed, not the intervention or the theory behind skill development programmes.

From the participants talk there is one difficulty that I identify with current intervention practices. These young men often had different understandings about why they were violent compared to the understandings informing the intervention programmes they were in. Logically, such contradictions would make choosing to be non-violent in the future as a result of the intervention, problematic for these young men. For example, Kelly drew on the idea that being intoxicated from drugs and being pressured by peers were the reasons he committed two aggravated robberies. $\mathrm{He}$ is likely to experience difficulty in making sense of how the Toughest Inmate Competition might assist him to be non-violent. Or Drew, who gets involved in fights to have fun with mates, to make friends and to achieve the position of 'man', would have trouble applying the prosocial skills learnt in a programme such as EQUIP to address his violence. This programme views violence as anti-social, but is unable to account for the practices of violence that enact manhood within discourses around manliness that Drew described. If discourses, such as those about traditional forms of masculinity, are used to explain why violence was perpetrated, then it is not 
workable to use intervention designed on the basis of another discourse, such as the popular theory of skills deficit.

The impetus to try to 'get it right as a man' means participants have little interest in intervention. After all, within dominant discourses defining normative masculinity, violence is one of the primary paths to manhood. Therefore not only is intervention seen as irrelevant, but also therapy-based intervention, such as counselling, is vehemently rejected because the positioning available within therapeutic discourses and practices strongly contradicts the 'man' position of traditional masculinity discourses. Being positioned as, 'disordered', or 'abnormal' equates to being vulnerable; not a manly position.

It seems that containment, with its focus on retribution and punishment, has more influence over what happens in these secure facilities than scientifically informed psychological approaches to therapeutic intervention. This is not withstanding that the containment practices are also based on positivist psychology. It may be that economic pragmatism is more dominant, since it costs less to contain offenders than it does to run therapeutic units. In addition, the political context must be considered. There is considerable public pressure to incarcerate more violent youth and increase sentences. However, there is also interest in secure facilities being intervention focused so that young men who have been violent can choose a different future.

In the next chapter, the discourses operating around sexual violence show a very different picture to those that relate to participants' general violence. This has implications for both theorising about sexual violence and intervention possibilities. 


\section{ChAPTER SEVEN}

\section{WHEN VIOLENCE IS SEXUAL}

This chapter explores the sexual violence of those five participants who had convictions for sexual offending, which included exposing genitals and masturbating in public as well as offences that directly engaged victims, that is, fondling, forced oral sex, as well as anal and vaginal rape. Three of these five participants also talked of their involvement in general violence, which I have analysed in the previous two chapters. Here I investigate the differences between participants' talk of sexual violence and their talk of general violence. When I initially designed this research, I intended to examine both types of violence, general and sexual, and expected to be analysing and reporting on these globally. However, the differences in the way participants talked about these two types of violence were so significant that it has necessitated dealing with them separately.

In this chapter, I explore their sexual crimes and participants' understandings of them. I provide a reading of the various constructions of sexual violence and locate these in the wider discourses of traditional manliness and within the dominant discourses that various theories of mainstream psychology use to explain sexual violence. I also examine the subject positions made available to these young men within these discourses and the potential effects these have.

I begin with the difficulties these young men had in discussing their sexual violence and what made this so challenging for them. Just as I had asked participants to share with me their stories about their general violence and how they understood it, I asked about the sexual violence they had committed. However, most of the young men were very reluctant to talk at all about their sex offences. The particular negative effects of being positioned as a sex offender are discussed and I show how they help 
explain the participants' reluctance to talk. A discursive analysis of what little detail about their actions that was provided by some participants indicated a number of contradictions in the young men's positionings. Participants also had significant difficulty in describing any ideas about why they had been sexually violent when I asked them directly, but I explore a number of ideas that emerged in their talk on the potential effects of their sexual violence on their victims.

\section{Talk of Sexual Violence}

The reluctance of participants to talk about their sexual violence became evident very quickly in the interviews. The idea that we would be talking in detail about the sexual offences that had led to their imprisonment at all was a shock to some of them. Even that I would know about these offences was a surprise for Quentin:

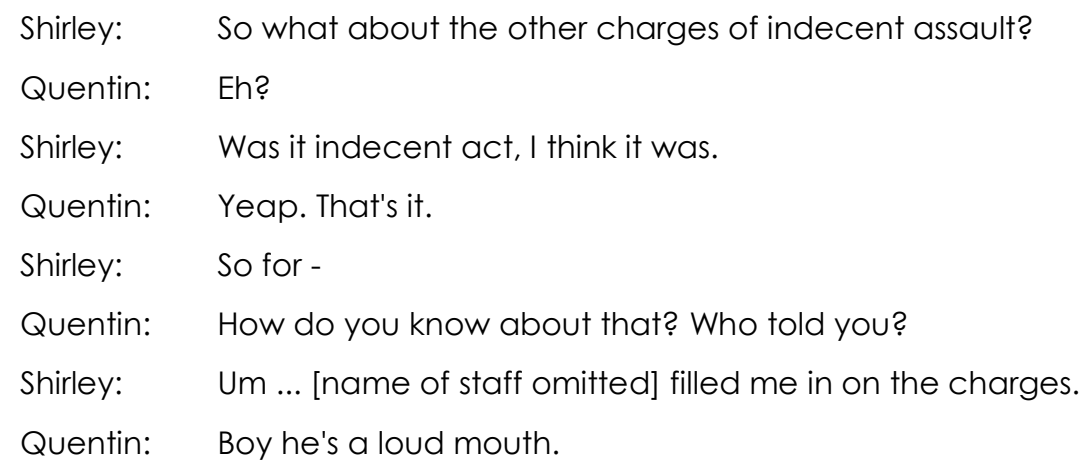

Quentin seemed surprised and alarmed that I wanted to talk about his sexual violence as well as his general violence, "How do you know about that? Who told you?". Quentin's questions suggested he had an expectation of secrecy around his sexual violence. This contrasted markedly to general violence where there was no such expectation from any of the participants, including Quentin.

While secrecy is commonly associated with sexual violence and is often viewed as essential to its existence (Salter, 2003), such an expectation of secrecy may, alternatively, be read as constructing sexually abusive activity as not being violent, as indicated in Anthony's comment below:

Shirley: $\quad$ The one that I'm interested in is in relation to the sexual violation charge because okay lots of people call that violence, now I don't know whether you call that violence, does that kind of fit your idea about violence? 
Anthony: Na not really.

When I asked participants to describe what they thought violence was, almost all referred to general violence that involved some form of hitting. Not seeing sexual abuse as violence may be because the majority of the dominant ideas about sexual violence construct it as taking non-abusive, consensual sexual activity too far, such as adolescent sexual experimentation, or as normative practices of coercion (Gavey, 1992). Alternatively, if general violence is a way young men can perform 'man' correctly, then it may be difficult to make sense of sexual abuse as being violent because sexually violent perpetrators are positioned as not getting 'man' right: instead, they are more likely to be positioned as 'abnormal' and 'deviant' within pathologising discourses. In contrast, from a feminist perspective on male violence, it is possible to construct sexual violence as being a practice that is seen as functioning as a man's entitlement and hence may not be considered as violence.

When I began to talk to Anthony about his sexual violence, he appeared wary and unwilling, wanting to avoid the topic:

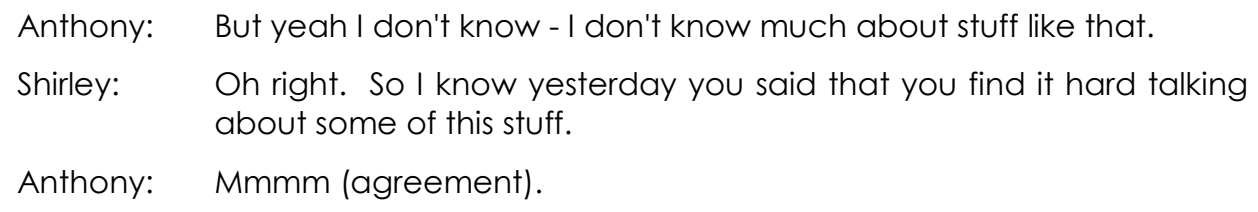

One reading of Anthony's comment, "I don't know much about stuff like that" could be that he may have understood/read me as expecting him to be knowledgeable on the topic of sexual violence since he had committed sexual offences. Given that talking about sexual violence is not a topic that most people openly discuss, it would be possible to position me as some kind of 'pervert' because my interest could be constructed as what most 'decent' people, particularly a woman, would not even think about, let alone want to talk about. Alternatively, Anthony's statement can be read as signalling to me that he did not want to discuss the topic at all, but without him having to say so specifically, which may have been difficult for him as like many young people, he did not wish to go against the wishes of an adult.

Such reluctance to talk about their sexual violence on the part of most participants led me to ensure that I made it very clear that they had permission not to talk about anything they did not wish to. Sean was able to assertively declare that he would not: 


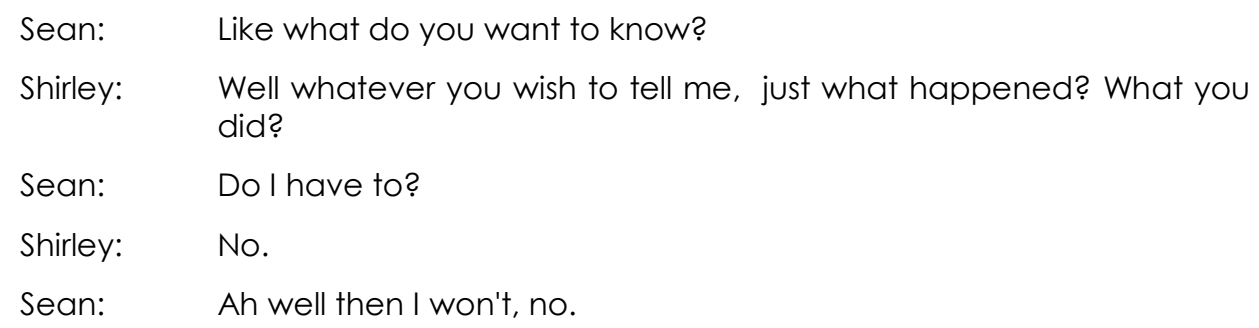

While Sean made it very clear that he would not talk about his sexual violence, "Ah well then I won't, no", he initially signalled his wariness around the topic by asking me "Like what do you want to know". It was only with the sexual offences that participants asked me to spell out what I wanted to know; this was not the case when I asked them about their general violence. Perhaps seeking clarification from me about what I wanted to cover with regard to their sexual violence was a way to give the discussion clear limits; the young men would not be volunteering any information beyond what was required. Placing restrictions may be one way to maintain silence around sexual violence and their control of the discussion.

Quentin also made it plain to me that he did not want to talk about his sexual violence when he said to me: "Na I don't want to talk about them eh". But even after agreeing that we would not and despite our discussion turning to other areas, later in the interview it became clear that the topic of sexual violence was never far away for Quentin:

\begin{tabular}{|c|c|}
\hline Shirley: & $\begin{array}{l}\text { So what about - have you thought about some of the reasons why } \\
\text { you did what you did? [Noise of Quentin playing with drink } \\
\text { container] }\end{array}$ \\
\hline Quentin: & Did what I did - what does that mean? \\
\hline Shirley: & $\begin{array}{l}\text { Well have you tried to sort of think about - tried to make sense of } \\
\text { why you did it? }\end{array}$ \\
\hline Quentin: & Did what though? \\
\hline Shirley: & Um the assault? [l'm thinking of the general violence offence] \\
\hline Quentin: & Oh is this just about the assaults? \\
\hline Shirley: & Yeah \\
\hline
\end{tabular}

Quentin could be seen as being cautious, seeking clarification on what I was referring to by asking "Did what though?" and he seemed relieved, "Oh is this just about the assaults?", when he was reassured that we were only talking about his general violence and not his sexual offences. Such vigilance with regard to his talk may be read as guarding against falling into a discussion of his sexual violence. This 
contrasts substantially with participants' willingness to talk about their general violence and suggests a form of protection regarding their subjectivity, their sense of self. Perhaps by not talking about their sexual violence prevents them being spoken into existence as sexual perpetrators.

The silence around participants' sexual violence was revealed in their inarticulateness even when they seemed motivated to refer to these offences. They seemed to have difficulty trying to find appropriate language as Quentin demonstrated when suggesting that a judge wanted to give him a lengthy jail sentence because of his sex offences:

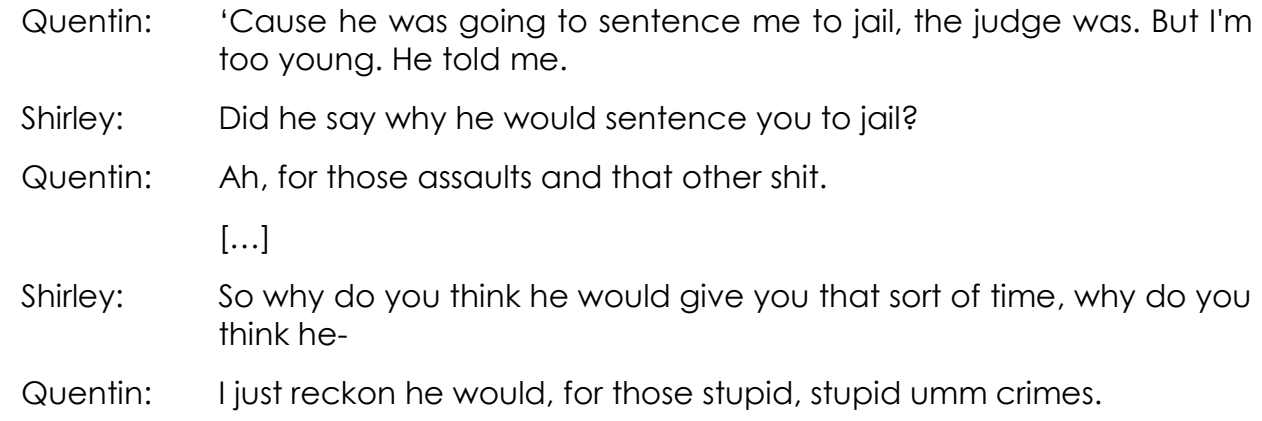

Quentin seemed to be referring to his sexual violence as "that other shit" and "those stupid, stupid umm crimes" whereas his general violence was described simply as, "those assaults". Such a different use of language around his sexual violence is suggestive of a more negative view of the sexual violence as compared to his general violence. While participants did not want to talk about their sexual violence, it also seemed that there was no language that they could access to do so. Given the nature of this violence, any talk about it would have to include some discussion of its sexual aspect. Sex is certainly discussed in a number of forums, such as in settings designed for educational and clinical purposes, in casual discussions with mates that are sometimes risqué or boastful, and in the media, within movies, magazines, television shows and advertising. Yet there is a general avoidance of the detail around sexual activity, and when detail does exist it is often constructed as pornography. Therefore anxiety and embarrassment may be expected when young men attempt to talk matterof-factly about sex with an adult, especially one who is a woman. But to discuss the details of sexual activity when it is violent may be particularly difficult. There are specific contexts in which it may be considered appropriate to talk about sexual 
violence, namely, with police, in court or in therapy. Therefore the discourses that make it possible to discuss sexual violence include discourses around justice and discourses of therapeutic intervention.

\section{Negative feelings and silence}

Not being able to find appropriate language to talk about their sexual violence may have been part of what constituted the participant's silence. I was interested in exploring this silence further. When I asked about what made it so difficult for them to talk about their sexual violence, participants were better able to discuss this silencing aspect. Bringing up negative feelings was a common explanation, as Anthony's comment indicated:

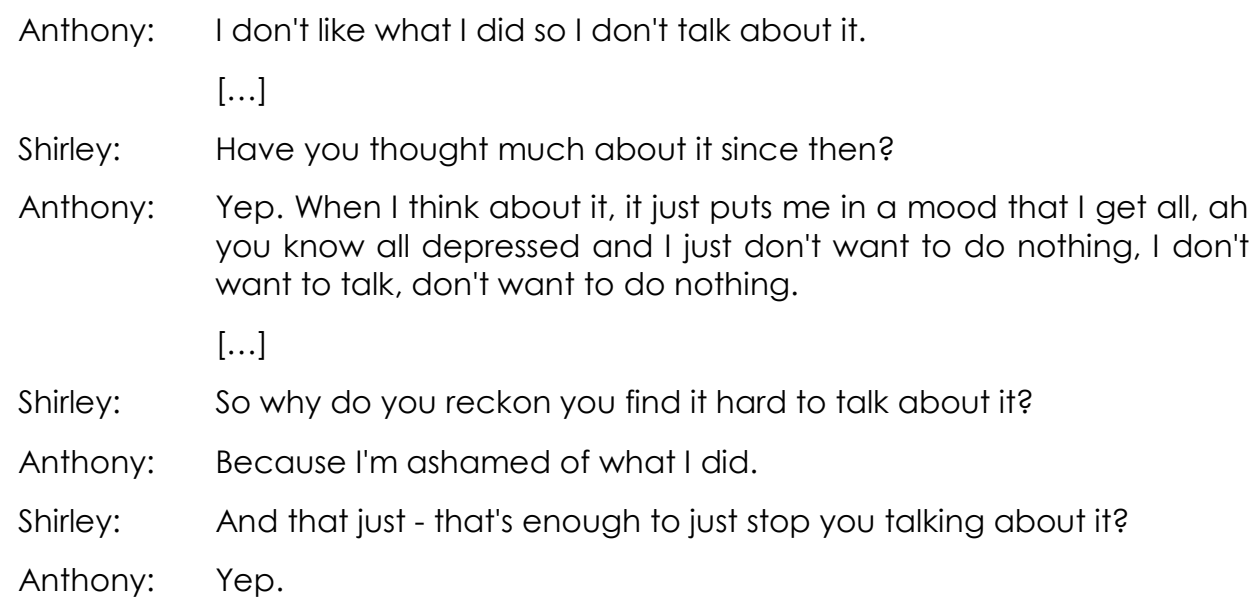

While Anthony used rational reasoning, "I don't like what I did so I don't talk about it" to explain why he did not talk about his sexual violence this same reasoning is not used for general violence, where there is no reluctance to talk. Anthony then focused on his emotions. He described getting "all depressed" when he thought about what he did and found that he did not "want to talk, don't want to do nothing". Anthony was also able to say why he felt this way, “cause I'm ashamed of what I did”. From these comments, Anthony can be read as taking up the position of being remorseful.

Quentin, on the other hand, cannot be positioned as remorseful. He talked about different emotions, including anger, when trying to explain why he did not want to talk about his sexual violence:

Quentin: Don't really. I'm not really impressed with them.

Shirley: Okay. That's cool. 
Quentin: $\quad$ Pissed me off.

Quentin was "not really impressed" by his sexual offences because they "pissed him off'. Through this talk he turned these offences into objects that were external to himself, which then enabled him to be positioned as having an objective opinion of them, much like anyone else can. Quentin objectified his own embodied involvement in the assault and so disconnected himself from the event. This distancing from the violence through an objective gaze may be read as making it possible for Quentin to live with what he had done.

Like Anthony, Sean spoke of talking bringing the memory of his sexual violence back and like Quentin, he talked of anger:

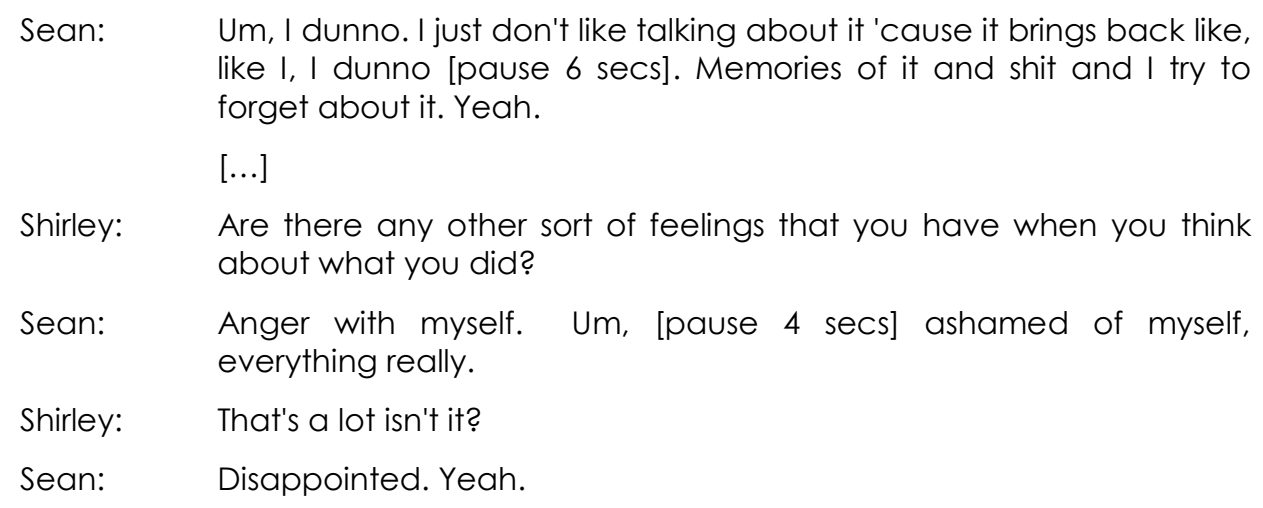

Sean's anger was directed at himself because he was "ashamed". While reflection on their sexual offending appeared to be a painful process for participants, this was not the case for them when they spoke of their general violence. Instead they were able to talk more openly about what they did. While shame can be considered to be playing a considerable role in their silence about their sexual violence, the participants also spoke of feeling ashamed about their general violence, yet the same silence was not an outcome. The intense shame and associated silence appears to be related to how sexual violence is constructed and how its perpetrators are positioned more negatively than those of general violence.

One way that a therapeutic perspective views shame is to consider it as a potentially useful mechanism that may prevent further violence. The basis of this expectation is that because young men want to avoid feeling any more shame they will not commit further violence (Frances, 1995). Unfortunately, this was not the case for some of the 
participants who, despite describing feeling intense shame, had offended sexually on more than one occasion or who then went on to commit general violence.

\section{Shame and suicide}

Although producing shame and remorse is often a target for intervention, having a high level of shame may produce other effects besides the hoped-for positive effect of preventing future violence. Immense shame about oneself can lead to questions about whether to continue living, as was the case for Sean:

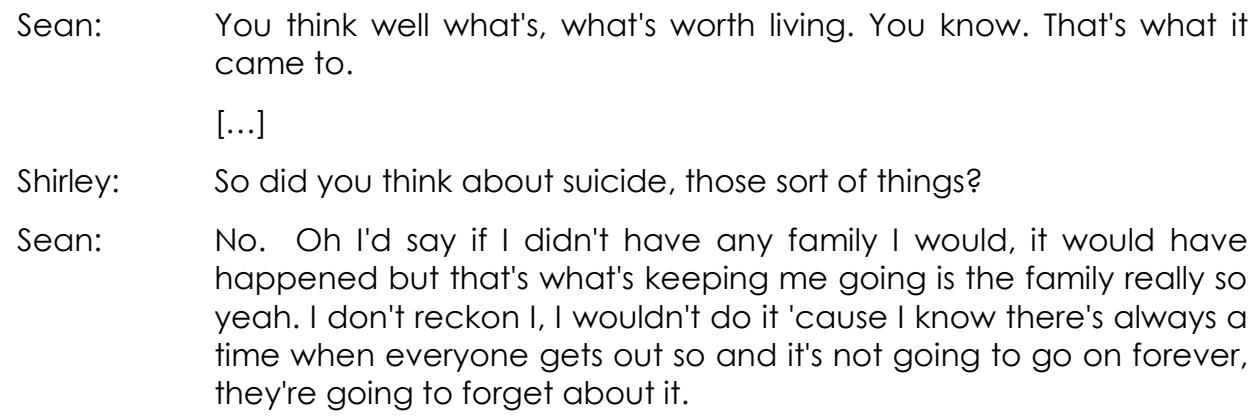

But for his family, Sean's suicide "would, it would have happened". Also the idea that there is "always a time when everyone gets out" and that people are "going to forget about it" provided Sean with the rationale to choose to live. In Western cultures, there is often a great deal of shame associated with committing suicide. Paradoxically, while feeling ashamed for what he did may have led Sean to consider suicide, the shame connected to the act of suicide itself may have played a role in his not taking that path. Within discourses around traditional masculinity, suicide is constructed in various and contradictory ways. Firstly, it can be seen as a weak and cowardly act that 'real' men would not contemplate (Connell, 2000). But as a counter to this, there is the hyper-masculine notion of young men living hard and fast and dying young, even from suicide, as being preferable to growing old. Whether a suicide attempt is successful or not also seems to be relevant, since success is part of 'getting it right as a man', and being successful at suicide may be read as achieving this, whereas a failed attempt does not (Phillips, 2004). Given these contradictions around suicide, consideration of this act becomes a complex one for young men like Sean. Such complexity cannot be accommodated by mechanistic psychological theories on suicide, which construct it as being caused by depression and other 
mental disorders (Fleischmann, Bertolote, Belfer, \& Beautrais, 2005), therefore the act cannot be considered a rational one.

\section{Distancing and separating from sexual violence}

Further exploration of Sean's feelings about what he had done indicated that he was somewhat disbelieving that he had been sexually violent at all:

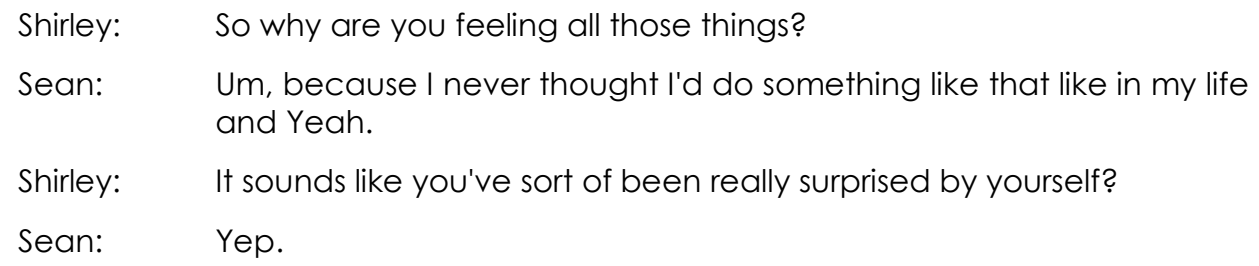

Sean can be read as viewing himself as 'other', as a stranger because he, "never thought I'd do something like that like in my life".

Like Sean, Wade was also surprised that he had been sexually violent. This was in spite of his having been sexually violent in the past:

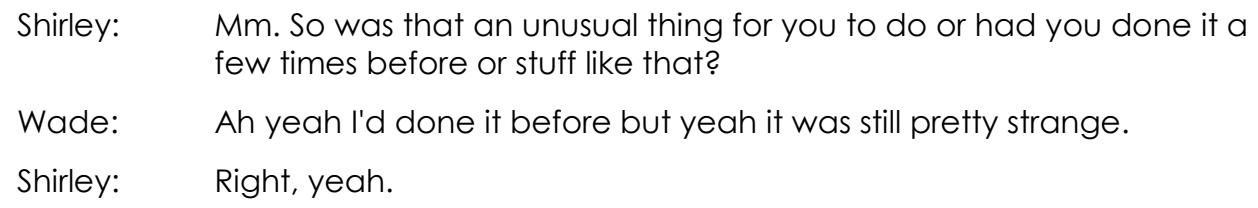

But this previous experience did not provide any illumination for Wade, as he considered it to be, "still pretty strange" for him to have been sexually violent. Whatever the impact on him, for example, shame or guilt, it did not function as a preventative for Wade.

Both Wade and Sean spoke of the 'part of themselves' who committed the sexual violence as alien and separate from the part of themselves who would judge that action as appalling. Yet they did it. In this way they can be read as showing how one's own multiple subjectivities are engaged (Davies, 1994). Since mainstream psychology is founded on the concept of a unitary, coherent subject, any evidence of multiple subjectivities in 'clients' who are brought into 'treatment' would likely lead to a diagnosis of disorder. Their disowning parts of themselves could be regarded as a clinical indicator of abnormality, of dissociation (American Psychiatric 
Association, 1994), rather than evidence of the possible existence of multiple subjectivities.

Wade referred to such multiplicity when he described how he viewed himself as being separate from his body:

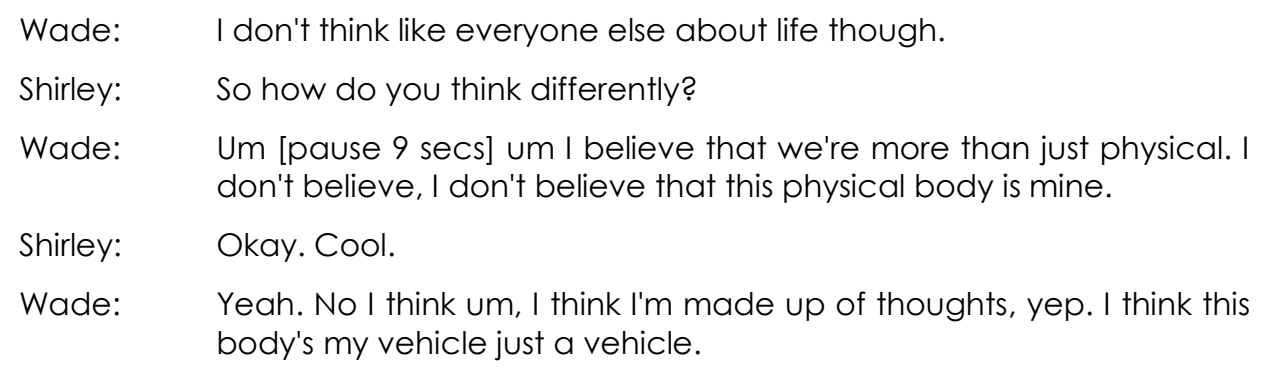

"Within dominant discourses of [consensual] heterosexuality, young men's experience of their bodies is said to include guaranteed physical pleasure, facile bodily arousal and perpetual biological readiness for sexual activity" (Allen, 2002, p. 130). However, there is also a contradictory construction of sexual disembodiment in these discourses. Wade's view of himself as being "made up of thoughts" and "this body's my vehicle just a vehicle" may be read as indicating a split between mind and body. Such a split is consistent with the cognitive-emotion dualism, in which nature (the body) can be controlled by the rational man (mind) and is also to be found within normative discourses of male sexuality, that constructs the body as a machine to be used (Allen, 2002). Young men's disconnection from their body in relation to (hetero)sexual activity has also been theorised as dys-embodiment, that is as 'dysfunctional' because the attention they gave to their body focused on their dissatisfaction with it (Allen, 2002). This dissatisfaction is related to concerns about not achieving a masculine ideal. If young men experience such sexual dysembodiment in consensual sexual activity then this concept appears relevant in explaining the participants' disconnection from their bodies. If Wade is not his body, "I don't believe that this physical body is mine" yet it was his body that committed the sexual offences, then this dys-embodiment makes it possible for Wade to successfully disassociate himself from his sexual violence. 
While splitting from one's body is one way to be disconnected from the sexual violence they perpetrated, participants were also keen to move away from their offences by leaving what they did in the past:

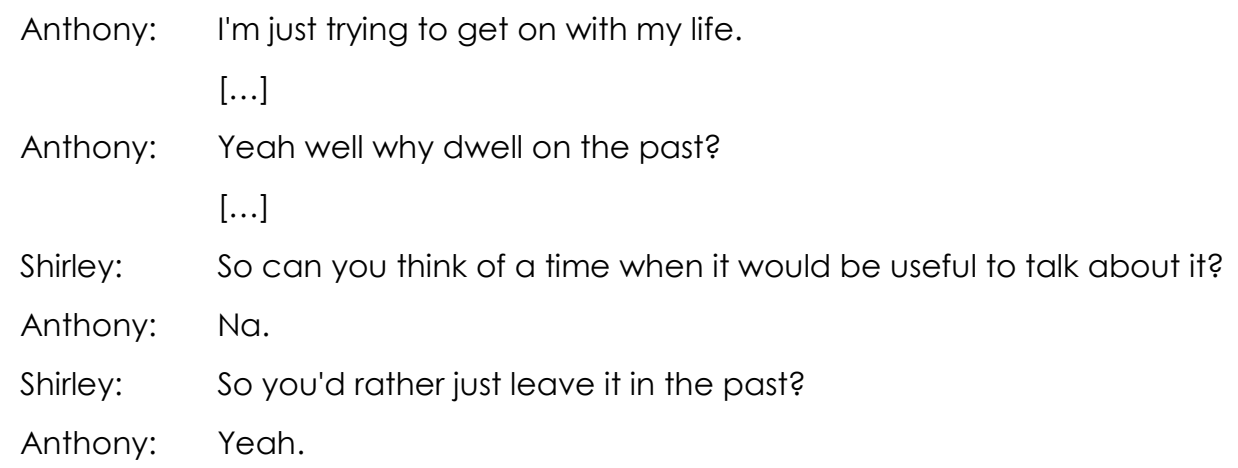

Talking about his sexual violence discursively functioned to make it present and may be read as stopping Anthony's ability to "get on with my life", thus he can be seen as being held and controlled by history. From some therapeutic perspectives, exploration of past experiences that are thought to have had a significant emotional impact is considered a beneficial process (Hubble et al., 1999). However, within dominant discourses around masculinity, feeling, expressing and exploring emotions may be regarded as un-masculine, unnecessary 'sissy' stuff (David \& Brannon, 1976). Hence, the best way forward is to forget the past and move toward the future. Whether splitting oneself from some part of them self, their body or from their history, all act to achieve disowning the sexual violence participants committed. However, these strategies cannot influence how others will position young men who have committed sexual violence.

\section{Positioning as a Sex Offender}

\section{Experiencing stigma inside secure facilities}

Not talking about their sexual violence assisted these young men to avoid remembering or thinking about what they did and in dealing with the emotions that their actions raised; it also allowed them to move on and leave the event in their past. In addition, silence helped them to avoid being positioned negatively as a sex offender by others. Wherever possible, participants ensured that no-one knew about their sexual offences and kept what they had done to themselves. Participants did not want their friends or other inmates finding out about their sexual violence. The 
consequences of being positioned as a sex offender were viewed as being potentially harmful. This silencing that participants shared with me around their sexual violence contrasted distinctly with their openly telling others about their general violent offences and other crimes. Such silence then is not likely to be about feeling shame for doing anything illegal or 'antisocial' nor is it likely to be about being embarrassed for being caught. The silencing is clearly unique to the sexual nature of the violence.

Some participants, however, were not able to keep their sexual violence secret. There were a number of reasons for this, for example, not getting name suppression in the courts and their offences being reported in the newspapers. This resulted in other inmates knowing about what they had done, as did their friends. Being known as a sex offender inside created problems for participants. Rick spoke of being "teased" by inmates and this included them making suggestions that Rick had committed a variety of sexual acts ("people say that you've done this, and this and that"). Rick's response was firstly to ignore them and isolate himself, but at other times he also got into fights as a result.

Sean experienced similar difficulties:

Sean: Like most of, like everybody in there knows what I'm in there for but I, it's just the details of going into what I've done is, is just so hard and really because they do, they do take the shit out of you when you first come in, in here.

While Sean found that the other inmates, "do take the shit out of you", like Rick, he described being able to resolve these difficulties through the use of general violence or at least the threat of general violence. Being positioned as a sex offender was highly negative for participants, but it was clear that for some of them, using or threatening to use general violence was a way to improve their standing within the inmate hierarchy. If Rick and Sean were successful in winning their fights, then the "teasing" (Rick) about being sex offenders was likely to end. While this did not change their subject position as a sex offender, the fighting did make available another subject position, that of a good fighter, which merits respect within discourses of normative masculinity (Wadham \& Pudsey, 2005). 
Wade on the other hand did not talk of using general violence as a way of managing being positioned as a sex offender. Instead, he isolated himself from others for selfprotection:

Shirley: $\quad$ Right. So what do you do?

Wade: I just keep to myself. I don't always have a shower.

Besides "teasing" (Rick) and fighting, Wade's comment: "I don't always have a shower" suggested that he was concerned that sexual violence could be used against him by other inmates. Such a fear highlights a commonly held belief about what is expected to happen to sex offenders inside secure facilities, that is, the notion that retaliation will be taken against sex offenders by other inmates in a form that matches their sexual offences, such as rape. One way of reading this expectation is that justice is seen to be meted out to sex offenders in prisons in a way that many in our communities may wish for but are unable to bring about. Therefore 'real' justice is left up to other inmates because they are positioned as already capable of such violence. In addition, there is nothing to stop them since sex offenders are positioned as the lowest of all inmates. So prisons and inmates can be read as fulfilling a function of retaliation that no one in the wider community would want to admit to.

\section{Responses of others}

While participants felt the material effects of the subject position of 'sex offender' in the various institutions in which they were incarcerated, the responses of their family and friends when they found out about their sexual violence can also be read as being mostly negative. Participants talked of family members being particularly upset and displeased even though most were still supportive of them, as was the case for Wade:

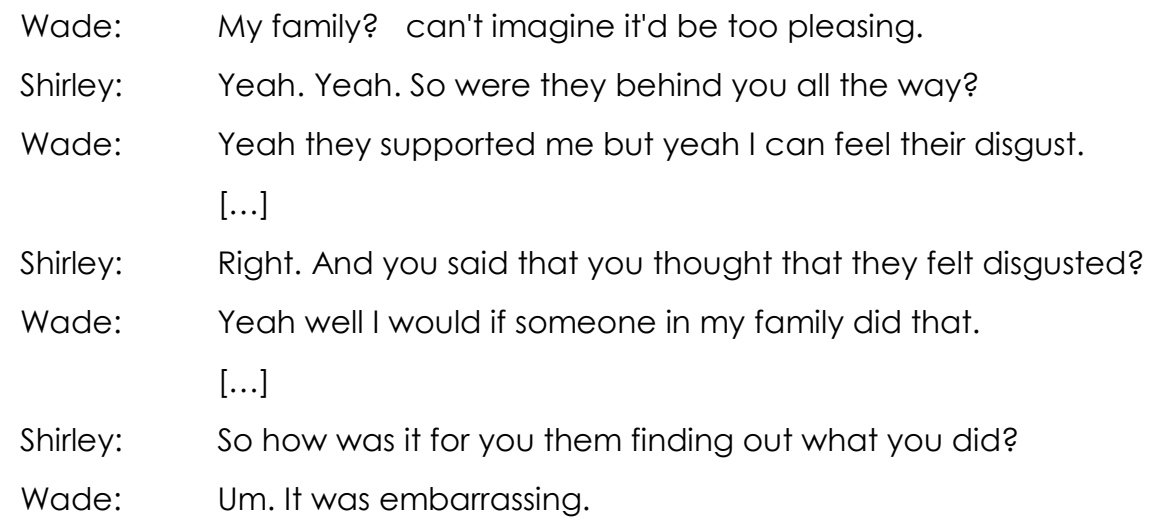


Wade acknowledged that it was "embarrassing" for him when his family found out about his sexual violence. He could also "feel their disgust" with what he did. Interestingly, Wade saw disgust as an appropriate reaction to his sexual violence, one he would also feel, "well I would if someone in my family did that". This constructed sexual violence as a disgusting and embarrassing form of violence and thereby positioned Wade as disgusting and as an embarrassment to his family. Such a construction is consistent with a clinical psychological view that considers those who perpetrate sexual violence are 'abnormal', 'deviant' and 'disordered', and that offers specific diagnostic labels for different types of sexual violence, for example, paedophilia, exhibitionism, fetishism, sadism (American Psychiatric Association, 1994).

Sean described his sexual violence as being particularly hard for his mother but he also found that the responses of other members of his family positioned him negatively:

$\begin{array}{ll}\text { Shirley: } & \text { Okay. Mm. So with your step dad and your brother and sister, um } \\ \text { how do you think, how did they react when they heard about what } \\ \text { you'd done? } \\ \text { Sean: } \\ \text { My brother he didn't really understand why I done it and [pause } 7 \\ \text { secs] Dad I don't know, because we haven't talked for a while. And } \\ \text { my sister um [pause } 6 \text { secs] I think she's more disappointed in me } \\ \text { than anything. [upset, shaky voice]. }\end{array}$

If Sean and his step-father "haven't talked for awhile", it may be that Sean's sexual violence could be the reason and it may suggest how his step-father felt about it. However, Sean was clear that he thought his brother "didn't really understand why I done it" and his sister was "more disappointed in me than anything". Within his descriptions of his family's reactions, Sean can be read as not getting it right as a son or brother. He had not achieved the expected performance of these positions and his level of distress demonstrates how significant that is for him.

Wade also talked about issues of understanding in his family:

Shirley: $\quad$ Right, $\mathrm{mm}$. So did they have much of an understanding about what happened?

Wade: No I don't think, no they didn't. [pause 3 secs] They can, they know what I done, but they don't have the slightest understanding of it.

$[\ldots]$ 
Shirley: $\quad$ Yeah. So how did they respond when they first found out?

Wade: $\quad$ Um, well they were supportive but more "get help".

Although Wade thought his family were "supportive" of him, they wanted him to “get help". Like Sean, Wade also referred to his family's lack of understanding about what he did: "they don't have the slightest understanding of it". Claiming that another does not understand can be read as a way to position the other as being unreasonable in their reactions. It suggests that they are at fault somehow for not understanding and if only they did understand they would be forgiving. For Wade that would mean not feeling disgusted. In some way, gaining understanding is constructed as being able to mend the damage and potentially as leading to forgiveness. In comparison, participants' descriptions of their families' response to their general violence was in the main less emotive and without this desire to be understood and there was no suggestion that they needed help.

The "disgust" (Wade), the "embarrassment" (Wade), the "disappointment" (Sean) and the lack of "understanding" (Wade) that families communicated to participants are reminiscent of those ubiquitous media reports where family members or neighbours express their surprise and shock when they discover that someone they knew well had done an act that appalled them, such as sexual violence, an act that they would have described as being completely 'out of character' for the perpetrator. Hence, young men who have been sexually abusive may be demonised, resulting in all their behaviours, relationships and interactions, both current and past, being scrutinised anew against this discovery about him, this new position of a sex offender. Such a perspective helps to re-constitute the unitary, humanist subject through the process of viewing the deviancy as characterising the young man's essential self.

Unlike the responses of family, the reactions of some friends were described as being more forgiving. Some of Wade's friends maintained their friendship with him and visited him in jail:

$\begin{array}{ll}\text { Shirley: } & \text { Yep and they're still your mates? } \\ \text { Wade: } & \text { Yeah. } \\ \text { Shirley: } & \text { Mm. So what does that say? }\end{array}$


Wade: [pause 5 secs] Um, [pause 3 secs] they don't care about what l've done.

Wade arrived at this conclusion after some thought, reasoning that because they remained his friends this meant that "they don't care" about what he did. While this can be read as implying that his friends accepted him for 'who' he was rather than what he did and so perhaps even forgave him, it also suggests that Wade may have considered his friends to be unconcerned or even dismissive of the serious harm his sexual violence may have caused since he thought "they don't care".

While Sean lost friends because of what he had done, he also kept some. He talked of one friend in particular and of having visitors who were aware of what he had done:

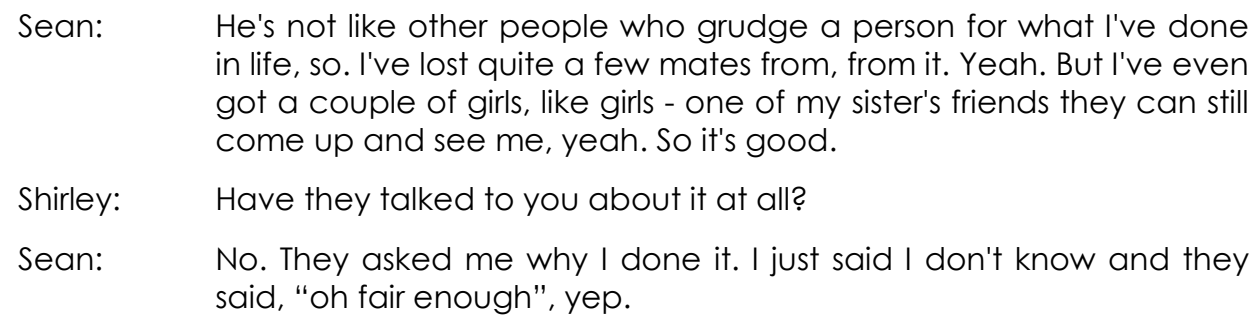

Sean explained that his friend is, "not like other people who grudge a person for what I've done in life", and seemed to suggest that his friend was unconcerned about his sexual violence. Indeed, he went on to mention that "I've even got a couple of girls, like girls" visiting him. Sean's emphasis on their gender can be read as putting forward the idea that if girls are still his friends then his crime can be positioned as not particularly serious, since his crime was against one of their own gender, that is, another girl.

While Sean and his friends had not talked about his sexual violence in any depth, some asked him, "why I done it" and were satisfied ("oh fair enough") with his explanation ("I don't know"). The silence around sexual violence can be read as not being restricted only to the offenders; rather Sean's friends can be read as accepting his silence without wanting to inquire any further. It may be that hearing about sexual violence is as difficult as talking about it.

In talking about his friends, Wade made the point that they had not been sexually violent:

Shirley: $\quad$ And what do they think about it? 
Wade: I don't know what they think about it but we don't talk about it. But they haven't done anything like that.

Wade's statement that his friends "haven't done anything like that" may be read as his attempt to position his friends as 'normal' because they do not sexually offend. In this way he cannot be positioned as being part of a group that is sexually violent, hence, he cannot be positioned as being more 'deviant'. Unlike the case of general violence about which participants spoke frequently of doing violence with their friends, for example, gang fights and aggravated robberies, no participant described taking part in sexual violence with a group of friends.

Perhaps one of the more negative subject positions available for young men who have been sexually abusive is to have done so with a co-offender. From the perspective of therapeutic intervention, if there is more than one young man involved in perpetrating a sexual offence, then they are considered to be more dangerous, more deviant and a higher risk of re-offending (Johnson, 2007). Given that sexual abuse primarily occurs within a sphere of secrecy and silence (Salter, 2003), then committing sexual violence with another perpetrator can be viewed as necessitating some kind of planning and communication. In addition, the possibility of cooffenders discussing the sexual assault afterwards and perhaps enjoying this and even sharing victims, can constitute the sexual violence as more 'abnormal' than that perpetrated by a solo offender and more serious because further offending is predicted.

When sexual violence is planned, it is viewed negatively. Within dominant discourses and practices of justice, as with any crime of violence, the notion of intention positions the violence and the offender more negatively than when the notion of passion is used (Gelsthorpe \& Padfield, 2003). Violence resulting from outof-control sexual or emotional arousal, such as anger, is often referred to as a 'crime of passion'. Premeditated violence, on the other hand, is planned and is punished more severely than an impulsive act stemming from passion. The involvement of emotions such as passion is taken to be a mitigating factor, whereas the act of planning can be read as implying the involvement of a conscious, rational mind in the decision to perpetrate the violence, that is, instrumental violence. In instances of premeditated, planned sexual violence it becomes difficult for an offender to position 
himself as 'not understanding what happened' or to speak of 'sexual urges' being the cause of his violence.

The negative subject positions available for young men who have committed sexual violence depends, in part, on the context of that violence. Co-offenders who commit sexual violence are generally positioned as being more 'sick' or 'weird' than single offenders within discourses of deviancy. The act of a gang-rape, while an act with co-offenders, however, is constructed in multiple ways. First, it can be viewed as action that requires some planning and communication, thus demonstrating some rationality and premeditation. Second, this type of sexual violence can be constructed as irrational, as being out of control. In this construction, perpetrators are considered unable to manage their sexual arousal. However, gang-rapes involving young men can also be read as starting as teenage sexual experimentation, in which group sex is part of the performance of manhood. Such an explanation can have a 'boys will be boys' flavour to it, which positions the offenders as simply making a grave error because they are high-spirited young men, who, 'naturally' have a barely controlled urge to have sex (Allen, 2002). However, this position can only be relevant if the victim of the gang-rape fits with discourses around normative (hetero)sexual relationships. The victim must be an adolescent girl for the explanation to work: that it was sexual experimentation gone wrong. Hence gang-rape when constructed as group sex enables young men to get it right as a 'man' within dominant discourses of manliness. Any other type of victim would position the co-offenders as 'deviant'.

\section{Speaking the Detail of Sexual Violence}

With most of the participants avoiding talk about their sexual violence, it was no surprise that only two (Wade and Rick) provided any detail on the sexual offences they committed that resulted in their being in jail. The most detailed account came from Rick. He was the only participant who talked freely about what happened and he was the only participant who claimed that he was innocent of the sexual violence charges. At the beginning of the interview, Rick ensured that I was made aware of his claim of innocence: 
Shirley: $\quad$ Thanks for coming. Maybe we'll just start with looking at what it's like here for you?

Rick: $\quad$ Yeah. Oh, it's quite um annoying actually. Um, just because of the fact that um I was found guilty but pleaded not guilty because like I didn't do it. But um the grounds that they had, there was no DNA evidence. Um. The only evidence they really had was three people saw some person leaving the scene. Um they were examined and all that sort of court process, um but their reconciliation of what the person was wearing and who, what the person looked like was quite different to the person I am, yeah.

Shirley: Oh. Okay. So you're saying that you didn't do what you're in here for?

Rick: Yeah. Yeah. Yeah.

Rick “pleaded not guilty because like I didn't do it" but was nevertheless convicted of the sexual offences. I needed to clarify that his not guilty plea was because he was claiming innocence, "So you're saying that you didn't do what you're in here for". Being innocent of a crime is not necessarily the only reason for pleading not guilty in court. In my professional experience, I have worked with men who attend therapy sessions in which they admit to their sexual violence but still plead not guilty in court in the hope they will not be convicted. Despite his claim of innocence, Rick was able to provide considerable detail of the assault, saying that he heard it all during the court process:

$\begin{array}{ll}\text { Shirley: } & \text { So what did they say that you'd done? } \\ \text { Rick: } & \text { Um. They said that I raped a } 17 \text { year old girl. Um. They said that } \\ & \text { there was a party at [location omitted] and um some, some of the } \\ & \text { stuff did happen like I'm they said I walked to a corner and um we } \\ & \text { had an argument which that did happen. But after that I left. Um. } \\ & \text { Apparently what they're saying is I got aggressive to her and } \\ & \text { pushed her in a bush and pulled down her clothes and physically } \\ & \text { raped her and um they said that she was screaming and oh all that } \\ & \text { sort of stuff and which made my term here a bit longer due to the } \\ & \text { fact that um the person didn't get off her or whatever the witness } \\ & \text { said. So yeah. } \\ & \text { [...] } \\ & \text { Right. I'm sort of getting the picture now, yeah. So was she raped } \\ & \text { by somebody else do you think? } \\ & \text { Um well there was signs of um a tore, a tear or something to some } \\ \text { Shirley: } & \text { part of her vagina or something like that. Um, but apparently there } \\ & \text { was someone else seen in the area um more to a description of um } \\ \text { Rick: } & \text { the witnesses. }\end{array}$

A frequent defence used to claim innocence is to also claim that the sexual violence did not occur. However, Rick did not question that the victim was raped, he accepted the physical evidence ("a tear or something to some part of her vagina") but then assumed that someone else was responsible. Rick described what happened when he 
mentioned how others spoke about him getting "aggressive to her and pushed her in a bush and pulled down her clothes and physically raped her", "she was screaming". I read Rick's willingness to talk and the detail that he provided as language produced by his claim to innocence because the shame, embarrassment and guilt feelings that other participants' described as stopping them from talking could not be a barrier to talking for Rick.

Wade also talked about his sexual violence. However, in comparison to Rick, his description of the assault was a very brief account with little detail, making it somewhat vague but nevertheless quite matter-of-fact:

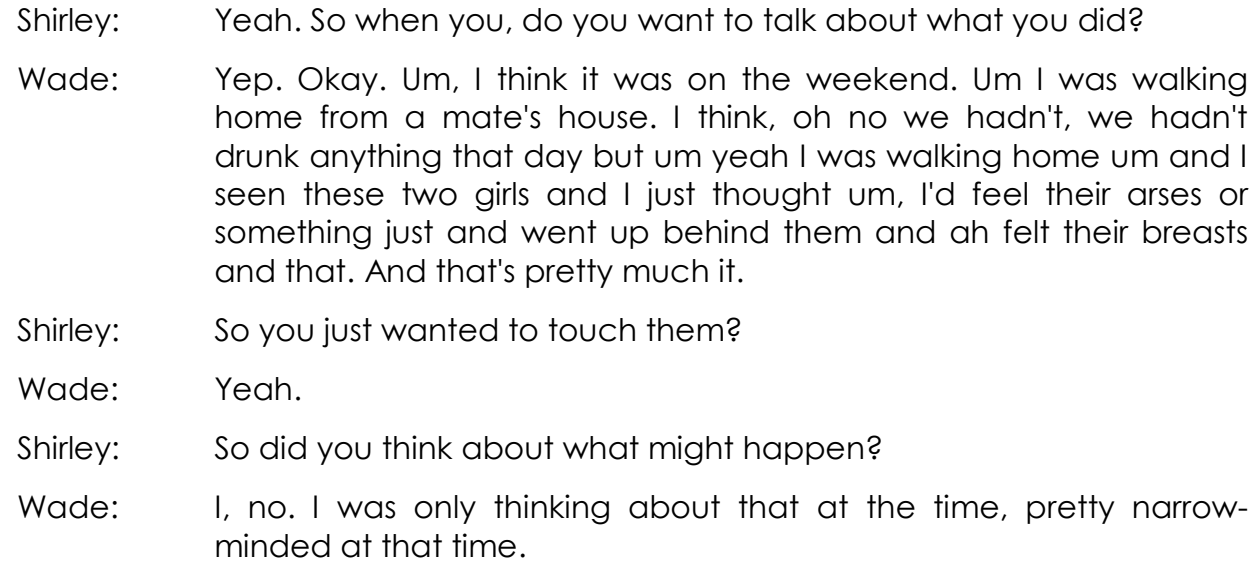

While there were moments of being specific, "thought um, I'd feel their arses", "felt their breasts", Wade then became vague with "or something" and, "and that". Additionally, his use of "just" within this description and ending with, "And that's pretty much it" operated to minimise the effect, suggesting these actions were not particularly harmful to the victims. Wade can be seen to draw on old patriarchal notions that it is acceptable for men to touch any woman's body parts: smacking women on their bottom was once viewed as a form of flattery. From this perspective it makes what he did seem less serious and almost unimportant since he was attempting to be a 'man'. Wade can also be read as being very focused on achieving what he wanted when he said he was "narrow-minded", that is, with a rationally driven goal to touch these young women. This can be seen to fit the notion of masculine entitlement being legitimate within dominant discourses of the gendered order (Connell, 1995). 
Using a life history approach with two young men who had sexually offended, Messerschmidt (2000a) described their sexual violence as an available masculine resource they used to become "real" men. Messerschmidt interpreted the young men's sexual violence as being a "resource for overcoming the masculinity challenges" (p. 286) these young men experienced by their peers in school. These challenges are defined as those "contextual interactions that resulted in masculine degradation" (p. 298). Therefore these young men described feeling powerful when sexually assaulting their victims and drew on notions of male entitlement to justify their actions. However, this means of 'doing' manliness did not improve their victimization at school. Paradoxically, from a poststructural perspective, it is possible to also read the sexual violence of these young men as not 'manly'. When being sexually violent, the young men also described themselves negatively, for example, as feeling worthless. Such a reading highlights the contradictions multiple subjectivities entail.

Wade also went on to talk of feeling "excited before it happened" and even though he "knew it was wrong" it seemed that carrying out the assault was all he "cared about at the time". Wade can be read as constructing the situation as one in which he was unable to control his emotional reaction through rational means and so he committed the offence.

When asked about the victims' reactions, Wade emphasised how quick the assault was:

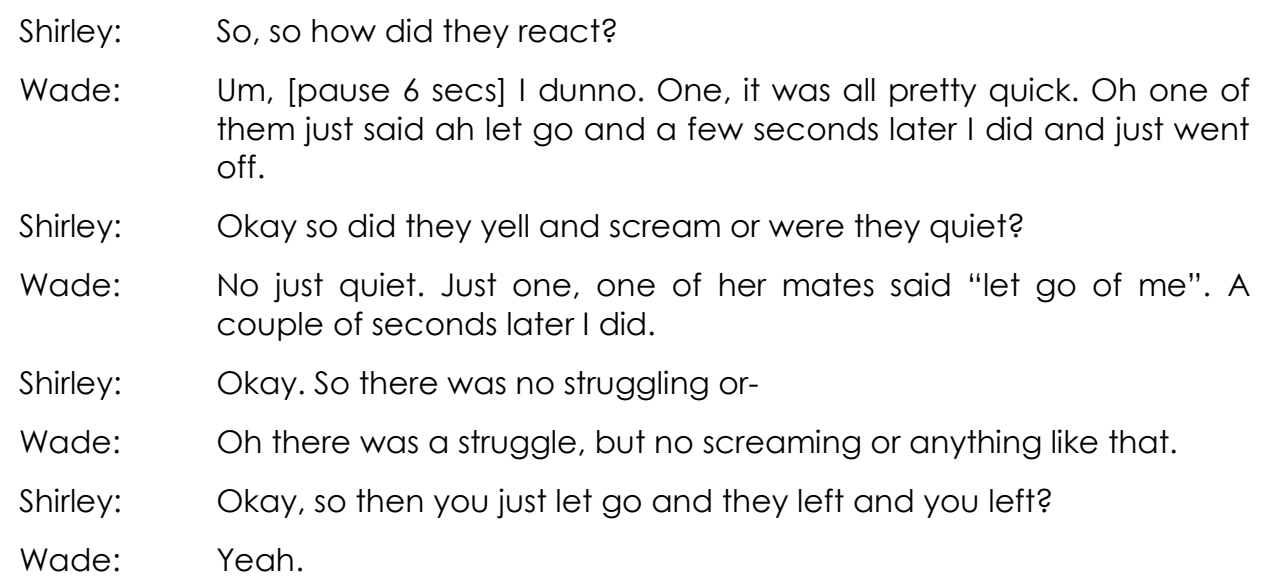


Wade's description may be read as making the assault sound relatively harmless because "it was all pretty quick". The short length of time the sexual violence took became even more prominent in Wade's description when he said it was over in "a few seconds". It is possible to position Wade as not as bad as those sex offenders who subject their victims to long-term abuse, but it is also a way of minimising what he did because it implies a corresponding lack of harm for the victims. Wade can also be positioned as a 'gentleman' because when one of his victims, a young woman, said "let go of me", to which he acquiesced "a couple of seconds later". Despite Wade's earlier description of being unable to control his desire to touch his victims, here his action of stopping the assault quickly can be read as constructing his actions as highly rational and in control.

Wade also talked about how he felt guilty after the assault:

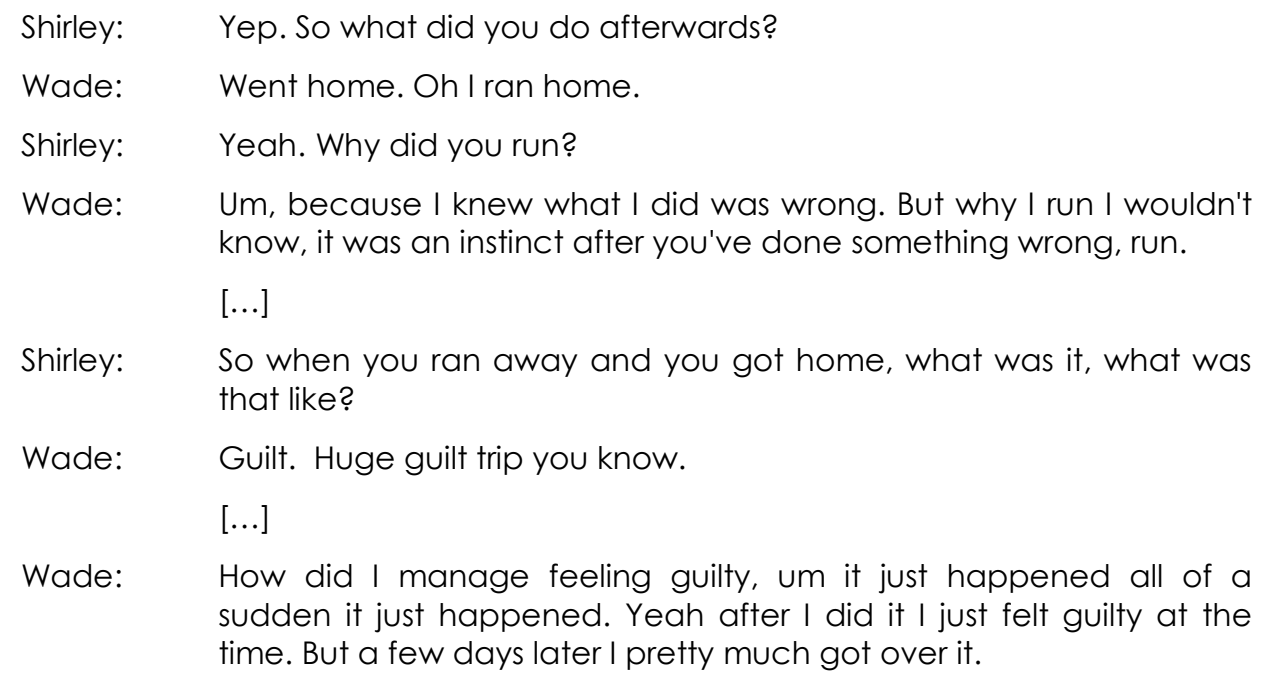
sudden it just happened. Yeah after I did it I just felt guilty at the time. But a few days later I pretty much got over it.

Wade "ran home" because he "knew what [he] did was wrong", and it was not until after the assault that his rationality was restored and a strong emotion of a different sort took over: "Guilt. Huge guilt trip". One reading is that feeling guilty positions Wade as experiencing remorse for what he did.

However, he then went on to say that "a few days later I pretty much got over it". Unfortunately for Wade, his ability to get over his guilt in a matter of days, positioned him negatively as not caring and not being sincere in his remorse. This could lead to questioning whether he really felt any guilt in the first place or whether it was self-preservation, fear of getting caught? However, within discourses of 
manliness Wade's ability to manage and gain control over his emotions in just a few days enabled him to achieve 'man' since being a 'man' is about controlling emotions and having the power to overcome them, that is, no longer feeling the emotion.

On the other hand, within either the context of the justice system or the therapy setting Wade can be viewed negatively because his ability to overcome guilt in a short time positioned him as heartless and no longer remorseful. Therefore contradictory positionings exist; either to be a 'man' within dominant discourses around masculinity or to be judged as having no remorse within the justice or therapeutic discourses. Inhabiting multiple subjectivities enables movement between these available subject positions and so prevents any dilemma of contradictory positionings developing.

\section{Reflections on the Experience of Their Victims}

When I asked participants about the impact their sexual violence had on their victims, most participants unsurprisingly had difficulty talking about this aspect. Sean, on the other hand, was able to talk about how his raping of his victim will "have affected her life". He said that if they were ever to meet up again it would be "a harder thing for her" than for him. He said he tried not to think about it because it was emotionally painful for him, as did Anthony.

In comparison to Anthony and Sean, Wade had thought quite a bit about his victims and the impact his sexual assault may have had on them:

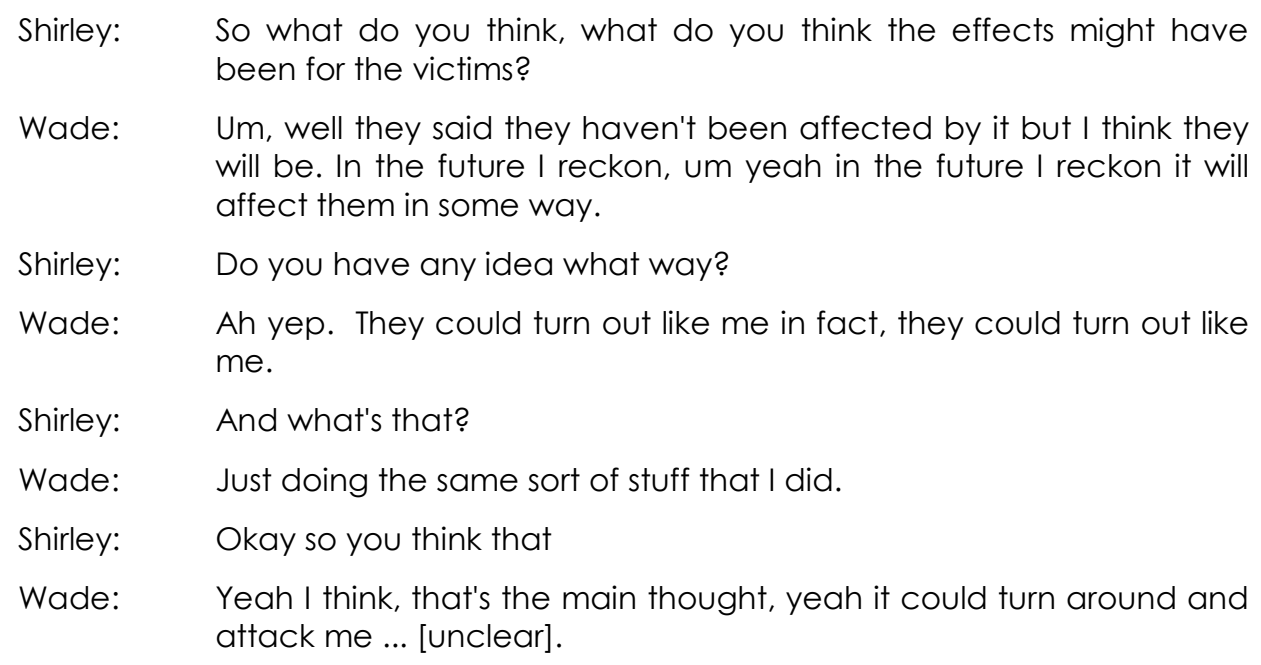




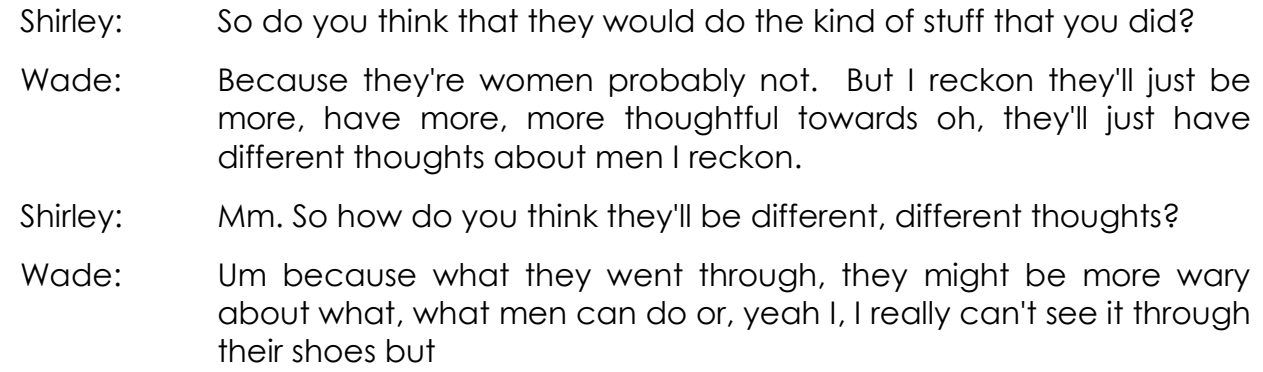

Even though Wade claimed the victims "said they haven't been affected by it", he saw it differently: "I reckon, um yeah in the future I reckon it will affect them in some way". In exploring this idea further, Wade stated that he thought his victims "could turn out like me", "doing the same sort of stuff that I did" and that they "could turn around and attack me". Wade's comments appeared to be constructing sexual violence as occurring because of the impact of the cycle of violence. (The cycle of violence construct was covered in Chapter Five) This cycle suggests that if a person becomes a victim then they will perpetrate that same violence in the future.

However, in trying to apply this logic to his own victims, Wade seemed to run into difficulty. As I have already argued (see Chapter Five), within the cycle of violence theory, the impact of gender is not well accounted for, which may explain why Wade seemed unable to sustain his idea, precisely because his victims were women, "Because they're women probably not".

Although Wade rejected his own theorising about his victims turning out like him and becoming sexually violent, he put forward the idea that "they'll just have different thoughts about men", and be "more wary about what, what men can do". This prediction of his victims being suspicious of and losing trust in men fits well with a feminist analysis of men's sexual violence against women (Bograd, 1990; Brownmiller, 1975; Gilmartin, 1994; Segal, 1996). Wade can be read as acknowledging that the impact of his sexual violence could have had a harmful effect on his victims. Thus he could be positioned as being empathic towards his victims.

As Wade contemplated the differences between his women victims and men generally, he gave further consideration as to why he did not think they would become sexually violent, like him. Firstly, he suggested "their self esteem is much 
more different compared to a man" and then went on to explain how he saw this difference:

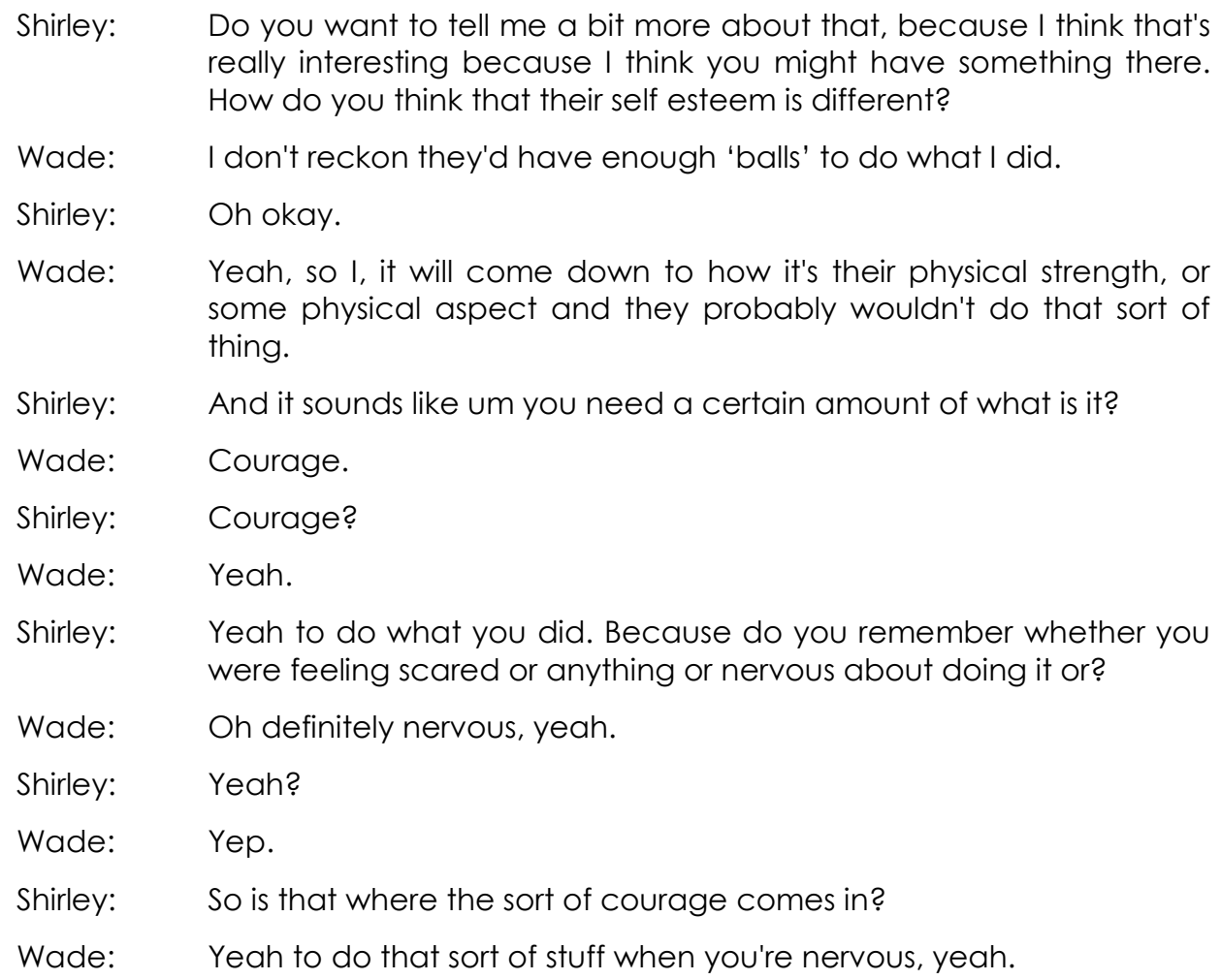

When Wade began talking of women's self-esteem as being different to men's and claiming that that is why they would not sexually offend, I was interested in what he had in mind. I was very surprised, though, when he described the difference as "I don't reckon they'd have enough 'balls' to do what I did" and that committing sexual violence takes "courage". He reasoned that women would not be sexually violent because they would have neither the physical strength nor the necessary courage. I read Wade's reference to 'balls' as a metaphor for enacting masculine power, therefore, Wade could be read as constructing sexual violence as a way to successfully perform 'man' because of the strength it takes and he demonstrated his courage by overcoming his nervousness. Of course, this also positions women as lacking in all these attributes and as being 'other' to man.

\section{Possible Explanations for Sexual Violence}

Although participants were unable to offer explanations for their sexual violence when asked directly, they provided some ideas and indications of their reasoning 
indirectly. One idea; that the discourses of traditional masculinity were involved in producing sexual violence against women, became evident in Rick's comments. He spoke of believing that sexual violence occurred from young men's attempts to be "macho" men, which he also considered was the reason for young men's involvement in gang fights.

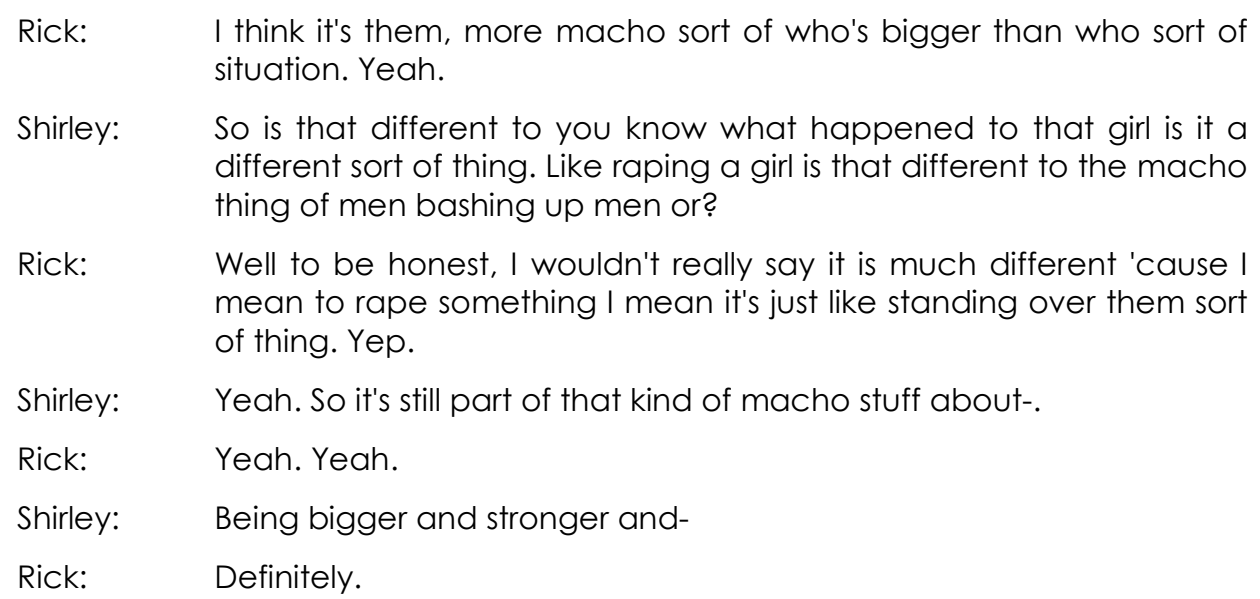

Rick's comments can be read as suggesting that power and control are involved in sexual violence when he offered the idea that rape is about men being macho, "it's just like standing over them". Rick may be seen to draw on a feminist discourse of rape when he explained that the reason men rape women is to be "macho", the same reason he said men assaulted other men, "I wouldn't really say it is much different". He was contradicting the notion that rape is a result of a man being 'out of control' with sexual urges, instead he suggested that rape was a way of gaining control and thereby being a 'man'. It is possible that because Rick has made the claim of innocence in regard to sexual violence that he is able to take such a position that enables him to make 'antimacho' comments.

While participants utilised ideas of traditional masculinity in their constructions of sexual violence, the notion that such violence was about sex was also raised. Wade did so as he talked about issues around sex being relevant to his sexual violence. He began by discussing his discomfort when he was around women:

\footnotetext{
Shirley: $\quad$ So do you feel uncomfortable around women or are you scared you'll do it again or?

Wade: $\quad$ No l just feel uncomfortable around some women, $\mathrm{mm}$.

Shirley: $\quad$ Do you know what kind?
} 
Wade: $\quad$ Mm attractive women.

Shirley: So what's that about do you reckon, why is that?

Wade: [pause 8 secs] Oh I dunno. ... [unclear] sex or something. [slight chuckle].

When asked, Wade thought that being "uncomfortable around some women" was somehow related to "sex or something". Wade's chuckle when he said this could be read as him finding the idea of sex or talking about sex as somewhat embarrassing or anxiety provoking. If sexual violence is seen as being about sex, then Wade can be positioned more positively within the discourses of normative sex, perhaps as a young man experimenting with sex.

Wade extended the concept of sexual violence being about sex when he talked of what seemed to be a simple solution to stop his sex offending, "I don't know why I just don't go out and get a girlfriend or something like that." However, he did not want to, "Because women are too complicated." Wade can be read as positioning women as mysterious objects, as if they are a different species to men, requiring a great deal of understanding in order for it to be possible to have a relationship with them. This concept of women as 'other' fits the concept of hegemonic masculinity and the gender order in which men are defined as 'not women' (Connell, 1995).

Wade continued to describe more of his reasons for not wanting a girlfriend:

Wade: $\quad$ Um [pause 7 secs]. Well I don't really want to, I don't want to be with a woman like everyone else is. I don't want to, I don't want to have to have a girlfriend or something like that. I just want to be able to satisfy my needs and get it over and done with. Yeah I don't want any attachment of any kind.

Wade applied an instrumental logic to his idea that having a girlfriend might stop his sexual violence. It did not seem to be a solution because not only did he not "want to have to have a girlfriend", but also because he just wanted "to be able to satisfy [his] needs". If women are "too complicated", then developing a relationship would seem to be too much trouble for Wade when all he wanted was to satisfy his physical needs. Aspects such as emotional connection or romantic love that are often associated with normative sexual relationships were excluded, "I don't want any attachment of any kind". Wade constructed sexual intimacy as a mechanistic act in which he actively rejects emotional or bodily intimacy. He wants to "get it over and done with". Such a focus on exclusively meeting his physical "needs" may seem to 
enable him to achieve the 'man' position within dominant discourses around masculinity. However, Wade can also be positioned as 'getting being a man' too right since he has taken the focus on meeting his physical "needs" to an extreme. It has been argued that within the 'male sexual needs' discourse there is a "glorification of the male 'sex drive' and male orgasm 'needs' amounts to justifying men in whatever they have to do to get intercourse - even rape - and this defines the 'normal' male as one who is 'hungry' for intercourse" (Hite (1977) as cited in Gavey, 1989, p. 470).

While Rick denied he committed the sexual crime for which he was jailed for, the victim claimed it was him. Notions about romantic relationships and their ending were implicated in Rick's comments when I asked about what relationship he had with the victim:

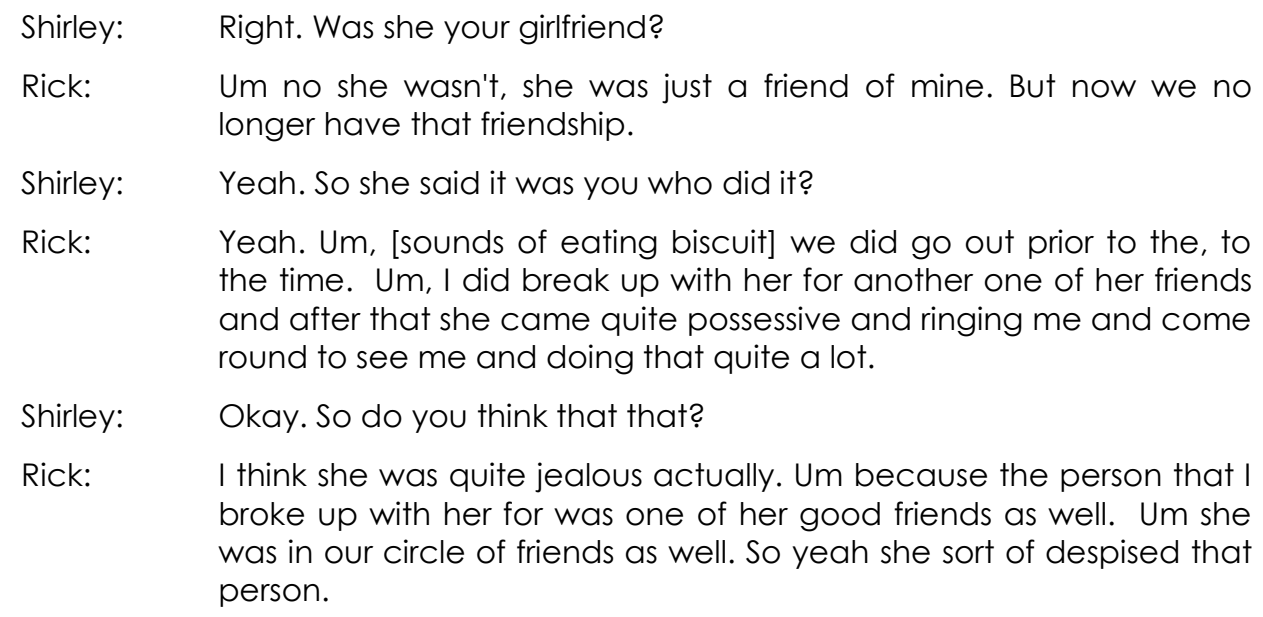
the time. Um, I did break up with her for another one of her friends and after that she came quite possessive and ringing me and come round to see me and doing that quite a lot.

Shirley: Okay. So do you think that that?

Rick: I think she was quite jealous actually. Um because the person that I broke up with her for was one of her good friends as well. Um she was in our circle of friends as well. So yeah she sort of despised that person.

Although the victim was not his girlfriend at the time of the rape, she was an exgirlfriend. In explaining why she would accuse him of raping her when he stated he did not do it, Rick drew on the classic notion about the vindictiveness of a spurned woman when he suggested that she had became "quite possessive and ringing me and come round to see me" and "quite jealous actually" after he broke it off with her to go out with her friend. Since Rick had claimed innocence for the rape, he may also be attempting to position the victim as a young woman making false rape allegations, thus positioning him as the victim. Instead of the idea that the rape was perpetrated by another man as Rick suggested earlier, this proposal of a false rape claim tended to work in his favour when it was coupled with the idea of consensual sex in the past. 
The effect of false rape allegations is to make defining any practice as either sexual violence or consensual problematic within the justice system as it often becomes a debate that is reduced to a man's word against a woman's and potentially reinstates old rape 'myths' (Gavey \& Gow, 2001).

\section{Conclusion}

This research suggests that sexual violence is constructed as a non-rational event, and is therefore not able to be discussed rationally, making it difficult for young men to talk about. As rationality is associated with performing 'man' correctly, the participants' silence around their sexual violence can be seen to support this positioning. Participants' considerable reluctance to talk about their sexual violence was also related to the negative emotions that the issue raised for them when they reflected back on what they did.

When asked directly about why they thought they had been sexually violent, participants struggled to come up with any ideas. However, it was possible to identify some of their ideas, particularly when they talked about their victims and to locate these ideas in wider discourses. There seem to be few possibilities for young men to explain their sexual violence without being positioned negatively as 'abnormal' and 'deviant' within discourses around pathology. However, when they drew on dominant discourses of manliness they constructed their sexual violence as involving bravery and courage and also of controlling others.

From this analysis of participants' talk, sexual violence is unexplainable, it is not rational, not able to be subjected to reason and it is not able to be spoken. This is a very different picture to participants' talk of their general violence. Participants are positioned differently in the discourses around general violence compared to the discourses of sexual violence. As perpetrators of general violence they are considered to be strong young men, defending their reputations as being 'tough', being in control, standing up for themselves and not backing down. These are all attributes that are seen as positive within dominant discourses of traditional masculinity. In contrast, as sex offenders they are positioned as 'weird', 'abnormal' and 'sick'. The young men who have committed both types of violence are therefore 
positioned in contradictory ways and so inhabit multiple subjectivities in relation to their violence. The differences and contradictions between their general and sexual violence are also evident in the next chapter where I explore the issue of intervention for participants in relation to their sexual violence. 


\section{CHAPTER EIGHT}

\section{INTERVENTION FOR SEXUAL VIOLENCE}

After exploring participants' talk and silences, and after identifying their ideas around their sexual violence in the previous chapter I now turn to their talk about intervention in relation to their sexual violence. Just as there were differences between their talk about their general violence compared to their talk about their sexual violence, so it was with their ideas on intervention. In my exploration of intervention, noticeable differences emerge between how the young men viewed intervention for their sexual violence and how they viewed intervention for their general violence. These differences were striking. Participants had not had nor were they involved in any interventions for their sexual violence, therefore, in this chapter, I look at what relevance their exposure to intervention programmes for their general violence had for their sexual violence. Next, I trouble the participants' quest for answers and for understanding about why they were sexually violent. I also scrutinise their desire and expectations for specialist intervention. Finally, I explore the fears some participants expressed about attending a sex offender intervention programme in the future within the adult prison. Throughout this coverage, I consider the influence and implications of the dominant theories and intervention approaches of mainstream psychology and also highlight how performing man within dominant discourses of traditional masculinity may be achieved.

\section{Intervention Experiences}

In Chapter Six, I explored participants' experiences of various interventions targeting their general violence or other crimes. I was interested in whether they thought there 
were any strategies that were useful or relevant to their sexual violence. Unfortunately, none of the participants talked of benefiting from these interventions in relation to their sexual violence, or of being able to understand why they were sexually violent. Wade made these points and also described his disappointment at not getting enough individual attention in the unit:

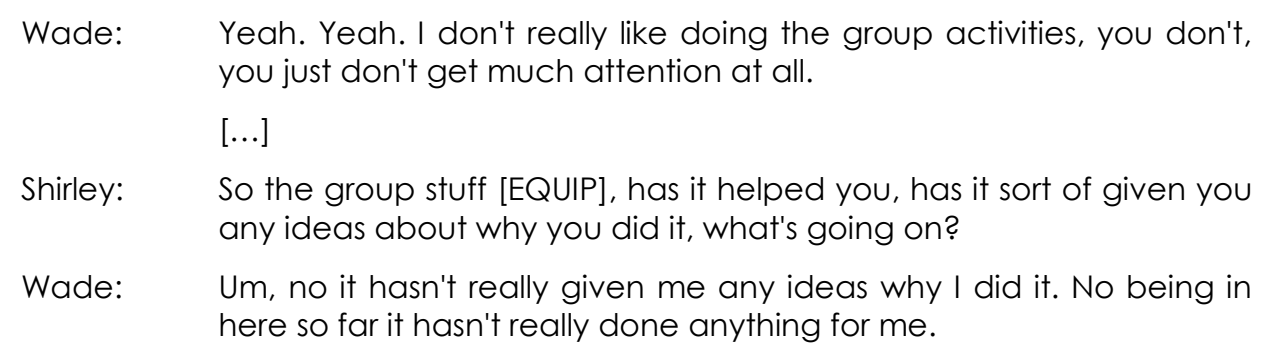

Similarly for Anthony, in referring to an intervention programme designed to identify his pattern of offending, it seemed that he was unable to apply any learning to his sexual violence:

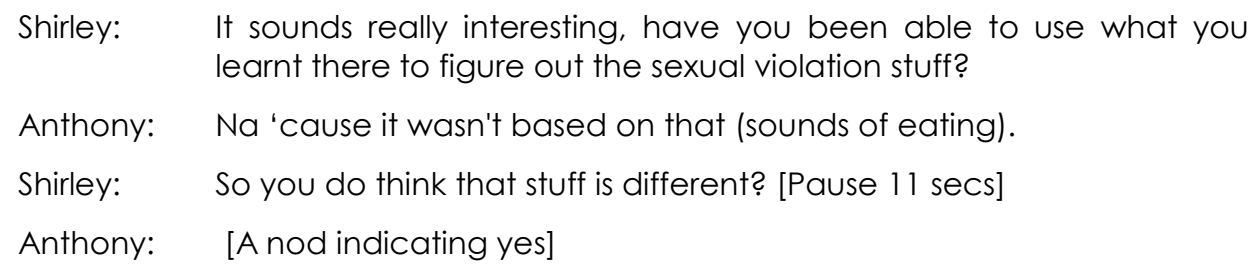

Anthony could not apply the concepts from this intervention programme to his sexual violence. This is despite the majority of the interventions for sexual violence, such as relapse prevention, also utilising a similar approach to the programme Anthony spoke of, which examined what is known as a pattern of offending (Johnson, 2007). Such an inability to apply these ideas may be because Anthony constructed his sexual crimes as being different to his general violence or other crimes. As we have already seen, the two types of violence, general and sexual, are spoken about by participants as being very different and as being disconnected from each other. Therefore believing that different intervention approaches are required for each of them follows this logic. Even within the literature and intervention practice, this difference is reflected. Working therapeutically with sexual offenders has become a highly specialised field of enquiry and professional practice. However, it is possible to see that the broad concepts thought to be implicated in causing general violence, such as the cycle of violence, a lack of social skills, the inability to 
control arousal or the effect of drugs and alcohol are also considered as causal factors for sexual violence. Consequently, the intervention approaches for both types of violence share many similarities.

Despite intervention programmes in New Zealand for young men who have been sexually abusive existing in both the community as well as one specialist secure facility, I was surprised to find that none of the participants talked of being offered any intervention that was designed to specifically address their sexual violence. Instead, what was available was a mandatory specialist sex offender intervention programme that some of these young men would be attending that was located within the adult prison system. Although, participants could not enter this programme until they were adults themselves (18 years old), which was more than a year away for some. Participants spoke of their frustration about having to wait for such specialist intervention:

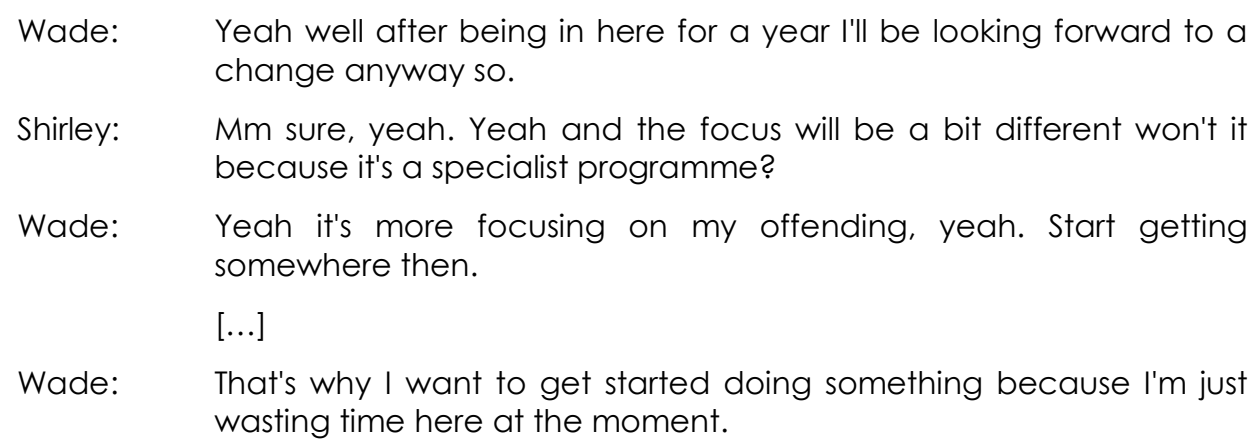

Unlike participants' reactions to intervention for their general violence, Wade conveyed an interest in attending intervention, "Start getting somewhere then", but he can also be read as expressing frustration at not yet receiving specialist intervention when he spoke of "I want to get started and I'm just wasting time here". Wade appeared to be ready for action and motivated, both characteristics that are viewed positively from an intervention perspective and that positions Wade as a good candidate for intervention. In addition, Wade's focus on action can be read as agentic and so as performing 'man' correctly.

Wade directly expressed his interest in undertaking intervention for his sexual violence when I asked him whether he thought he should be locked up:

Wade: $\quad$ Um, no not confinement. I think I should be getting help. 
Wanting "help" is in sharp contrast to how participants spoke about intervention for their general violence in Chapter Six; where intervention was seen as being mostly irrelevant for them. To explore this contradiction further, I focus on participants' talk about their not understanding why they were sexually violent.

\section{The Why Question: A Target for Intervention}

Most approaches to intervention claim that some form of change in the object of the intervention is an aim. In order to effect change it is logical to expect that identifying a target for change is necessary. Therefore what a person considers to be the cause of their problem is generally explored. When asked about their reasons for being sexually violent the predominant response from participants was not knowing why. Anthony, for example, could say little beyond uttering a few minimal responses such as, "Dunno". Like Anthony, Wade came up with the same answer, that is, he did not know why he was sexually violent:

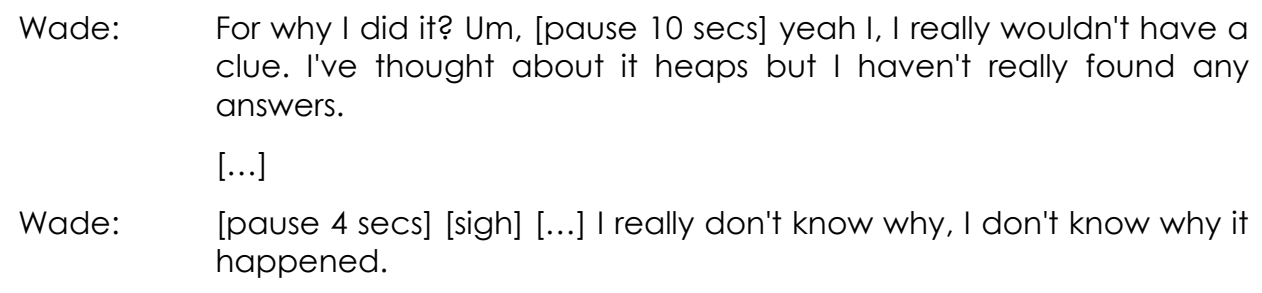

Not withstanding their reluctance to talk about their sexual violence, some participants were keen to talk at length about their not knowing why they were sexually abusive. Even though Wade had "thought about it heaps", he still had not "really found any answers". Sean also spent a great deal of time thinking about why he did it:

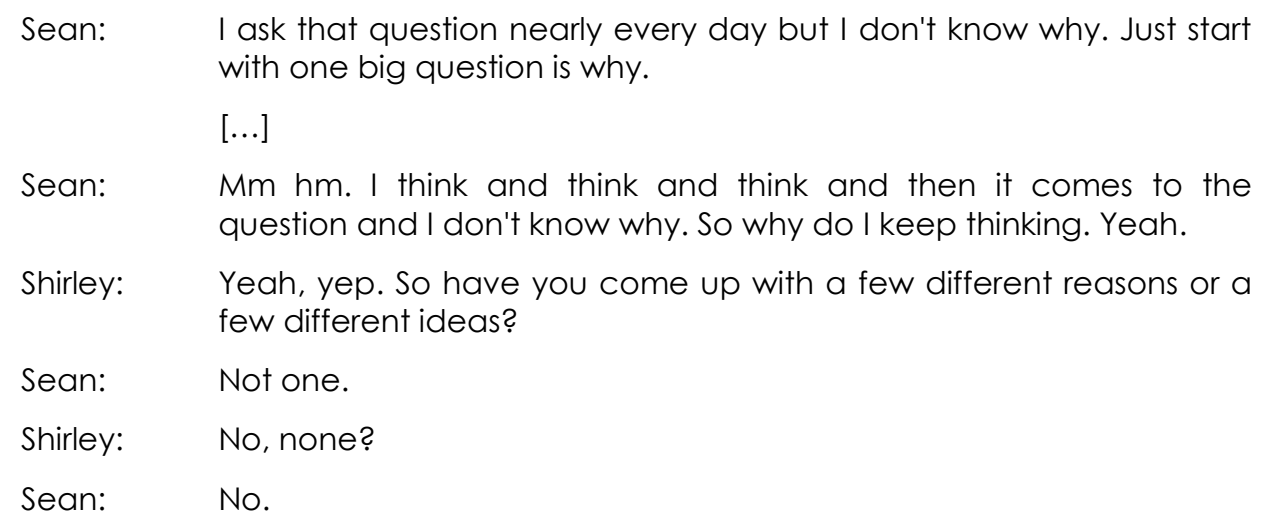


One reading of the focus these young men have on not being able to explain their sexual violence is that it is a successful way of preventing any further conversation about their ideas on the topic. Their puzzlement and their attempts to figure it out, however, may be read as applying significant effort to rational reasoning (therefore 'manly') in that they can be seen as trying to undertake a very difficult task, as Sean said "I ask that question nearly every day", "I think and think and think". But their lack of success that Sean described "I don't know why" and their lack of ideas, "Not one" according to Sean, can be read as indicating that an answer does not exist. Therefore the failure is not theirs.

Nonetheless, both Wade and Sean made it clear to me that they wanted to know why they were sexually violent. Firstly, Sean linked this to his desire to know himself:

Shirley: $\quad$ So what's it like having questions and you can't answer them?

Sean: Hard because I like to know myself and then I think that like if I don't answer them well I'm never going to know, so.

Next, Wade described his many 'why' questions:

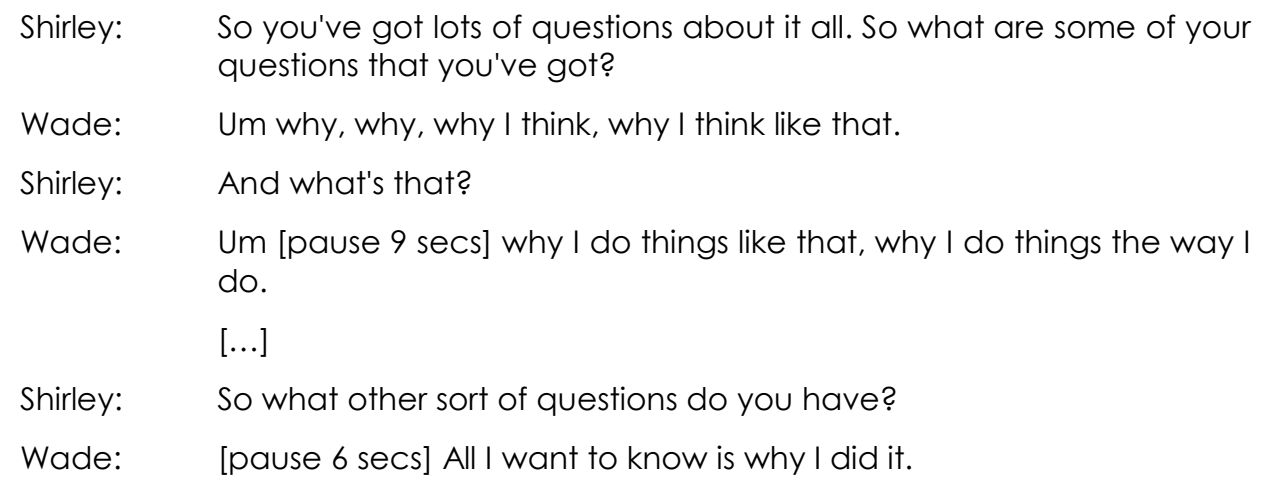

Despite Wade having many questions, "why I think like that", "why I do things the way I do", ultimately his questions all coalesce around, "All I want to know is why I did it". Finding the answer to his one question of , "why I did it", can be seen to have become something of a quest for some of the participants that they were not able to move beyond. These young men can be read as constructing their sex offending as difficult, if not impossible to explain, but being able to explain would make it controllable. In contrast, they had no difficulty in offering multiple reasons for their general violence; indeed, there was little consideration of 'why' they were physically violent. 
A dominant construction of sexual offending is that it is 'deviant' or 'abhorrent' behaviour that is unacceptable. Therefore those perpetrating such violence are positioned as 'abnormal', as 'sick' or as 'deviant'. Within this context, continually asking or wondering 'why' they did it enables participants to avoid such negative positions. If the 'why' questioning is read as a circular process, then there can never be a satisfactory answer and thus the perpetrator can never be finally positioned as 'sick'. According to Jenkins (1990), the search for causal explanations for sexual violence is of little benefit since it can be an endless quest. Not only is any answer possible, but every time 'why' is answered, the answer leads to another 'why' question being asked, thus becoming a circular process. For example, one possible answer to, 'why was I sexually abusive?' is 'because I wanted to humiliate her', which leads to another question, 'why did I want to humiliate her?', which could be answered, 'because she made fun of me', which leads to another why question, 'why did she make fun of me?' and so on. This circular process is an endless and fruitless endeavour that ultimately results in blaming others. The 'why' questioning then can be seen as an effective means to avoid responsibility for sexual violence, but more importantly, from a discursive perspective, staying with asking why constructs sexual violence as unfathomable and so the young men can avoid the negative position of being 'abnormal' within the dominant discourses of sexual offending.

If, on the other hand, sex offending was 'normalised' or even admired (as can be read as occurring for general violence), then these young men would not be trying to work out why they did it. Instead, they would be drawing on the idea that being sexually abusive is an 'everyday', taken-for-granted, 'normal' male activity. While this notion does not fit the dominant discourses around sexual violence that views such behaviour as 'detestable', a feminist analysis offers an alternative that views men's sexual violence against women and children as indeed 'everyday' because it is part of the practices of men's dominance and the patriarchal order in which determining a distinction between consensual and non-consensual sex becomes difficult (Gavey, 1992). This suggests that a public/private dualism exists in which sexual violence is publicly denounced, but in private, practised extensively. 
The explanations that are available from feminist analyses of male violence do not position offenders as 'sick'. Instead, they are positioned as active members of a social system whose violence is enabled by the patriarchal gender order, which in turn supports this social structure (Brownmiller, 1975; Segal, 1996). One fundamental idea about using violence to maintain male dominance is that while not all men are violent, all men are nevertheless seen to benefit from the resulting patriarchy, and it is not possible for men to escape this benefit (Connell, 1995). Rape for example, may be an act by one individual man, but the fear of rape amongst women may position all men as potential rapists and therefore to be feared. Being feared is a position of power.

Within a construction of sexual violence as male patriarchy, one subject position available for sexual offenders is that of being a rational actor and part of a larger social system. This may be a challenging position for young men. Such a rationalist position suggests that they actively choose this form of violence to achieve what they want. They are therefore knowingly responsible, and the answer to 'why did I do it?' might be something like, "I did it because I wanted to, saw an opportunity to do so and then went ahead'. Such an answer would likely position the perpetrator within discourses of pathology as 'abnormally bad', as cold and calculating, being without empathy and as being very dangerous since he used rationality to justify his violence.

Neither of the two positions available, that is, 'abnormally bad' or 'sick', are likely to be very attractive to participants, given the power of normative constraints within dominant discourses of manliness (Connell, 2000). Therefore it may be preferable for the young men to continue not understanding why they were sexually violent, and equally to continue to desire an answer to their 'why' question. This offers what might be thought of as an 'unknowing' position that may be a more bearable alternative. Asking 'why' is rational and excludes consideration of a worst alternative - that they were not manly. 


\section{Participants' Expectations of Intervention}

\section{Wanting answers to why: Young men's hopes}

Sean and Wade talked extensively about what they hoped to gain from attending the specialist sex offender intervention programme. Both were hopeful of finding answers to their 'why' questions, as Sean explained:

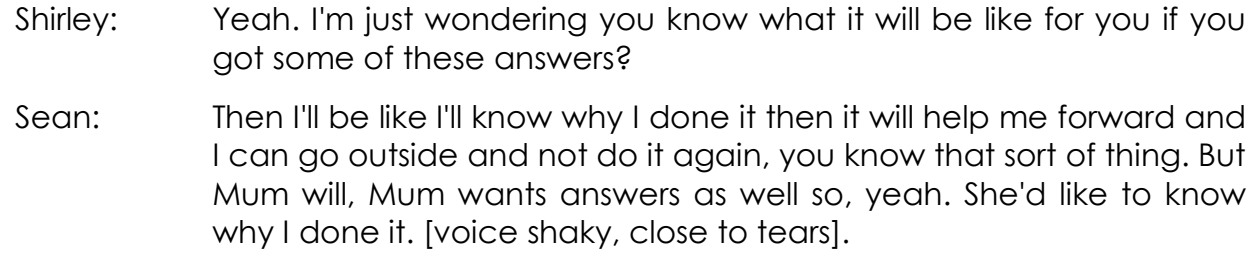

It seemed that finding answers was viewed as being able to achieve a number of things. Sean was close to tears when he said his "Mum wants answers as well". Sean's emotional response may be read in any number of ways. One way is that Sean was demonstrating empathy for his mother, particularly with regard to her incomprehension of what her son had done; this also seemed to fit well with his own experience. Another way he can be read is as connecting with his own hopes that once his mother understood she may then be able to accept him as a son.

In addition, Sean equated gaining understanding of why he was sexually violent, "I'll know why I done it" with not being sexually violent again, "I can go outside and not do it again". This implies that once Sean has the answer to why he did it, then presumably either that knowledge itself will somehow be enough to prevent a reoccurrence of him being sexually violent or he will be able to take some action that will ensure he does not do it again. This constructs his behaviour as a mistake, one, which if he had known better, he would not have made in the first place. This is suggestive of a rational approach that is revered in dominant notions of masculinity as well as constructing the human body as analogous to a 'machine'. The latter approach is not an unusual viewpoint in positivist psychology, as mechanistic terms are often used to explain human behaviour. For example, in the information processing approach human cognition is seen as equivalent to computer functioning (McShane, 1991). Thus rationality will prevail, as the machine operates by predetermined rules of physical mechanics. It is easy to see the parallels to the positivist scientific paradigm, in which understanding is linked deterministically to 
knowledge; and to the modernist concept that scientific knowledge leads to our freedom, and gives us control over our bodies, over nature, over the world (Gergen, 1990). Of course, within this construction there is no room for such a question as: What happens if he does not understand why he was sexually abusive?

\section{The talking cure}

In order to get the answers they sought, participants spoke of talking about their sexual violence within a therapeutic context. Unlike participants' views of counselling as being irrelevant to their general violence and the strong dislike they expressed about it, when it came to their sexual violence no such barriers seemed to exist, as Wade described below:

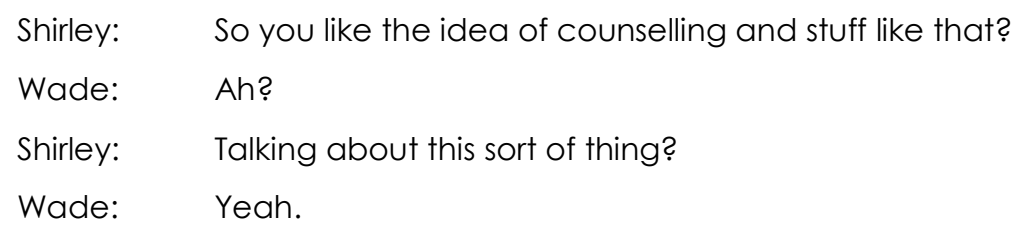

Despite the difficulty these young men had in talking about their sexual violence, they appeared to accept that it was a necessary part of the specialist therapeutic intervention process. Sean explained that to answer his 'why' question he would also be required to provide answers within the specialist sexual offender intervention programme:

Sean: $\quad$ Because I know that it will be a lot harder than here because you
have to talk about everything you did and they're not going to
take, I don't know for an answer, so yeah. [small chuckle]

Sean can be read as suggesting that the ubiquitous "I dunno" response is actively used to avoid talking about this issue, but would not be acceptable. Equally, nor will denial be accepted, according to Wade:

Wade: $\quad$ To help the courses work, I think honesty, (pause 4 secs) about sex and every thing.

Both Wade and Sean may be read as being open, willing and motivated to engage with specialist intervention as well as taking some responsibility for making intervention work for them, that is, in answering their 'why' questions. They also showed an awareness of the expectations that such intervention would have on them. They may therefore be positioned as willing therapeutic subjects, who already have 
an understanding that talking in detail about their sexual violence will be an important part of the therapy process and any reluctance will be considered denial or dishonesty and constructed as resistance (Marshall, Fernandez, Hudson, \& Ward, 1998; Salter, 2003). Hence this position as therapeutic subject will enable their talk, and it has already enabled Wade and Sean to accept that this is precisely what they will do within intervention.

Within particular contexts, talking has been constructed as having powerful effects. Within a Foucauldian concept of confessions (Rouse, 1994), the practice of counselling has strong parallels to the practice of the confessional in Christian religions, for example, the confidentiality aspect, the positioning of the counsellor as the professional expert, the cathartic effect, of 'getting it off one's chest' all of which may be regarded as similar to handing the problem over to a higher power. Even the non-judgemental attitude of the counsellor can be experienced as forgiveness and so likened to the absolution offered by a priest.

Whilst Sean and Wade can be read as demonstrating their willingness to be a part of intervention, in recognising the difficulty of being able to talk about their sexual violence, Wade explained that the most important task for new inmates is, "learning to talk about it first". But he suggested that this talking should focus on their thinking:

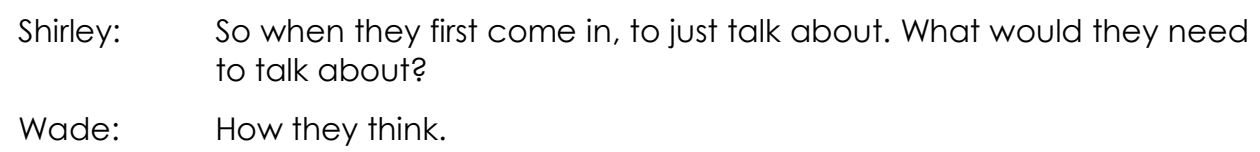

Wade is very precise that "How they think" should be considered appropriate material for talking about their sexual violence. This fits well with rationalist notions of manliness. Talk of feelings and emotions was notably absent from Wade's proposition. Such a construction of counselling-type intervention makes it more acceptable as a 'man' if it is focused on thinking rather than on feelings. In this way, the therapeutic gaze may be more technical rather than reflective, so that even the exploration of emotions and feelings can be dealt with mechanically. Cognitivebehavioural therapy which is frequently the current therapy of choice may be read as offering just such an approach. Within the sex offender 'treatment' field any thoughts 
which are considered to have caused the sexual violence that are 'discovered' are judged to be cognitive distortions, that is, thinking errors that are used as excuses to be violent (Johnson, 2007). Such erroneous thinking is seen to fall outside what is viewed as rational because it resulted in a non-rational crime (sexual violence) and is thus separated off as an error that once identified can be expunged. Therefore a cognitive-behavioural approach is consistent with the rationality within dominant discourses around traditional masculinity.

\section{Wanting to 'remodel' thinking}

Wade was able to further articulate his ideas around the need for intervention to focus on thinking. He also described, in considerable depth, the specific issues that he thought were the important ones he needed to deal with. The next quotation from Wade provided a picture of the issues with which he seemed to struggle in relation to his sexual violence. He spoke of his need to change his thinking because he was able to link this to the action of being sexually violent. Wade described what he wanted the specialist intervention programme to help him with:

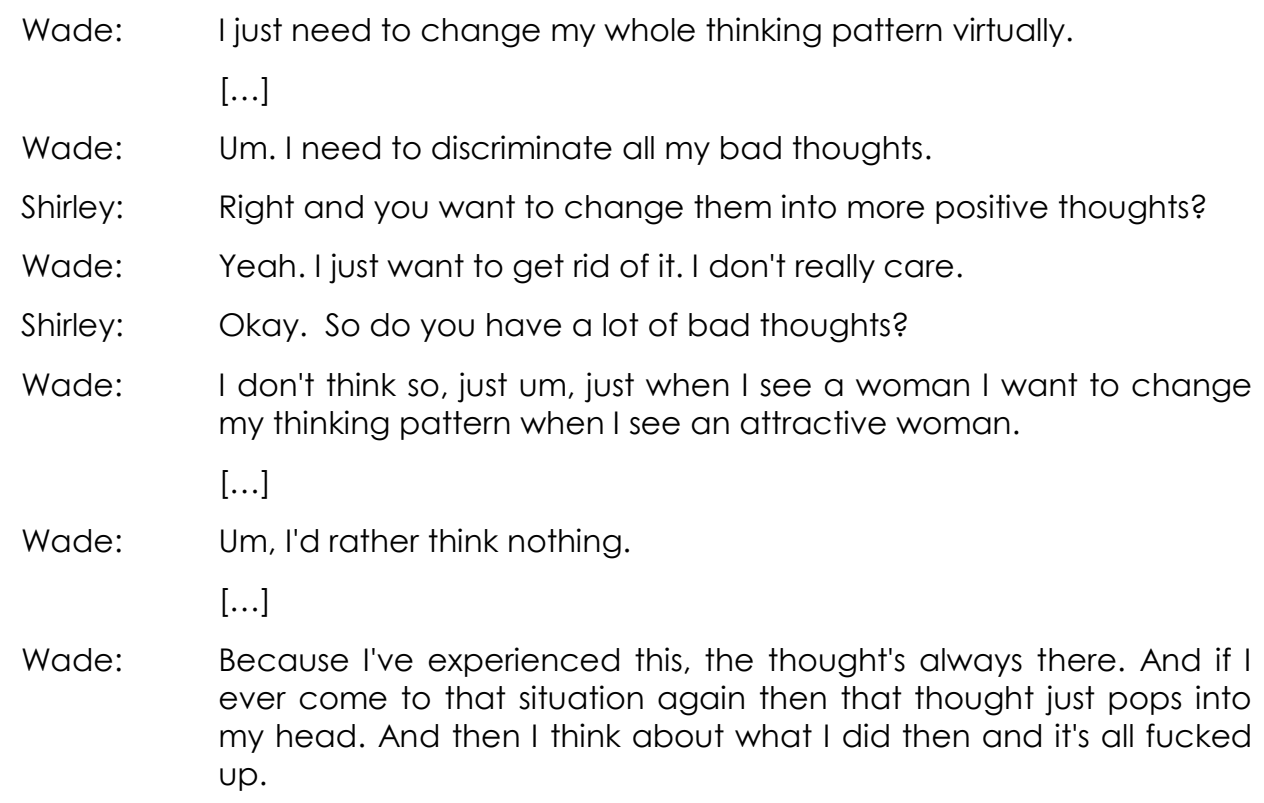

The way Wade talked of changing his "whole thinking pattern" suggested a mechanistic process of fixing a fault, a task that he constructed as achievable and perhaps relatively simply. From this perspective, thinking can be seen as a rational object that is separate from himself as a young man and separate from any emotions. Within the context of sexual violence the notion of having "bad thoughts" and his 
concern about acting on them can be read as Wade thinking about doing hurtful, violent or even sadistic things to the "attractive women" that he noticed, thus positioning Wade as dangerous and 'sick'. From an intervention perspective, having such "bad thoughts" can position Wade as volatile and a high risk of re-offending.

Equally though, the "bad thoughts" that Wade mentioned can be read as being associated with the concept of sex because sex is often constructed as 'bad', 'naughty', or 'dirty'. From this perspective Wade's "bad thoughts" may be viewed as a common expression of being a 'man' within discourses of traditional masculinity. Wade also spoke of only having "bad thoughts" when he sees "an attractive woman". This could mean that he does not experience such thoughts when seeing women who are not attractive to him. This can be read as drawing on a commonly-held idea about sexual violence, that is, that such violence is about sex (Segal, 1996). From this perspective, then, Wade can be positioned as a healthy, 'normal' heterosexual young man who is sexually interested in the opposite sex, but only those who measure up to the dominant Western concept of beauty.

Wade can be read as not taking up the positions of 'abnormal', 'sick' or 'weird' if his victims are attractive women. This is because such a choice may be considered to be the closest match to what is viewed as the dominant normative sexual relationships, that is, similar aged, heterosexual partners. Therefore Wade can be positioned as a 'normal' young man, even if slightly misguided, within discourses of manliness.

Wade talked of how he thought about his sexual violence when he found himself in a similar situation, "and its all fucked up". One reading of his comments could be that for Wade, remembering his sexual violence led to his being sexually violent again. His experience of the "thought just pops into my head" is suggestive of a lack of control over his thinking. Viewing Wade's comments from the perspective of a sex offender intervention programme, it is possible to position Wade as a high risk for further sexual offending. This is because, firstly, his thinking is read as not being under his control, which is presumed to be about wanting to be sexually abusive; and secondly, Wade's ability to identify his thoughts as being bad may suggest some familiarity with them, which may in turn be read as indicating an ingrained pattern of 
thinking, perhaps fantasising, which is often viewed as rehearsal for future offending (Johnson, 2007).

At the same time, Wade can be positioned as being a very good candidate for intervention because not only does he admit to what he did, but he is also prepared to talk about his sexual violence. He can be read as demonstrating a strong motivation to change and as being 'psychologically-minded', that is, focused on his internal experience (Hubble et al., 1999). This positioning which deems Wade suitable for intervention and which suggests that intervention may be successful with him can therefore see him as having a lower risk of re-offending.

On the other hand, these same characteristics that Wade demonstrated can position him negatively. Much of the intervention for sexual violence based on mainstream psychology utilises some type of psycho-educational component that includes such concepts as offence chains, patterns of offending or relapse prevention (Johnson, 2007). As a result, those attending such programmes are expected, over time, to be able to identify various elements in their own violence. Therefore Wade's willingness to talk openly and his ability to already identify the role his thinking plays in his sexual violence, without having first undertaken specialist intervention, can lead to his being positioned as 'weird' and as a more high-risk offender. He has come to this conclusion without intervention, which may suggest a high level of engagement with these ideas. Consequently, he may be positioned as being firmly entrenched in these offending patterns.

\section{Faith in the powers of experts}

Wade's interest in intervention seemed to hinge on his need to change his thinking and he talked of not being able to do this alone:

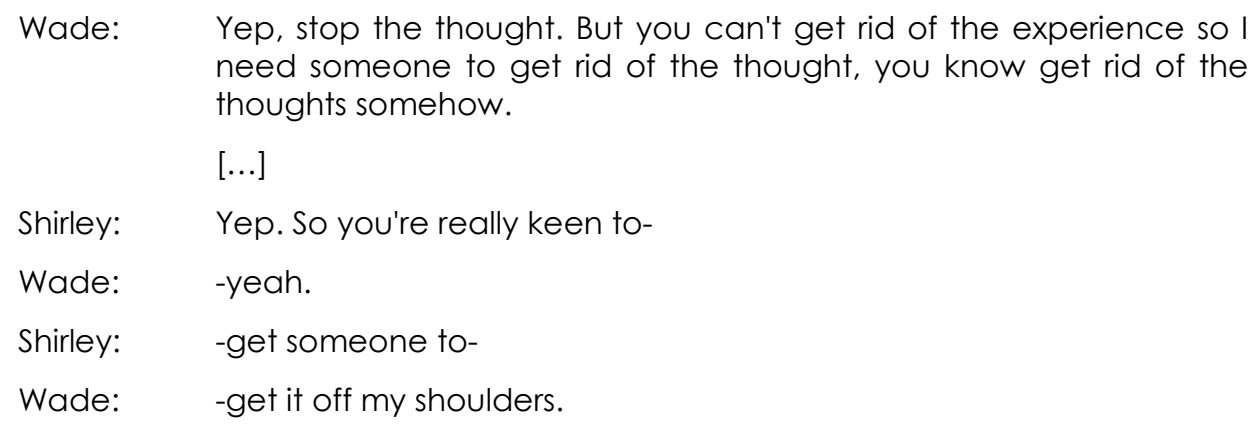




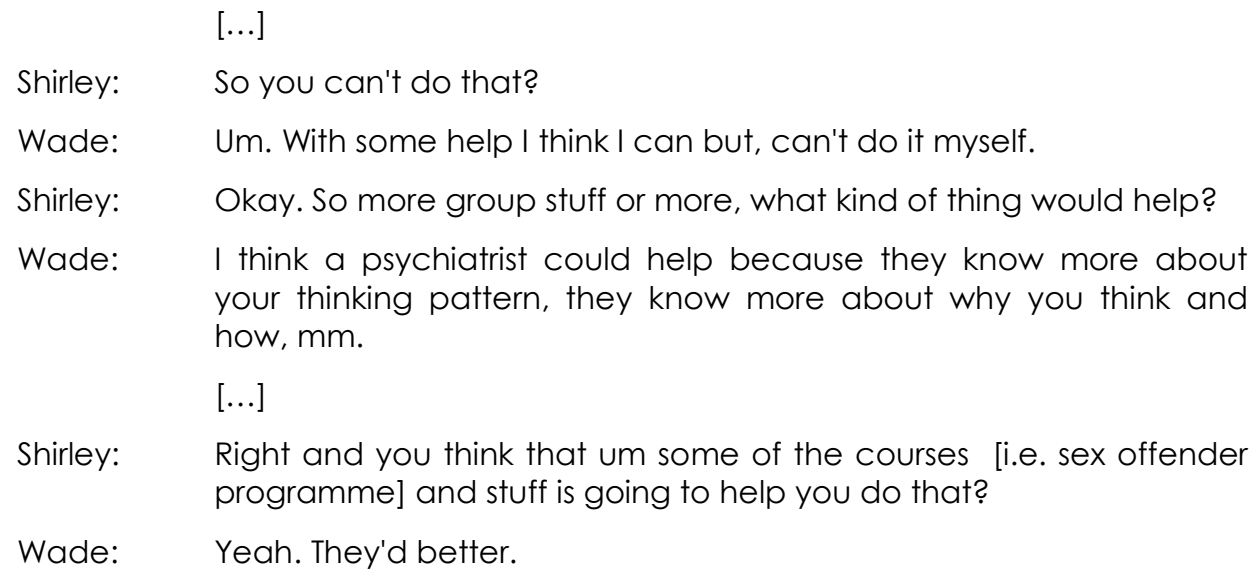

Although he would like to "get rid of the experience" of his sexual violence, Wade stated that he knew that was not possible, and returned to focusing on his thinking because he needed "someone to get rid of the thought" and "someone to get it off my shoulders". He talked of the need for professional assistance from "a psychiatrist" because he said he "can't do it myself". Wade had high expectations of the sex offender programme and thereby the assistance that professionals could provide and his "They'd better" can be read as not only placing the responsibility for 'fixing' him onto an outside source but also as having an element of threat behind it. That is, if the intervention did not get "rid of the thought" then maybe something will happen, although it is not possible to speculate what that might be. If he continued to be sexually abusive, then the fault will lay with the ineffective intervention programme for not 'fixing' him.

As participants can be read as taking what I consider to be an 'unknowing' position about their sexual violence, then it becomes possible to take up the therapeutic subject position and engage with the professionals. Wade's wish to see a psychiatrist drew on the expert status of that profession as being able to provide him with the correct answer, 'the truth', that he sought. Effectively, this positioned professionals within the sexual intervention field as experts who could 'fix' him, and he can be read as an object to be 'treated'. This appeared to ignore any agency he might have, and his positioning of professionals as the experts reduced Wade's responsibility for intervention to be a success. Therefore, ultimately, he is not responsible for stopping his sexual violence in the future. 
Despite the positivist psychological theories of youth violence that can be read as positioning young men as not responsible for their violence, one of the mainstays of sexual offender interventions is the requirement that offenders 'face up' to their offending and take full responsibility for it (Johnson, 2007). However, taking responsibility can be read as a rationalist idea that implies knowing, that is, knowing what they did, why they did it and possibly whether they will do it again. From this perspective, if Wade was to take responsibility for his sexual violence, then he could be positioned as knowing. However, such a position of knowing can be viewed negatively because to be rational is to have control and control means an ability to choose one's actions. Choosing to be sexually violent positions the perpetrator as dangerous. Wade is therefore positioned more positively by not taking responsibility, by not knowing, and by relying on the experts to find out what went wrong with him and to fix him. Indeed this fits with a pathologising view of these young men as 'abnormal', requiring professional help to become 'normal'.

One effect of positioning men who have been sexually violent as 'abnormal' is that a feminist analysis of men's violence cannot be applied, which offers a rational positioning and therefore a knowing one for young men who have been sexually violent. The statement: 'I did it because I chose to' is therefore allowable. But this cannot be said in the dominant discourses around sexual offending in which sexual violence is constructed as being perpetrated by only a minority of 'sick' men who need to be 'treated' to become 'normal' so that they will not rape again. The effect this construction has on intervention is that the task is immense: the efforts of experts are focused on changing a deviant 'abnormal' offender into a 'normal' individual. Therefore any failure to 'fix' sex offenders will not be the responsibility of the expert since the 'fault' or 'abnormality' that leads to committing sexual violence is an internal one, located in the individual offender. Further, the responsibility to change ultimately rests with the offender. Failure for the success of intervention can arise from the offender's 'resistance', 'non-compliance' or 'not facing up' to their violence. 


\section{Fears About the Adult Sex Offender Programme}

While Sean and Wade were both keen to attend the adult sex offender intervention programme when they turned 18 years old to gain what they desired, that is, understanding or explanations for their sexual violence so they would not be sexually violent again; they also had misgivings because it would mean going into the adult prison system. While Wade believed the environment would be "more like a rehab than a prison", Sean was concerned about encountering a high level of violence by the adults:

Shirley: What is it about getting in with the adults that concerns you?

Sean: Just the sort of things that you hear that goes on and that in the adult places and just being, being sort of teenager [small chuckle] and you think you'll be like a bum boy sort of thing really, yeah. Yep. [...]. It's only if you've got a mouth on you that you actually get beaten up [...]. A couple of people have been stabbed.

For Sean the adult prison as he described it was a dangerous place where there would be a great deal of physical violence and where as a young man he expected that he would be selected as a "bum boy". Sean appeared to be drawing on a commonly-held view that young men's experience in adult prisons involved being forced to be sexual partners for inmates who had considerable power within the system. This points out a contradiction within discourses around manhood. Using sexual violence to dominate other men appears to be the most extreme form of control and power within prison systems and those men that are successful with this retain a high position in the inmate hierarchy (Jewkes, 2005; Town, 1998). Yet, men having sex with other men is not acceptable within traditional masculinity. Hegemonic masculinity is homophobic (Plummer, 1999; Town, 1998). Homosexuality is one form of masculinity that is subjugated, excluded as being manly (Connell, 1995). One way to resolve this contradiction is to consider that male-male rape confers the position of woman onto the male victim, for example, by being referred to as the rapist's 'bitch'. This positioning is necessary because only women are subjugated in a hypermasculine world.

Wade's concern of being in the adult prison took a different turn. He did not like the idea of being with adult sex offenders, "I'm not too keen on going and mingling with all those other people". He explained why: 


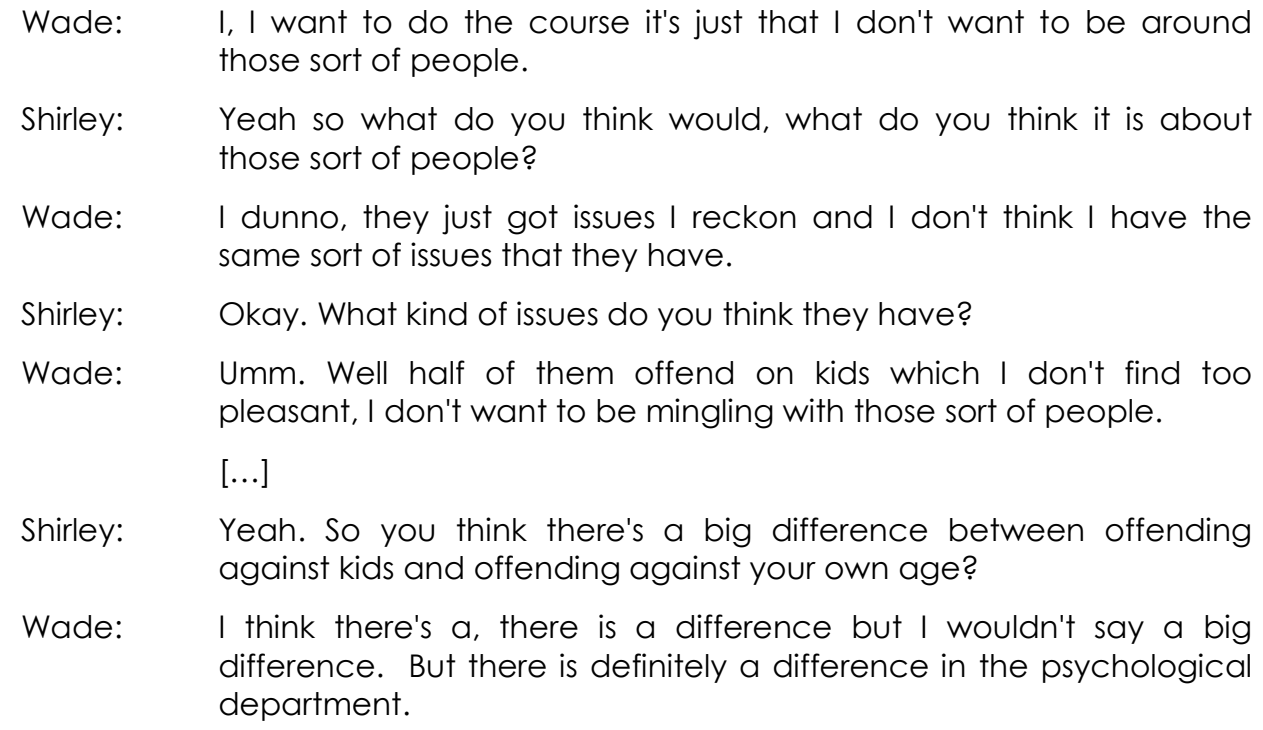

Wade's reason for not wanting to be around the adult inmates in the sex offender unit is because he believed that "they just got issues" that are different to his, "I don't think I have the same sort of issues that they have". The basis of Wade's distaste and reluctance to "be around those sort of people" revolved around who their victims were: "Well half of them offend on kids which I don't find too pleasant". Wade was not able to say what the difference was between those who offend against children and those who sexually offend against someone their own age but he was sure there was a difference in the "psychological department"; that is, an issue with the mind, positioning them as 'sick' mentally.

One reading of Wade's comments is that he drew upon a construction of sexual violence as a hierarchy based on the type of victim. Such a hierarchy could be envisaged as the top being the least 'deviant' and made up of victims and sexual acts that most closely match the dominant normative heterosexual relationships; in the middle of the hierarchy could be other males and child victims; whilst the bottom of the hierarchy is least like the norm, including, sexual contact with animals and dead people. Those offenders who are at the bottom end of such a hierarchy would be positioned as being more 'sick' and more 'weird' than those at the top. Descriptors such as 'unnatural' and 'abnormal' are more likely to be associated with those offenders closer to the bottom of the hierarchy. Intervention positions these men as more serious and dangerous as there is a purported absence of control (Johnson, 2007). 
Since Wade's victims were young woman who were of a similar age to himself whom he also considered attractive, according to this construction he can be read as being positioned at the top of the offender hierarchy. In contrast, the sexual violation of children does not match up well with what is considered normative sexual relations. Hence, Wade positioned these adult inmates as being further down the hierarchy and as being qualitatively and negatively different to himself in his effort to take up a position closer to the normative practices of consensual heterosexual relationships. He can be read as referring to and complying with this hierarchy in which he positioned these adults as being far worse than him, while at the same time knowing that his position also as a sex offender would link him to them.

In addition, Wade's claim to peer age victims may be read as constructing his sexual violence as some form of sexual experimentation that most young people engage in as part of their developmental processes (Messerschmidt, 2000b), rather than something able to be constructed as 'abnormal' or 'sick'. Such a construction is often called upon to explain sexual violence perpetrated by young men and in effect enables such violence to flourish. However, Wade had two young women as victims at the same time, which makes such a claim a little more difficult to sustain, since it falls somewhat outside the usual experiences of adolescent experimentation. Alternatively, from the perspective of traditional notions of manliness, having two young women as victims rather than one could position Wade as being more successful as a 'man'. Paradoxically, he claims to need psychological help implying he is indeed 'sick' or 'abnormal'.

Wade's youth can also be used to position him more favourably than adults. Often young offenders are not seen as being as serious as adults because of their developmental stage (Walsh \& Ellis, 2007), eliciting a level of indulgence for their indiscretions on the basis that they did not understand what they are doing because of their age. Attention to developmental issues is widespread within sexual offender intervention. From a dominant developmental perspective young sex offenders are viewed as becoming progressively more serious, continuing to re-offend unless intervention is provided and the younger age is seen to be more amenable to 'treatment' (Hollin, 1996). 


\section{Conclusion}

The picture that emerges from this analysis of intervention for sexual violence is one of contradictions. Participants had very different ideas about intervention in relation to their sexual violence compared to their general violence. Intervention for their sexual violence was wanted, particularly specialist therapeutic intervention of a psychological nature, whereas such strategies were considered inappropriate and so as irrelevant for their general violence.

Their crimes were not understandable/intelligible to them. Participants took up an 'unknowing' position, in that they did not understand why they were sexually violent, making control over it therefore unlikely. Therapeutic intervention seemed to be considered by participants, not just as helpful, but as essential for them and was talked of as being vital to ensuring they were not sexually violent again. Significantly, such intervention was spoken of as providing a way for them to know why they had committed sexual offences. In addition, their sexual violence was constructed as resulting from some unknowable flaw inside them that required experts to remedy. Despite some fears of being involved in a programme within an adult prison, participants were keen to get started and described high expectations of being 'fixed' by the professional staff involved.

Yet, wanting therapeutic intervention does not match up with performing 'man' correctly within dominant discourses around manhood. Being a therapeutic subject of intervention positions participants as 'abnormal' and 'sick', which implies not being in control. This lack of control further positions them as not masculine. However, taking up an 'unknowing' position with regard to their reasons for being sexually violent may hold the 'abnormal' positioning in abeyance and the rational, masculine concept of the body as a machine that needs to be mended maintains their manhood. 


\section{CHAPTER NINE}

\section{DISCUSSION AND CONCLUSIONS}

This thesis offers a way of looking at, or (re)thinking, youth violence in a way that differs from a mainstream psychological approach. I have brought a critical psychology framework alongside poststructural concepts and discourse analysis firstly, to critique dominant theorising of youth violence and the subsequent intervention approaches; and secondly, to critically analyse young men's understandings and explanations of their own violence as well as their ideas about intervention. I offer suggestions on ways to (re)think youth violence that is informed by the complexities highlighted in my analysis.

When I began this research it was clear to me that attention to context and complexity were needed to achieve comprehensive and robust theorising and effective intervention for youth violence. The critique I offer here shows that it is not possible for psychological approaches based on a positivist scientific paradigm to attend to important social, political and historical contextual issues nor can they effectively account for or engage with the complexities and contradictions of the multiple subjectivities involved. I have argued that a modernist psychology is limited by its philosophical and theoretical foundations. In Chapter Two, I described these foundations as being a positivist science with an objectivist epistemology and realist ontology. Such a basis can be read as restricting the subject to that of a mechanistic, coherent, stable and rational individual (Henriques et al., 1984). In contrast, a discursive approach that is informed by poststructural concepts provides a way to incorporate important contextual issues and address the complexities demonstrated by these young men who have been violent. Discourses provide various contexts within which we are constructed as subjects, and the poststructural concept of 
multiple subjectivities enables an exploration of people's complexity that accepts all of their contradictions.

In this chapter, I cover the major conclusions I have reached in this thesis and discuss their significance for (re)thinking youth violence; I also consider possible implications for intervention. First, I outline how my analysis of the talk of the seven participants has revealed numerous contradictions and differences that are of significance when (re)thinking youth violence. I highlight the differences that I consider relevant between general and sexual violence. This is followed by my exploration of aspects of rationality and emotion. I also consider the notion of responsibility with regard to theories of youth violence and intervention approaches and explore the talking and the silences of participants. Next, I discuss how I have read participants' intervention experiences. Finally, I offer some possible ways forward.

\section{Contradictions and Differences}

The analysis I present in this thesis shows that contradictions and differences abound. They occur within the texts by the same participant, between participants and amongst the different subject positions available, as well as between the various discourses identified. Dominant discourses around traditional masculinity provide significantly different ways of constructing youth violence compared to discourses of pathology located in mainstream psychological theories. Important differences emerged between general and sexual violence that participants committed. Distinctions were also apparent in participants' deployment of rationality and suppression of emotion. There were also contradictions between participants' talk and their silences, and their acceptance and dismissal of intervention.

The inconsistencies that emerged could be viewed from a positivist scientific paradigm as unsatisfactory because consistency and regularity are highly valued as 'normality'. This view is congruent with the positivist assumption of a coherent fixed and stable, singular 'truth'. Anything outside this ideal coherence is considered 'abnormal' and so requires 'fixing'. In intervention terms, that means being 'treated' in order to attain the requisite unitary, rational subject. 
In contrast, inconsistency, contradiction, confusion and uncertainly are embraced by a poststructural discursive perspective. From such a view, it is possible to see that a variety of discourses converge around youth violence. Given that discourses produce what they name, (Foucault, 1969/1972) they therefore provide the social context that constructs youth violence. Discourses combine, cross-over, feed into one another, as well as merge and blend. It is within this interplay that contradictions arise, since each discourse offers its own set of subject positions and divergent ways of constructing objects (Davies, 1994; McHoul \& Grace, 1998). For example, within dominant discourses around manliness the protection of others from the violence of other men provides a subject position of 'protector' (Eagle, 2006), some participants took up this position at a very young age when protecting their mother from their father's violence. However, these same participants have sexually violated young women, which goes against this notion of protection. Although, paradoxically, this action can potentially fit with the normative idea that men are entitled to sexual gratification.

\section{Multiple subjectivities and contradictions}

Like all people, young men who have been violent hold different subject positions within different discourses at the same time. For example, within discourses around family relationships a young man may perform the position of a son or brother; an inmate within discourses around prisons; or in discourses of crime he may be positioned as a rapist or robber; as a student within normative notions of teaching and learning; in romantic discourses he may take up the position of boyfriend, in discourses of friendship he may take up the position of mate. These various positions result in these young men inhabiting multiple subjectivities at the same time from which they experience the world, and hence are inherently contradictory. This explains not only the contradictions in what they say and do; but also the contradictory or ambivalent motivations they have at different times. This explains how they can appear to be different people to various others, such as teachers, police, friends, family and professionals, since these others are interacting with these young men from the specific discourses and subject positions they inhabit. For example, Wade was positioned in numerous ways by others. He took the position of being a leader in his group of mates by convincing them to do crime with him. In contrast, 
the manager of the unit described him as a follower who was easily led by his bigger mates. He was positioned as a violent thug by the service station attendant whom he robbed, who was so scared of him and his mate that he could not move and begged not to be hurt. Taking the position of 'good son', Wade talked of missing the full contact visits with his mother. Finally, taking the position of research subject during our interview, Wade was a friendly young man who enjoyed talking about himself and what he had been doing.

Such a discursive perspective with its inclusion of multiple subjectivities offers a picture of the diversity and complexity that has been highlighted in this thesis. Incorporating such complexity may be a valuable concept in theorising youth violence differently and also offers another direction for intervention approaches. For young men, the ability to acknowledge differing subject positions may facilitate the understanding of their own violence and may encourage them to take up nonviolence as a preferred choice. Future theorising around youth violence could take up this challenge and intervention approaches may be developed to incorporate this notion of multiple subjectivities.

\section{Competing discourses: 'Abnormality' and 'manliness'}

Before undertaking the research interviews, I assumed there would be a measure of influence from normative notions of masculinity in the participants' talk about their violence. I was, however, not expecting the pervasiveness of its influence. 'Getting it right as a man' seemed to underlie much of what participants said and did not leave many topics or areas untouched. As a result, my interest in applying a critical psychology framework to critique dominant theorising about youth violence and intervention widened to include comparisons with the discursive impact of the dominant discourses of traditional masculinity.

Within pathologising discourses young men who commit violence are positioned as 'abnormal' because the factors that are theorised to cause youth violence are considered to result in individual pathology. Thus, the therapeutic subject position offered is a pathologised one, one that requires 'treatment' to become 'normal'. In contrast, dominant discourses of manliness offer the subject position of 'man'. I read 
participants' desire to 'get it right as a man' as being important to them, and violence was an accessible way to enact this position. Performing 'man' correctly was a positive position for these young men. For example, fighting in gangs was described as an attempt to be a macho man, being respected by other men and gaining a reputation for being tough.

In comparison, the pathologised position of the therapeutic subject does not assist young men to 'get it right as a man' and can even be read as conflicting with their attempts to do so. Being positioned as 'abnormal', irrational and out of control does not enable young men to perform 'man' correctly, since being a 'man' is the epitome of rationality and control. As they are contradictory notions, it is not possible for young men who have been violent to be positioned both as a therapeutic subject and as a 'man'. This is similar to the proposal that men cannot be both a victim and a man (Eagle, 2006).

From this discussion, it follows that any theorising and intervention in youth violence must take account of the complex effects between normative notions of manhood and normative explanations of violence and their impact for young men who have been violent. Acknowledging the pervasiveness of dominant discourses around masculinity for these young men is required.

\section{Self and others}

The dominance that theories derived from traditional psychology have on youth violence was evident when the young men talked about the violence of others. Although participants did not often draw on these theories to explain their own violence, when they attempted to account for the violence of other young men they accepted them uncritically. For example, participants used the concept of the cycle of violence and social skills deficiencies to explain the violence of other inmates, yet, they did not use these concepts to account for their own violence. This difference makes any theorising that is based on research using young men's opinions about the violence of others quite limited.

Participants' use of these dominant psychological explanations for other young men shows that such theories were well-known to participants and accepted as common- 
sense explanations of youth violence by them. Given such acceptance, it could be expected that participants would apply these same explanations to their own violence. However, these young men did not recognise themselves within such theories. One reading of this is that the pathologised positions these dominant explanations offer, such as 'abnormal' and 'deviant', were resisted by participants as they compete with the position of 'man', thus, presenting an unbridgeable gap for them. Different explanations need to be constructed that are inclusive of the various subject positions young men take up in relation to their violence in future theorising and interventions.

\section{General and sexual violence}

Similar theorising is generally used to explain both general and sexual violence perpetrated by young men. Some examples include: the cycle of violence notion that proposes victims will become perpetrators (Chapple, 2003; Lambie et al., 2002; Widom, 1989); the mitigating-substance view that the violence results from being intoxicated by alcohol or drugs (Walsh \& Ellis, 2007); the social cognitive view that violence occurs because young men have deficits in their social skills (Goldstein \& Keller, 1987; Marshall, Anderson, \& Fernandez, 1999). Yet the five participants who committed both types of violence viewed their general violence and sexual violence differently: they were experienced differently, understood differently and explained differently by these young men.

There was a striking difference in participants' talk between general and sexual violence: whereas general violence was spoken of in rational terms, sexual violence was associated with irrationality. Participants were forthcoming about their general violence and were able to offer a range of explanations. In comparison, they had difficulty in talking about their sexual violence and were generally confounded as to why they did it. Differences also emerged between general and sexual violence when it came to issues of responsibility and participants ideas about intervention (topics I discuss later in this chapter).

Different discourses, subject positions and subjectivities are involved when a young man is being sexually violent, compared with committing general violence. I have 
argued that the dominant discourses around traditional masculinity have a significant influence. General violence enables young men to perform the subject position of 'man' correctly. This makes any intervention to stop their general violence unwanted as it takes away an accessible means of being a 'man'.

In contrast, the young men had no language to talk about, or to help them understand their sexual violence: they were almost able to negate the experience. The participants took up a 'not knowing' approach to their sexual violence; that is, they could not explain why they had been sexually violent. The consequences of this were that they did not have to agree to the existence of their sexual violence in a way that positioned them as 'sick' or 'deviant'; pathological positions made available through discourses of abnormality. But a further contradiction emerged: the young men were unable to take up such positions of abnormality as they were emasculating. The 'unknowing' position they had taken up, leaves open the possibility of 'getting it right as a man'. Participants, therefore, may not be rationally knowable or readable, plausible men as sexual offenders.

While discourses around manliness appeared to facilitate the participants' general violence, sexual violence may be read as not performing 'man' correctly because of the idea that a 'real man' does not need to force a woman to have sex with him. Instead, a 'real man' has women wanting to have sex with him. However, a contradiction exists. It is still possible to read sexual violence as getting the position 'man' correct because the young man is taking what may be considered his right: this is indeed the way Rick described it (in Chapter Five) when he talked of rape being macho. But this construction is only possible if the victim fits the normative sexual partner, that is, being of the opposite sex and of an appropriate age; otherwise the sexual violence is read as deviant. A further contradiction exists. Within specific contexts in which a man uses sexual violence to control another, such as in war and within prisons, even if the victim is a man, the perpetrator can be read as having performed 'man' correctly. This is possible because he has demonstrated his power and control over others. The violence is constructed as instrumental, as having a rational purpose and thus, as having little to do with the perpetrator's body in terms 
of gaining sexual pleasure. Rather, it becomes construed as a disembodied experience (Allen, 2002).

An alternative subject position is available for young men who have sexually offended: the rational subject. Dominant discourses of traditional masculinity do not offer a way for these young men to understand their sexual violence, since one reading is that a 'real man' does not need to take a woman by force. A feminist analysis, in which sexual violence is viewed as a function of gaining and maintaining patriarchal control and power within the gender order suggests a rational subject position (Bograd, 1982; Brownmiller, 1975; Herman, 1992). Such a position may be read as fitting with traditional conceptions of being a man and emphasises that young men make a rational choice to offend sexually, based on their sense of entitlement as a man. This notion of entitlement coalesces around the male sexual needs discourse in which the male sex drive is paramount to achieving orgasm, thus, meeting their sexual needs (Gavey, 1989, 1992).

Whilst a feminist analysis may seem to offer a way out from the unmanly, 'sick' position of pathologising discourses, this rationalist manly position can also be read as a deviant one because the instrumentality involved suggests an unfeeling, uncaring 'sub-human' (Hare, 1999) and so can exclude this position for young men who desire to be 'real' men. Therefore, the 'unknowing' position that the participants have taken up, in which they could not explain their sexual violence, is preferable as it locates them outside the dominant discourses that position them more negatively. Discursively, there is no language for sexual violence that perpetrators can draw upon that does not either position them as deviants or as therapeutic subjects. Neither position is viable according to normative notions of manhood.

\section{Rationality and emotion in youth violence}

From a scientifically informed psychological perspective, one of the ways violence is categorised is either as instrumental or expressive violence. This categorisation is based on what function violence is thought to serve. Instrumental violence is seen as aiming to achieve goals, such as obtaining money, whereas expressive violence is viewed as a response to an emotional state (Blackburn, 1993). Rationality and choice 
can be thought to operate for instrumental violence but not expressive violence. Rather, expressive violence is viewed as an absence of rationality because the emotion, such as anger or sexual arousal, is not being controlled.

For many theories within scientific psychology, rationality is what mediates emotions (Walkerdine, 1988). Yet, participants in this study described an interesting mix of emotion and rationality in a way that contradicts a clear division between instrumental and expressive violence. Even in the midst of committing a violent act in which a high level of anger is theorised to exist, it was apparent that the participants continued to make rational choices. For example, during gang fights they described choosing where to hit on the body and how to deploy weapons (see Chapter Five). In addition, emotions were not absent in participants' instrumental violence. For example, participants identified fear, excitement and anger with victims as being involved in the armed robberies that had the instrumental purpose to obtain money.

Positivist psychology primarily constructs youth violence as 'abnormal' and subsequently accounts for expressive violence in this way. This positions those young men who perpetrate violence in terms of their pathology; commonly, as having an overabundance of a negative emotion, such as anger, and a deficiency in the skills necessary to manage these emotions (Goldstein \& Glick, 1994; Novaco, 1997).

In contrast, the ability to adequately explain instrumental violence from a pathological perspective is problematic. The use of rationality, for example, participants made a 'conscious, rational' decision to use violence to obtain something they wanted, makes it difficult to argue that pathology is involved in their violence. Since rationality is revered as the most appropriate mode of thinking to achieve appropriate behaviour, and hence, theorised as the best way to 'manage' emotions, performing instrumental violence becomes a demonised subject position - as 'evil' as it is a perversion of rationality (Staub, 2003).

It is still, however, possible to overcome the difficulty that instrumental violence presents. The search for some form of historical pathology in individuals can be used 
to explain present-day violence. Therefore, even rational motivation for violence can be viewed as ultimately having an irrational or pathological historical cause. For example, for Drew's act of committing an armed robbery for money, to be able to party on the weekend, cannot be viewed as pathology in itself because he made a rational decision, but it can be argued that its origins came from an historically 'dysfunctional' or abusive family life (Widom, 1997) where the appropriate skills and values, such as moral development, have not been attained (Gibbs, 1993).

Additionally, there is another way that instrumental violence can be constructed as pathology and so position participants as 'abnormal' and, that is, by the process of categorising individuals according to mental disorders. For example, personality pathologies such as conduct disorder, sociopathy (American Psychiatric Association, 1994) or psychopathy (Hare, 1999) all refer to the commission of violence as one of several factors involved in these diagnoses. Such disorders also characterise perpetrators as having little emotional connection to their violence.

Young men whose violence is judged as expressive can be positioned more positively than perpetrators of instrumental violence because committing expressive violence can be judged as not having control over their emotions. Therefore, they cannot be blamed for what they do, that is, they have 'lost control'. Instead, they are positioned as 'abnormal' and needing 'treatment'. Paradoxically, intervention to control emotions often utilise cognitive-behavioural therapy strategies, which in turn specifically rely on rationality for their efficacy.

To complicate the picture further, rationality is a fundamental aspect of dominant discourses around masculinity (Seidler, 1994). The young men in this study perform 'man' by rational means. This comes across in participants' talk in numerous ways, for instance, they chose drugs and alcohol in relation to the type of violence they envisaged perpetrating. Such choices provide an alternative way to conceptualise the role that drugs and alcohol are thought to play in youth violence. Dominant notions of intoxication suggest a lack of rational control and the effects are thought to cause violence, yet, participants decided the specific type of intoxication they were after, depending on the type of violence they planned. Rationality equates to being in control within dominant discourses of manliness. In contrast, emotionality is about 
being out of control, often associated with being female and thus 'not-man'. Hence, these young men resisted being positioned as not having control by emphasising agency and rationality in their decisions about drug taking. Much of objectivist psychological theorising is unable to account for and hence, adequately respond to this use of rationality portrayed by participants.

\section{Taking responsibility and not taking responsibility}

Taking personal responsibility for one's actions is an idea that is extensively promoted as an important aspect of what is constructed as having 'good' character and living a moral, ethical life. Being responsible is extolled within most religions and enshrined or inferred in many legislative and regulatory practices. For example, one requirement of registration for social workers in New Zealand is that they be a 'fit and proper' person (Staniforth \& Fouché, 2006), which suggests expectations of accountability through a character trait of being a 'responsible' person. It is no surprise then to find that responsibility is an issue that frequently comes up within the context of theorising about and applying interventions for youth violence.

I have argued that one outcome of dominant psychological theories of youth violence is that the young men are not held responsible for their violence, whether it is general or sexual, or expressive or instrumental violence. The reason for this is that the cause of the violence is believed to lie in the young person's past environment or it is attributed to present-day external events. An example of this would be the position of being a past victim of violence (such as Sean or Rick who contended with violent fathers) or of being intoxicated (such as Kelly and Quentin who committed violence whilst "stoned"). Since the young men cannot influence the past or control the effect of drugs, then it is possible to contend that they cannot be held responsible for the violence they commit.

However, it is possible to read the young men in this study as actively taking up a position of responsibility for their general violence and as not wanting to blame others. They do not transfer responsibility onto their mates or family, external circumstances or the use of substances. For example, Rick made it very clear (Chapter Five, p. 125) that he did not think his family was to blame for what he had 
done. Participants' also emphasised that they made the choice to be violent, and spoke of having control over their decisions. Within dominant discourses of traditional masculinity, to have such agency is vitally important in being manly. Thus, these young men can be positioned as taking personal responsibility for their violence because they are making rational choices and are in control and in doing so, become a 'man'.

Understandings and meanings are contingent on the social context (Foucault, 1969/1972). These young men also at times drew upon well-known psychological theories to explain their violence, with the effect that this allowed them to avoid responsibility for what they had done. This avoidance often seemed to arise within specific contexts in which there was either some cost to the young man, such as in the justice system where sentencing was determined, or where there may be some advantage to him, for example, eliciting favourable treatment or sympathy from an authority figure, such as a parent or residence manager. Within these contexts, the benefit of avoiding responsibility can be read as outweighing the usual priority for them, which was to perform 'man' correctly. The differing contexts within which these young men were variously located significantly shifts the meanings they attribute to their violence and therefore offered differing subjectivities as they navigated across different discourses.

While participants took up a position of being responsible for their general violence, these young men did not take responsibility for their sexual violence. I have argued in Chapter Seven that they achieved this by taking up the 'unknowing' subject position. At the same time, participants considered therapeutic intervention as a way of providing the means to help them find out why they had been sexually violent. This combination of an 'unknowing' position, together with a willingness to accept intervention, can be read as providing participants with useful protection against being confronted or challenged about their sexual violence and against being held responsible.

For a young man who has been violent, taking responsibility is a concept that is considered, particularly from within the specialist offender intervention field, as involving more than simply the admission of guilt. Taking full responsibility also 
includes acknowledging the harm caused, demonstrating remorse, showing a willingness to make amends, providing an apology and giving some indication that the young man does not intend to do it again, for example, by developing relapse prevention plans (Johnson, 2007). However, such tasks are problematic for young men who have been sexually violent and who take up the position of 'unknowing' and who construct their sexual violence as irrational. This is problematic because the concept of responsibility suggests the application of rational reasoning links perpetrator and action, and action with effect. Participants' enthusiastic talk of wanting specialist intervention for their sexual violence therefore poses a dilemma. Whilst their willingness for intervention suggests they are also motivated to take full responsibility for their sexual violence, at the same time, the 'unknowing' position prevents them from engaging in the rational process of taking responsibility within intervention programmes. In addition, since the 'unknowing' position also prevents them from being positioned as 'deviant' and 'abnormal', taking up the position of therapeutic subject of intervention becomes difficult. Intervention approaches could be developed to take account of these various subject positions.

\section{Responsibility for success of intervention}

Young men can be positioned as not being responsible for their violence when dominant explanations of youth violence suggest that the causes of their violence are external, occurring outside their control. However, when it comes to intervention informed by these same dominant explanations, young men are held responsible for its success in specific ways. Such intervention programmes tend to propose that therapeutic subjects change their thinking (which is viewed as faulty), learn the necessary skills to overcome their deficiencies, stop their unacceptable behaviour and control their unruly emotions (see for example, Hollin \& Howells, 1996; Johnson, 2007). This constructs intervention as 'treatment' that thereby requires the therapeutic subject position to be a compliant one. It is only by following the instructions provided by professionals that young men are able to successfully complete the programme. If undertaking these tasks does not lead to stopping the violence, then it is the young man who is responsible for this 'failure', since it is thought that he has not fully complied with all instructions. At times, such 'failure' 
may lead to repeating the programme to enhance 'learning' of the required tasks; the effectiveness of such intervention programmes is often viewed as being temporary and short-term (Marshall et al., 1998). Alternatively, a lack of success in stopping violence after intervention may be considered within a traditional psychological perspective, as being due to the young man having fundamental character flaws, which in turn can result in him labelled with a personality disorder diagnosis (American Psychiatric Association, 1994).

Participants' responses to intervention differed markedly between their general violence compared to their sexual violence. Intervention for general violence was deemed irrelevant and not needed by participants. This was primarily because their general violence functioned as a way to perform 'man' correctly and as such was considered an ordinary and necessary part of their everyday life. Therefore, these young men did not take responsibility for intervention designed to stop their violence because this would end this means to be a 'man'. In contrast, participants positioned themselves as not understanding their sexual violence nor why they did it, they were therefore relying on specific intervention expertise to assist them to understand it. They constructed intervention for their sexual violence as them needing to be 'fixed' by experts because it was beyond their skill or even comprehension. Hence, they cannot be held responsible for its success when the intervention requires considerable expertise.

The notion, within intervention programmes, that taking full responsibility for one's violence is essential to preventing future violence appears to be particularly problematic when applied to young men's general violence. As discussed earlier, participants can be read as having taken responsibility for their general violence when they drew on dominant discourses of manliness to describe the control they had and the rational choices they made to be violent. How participants used the concept of responsibility in relation to their general violence differs markedly, however, from that same concept used in an intervention setting. For example, within intervention approaches, taking full responsibility requires acknowledging the harm the violence caused. In contrast, participants used the level of harm they caused as a measure of their success in being a 'man'. They spoke of trying to inflict damage to their 
opponents in gang fights in boastful ways. The usefulness of the concept of taking responsibility within intervention programmes is therefore of questionable value when taking into account the multiple discourses that produce differing meanings of young men's general violence. Some readings of responsibility as the example above shows may produce violence rather than reduce it. A different conceptualisation around the construction of responsibility is required for (re)thinking youth violence and within interventions.

\section{Talk and silence}

The various subject positions taken up by the young men in this study were often inconsistent with the positions made available within the dominant discourses around abnormality and deviancy that are found in scientifically based psychological theories concerning youth violence. The young men talked about themselves as being acceptable as men; as achieving manhood by being in control. They spoke more about what they gained from their violence than what they lost. The positions taken up by the young men regarding their general violence were different to their positions regarding their sexual violence; they resisted being positioned as 'sick' by taking up an 'unknowing' position. In contrast, both general and sexual violence are often theorised in similar ways: as irrational, out of control, and 'abnormal' and 'disordered'.

There are differences between how these young men talked about, experienced and constructed their violence, and how a scientifically informed psychology constructs youth violence. The positivist scientific paradigm privileges knowledge that is 'discovered' by the application of the scientific method. Subjective knowledge and experience, such as that described in the participants' talk, is not legitimated as 'fact' within the objectivist paradigm until it is observed scientifically, interpreted and another construction offered. From this perspective, the young men are likely to be positioned as being wrong, uninformed and not knowledgeable about their own violence.

From a poststructural perspective, the young men are read as providing different 'truths' to those proposed by dominant theories. If such theories are not accepted as 
the 'truth' by the young men, then these ideas and any intervention based on them are seen as irrelevant for them. Thus, intervention informed by these notions can be read as problematic for young men as it risks emasculation if they accept 'treatment' for behaviour that they construct as 'unmanly'. Alternative interventions therefore require development that are relevant to young men's understanding of their violence and takes account of the impact of discourses around hegemonic masculinity.

\section{Silences and sexualities}

Although participants were talkative about their general violence and had little hesitation in describing to me what they did, silence was the main response I received when I asked them about their sexual violence. Shame and embarrassment were the primary explanations participants gave for not wanting to talk about their sexual offences.

Precisely because sexual violence involves a sexual component, discussion necessitates talking about sexual matters. However, detailed and open discussion of sex remains socially unacceptable. Various discourses of sex are used to keep the topic out of reach of open dialogue and to keep it taboo, as it is both mystified and demonised. At the same time, it is also used in advertising to sell commodities and is presented as tantalising. I have argued that the shame and embarrassment participants spoke of may be as much associated with the difficulty of talking about sex as it is about the violence they committed. If sex was a topic that was constructed in such a way that enabled it to be talked about more openly and not as pornography, then talking about sexual violence might be more likely.

Within dominant discourses of manliness, the body is constructed as a machine controlled by men's rational mind (Connell, 2000). Yet, sex and sexual violence engage the body in a way that often defies a rationalist mind-body split (Allen, 2002). For example, sexual arousal and orgasm engage the mind intimately in bodily experience, but such unavoidable bodily experience may, nevertheless, be brought into conflict with rational control. It is possible that the silences, shame and embarrassment of participants result from the fact that sexual violence can be read as involving a lack of rational autonomy and control and thus, not being masculine. 
Hence, the silences of participants may have more to do with experiencing the shame of being positioned as 'unmanly'; that is, the lack of rationality than the shame of harming another.

\section{Interventions}

In this thesis, I not only explored participants' understandings of and ideas about being violent but also the interventions they experienced and what they considered useful. Unexpectedly, few participants spoke of being involved in therapeutic intervention inside the secure facilities. Those who did, described attending a group programme compulsory for all inmates within a particular facility. None talked of having individual one-to-one intervention. Much of the discussion about intervention with participants concerned experiences they had prior to the current offences for which they were incarcerated. Despite some participants' desire for therapeutic assistance for their sex offending, having to wait a year before a specialist intervention programme was available to them was a frustration. From a critical psychological perspective, the lack of therapeutic intervention is surprising, given the extent to which the 'psy' complex (re)produces the dominant discourses that construct youth violence as 'abnormal' and its dominance over the practices of such social institutions (Rose, n.d.).

The dominant psychological theories used to explain youth violence appear to be somewhat disconnected to what actually happened to these young men in the secure facilities. For example, as discussed in Chapter Six, the Toughest Inmate Competition used techniques of motivation to urge inmates to push the limits of their bodies in completing a series of activities designed to demonstrate physical strength and endurance. It is difficult to envisage how this would contribute towards stopping young men from being violent in the future. This hyper-masculine competition that used abusive verbal encouragement, such as swearing and putdowns (re)produces violence as a means to achieve manhood. Therefore careful consideration is required in relation to institutional practices to avoid supporting such performances of violence. 
Participants talked of attending intervention programmes, such as anger management, that is used for a theorised lack of arousal control, or EQUIP, which focused on the development of prosocial skills. However, the extent to which these programmes were effective at stopping these young men being violent may be questioned when considered from the discursive analysis I present here. Sean made this explicit when he continued to be involved in fights with other inmates, despite claiming that intervention helped with his anger (see p. 181). It is notable that Sean had not viewed anger as being a problem related to his violence. This suggests that intervention programmes are administered enmasse to groups of offenders regardless of whether the issue being targeted, such as control of anger or a lack of social skills, is relevant to them or their violence. Therefore, the individual, therapeutic subject disappears during the practical application of intervention in which all young men who have been violent are thought to benefit from the same intervention. Alternative intervention approaches could be designed to better match individual young men's understandings of their own violence.

\section{The institution as intervention}

All the participants in this study positioned themselves as positively as they could in comparison to other inmates. Such positioning may be read as an effect of dominant discourses of traditional masculinity. It has been argued that friendships between men are constituted by a wariness or vigilance of the hierarchical aspects of the gender order, in which case friends are constructed as adversaries (Phillips, 1986). The inmate hierarchy produced by the competitive hyper-masculine environment of the secure facilities results in a disciplinary process whereby violence and the threat of violence amongst inmates acts as a technique of discipline (1975/1977), with sanctions against inmates being meted out by other inmates (Jewkes, 2005). This hierarchy was made evident in this study when participants described such disciplinary practices and accepted them as being necessary to maintain order and establishing their own location in the pecking order.

There are some likely benefits to the institution from these inmate disciplinary processes. Firstly, fewer resources are required to maintain the system. Secondly, the processes assist in the socially constructed view that prison environments act as a 
deterrent to others. Any tolerance for violence within secure facilities (re)produces violence as part of the broader institutional practices of regulation and control. For example, despite the potential that inmate fighting can attract additional charges for them, participants were not always charged. Drew spoke of believing that one decision not to charge him was made because he had lost the fight (see p. 114).

Within secure facilities, institutional practices of regulation use offender management systems that employ behaviourist principles in their routines and reward and punishment systems (Domjan, 2006). Such systems focus on the provision or removal of privileges in an inmate's daily regimented schedule after an assessment of their specific behaviours each day. These methods of managing offenders appear to operate as an intervention designed to change behaviours and so are presumed to 'rehabilitate'. Facilitation of non-violence as a choice for young men would seem to be a more complex issue than any simplistic reward and punishment milieu can accommodate. Whilst behaviourist reward and punishment systems are designed to modify individual behaviour, they cannot effectively deal with the institutional practices to which these young men are responding, such as an inmate hierarchy based on competition and violence.

The management of offenders cannot act as a substitute for interventions designed to stop future violence since each have different aims and approaches. Management of offenders involves the control of a population of offenders wherein security issues are paramount. Intervention, on the other hand, is constructed as revolving around individual change that goes beyond daily behaviour and focuses on reducing the likelihood of re-offending.

As I have read from participants' descriptions, the hyper-masculine environment of secure facilities is produced through several means, including the extensive level of fighting inside (not prevented by the offender management systems) and such institutional activities as emphasising physical prowess that in turn emphasises competition among inmates. The encouragement of activities that not only test strength but also pit individuals against each other would seem to be at odds with the purposes, first, of incarceration (with its implications of rehabilitation), and second, of intervention (with its inherent expectations of preventing future violence). 
Therefore, the institutional context can be read not only as (re)producing violence, but (re)producing violence as a way to perform 'man' correctly through an emphasis on control over the physical and combative inmate hierarchy.

\section{Violence: A focus of intervention?}

If one purpose of incarceration is to address offending, then there is a commonsense expectation that intervention informed by mainstream psychology would directly explore the offending events. None of the therapeutic interventions participants experienced involved an exploration of their violent act. They did not talk about their violence. They did not explain why they were violent. They did not share their understandings of what they did. This absence/silence of offence-focused intervention is unexpected given that intervention is generally expected to target the prevention of future violence.

However, there may a way to explain this silencing. Avoidance of examining what the young men did also avoids having to engage with the apparent rationality to perform violence. One criticism of mainstream psychology, from a critical psychological perspective, is that the discipline constructs substantial areas of human behaviour as pathology and contributes to the production of dominant discourses around 'abnormality' (Laws, 2001; Rose, 1985). Within these discourses youth violence becomes constructed as 'abnormal', or 'deviant' behaviour, and as a consequence rationality cannot be attended to.

The silencing of violence within intervention designed to prevent future violence implicates the workers involved. Research targeted in this area may offer suggestions for future training of professionals.

Unfortunately, when intervention ignores addressing these young men's violence directly, there are no discursive opportunities for young men to develop new understandings about their actions, nor to explore alternative discourses or subjectivities. Participants in this study were not able to make a connection between indirect interventions and their violence. For example, Wade did not see how learning to socialise was relevant to addressing his sexual violence (see p. 181). If violence is not talked about and named, then non-violence cannot be constructed as 
an accessible choice for these young men. If violence is talked about, then alternative discursive positions can be constructed, but until that happens the possibility is nonexistent. Therefore, interventions must be designed to enable this to occur.

\section{Intervention and general violence}

A dilemma exists for designing intervention approaches that will adequately address young men's general violence. Therapeutic intervention for their general violence was meaningless to participants. They were unable to construct their general violence as pathology; rather it was constructed as an important means to become manly. This raises questions about the aims of general violence intervention programmes. A key question is: whether non-violence is a realistic goal.

Youth violence is constructed differently according to different discursive contexts. By changing the discursive context within which the violent actions of young men occur, the meaning of their violence shifts. For example, sport is regarded as a legitimate context where men can be violent to other men and not result in criminal arrests. It is, instead, governed by the agreed rules of the sport. Another example where violence is acceptable is within military contexts, where rules of war designate enemies and specific action is authorised accordingly. Both of these examples can discursively position men according to dominant notions of manliness: they are positioned as demonstrating sporting prowess or military honour. Non-violence may not be a realistic goal for intervention, a provocative alternative may be to open up other, different possibilities in which young men's performances of violence are constructed as activities that are legitimised within society.

\section{The value of talking}

Participants made it clear to me that while talking was important for them, counselling was not. They highlighted the benefits they gained from talking with their family and friends as well as with other inmates who were supportive. The ability to talk on numerous topics with others was perceived to be a key component to having good relationships. Taking the advice of friends or other inmates was also thought to be helpful. However, counselling was viewed unfavourably by most participants. They spoke of it as being unnecessary in relation to their general 
violence and described the idea that anyone would enjoy or find it helpful talking to a stranger as an odd one and such talk could potentially be viewed as boasting about what they had done. Yet most of the participants stated they found talking to me (a stranger) as acceptable to them. Some described it as satisfying, even suggesting that talking about what they had done in a similar way that we had during the interview, would be a useful intervention strategy.

In my analysis, the act of talking about their general violence with a stranger was not the problematic issue; rather, it was the discursive context of counselling. For these young men a requirement to attend counselling positions them as therapeutic subjects - that is, as 'disordered' - who must be 'fixed' by an expert so they will not be violent again. As we are constituted by, and constitute ourselves through language, talking is an integral part of being human and part of the subjection process. Foucault (Foucault, 1975/1977) emphasised the impact that self-surveillance has: we manage our conduct to ensure we are accepted and become an appropriate subject. For these young men, agreeing to undertake counselling would result in their being active partners in a process of creating their own subjectivity as therapeutic subjects. An ever present concern of these young men was becoming-a-man. Hence, subject positions offered within the discursive context of therapy that speak of 'disorder' are emasculating. The therapeutic subject position is an untenable one for these young men.

\section{Intervention and sexual violence}

Unlike general violence, sexual violence can be read as being a suitable target for therapeutic intervention by the participants in this study. Sexual violence is constructed as 'deviant' and offenders are pathologised. Dominant discourses exclude the possibility of a rational man being sexually violent. In this regard, positivist psychology and dominant discourses of traditional masculinity agree. The 'unknowing' position that participants took up in relation to their sexual violence allowed participants to resist being positioned as 'deviant' and at the same time enabled them to construct their willingness for intervention as a rational search for understanding. The participants who were due to attend a specialist sex offender programme (Sean and Wade) wanted intervention. They explained that this would 
help them understand why they were sexually violent and that this understanding would therefore stop them doing it again. They actively took up the therapeutic subject position made available to them.

In turn, the 'unknowing' position taken up by participants made intervention by experts essential for them to ensure they were not sexually violent again, since (rationally) they cannot 'know' how to stop if they do not 'know' how or why they were sexually violent. Experts are required because they represent someone who 'knows' about sexual violence, who can explain it, and who can therefore 'fix' them. Creating expertise has the effect of also creating and maintaining the silence of those who are not experts. Intervention was desired by participants; it provided the means to understand, but also enabled them to maintain their silence around their sexual violence. A rationalist approach, however, cannot reveal the 'unknowing' position described in this thesis and consequently maintains the silence about the embodied sexual experience involved.

The reluctance and silences of the participants in this research were similar responses to those I had found in my professional practice of working with young men in a mandatory sex offender 'treatment' programme (see Chapter One). Yet, within such programmes, offenders do develop a willingness to talk. One possible reading of this willingness relates to the young men being positioned as therapeutic subjects. Intervention is a context within which not only are there expectations that they will talk about what they did and why, but also the role of the therapist is to facilitate such talk (Johnson, 2007; Salter, 2003). Those participants in this study who were to attend the sex offender 'treatment' programme when they turned 18 years old were aware of such expectations. They knew that they would be expected to talk in detail about what they had done and accepted this as part of the intervention context. However, within a research context such an expectation does not exist. Participants in this study were instead positioned as co-producers of knowledge who were free to contribute as they wished and for those in this study, this meant they chose to reveal very little detail about their sexual violence. In doing so, maintained a position congruent with an 'unknowing' subject. 
Sexual violence is constructed differently within different discourses, thereby producing differences in the desire for intervention by perpetrators. In other contexts, war campaigns, for example, the rape of women is well understood (Denov, 2006). Sexual violence can be used either as a reward for soldiers, as a specific tactic to demoralise the enemy or as an attempt at ethnic cleansing through affecting the gene pool of the enemy. In such a discursive context, there is no need for intervention as there is no quest for understanding, the actions are able to be justified. Therefore, it is possible that sexual violence can be a rational event that is understood by perpetrators. This differs markedly from the participants in this study, none of whom could speak of any rational reason for their sexual violence, hence their 'unknowing' position.

If intervention approaches are to be different for young men who have been sexually violent, it will be necessary to find a way to work with their 'unknowing' position, which negates the possibility of them engaging with their sexual violence. The act of sexual violence needs to be considered in relation to its discursive context so that alternative discourses become accessible.

\section{Possibilities for youth violence intervention}

Young men who have been violent are positioned as therapeutic subjects in dominant discourses around youth violence. They become known as a 'client' within discourses around intervention. Science-informed psychological therapeutic models are generally individualistic whereby the therapist engages with a voluntary client who is, in turn, theorised as being actively engaged and motivated to improve their current situation, albeit in complex ways (Hubble et al., 1999). Within this discursive context, the idea that a person must want to change in order for change to occur is a common notion. Therefore, undertaking intervention with young men who have been violent and who are positioned as requiring mandatory 'treatment' because they are 'disordered' has long been recognised as a source of tension in intervention settings (Salter, 1988). As the participants of this study clearly indicated, they were averse to intervention for their general violence, and whilst desiring intervention for their sexual violence, their 'unknowing' position provided an additional challenge. It is therefore a complex task to effectively work with both a 'client' who is also a 
mandated 'violent offender', since the later can be read as contradicting the basic premises of how to provide intervention to a presumed voluntary 'client'.

Despite being positioned as a therapeutic subject, young men who have been incarcerated for criminal violence do not have the same opportunities as other 'clients'. Some groups of 'clients' have developed strong political movements to address their needs better. For example, sexual assault survivors (Bass \& Davis, 1988) and mental health service users (Coleman, 2004) have been able to influence the discourses around intervention to some extent, resulting in improvements in services and increased community awareness; despite their contributions not always being accepted by positivist psychology. Young violent offenders however, cannot name the type of services they require, nor can they provide feedback on whether an intervention was appropriate or useful for them. Instead, evaluation of offender intervention programmes is conducted within a positivist research paradigm, generally using recidivism rates of re-offending to measure the effectiveness of the intervention (Martinson, 1974). The development of intervention for young men who have been violent is therefore constructed on the basis of expert opinion rather than on any expressed needs of the 'client' as the discursive context of mandatory 'treatment' silences young offenders. A provocative alternative would be to evaluate programmes with input from young offenders.

In relation to possible intervention approaches, Phillips $(2001,2006)$ discusses how nurses, psychologists and other professionals are implicated in the reproduction of discourses of masculinity, therefore Phillips concluded that violence is enabled. She (2006) offers the following suggestion for professionals to take up "deconstructing dominant gender norms with our clients ... assisting clients in becoming critical thinkers, ... to question the consequences and benefits of ... practices of masculinity ..., encouraging clients and multidisciplinary colleagues to challenge, vocally and visibly, the pervasive cultural representations of a restrictive and governing 'normative' masculinity" (p. 421). Whilst critical resistance to dominant discourses around hegemonic masculinity can be considered a crucial aim for intervention, there are difficulties in precisely how to go about this. It is not possible for professionals to stand outside the dominant discourses as if a pre-discursive self exists. One approach 
to employing discursive resources to resist dominant discourses is offered by Laws (2001), who suggests professional practice be changed by drawing on alternative, even contradictory discourses in order to offer alternative subject positions to youth.

Regardless of the specific model of or approach to intervention employed, some type of change of the individual is generally put forward as the ultimate goal; that is, a change in behaviour, thinking, emotions, attitudes or adapting to circumstances. For dominant psychological approaches, this is based on the concept of the unitary conscious, rational subject (Henriques et al., 1984). However, such a goal is problematic from a poststructural perspective that instead holds a person to be a complex being made up of multiple subjectivities that is constantly being constituted and reconstituted through discourses. Therefore, if intervention is about seeking change, the question becomes: what particular subject position(s) and in which discourse(s) should the focus be to make alternative positions accessible whereby violence is not involved? As already shown, the participants in this study are positioned in numerous ways, many of which are unrelated to the production of violence. From a poststructural framework, then, strategies that aim to facilitate nonviolence would need to consider the multiple discourses involved and the various subject positions available and accessible. Working with young men's explanations and understandings of their violence using an approach informed by poststructural discourse analysis may be one way to hear their talk in all its complexity and so provide another reading of it.

For intervention approaches to be effective in assisting young men to choose a nonviolent future, consideration of how they view intervention is necessary. Young men in this study appeared to only engage with intervention if it was seen to be relevant to them and if it did not position them as unmanly. The content of the participants' talk strongly suggested a lack of engagement with intervention and they constructed intervention as not working for them. In their own words, they pointed to the issues that need further consideration.

A key question for intervention posed by the discursive positioning taken up by these participants is, how can intervention make non-violence an accessible choice for young men, while still acknowledging and enabling them to take up a position as a 
'real man'? To achieve this, intervention approaches would need to consider how to account for multiple subjectivities, question the dominant masculinity discourses that constructs violence as a legitimate performance of becoming a 'man', assist young men to resist the discourses and practices of violence and make alternative discursive positions available so that non-violence can become a legitimate and achievable choice for young men. These points highlight the potentialities of a discursive approach to intervention that science-based approaches are unable to attain.

\section{(Re)thinking Youth Violence}

Employing a poststructural discursive analysis of the participants' talk within a framework of critical psychology has enabled me to (re)think youth violence. The analysis I offer here has highlighted the limitations of, and questioned the relevance of positivist psychological theorising of youth violence and the subsequent interventions. In addition, by identifying the pervasiveness that dominant discourses of traditional masculinity have in youth violence it has drawn attention to the significance that normative notions of manliness have in the construction of youth violence and the production of young men's subjectivities.

A positivist, scientifically-based psychology cannot account for the complexity demonstrated in this thesis. Dominant psychological theories used to explain youth violence enable these young men to avoid responsibility for their violence by constructing the cause of violence as being external to them and as needing experts to 'fix' them. Intervention approaches become ineffective when they offer these young men positions of 'abnormality' and when they are unable to offer nonviolence as an accessible and acceptable choice within masculine discourses.

A psychology based on modernist assumptions has little interest in, and cannot contend with contextual issues, whether socio-political, historical or even contexts of gender. The broad literature from critical psychology has made this point clear (see for example, Fox \& Prilleltensky, 1997; Prilleltensky \& Nelson, 2002). The extent to which the 'psy' complex dominates the field of youth violence acts to legitimate positivist psychological claims to authority (Rose, n.d.) over what can and cannot be said about these young men and how research should proceed. 
This study has raised numerous contextual issues relevant to youth violence by identifying the effects of discourses and the subject positions that are produced. Normative psychological approaches may intend one thing but different discourses change their meaning; what can be said and done in one discourse, for example, a discourse of 'abnormality', cannot be said or done in another, as it produces another meaning. A positivist paradigm cannot incorporate such shifting meanings. This study suggests that these participants regard or disregard interventions differently in accord with the discursive positioning being offered to them.

The ideas I have put forward in this thesis cannot be simply taken up and used by mainstream psychology as an adjunct to its positivist science. There would be insurmountable difficulties in attempting to employ ideas developed in one paradigm for use by another. For example, a positivist assumption that only one stable 'truth' exists would render accounts from young men about their violence that differ within different discourses as invalid. They may be positioned as liars or mistaken, rather than viewed as expressing different subjectivities.

(Re)thinking youth violence requires taking account of the significant impact that dominant notions of manliness has on young men's constructions of their violence, as well as the subject positions made available and the subsequent subjectivities. Within these pervasive discourses of manhood, violence equates to being manly. One of the conclusions I have reached from this research is, that the only way intervention can hold any promise for stopping youth violence is by looking at ways that nonviolence can become a legitimate and accessible choice for young men who are trying to get the subject position of 'man' right. Unfortunately, the analysis in this study has shown that intervention and the therapeutic subject position are constructed as not-masculine, making intervention unappealing for young men.

Alternative discourses around being a 'man' are of prime importance so that young men can still 'get it right as a man' without criminal violence. Connell (1995) argues that multiple masculinities exist. The masculine gender order is combative and hierarchical and institutional practices (re)produce this hierarchy. These practices, in turn, cannot be isolated from the wider social context. Hence, alternatives to criminal 
violence and alternative masculinities cannot be considered independent of discourses in which becoming-a-man is constructed.

This thesis suggests there is value in finding ways to re-think youth violence theories and intervention approaches; ways that go beyond the limitations that mainstream psychology offers and thus, beyond the strictures of positivist science. Embracing the complexities around multiple subjectivities, and the contextual issues revealed by the discourses involved, means accepting and exploring paradox and contradictions. This study has shown that without attending to the ways in which violence and intervention interact with personal projects of becoming a 'man', efforts to reduce youth violence will likely be ineffectual. 


\section{References}

Adams, P. J., Towns, A., \& Gavey, N. (1995). Dominance and entitlement: The rhetoric men use to discuss their violence toward women. Discourse and Society, 6(3), 387-406.

Allen, L. (2002). 'As far as sex goes, I don't really think about my body': Young men's corporeal experiences of (hetero)sexual pleasure. In H. Worth, A. Paris \& L. Allen (Eds.), The life of Brian (pp. 129-138). Dunedin, New Zealand: University of Otago Press.

Althusser, L. (1971). Lenin and philosophy and other essays (B. Brewster, Trans.). London: New Left Books.

American Psychiatric Association. (1994). Diagnostic and statistical manual of mental disorders (4th ed.). Washington, DC: Author.

Bandura, A. (1977). Social learning theory. Englewood Cliffs, NJ: Prentice Hall.

Bandura, A. (1986). Social foundations of thought and action: A social cognitive theory. Upper Saddle River, NJ: Prentice-Hall.

Bandura, A. (1997). Self-efficacy: The exercise of control. New York: W. H. Freeman.

Bandura, A. (2006). Toward a psychology of human agency. Perspectives on Psychological Science, 1(2), 164-180.

Barnett, H. A. (2004). A feminist critique of clinical psychology training programmes in Aotearoa New Zealand. Unpublished PhD thesis, Victoria University of Wellington, Wellington, New Zealand.

Barnett, O., Miller-Perrin, C. L., \& Perrin, R. D. (2005). Family violence across the lifespan: An introduction. Thousand Oaks, CA: Sage.

Bass, E., \& Davis, L. (1988). The courage to heal: A guide to women survivors of child sexual abuse. New York: Harper \& Row. 
Bird, L. (2004). A queer diversity: Teaching difference as interrupting intersections. Canadian Online Journal of Queer Studies in Education, 1(1). Retrieved May 15, 2007, from http://jqstudies.oise.utoronto.ca/journal/viewarticle.php?id=4\&layout=html.

Bird, L., Cornforth, S., Duncan, D., \& Roberson, S. M. (2005). Professionals becoming researchers: Collective engagement and difficulties of transformation. International Journal of Critical Psychology, (13), 96 -116.

Blackburn, R. (1993). The psychology of criminal conduct: Theory, research and practice. Chichester, England: John Wiley \& Sons.

Bograd, M. (1982). Battered women, cultural myths and clinical interventions: A feminist analysis. Women \& Therapy, 1(3), 69-77.

Bograd, M. (1990). Why we need to understand human violence. Journal of Interpersonal Violence, 5(1), 132-135.

Bondi, L. (2003). Empathy and identification: Conceptual resources for feminist fieldwork. ACME: An International E-Journal for Critical Geographies, 2(1), 64-76 Retrieved May 12, 2007, from http://www.acmejournal.org/vol2/Bondi.pdf.

Briere, J., \& Scott, C. (2006). Principles of trauma therapy: A guide to symptoms, evaluation, and treatment. Thousand Oaks, CA: Sage.

Brownmiller, S. (1975). Against our will: Men, women and rape. New York: Simon \& Schuster.

Bruinsma, G., \& Loeber, R. (2004). Challenges for criminology and criminal justice research. In G. Bruinsma, H. Elffers \& J. d. Keijser (Eds.), Punishment, places, and perpetrators: Developments in criminology and criminal justice research (pp. 3-20). Devon, UK: Willan.

Burman, E. (1994). Deconstructing developmental psychology. London: Routledge.

Burman, E. (2005). Contemporary feminist contributions to debates around gender and sexuality: From identity to performance. Group Analysis, 38(1), 17-30.

Burr, V. (1998). Overview: Realism, relativism, social constructionism and discourse. In I. Parker (Ed.), Social constructionism, discourse and realism (pp. 13-25). London: Sage.

Chapple, C. L. (2003). Examining intergenerational violence: Violent role modeling or weak parental controls? Violence and Victims, 18(2), 143-162. 
Cheek, J. (2000). Postmodern and poststructural approaches to nursing research. Thousand Oaks, CA: Sage.

Christians, C. G. (2000). Ethics and politics in qualitative research. In N. K. Denzin \& Y. S. Lincoln (Eds.), Handbook of qualitative research (2nd ed., pp. 133155). Thousand Oaks, CA: Sage.

Coleman, R. (2004). Recovery: An alien concept? Scotland: P \& P Press.

Connell, R. W. (1995). Masculinities. Berkeley, CA: University of California Press.

Connell, R. W. (2000). The men and the boys. Berkeley, CA: University of California Press.

Connell, R. W. (2001). Introduction and overview to men and masculinities: Discursive approaches. Feminism and Psychology, 11(1), 5-9.

Constantinople, A. (2005). Masculinity-femininity: An exception to a famous dictum? Feminism and Psychology, 15(4), 385-407.

Courtois, C. (2004). Complex trauma, complex reactions: Assessment and treatment. Psychotherapy: Theory, research, practice, training, 41(4), 412-425.

Crotty, M. (1998). The foundations of social research: Meaning and perspective in the research process. St. Leonards, Australia: Allen \& Unwin.

Danaher, G., Schirato, T., \& Webb, J. (2000). Understanding Foucault. St Leonards, Australia: Allen \& Unwin.

Davey, L., Day, A., \& Howells, K. (2005). Anger, over-control and serious violent offending. Aggression and Violent Behavior, 10(5), 624-635.

David, D. S., \& Brannon, R. (1976). The male sex role: Our culture's blueprint of manhood, and what it's done for us lately. In D. S. David \& R. Brannon (Eds.), The forty-nine percent majority: The male sex role (pp. 1-45). Reading, MA: Addison-Wesley.

Davies, B. (1989a). The discursive production of the male/female dualism in school settings. Oxford Review of Education, 15(3), 229-241.

Davies, B. (1989b). Frogs and snails and feminist tails: Preschool children and gender. Sydney, Australia: Allen \& Unwin.

Davies, B. (1990). The problem of desire. Social Problems, 37(4), 501-516. 
Davies, B. (1994). Poststructuralist theory and classroom practice. Geelong, Australia: Deakin University Press.

Davies, B. (1997). The subject of post-structuralism: A reply to Alison Jones. Gender and Education, 9(3), 271-283.

Davies, B. (1998). Psychology's subject: A commentary on the relativism/realism debate. In I. Parker (Ed.), Social constructionism, discourse and realism (pp. 133-145). London: Sage.

Delaney, C. H. (1995). Rites of passage in adolescence. Adolescence, 30(120), 891897.

Denov, M. S. (2006). Sexual violence against girls in situations of armed conflict. In S. M. Sturt (Ed.), New developments in child abuse research (pp. 129-142). New York: Nova Science.

Denzin, N. K., \& Lincoln, Y. S. (Eds.). (2000). Handbook of qualitative research (2nd ed.). Thousand Oaks, CA: Sage.

Derrida, J. (1997). Of grammatology (G. C. Spivak, Trans.). Baltimore, MA: Johns Hopkins University Press. (Original work published 1976)

Dishion, T. J., \& Stormshak, E. A. (2007). Intervening in children's lives: An ecological, family-centered approach to mental health care. Washington, DC: American Psychological Association.

Dobash, R. E., Dobash, R. P., \& Noaks, L. (1995). Thinking about gender and crime. In R. E. Dobash, R. P. Dobash \& L. Noaks (Eds.), Gender and crime (pp. 119). Cardiff, UK: University of Wales Press.

Doll, W. E., Jr. (1993). A post-modern perspective on curriculum. New York: Teachers College Press.

Domjan, M. (2006). The principles of learning and behavior (5th ed.). Australia: Thomson/Wadsworth.

Eagle, G. (2006). Masculine victims: A contradiction in terms? The International Journal of Critical Psychology, (17), 47-76.

Finkelhor, D. (1994). The international epidemiology of child sexual abuse. Child, Abuse and Neglect, 18(5), 409-417. 
Fleischmann, A., Bertolote, J. M., Belfer, M., \& Beautrais, A. (2005). Completed suicide and psychiatric diagnoses in young people: A critical examination of the evidence. American Journal of Orthopsychiatry, 75(4), 676-683.

Flowers, R. B. (2003). Male crime and deviance: Exploring its causes, dynamics, and nature. Springfield, IL: C. C. Thomas.

Foster, D. (1998). Across the S-S divide. In I. Parker (Ed.), Social constructionism, discourse and realism (pp. 107-117). London: Sage.

Foucault, M. (1970). The order of things: An archaeology of the human sciences (Anon., Trans.). London: Tavistock. (Original work published 1966)

Foucault, M. (1972). The archaeology of knowledge (A. M. Sheridan Smith, Trans.). London: Tavistock. (Original work published 1969)

Foucault, M. (1977). Discipline and punish: The birth of the prison (A. Sheridan, Trans.). London: Penguin Books. (Original work published 1975)

Foucault, M. (1980). Truth and power (C. Gordon, L. Marshall, J. Mepham \& K. Soper, Trans.). In C. Gordon (Ed.), Michel Foucault. Power/knowledge: Selected interviews and other writings 1972-1977. Brighton, UK: Harvester Press.

Fox, D., \& Prilleltensky, I. (Eds.). (1997). Critical psychology: An introduction. London: Sage.

Frances, R. (1995). An overview of community-based intervention programmes for men who are violent or abusive in the home. In R. E. Dobash, R. P. Dobash \& L. Noaks (Eds.), Gender and crime (pp. 358-389). Cardiff, UK: University of Wales Press.

Frieze, I. H. (2005). Hurting the one you love: Violence in relationships. Belmont, CA: Wadsworth/Thomson Learning.

Garbarino, J., Gaa, J. P., Swank, P., McPherson, R., \& Gratch, L. V. (1995). The relation of individuation and psychosocial development. Journal of Family Psychology, 9(3), 311-318.

Gavey, N. (1989). Feminist poststructuralism and discourse analysis: Contributions to feminist psychology. Psychology of Women Quarterly, 13(4), 459-475.

Gavey, N. (1992). Technologies and effects of heterosexual coercion. Feminism and Psychology, 2, 325-351. 
Gavey, N., \& Gow, V. (2001). 'Cry wolf', cried the wolf: Constructing the issue of false rape allegations in New Zealand media texts. Feminism \& Psychology, 11(3), 341-360.

Geanellos, R. (1999). Hermeneutic interviewing: An example of its development and use as research method. Contemporary Nurse, 8, 39-45.

Gelsthorpe, L., \& Padfield, N. (2003). Introduction. In L. Gelsthorpe \& N. Padfield (Eds.), Exercising discretion: Decision-making in the criminal justice system and beyond (pp. 1-28). Cullompton, UK: Willan.

Gerard, J. M., Krishnakumar, A., \& Buehler, C. (2006). Marital conflict, parent-child relations, and youth maladjustment: A longitudinal investigation of spillover effects. Journal of Family Issues, 27(7), 951-975.

Gergen, K. J. (1990). Toward a postmodern psychology. The Humanist Psychologist, 18(2), 23-34.

Gibbs, J. C. (1993). Moral-cognitive interventions. In A. P. Goldstein \& C. R. Huff (Eds.), The gang intervention handbook (pp. 159-185). Champaign, IL: Research Press.

Gibbs, J. C., Potter, G. B., \& Goldstein, A. P. (1995). The EQUIP program: Teaching youth to think and act responsibly through a peer-helping approach. Champaign, IL: Research Press.

Gilmartin, P. (1994). Rape, incest and child sexual abuse. New York: Garland.

Goldstein, A. P. (1988). The Prepare curriculum: Teaching prosocial competencies. Champaign, IL: Research Press.

Goldstein, A. P., \& Glick, B., (with Carthan W. \& Blancero, D.A.). (1994). The prosocial gang: Implementing aggression replacement training. Thousand Oaks, CA: Sage.

Goldstein, A. P., Glick, B., with Reiner, S., Zimmerman, D., \& Coultry, T. M. (1987). Aggression replacement training: A comprehensive intervention for aggressive youth. Champaign, IL: Research Press.

Goldstein, A. P., \& Keller, H. (1987). Aggressive behavior: Assessment and intervention. Elmsford, NY: Pergamon Press.

Goldstein, S., \& Brooks, R. B. (2005). Why study resiliency? In S. Goldstein \& R. B. Brooks (Eds.), Handbook of resilience in children (pp. 3-16). New York: Kluwer Academic/Plenum Publishers. 
Grant, A. (2000). The historical development of treatment for adolescent sex offenders. Trends and Issues in Crime and Criminal Justice, (145), 1-6.

Grant, B. M., \& Giddings, L. S. (2002). Making sense of methodologies: A paradigm framework for the novice researcher. Contemporary Nurse, 13(1), 10-28.

Guba, E. G., \& Lincoln, Y. S. (1994). Competing paradigms in qualitative research. In N. K. Denzin \& Y. S. Lincoln (Eds.), Handbook of qualitative research (pp. 105-117). Thousand Oaks, CA: Sage.

Hare, R. D. (1970). Psychopathy: Theory and research. Oxford, England: John Wiley.

Hare, R. D. (1999). Without conscience: The disturbing world of the psychopaths among us. New York: Guilford Press.

Hawkins, K. (2003). Order, rationality and silence: Some reflections on criminal justice decision-making. In L. Gelsthorpe \& N. Padfield (Eds.), Exercising discretion: Decision-making in the criminal justice system and beyond (pp. 186-219). Cullompton, UK: Willan.

Hay-McKenzie, F. (2002). Tackling the bullies: In the classroom and in the staffroom. Australia and New Zealand Journal of Law and Education, 7(2), 87-140.

Hayward, K. (2006). The vilification and pleasures of youthful transgression. In J. Muncie, G. Hughes \& E. McLaughlin (Eds.), Youth justice: Critical readings (pp. 80-94). London: Sage.

Henriques, J., Hollway, W., Urwin, C., Venn, C., \& Walkerdine, V. (Eds.). (1984). Changing the subject: Psychology, social regulation and subjectivity. London: Methuen.

Henwood, K. L., \& Pidgeon, N. F. (1992). Qualitative research and psychological theorising. British Journal of Psychology, 83(1), 97-111.

Herman, J. L. (1992). Trauma and recovery. New York: Basic Books.

Hobbs, C. (2005). The prevalence of child maltreatment in the United Kingdom. Child Abuse \& Neglect, 29(9), 949-951.

Hollin, C. R. (1990). Cognitive-behavioral interventions with young offenders. Elmsford, NY: Pergamon Press. 
Hollin, C. R. (1996). Young offenders. In C. R. Hollin (Ed.), Working with offenders (pp. 243-266). Chichester, England: John Wiley \& Sons.

Hollin, C. R., \& Howells, K. (Eds.). (1996). Clinical approaches to working with young offenders. Chichester, England: John Wiley \& Sons.

Hollway, W. (1989). Subjectivity and method in psychology: Gender, meaning and science. London: Sage.

Hollway, W., \& Jefferson, T. (1996). Eliciting narrative through the in-depth interview. Qualitative Inquiry, 3(1), 53-70.

Horsfall, J., \& Stuhlmiller, C. M., (with Champ, S.). (2000). Interpersonal nursing for mental health. Sydney, Australia: MacLennan \& Petty.

Howell, A. J., Reddon, J. R., \& Enns, R. A. (1997). Immediate antecedents to adolescents' offences. Journal of Clinical Psychology, 53(4), 355-360.

Howells, K. (1986). Social skills training and criminal and antisocial behaviour in adults. In C. R. Hollin \& P. Trower (Eds.), Handbook of social skills training: Applications across the life span (Vol. 1, pp. 185-210). Oxford: Pergamon Press.

Howells, K. (2004). Anger and its links to violent offending. Psychiatry, Psychology and Law, 11(2), 189-196.

Hubble, M., Duncan, B., \& Miller, S. (1999). The heart and soul of change: What works in therapy? Washington, DC: American Psychological Association

Hughes, J. A. (1990). The philosophy of social research (2nd ed.). London: Longman.

Janesick, V. J. (1998). "Stretching" exercises for qualitative researchers. Thousand Oaks, CA: Sage.

Jenkins, A. (1990). Invitations to responsibility: The therapeutic engagement of men who are violent and abusive. Adelaide, Australia: Dulwich Centre.

Jewkes, Y. (2005). Men behind bars: "Doing" masculinity as an adaptation to imprisonment. Men and Masculinities, 8(1), 44-63.

Johnson, S. A. (2007). Physical abusers and sexual offenders: Forensic and clinical strategies. Boca Raton, FL: CRC/Taylor \& Francis. 
Johnstone, G., \& Van Ness, D. W. (2007). The meaning of restorative justice. In G. Johnstone \& D. W. Van Ness (Eds.), Handbook of restorative justice (pp. 523). Portland, OR: Willan.

Jones, A. (1997). Teaching post-structuralist feminist theory in education: Student resistances. Gender and Education, 9(3), 261-269.

Kelley, H. H. (1987). Attribution in social interaction. In E. E. Jones, D. E. Kanouse, H. H. Kelley, R. E. Nisbett, S. Valins \& B. Weiner (Eds.), Attribution: Perceiving the causes of behavior (pp. 1-26). Hillsdale, N.J.: Lawrence Erlbaum.

Kenway, J., \& Willis, S. (1995). Critical visions: Rewriting the future of work, schooling and gender. Canberra: DEET.

Kernsmith, P. (2006). Gender differences in the impact of family of origin violence on perpetrators of domestic violence. Journal of Family Violence, 21(2), 163171.

Kuhn, T. S. (1962). The structure of scientific revolutions. Chicago, IL: University of Chicago Press.

Kutchins, H., \& Kirk, S. A. (1997). Making us crazy: DSM: The psychiatric bible and the creation of mental disorders. London: Constable.

Kvale, S. (1996). Interviews: An introduction to qualitative research interviewing. Thousand Oaks, CA: Sage.

Laclau, E., \& Mouffe, C. (1987). Post-Marxism without apologies. New Left Review, 166, 79-106.

Lambie, I., Seymour, F., Lee, A., \& Adams, P. (2002). Resiliency in the victimoffender cycle in male sexual abuse. Sexual Abuse: Journal of Research and Treatment, 14(1), 31-48.

Lashlie, C. (2003). The journey to prison: Who goes and why (Rev ed.). Auckland, New Zealand: Harper Collins.

Lather, P. (1991). Getting smart: Feminist research and pedagogy with/in the postmodern. New York: Routledge.

Lather, P. (1992). Critical frames in educational research: Feminist and poststructural perspectives. Theory into Practice, 31(2), 87-99. 
Laws, C. A. (2001). Poststructuralism at work with marginalised children. Unpublished $\mathrm{PhD}$ thesis, James Cook University, Townsville, Australia.

Laws, C. A., \& Davies, B. (2000). Poststructuralist theory in practice: Working with "behaviourally disturbed" children. International Journal of Qualitative Studies in Education, 13(3), 205-221.

Lovett, B. J., \& Sheffield, R. A. (2007). Affective empathy deficits in aggressive children and adolescents: A critical review. Clinical Psychology Review, 27(1), 1-13.

Lutzker, J. R. (2006). Preventing violence: Research and evidence-based intervention strategies. Washington, DC: American Psychological Association.

Marshall, W. L., Anderson, D., \& Fernandez, Y. (1999). Cognitive behavioural treatment of sexual offenders. Chichester, England: Wiley.

Marshall, W. L., Fernandez, Y. M., Hudson, S. M., \& Ward, T. (1998). Sourcebook of treatment programs for sexual offenders. New York: Plenum Press.

Martinson, R. (1974). What works? - questions and answers about prison reform. The Public Interest, 35, 22-45.

May-Chahal, C., \& Cawson, P. (2005). Measuring child maltreatment in the United Kingdom: A study of the prevalence of child abuse and neglect. Child Abuse \& Neglect, 29(9), 969-984.

McHoul, A., \& Grace, W. (1998). A Foucault primer: Discourse, power and the subject (2nd ed.). Dunedin, New Zealand: Otago University Press.

McShane, J. (1991). Cognitive development: An information processing approach. Oxford, U.K.: Blackwell.

Merttens, R. (1998). What is to be done? (With apologies to Lenin!). In I. Parker (Ed.), Social constructionism, discourse and realism (pp. 59-73). London: Sage.

Messerschmidt, J. W. (2000a). Becoming "real men": Adolescent masculinity challenges and sexual violence. Men and Masculinities, 2, 286-307.

Messerschmidt, J. W. (2000b). Nine lives: Adolescent masculinities, the body, and violence. Boulder, CO: Westview Press. 
Minichiello, V., Aroni, R., Timewell, E., \& Alexander, L. (1990). In-depth interviewing: Researching people. Melbourne, Australia: Longman Cheshire.

Ministry of Justice. (2005). Review of prisoners complaints process. Wellington, New Zealand: Author.

Montero, M. (1998). The perverse and pervasive character of reality: Some comments on the effects of monism and dualism. In I. Parker (Ed.), Social constructionism, discourse and realism (pp. 119-131). London: Sage.

Morss, J. R. (1996). Growing critical: Alternatives to developmental psychology. London: Routledge.

Muncie, J. (2006). Failure never matters: Detention centres and the politics of deterrence. In J. Muncie, G. Hughes \& E. McLaughlin (Eds.), Youth justice: Critical readings (pp. 332-344). London: Sage.

Newbold, G. (2000). Crime in New Zealand. Palmerston North, New Zealand: Dunmore Press.

Noble, C. (1999). Silence: Absence and context. In I. Parker \& The Bolton Discourse Network (Eds.), Critical textwork: An introduction to varieties of discourse and analysis (pp. 191-200). Buckingham, UK: Open University Press.

Novaco, R. W. (1994). Anger as a risk factor for violence among the mentally disordered. In J. Monahan \& H. J. Steadman (Eds.), Violence and mental disorder: Developments in risk assessment (pp. 21-59). Chicago, IL: University of Chicago Press.

Novaco, R. W. (1997). Remediating anger and aggression with violent offenders. Legal and Criminological Psychology, 2(1), 77-88.

O'Neill, D. (1998). A post-structuralist review of the theoretical literature surrounding wife abuse. Violence Against Women, 4(4), 457-490.

Parker, I. (1992). Discourse dynamics: Critical analysis for social and individual psychology. London: Routledge.

Parker, I., Georgaca, E., Harper, D., McLaughlin, T., \& Stowell-Smith, M. (1995). Deconstructing psychopathology. London: Sage.

Phillips, B. N. (2004). An interpretation of four men's experiences of suicidality. Unpublished $\mathrm{PhD}$, Victoria University of Wellington, Wellington, New Zealand. 
Phillips, D. A. (2001). Methodology for social accountability: Multiple methods and feminist poststructural, psychoanalytic discourse analysis. Advances in Nursing Science, 23(4), 49-66.

Phillips, D. A. (2005). Reproducing normative and marginalized masculinities: Adolescent male popularity and the outcast. Nursing Inquiry, 12(3), 219-230.

Phillips, D. A. (2006). Masculinity, male development, gender, and identity: Modern and postmodern meanings. Issues in Mental Health Nursing, 27, 403-423.

Phillips, G. (1986). Men talking to men about their relationships. American Behavioral Scientist, 29(3), 321-341.

Plummer, D. (1999). One of the boys: Masculinity, homophobia, and modern manhood. New York: Harrington Park Press.

Pollack, W., (with Shuster, T.). (2000). Real boys' voices. Melbourne, Australia: Scribe.

Potter, J. (1998). Fragments in the realization of relativism. In I. Parker (Ed.), Social constructionism, discourse and realism (pp. 27-45). London: Sage.

Potter, J., \& Wetherell, M. (1987). Discourse and social psychology: Beyond attitudes and behaviour. London: Sage.

Prilleltensky, I., \& Fox, D. (1997). Introducing critical psychology: Values, assumptions, and the status quo. In D. Fox \& I. Prilleltensky (Eds.), Critical psychology: An introduction (pp. 3-20). London: Sage.

Prilleltensky, I., \& Nelson, G. (2002). Doing psychology critically: Making a difference in diverse settings. Hampshire, UK: Palgrave Macmillan.

Putnam, F. W. (2003). Ten-year research update review: Child sexual abuse. Journal of the American Academy of Child and Adolescent Psychiatry, 42(3), 269278.

QSR International. (2000). QSR N6 [Computer software]. Melbourne, Australia: Author.

Raye, B. E., \& Warner Roberts, A. (2007). Restorative processes. In G. Johnstone \& D. W. Van Ness (Eds.), Handbook of restorative justice (pp. 211-227). Portland, Or: Willan. 
Rennie, D. L., Phillips, J. R., \& Quartaro, G. K. (1988). Grounded theory: A promising approach to conceptualization in psychology? Canadian Psychology, 29(2), 139-150.

Rogers, R. (2001). Handbook of diagnostic and structured interviewing. New York: Guilford Press.

Rose, N. (1985). The psychological complex: Psychology, politics and society in England, 1969-1939. London: Routledge \& Kegan Paul.

Rose, N. (1996). Inventing ourselves: Psychology, power, and personhood. New York: Cambridge University Press.

Rose, N. (n.d.). Power and subjectivity: Critical history and psychology. Academy for the Study of the Psychoanalytic Arts. Retrieved April 14, 2007, from www.academyanalyticarts.org/rose1.htm

Rouse, J. (1994). Power/knowledge. In G. Gutting (Ed.), The Cambridge companion to Foucault (pp. 92-114). Cambridge, NY: Cambridge University Press.

Russell, D. (1983). The incidence and prevalence of intrafamilial and extrafamilial sexual abuse of female children. Child, Abuse and Neglect, 7(2), 133-146.

Salter, A. C. (1988). Treating child sex offenders and victims: A practical guide. Thousand Oaks, CA: Sage.

Salter, A. C. (1995). Transforming trauma: A guide to understanding and treating adult survivors of child sexual abuse. Thousand Oaks, CA: Sage.

Salter, A. C. (2003). Predators: Pedophiles, rapists, and other sex offenders: Who they are, how they operate, and how we can protect ourselves and our children. New York: Basic Books.

Sarup, M. (1993). An introductory guide to post-structuralism and postmodernism (2nd ed.). New York: Harvester Wheatsheaf.

Scharf, M., Mayseless, O., \& Kivenson-Baron, I. (2004). Adolescents' attachment representations and developmental tasks in emerging adulthood. Developmental Psychology, 40(3), 430-444.

Schwartz, J. P., Hage, S. M., Bush, I., \& Burns, L. K. (2006). Unhealthy parenting and potential mediators as contributing factors to future intimate violence: A review of the literature. Trauma, Violence, \& Abuse, 7(3), 206-221. 
Segal, L. (1996). Explaining male violence. In J. Munice, E. McLaughlin \& M. Langan (Eds.), Criminological perspectives: A reader (pp. 187-202). London: Sage.

Seidler, V. J. (1994). Unreasonable men: Masculinity and social theory. London: Routledge.

Sheridan, A. (1980). Michel Foucault: The will to truth. London: Tavistock.

Sparkes, A. C., \& Smith, B. (2002). Sport, spinal cord injury, embodied masculinities, and the dilemmas of narrative identity. Men and Masculinities, $4(3), 258-285$.

Staniforth, B., \& Fouché, C. (2006). An Aotearoa primer on 'fit and proper': School version. Social Work Review, 18(4), 11-19.

Staub, E. (2003). The psychology of good and evil: Why children, adults, and groups help and harm others. Cambridge, U.K.: Cambridge University Press.

Stubbe, M., Lane, C., Hilder, J., Vine, E., Vine, B., Marra, M., Holmes, J., \& Weatherall, A. (2003). Multiple discourse analyses of a workplace interaction. Discourse Studies, 5(3), 351-388.

Taylor, P. (2002, April 28 ). When good boys go bad. Sunday Star Times, pp. C2-C3.

Time to act on youth. (2002, September 19). The Press, p. 8.

Town, S. J. H. (1998). Is it safe to come out now? Sexuality and the education of ten young gay men. Unpublished Doctor of Philosophy, Victoria University of Wellington, Wellington, New Zealand.

Tupuola, A.-M. (1998). "Adolescence": Myth or reality for "Samoan" women? Beyond the stage-like toward shifting boundaries and identities. Unpublished $\mathrm{PhD}$ thesis, Victoria University of Wellington, Wellington.

Urbas, G. (2000). The age of criminal responsibility. Trends and Issues in Crime and Criminal Justice, (181), 1-6. Retrieved 14 April, 2007, from www.aic.gov.au/publications/tanddi/tandi181.html.

Ussher, J. M. (1992). Science sexing psychology: Positivistic science and gender bias in clinical psychology. In J. M. Ussher \& P. Nicolson (Eds.), Gender issues in clinical psychology (pp. 39-67). London: Routledge. 
Wadham, B., \& Pudsey, J. (2005). (Un)masking hegemony: Militarism, white masculinity and the logic of contemporary empire. International Journal of Critical Psychology, (16), 146-165.

Walkerdine, V. (1988). The mastery of reason: Cognitive development and the production of rationality. London: Routledge.

Walkerdine, V. (1989). Femininity as performance. Oxford Review of Education, 15(3), 267-279.

Walsh, A., \& Ellis, L. (2007). Criminology: An interdisciplinary approach. Thousand Oaks, CA: Sage.

Ward, T., \& Beech, A. (2006). An integrated theory of sexual offending. Aggression and Violent Behavior, 11(1), 44-63.

Ward, T., Laws, D. R., \& Hudson, S. M. (2003). Sexual deviance: Issues and controversies. London: Sage.

Weaver, S. (2001). Teenage boys talk: 50 New Zealand teenagers talk about their lives. Auckland, New Zealand: Random House.

Weedon, C. (1987). Feminist practice and poststructuralist theory. Oxford, U.K.: Basil Blackwell.

Weis, L., \& Fine, M. (2000). Speed bumps: Student friendly guide to qualitative research. New York: Teachers College Press.

Wengraf, T. (2001). Qualitative research interviewing: Biographic narrative and semi-structured methods. London: Sage.

Wetherell, M., \& Edley, N. (1999). Negotiating Hegemonic Masculinity: Imaginary Positions and Psycho-Discursive Practices. Feminism \& Psychology, 9(3), 335-356.

White, M., \& Epston, D. (1990). Narrative means to therapeutic ends. New York: W. W. Norton.

Widom, C. S. (1989). Does violence beget violence? A critical examination of the literature. Psychological Bulletin, 106, 3-28.

Widom, C. S. (1997). Child abuse, neglect, and witnessing violence. In D. M. Stoff, J. Breiling \& J. D. Maser (Eds.), Handbook of antisocial behavior (pp. 159170). New York: John Wiley \& Sons. 
Williams, S. (2000, September, 30). Mondayitis? You ain't seen nothing yet. Sydney Morning Herald, p. 25.

Willig, C. (1998). Social constructionism and revolutionary socialism: A contradiction in terms? In I. Parker (Ed.), Social constructionism, discourse and realism (pp. 91-104). London: Sage.

Willig, C. (2000). Introducing qualitative research in psychology: Adventures in theory and method. Buckingham, U.K.: Open University Press.

Wollcott, H. F. (1994). Transforming qualitative data: Description, analysis, and interpretation. Thousand Oaks, CA: Sage. 


\section{Appendices}

Appendix A. University Human Ethics Committee approval .................................289

Appendix B. Child, Youth and Family research approval ......................................2290

Appendix C. Department of Corrections research approval ...................................2291

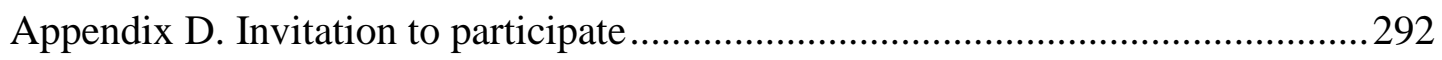

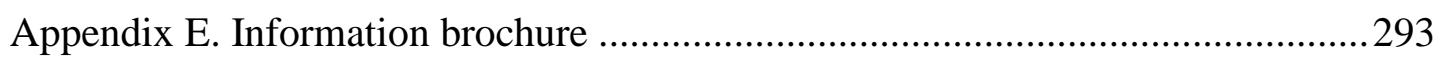

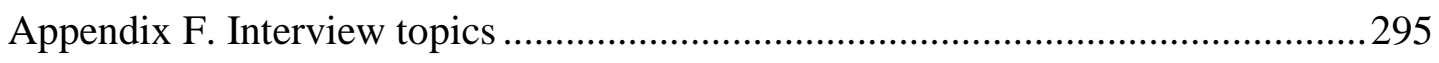

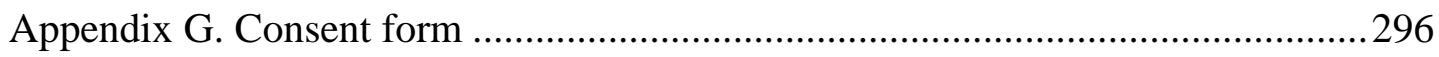

Appendix H. Transcriber confidentiality agreement ..............................................29 


\section{Appendix A. University Human Ethics Committee approval}

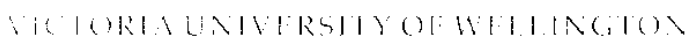

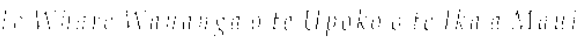

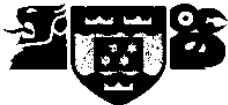

23 January 2002

Ms Shirley Roberson

79 Balfour Street

Mornington

WELLINGTON

Dear Ms Roberson

Thank you for your revised application for human ethics approval which was received on 20 November 2001. Your application has been considered by the Human Ethics Committee, after receiving a further report on supervisory arrangements. Dr Jenny Neale, who as Deputy Dean of Humanities and Social Sciences convenes the Faculty Research Committee which approves supervisory arrangements for research projects in Humanities and Socia: Sciences, met with Dr Lise Bird, Dr Jan Jardan and me on 28 November 2001 to consider the appointment of a clinical supervisor acceptable to the University and to CYFS. I am pleased to report that $\mathrm{Mr}$ Nick Findley, Practice Manager at the Kingslea Residential Facility in Christchurch, has accepted the University's invitation to act in this role.

On the basis of the revisions made to the initial application and the establishment of satisfactory supervisory arrangements, the Human Ethics Committee has approved your application. Approval is given for the period 23 January 2002 to 31 March 2003.

This has been an uncommonly drawn out process but the committee is delighted that it has reached a positive conclusion

With best wishes for your research.

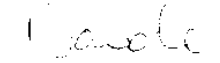

Graeme Kennedy

- Convener, Human Ethics Committee

cc: Lise Bird

Jan Jordan

Penny Hawkins, CYPS

Nick Findley

Jenny Neale 


\section{Appendix B. Child, Youth and Family research approval}

28 February 2002

Shirley Roberson

79 Balfour St

Mornington

WELLINGTON

Dear Shirley

\section{RE: Adolescent talk on Adolescent Violence}

Thank you for providing the Research Access Committee with the ethical approval from Victoria University for your research proposal. I am please to confirm that the RAC have now given final approval for your research.

The following sets out the terms by which the Child Youth and Family agrees to your access to information held by it.

\section{Access to our information}

Access to our files is contingent on your signing the attached Deed of Confidentiality as an acceptance of the way in which information held by the Agency will be used by you. It also reflects the seriousness of any breach of the information privacy principles contained within the Privacy Act 1993.

Draft

You will send to the Convenor of the Child Youth and Family Research Access Committee at National Office Wellington the penultimate draft of your report to ensure that legal, ethical and matters-of-fact are adequately addressed.

\section{Liaison with the department}

Your contact person within the Department is the secretary of the Research Access Committee, Sina Solia (extension: 244 ) and or the Convenor, Penny Hawkins (extension: \$\$030).

$$
\text { ?. }
$$

We wish you well in completing your research and look forward to receiving your final report.

Yours sincerely

Sina Solia

Secretary

Research Access Committee 


\section{Appendix C. Department of Corrections research approval}

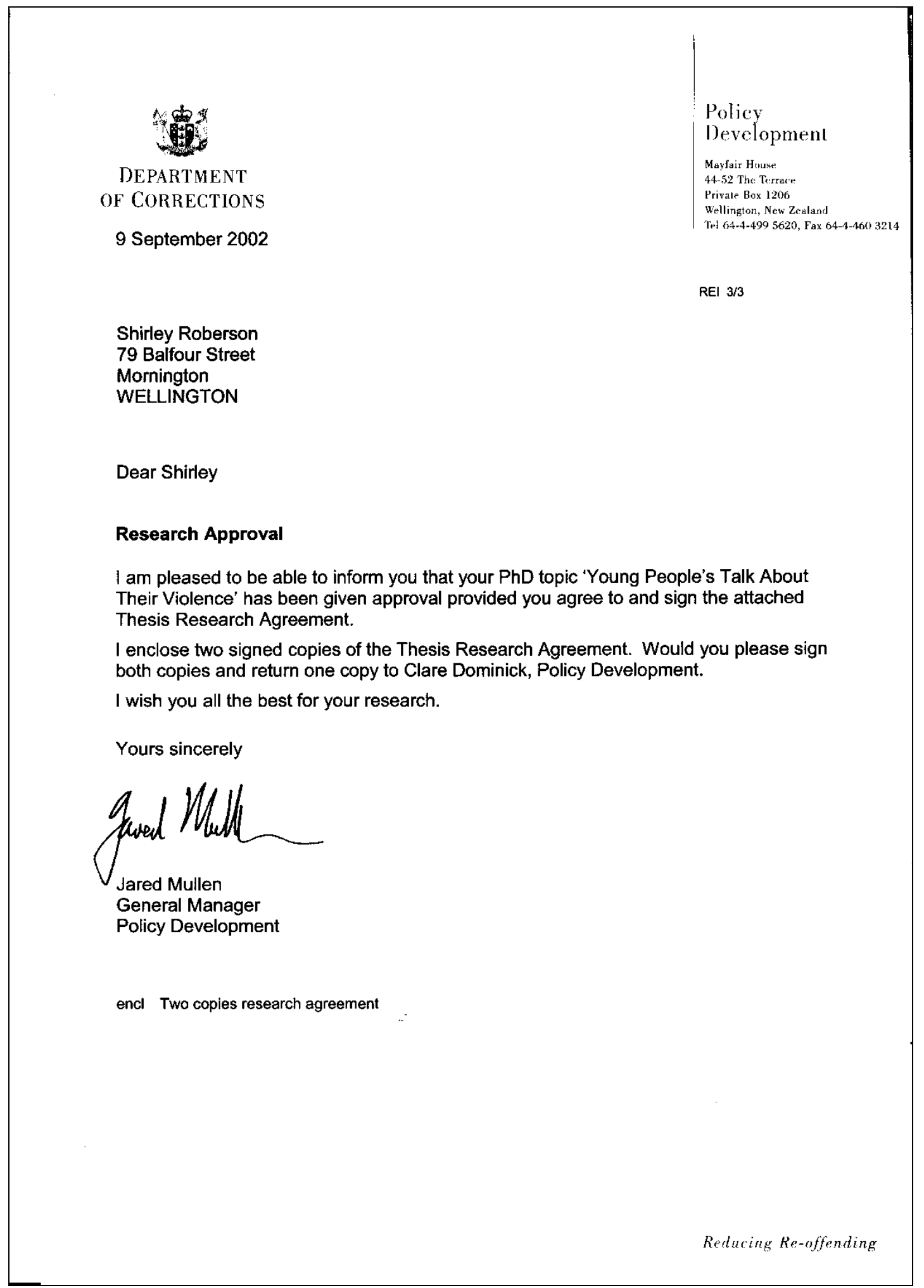


Appendix D. Invitation to participate

VICTORLA UNIVERSITY OF WELLINCTON

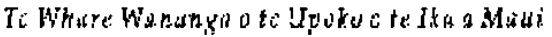

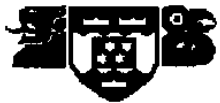

\title{
INVITATION TO PARTICIPATE
}

\author{
N A RESEARCH STUDY CALLED
}

'YOUNG PEOPLE'S TALK ABOUT THEIR VIOLENCE'

\section{THIS INVITATION 1S:}

ro:

\author{
Young people who: \\ th are between 13 and 18 years old. \\ t have done something that has been called violent.
}

FROM:

Shirley Roberson, who is a PhD student at Victoria

University of Wellington.

INUITES YOU TO:

Talk with Shirley about your experiences, ideas and understanding of what you did.

\section{WHAT HAPPENS NEXT?}

it If you would like to know more, your name will be given to Shirley and you can meet her. She will tell you more about the study.

¿ Once you have heard all about the study from Shirley you can take some time to decide if you want to take part.

IF YOU WANT TO MEET SHIRLEY:

The date is:

The time is:

t You can contact Shirley on: 0211576091 
Appendix E. Information brochure
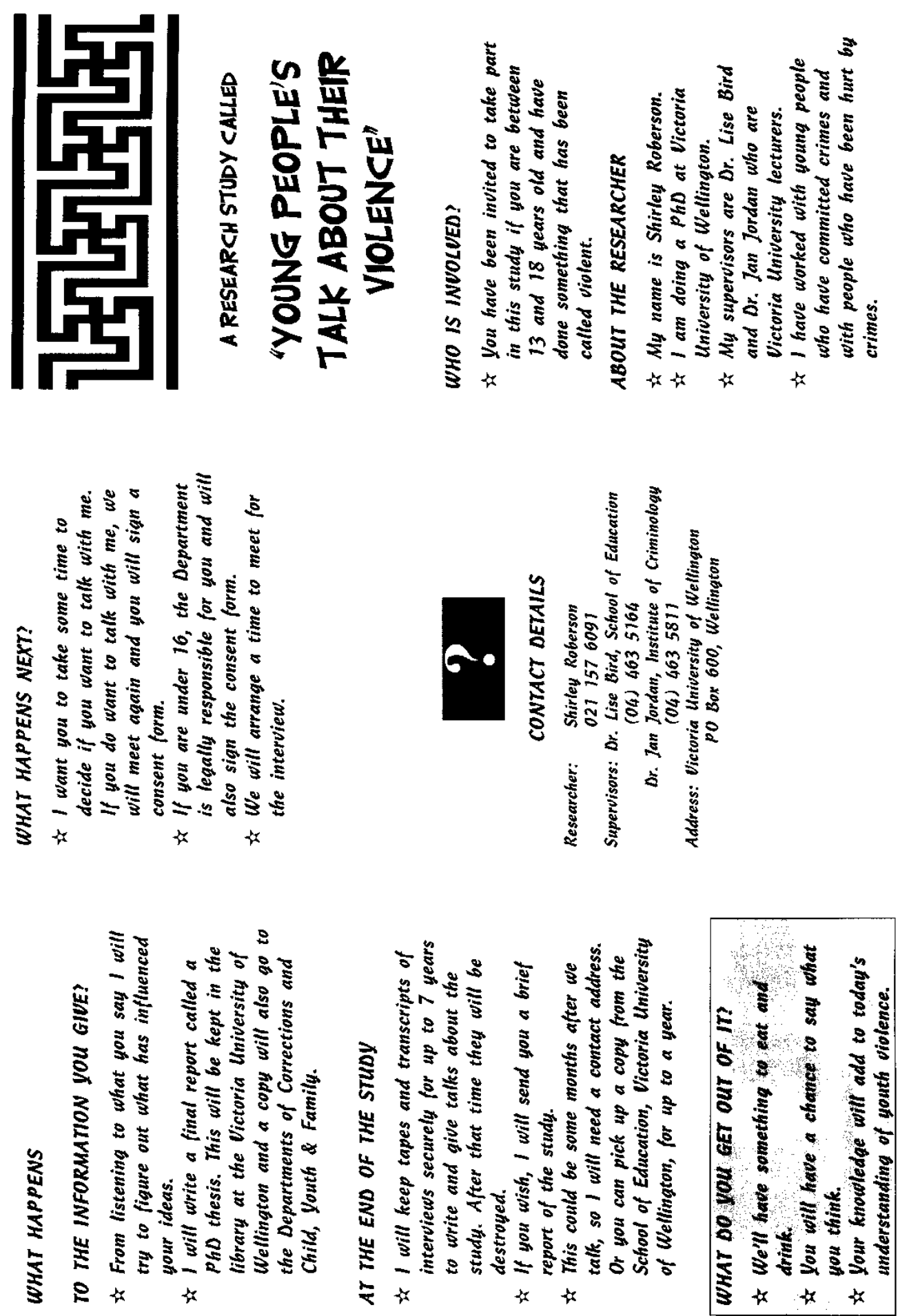


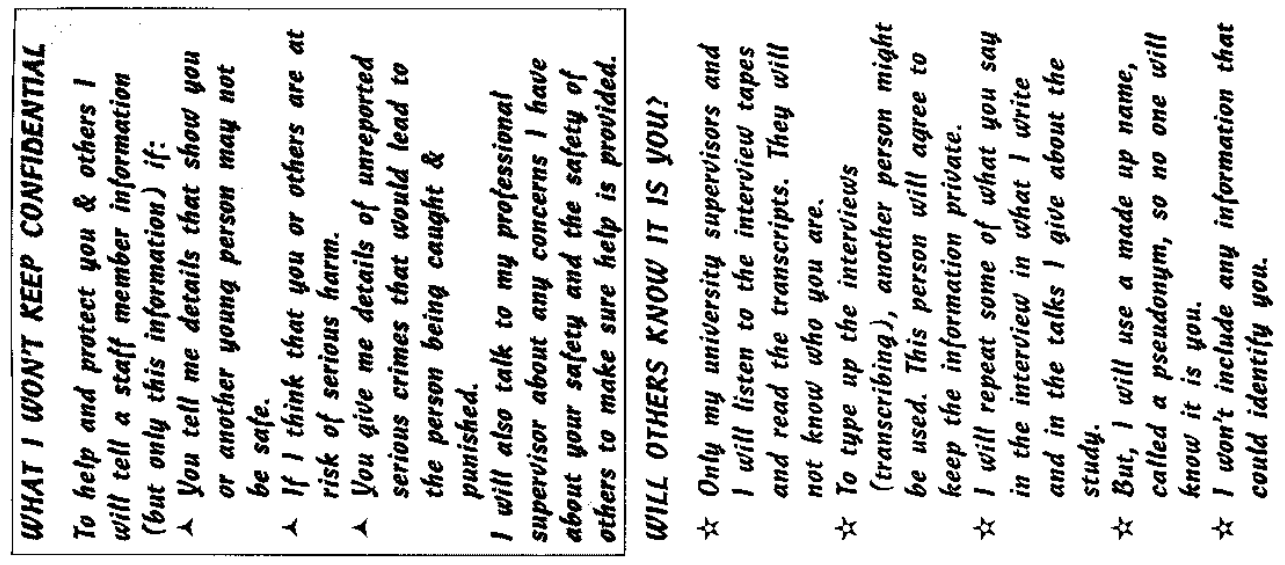

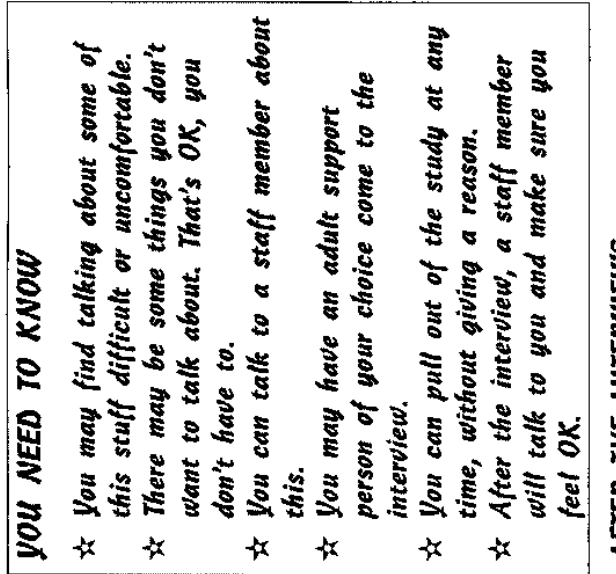

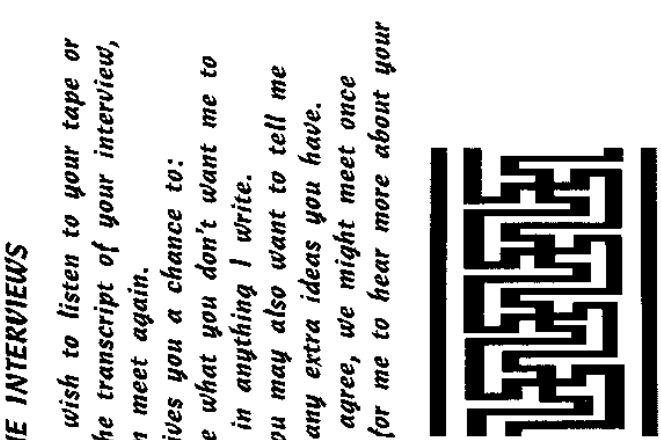

4

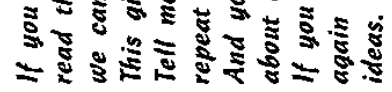

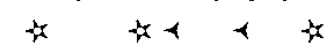
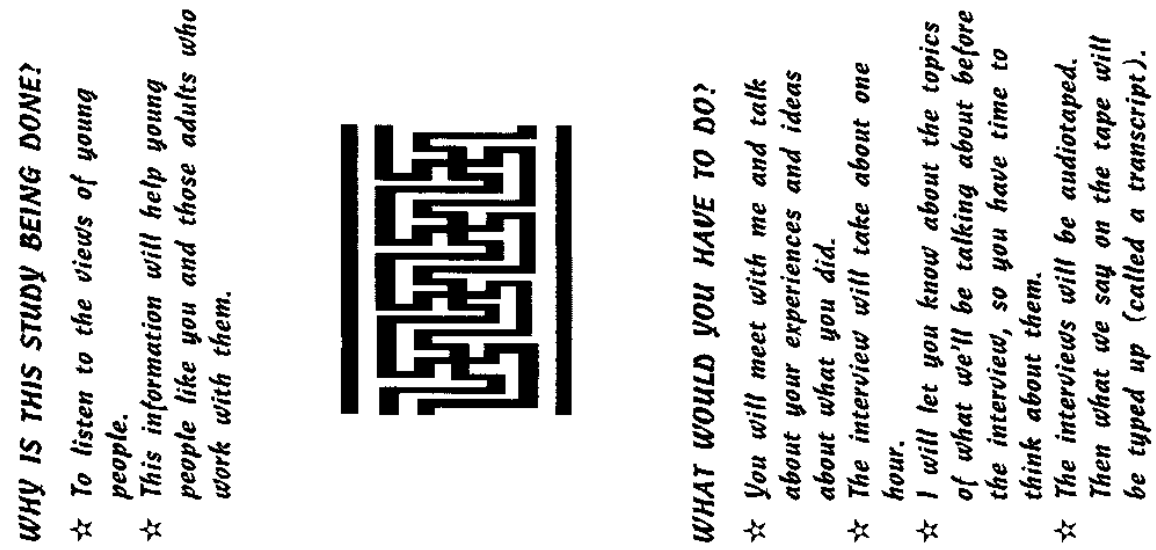


\title{
INTER VIEW TOPICS
}

\section{"YOUNG PEOPLE'S TALK ABOUT THEIR VIOLENCE"}

\author{
There are six topics l'd like to talk with you about. \\ You can start wherever you like. \\ Hou don't have to talk about some things if you don't want to.
}

you can stop the interview any time you want.

1. YOUR IDEAS ABOUT THE WORD UIOLENCE.

2. A DESCRIPTION OF WHAT YOU DID.

What it was like for you at the time.

How you imagine others would describe what you did.

3. YOUR IDEAS ON THE EFFECTS OF WHAT YOU DID.

it On you and your relationships.

it On others.

4. YOUR IDEAS ON WHY YOU DID WHAT YOU DID.

मे How you suppose others might explain why you did it.

5. ANY HELP YOU HAVE RECEIVED.

th What's been useful, and what hasn't.

\& Your view of why others have tried to help you.

6. WHAT IT'S LIKE FOR YOU TO TALK ABOUT WHAT YOU DID.

it Why you might want to talk.

th What's difficult, and what helps.

th your view's on talking in a group.

7. ANYTHING ELSE YOU WANT TO SAY.

THANK YOU FOR TAKING PART IN THIS STUDY 
Appendix G. Consent form

VICTORIA UNIVERSITY OF WELLINCTON

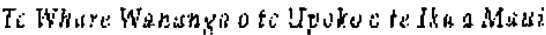

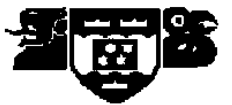

CONSENT FORM

TO PARTKIPATE N A RESEARCH STUDY CALLED

\section{"YOUNG PEOPLE'S TALK ABOUT THEIR VIOLENCE"}

th This research study has been explained to me and I understand what it is about.

\& I know I don't have to be involved.

* I am happy with the answers given to all my questions.

* I understand that if I provide information that sugqests either myself or others may not be safe or give details of unreported serious erimes, the researcher will tell a staff member this information, Gut only this information.

म I understand that talking about what I did might be uncomfortable for me. If

I need some help, I know I can tell Shirley and I can talk to stalf about it.

* I know I can stop the interview at any time.

+ I aqree to take part in this research study as it has been explained to me.

Name of participant:

Signed:

Date:

Contact phone number:

Current Address:

Address for Brief Report:

I would like to be sent an audio and brief writtert report of the results of this study when it is completed to the above address. (This will be about 12 months after the interviews).

FOR IHE CUSTODIAN OF PARTICIPANTS UNDER 16 VEARS OLD

1 consent to

who is in my custody to participate in this study.

Name of custodian:

Signed:

Date: 
Appendix H. Transcriber confidentiality agreement

\title{
TRANSCRIBER'S CONFIDENTIALITY AGREEMENT
}

AN A RESEARCH STUDY CALLED

\begin{abstract}
'YOUNG PEOPLE'S TALK ABOUT THERR VIOLENCE'
\end{abstract}
I agree to keep all information that I hear and see as a result of my wort as a transcriber canfidential.

Name:

Signature:

Date: 